$$
\begin{gathered}
\text { UNIVERSIDADE DE SÃO PAULO } \\
\text { ESCOLA POLITÉCNICA } \\
\text { DEPARTAMENTO DE ENGENHARIA DE PRODUÇÃO }
\end{gathered}
$$

LUCIANA DO CARMO LEITE SILVA

\title{
DESIGN PARA O AMBIENTE: ANÁLISE DA INTEGRAÇÃO DE ASPECTOS AMBIENTAIS NO PROCESSO DE DESENVOLVIMENTO DE PRODUTOS
}


LUCIANA DO CARMO LEITE SILVA

\section{DESIGN PARA O AMBIENTE: ANÁLISE DA INTEGRAÇÃO DE ASPECTOS AMBIENTAIS NO PROCESSO DE DESENVOLVIMENTO DE PRODUTOS}

Dissertação apresentada à Escola Politécnica da Universidade de São Paulo para obtenção do título de Mestre em Engenharia de Produção. 


\section{DESIGN PARA O AMBIENTE: ANÁLISE DA INTEGRAÇÃO DE ASPECTOS AMBIENTAIS NO PROCESSO DE DESENVOLVIMENTO DE PRODUTOS}

Dissertação apresentada à Escola Politécnica da Universidade de São Paulo para obtenção do título de Mestre em Engenharia de Produção.

Área de Concentração:

Qualidade e Engenharia do Produto.

Orientador: Professor Livre-Docente Paulo Augusto Cauchick Miguel 
Este exemplar foi revisado e alterado em relação à versão original, sob responsabilidade única do autor e com a anuência de seu orientador.

São Paulo, 23 de julho de 2012.

Assinatura do autor

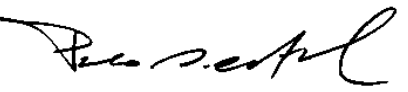

Assinatura do orientador

FICHA CATALOGRÁFICA

Silva, Luciana do Carmo Leite

Design para o ambiente: análise da integração de aspectos ambientais no processo de desenvolvimento de produtos $I$ L.C.L. Silva. -- ed.rev. -- São Paulo, 2012.

$166 \mathrm{p}$.

Dissertação (Mestrado) - Escola Politécnica da Universidade de São Paulo. Departamento de Engenharia de Produção.

1. Desenvolvimento de produtos (Aspectos ambientais) 2. Estudo de caso I. Universidade de São Paulo. Escola Politécnica. Departamento de Engenharia de Produção II. t. 


\section{DEDICATÓRIA}

Dedico este trabalho aos amores da minha vida: Às pessoas que sempre me fizeram acreditar na realização dos meus sonhos e trabalharam muito para que eu pudesse realizá-los, meus pais, Angelo e Maria de Lourdes.

$\mathrm{E}$ a quem compartilhou comigo as alegrias e sempre me apoiou nas horas difíceis, companheiro no amor, na vida e nos sonhos, meu noivo, Herbert. 


\section{AGRADECIMENTOS}

Á Paulo Augusto Cauchick Miguel, pela orientação, paciência e pelo constante estímulo transmitido durante todo o trabalho.

Aos meus pais, Angelo Innocêncio da Silva, in memoriam, e Maria de Lourdes Leite da Silva, por todo o amor, carinho, apoio e dedicação; por terem feito todos os esforços no sentido de me ensinar a importância da constante busca pelo conhecimento; e por terem me ensinado que a realização de nossos sonhos só é válida quando alcançada através dos nossos próprios esforços.

Ao meu noivo, Herbert de Camargo Kootke, por todo o amor, carinho, compreensão, apoio e sugestões durante esta jornada.

Aos meus sogros, Henrique de Camargo Kootke e Roseli de Almeida Moraes, pelo carinho, compreensão e apoio durante este trabalho.

Aos nossos cachorros, Rick e Lost, pelo seu companheirismo e pelas noites em claro.

Aos amigos e aos colegas de pós-graduação, em especial à Elaine Inácio Bueno, Mauro Yuji Ohara e Angelo Varandas Junior, pelas dicas, desabafos e apoio.

Aos meus irmãos, sobrinhos, familiares e amigos, que me apoiaram e compreenderam a minha ausência nestes anos.

Aos meus alunos pelo constante apoio e cooperação.

E a todos que contribuíram direta ou indiretamente, na execução deste trabalho. 
"O maior bem que o pai pode deixar aos seus filhos, é a educação"

(Autor Desconhecido) 


\section{RESUMO}

O mercado consumidor está cada vez mais propenso a exigir posturas corporativas sustentáveis das organizações. Nesse sentido, muitos estudos têm sido realizados sobre a incorporação destes conceitos nas organizações. A literatura apresenta diversos benefícios disponíveis para empresas com iniciativas ecologicamente corretas como benefícios financeiros, mercadológicos, valorização das ações da empresa e geração de inovações em produtos e processos, construindo vantagens absolutas sobre outras organizações. Esses benefícios têm desencadeado uma série de iniciativas voltadas para a integração de aspectos ambientais no Processo de Desenvolvimento de Produtos, particularmente, em grandes empresas. Este tipo de inovação envolve uma série de práticas, modelos de negócio e mudanças no pensamento individual e organizacional. No entanto, na maioria das empresas, prevalecem atitudes pontuais nos seus processos, com tolerância para atitudes de redução ou minimização da poluição. Estas posturas evidenciam que, apesar dos benefícios descritos, muitas empresas ainda resistem à implementação destas práticas, revelando que esta resistência pode residir nos custos ou na complexidade de implementação destas práticas. Neste contexto, o presente estudo tem como objetivo realizar uma análise sobre como ocorre a integração de aspectos ambientais no Processo de Desenvolvimento de Produtos (PDP). Para tanto, estruturou-se uma pesquisa com base na teoria vigente e na condução de um estudo de caso múltiplo com duas unidades de análise. Com o estudo de caso, o trabalho busca responder as questões de pesquisa relacionadas à como ocorre a escolha e a incorporação de métodos e/ou ferramentas de apoio no PDP. A principal conclusão do estudo é que questões como contexto mercadológico, porte, setor de atuação, severidade da legislação ambiental no setor, cultura organizacional e nível/estágio de implementação do DfE contingenciam as formas de Integração de aspectos ambientais no PDP, apontando para a necessidade de criação de um modelo contingencial para este processo.

Palavras-chave: Desenvolvimento de Produtos. Design para o Ambiente (DfE - Design for Environment). Revisão da Literatura. Estudo de Caso. 


\begin{abstract}
The consumer market is increasingly likely to require sustainable corporate postures from the organizations. Many studies have been conducted on the incorporation of these concepts in organizations. The literature presents many benefits available to companies with green initiatives as financial and marketing benefits, the valuation of the company's stocks and products and processes innovations, creating competitive advantage. These benefits have sparked many initiatives aimed at product development focused on environmental issues, specially, in large companies. This type of innovation involves a series of methods, business models and changes in individual and organizational thinking. However, in most companies, prevail specific attitudes in their processes, with tolerance for attitudes of pollution reduction or minimization. These attitudes show that, despite the benefits described, many companies still resist the implementation of these methods, revealing that resistance may reside in costs or complexity of implementing these methods. In this context, this study aims to conduct an analysis on how the integration of environmental issues in Product Development Process (PDP) occurs. To do so, a research was structured based on current theory and conducting a multiple case study with two units of analysis. With the case study, the work seeks to answer research questions related to how does the selection and incorporation of methods and/or tools in the PDP occurs. The main conclusion of the study is that issues such as marketing context, size, sector of operation, severity of environmental legislation in the sector, organizational culture and level/stage of implementation of DfE sets out the forms of integration of environmental aspects in the PDP, pointing to the need to establish a contingency model for this process.
\end{abstract}

Key Words: Product Development. Design for Environment (DfE). Literature Review. Case Study. 


\section{LISTA DE ILUSTRAÇÕES}

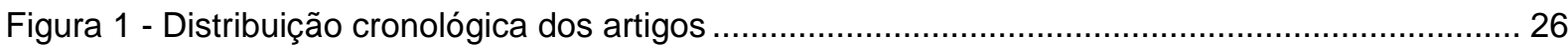

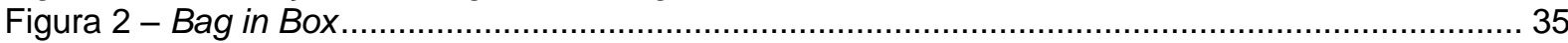

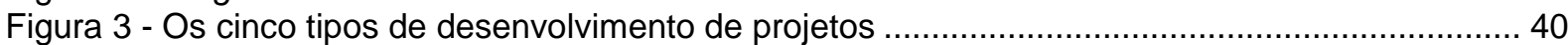

Figura 4 - Atenção e Influência da ação gerencial, impacto no tempo .............................................. 42

Figura 5 - Design para o Ambiente (Design for Environment - DfE) ……...................................... 44

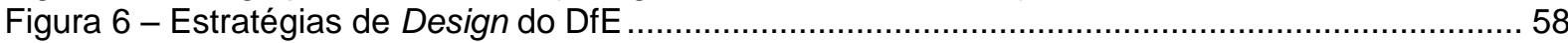

Figura 7 - Enquadramento das empresas estudadas em níveis de implementação do DfE ............. 129

Figura 8 - Modelo Contingencial de implementação para o DfE.................................................... 129 


\section{LISTA DE TABELAS}

Tabela 1 - Artigos sobre Sustentabilidade e DP - por tipo de documento ........................................ 21

Tabela 2 - Palavras-chave agrupadas por assunto em Sustentabilidade e DP ................................. 22

Tabela 3 - Palavras-chave agrupadas por assunto em Sustentabilidade Ambiental e DP ................ 23

Tabela 4 - Processo de Agrupamento e Seleção de Palavras-chave relacionadas a Design for

Environment

Tabela 5 - Quadro Resumo da segunda fase de triagem ........................................................... 24

Tabela 6 - Quadro Resumo de termos selecionados após a retirada de artigos duplicados ............... 25

Tabela 7 - Quadro Resumo de artigos após leitura dos resumos.................................................... 26

Tabela 8 - Diferenças e similaridades entre as unidades de análise .............................................. 29

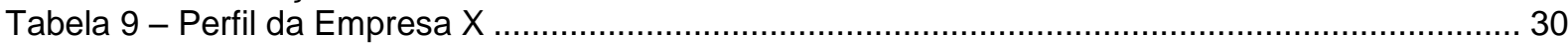

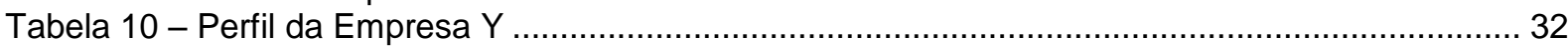

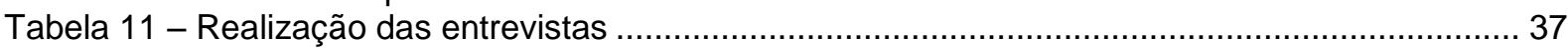

Tabela 12 - Requisitos para os Métodos de Apoio ao DfE - parte 1 ............................................ 78

Tabela 13 - Requisitos para os Métodos de Apoio ao DfE - parte 2 ….......................................... 79

Tabela 14 - Requisitos para as Ferramentas de Apoio ao DfE - parte 1 ....................................... 96

Tabela 15 - Requisitos para as Ferramentas de Apoio ao DfE - parte 2 …................................... 97

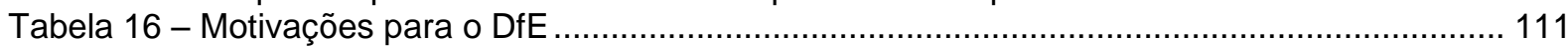

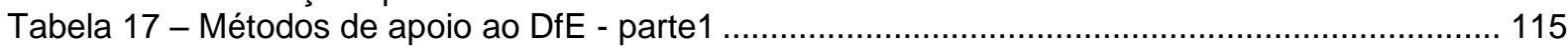

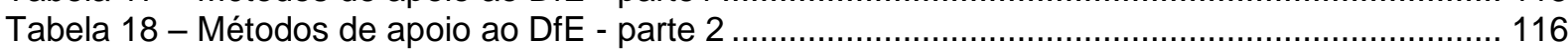

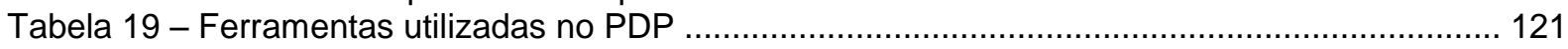

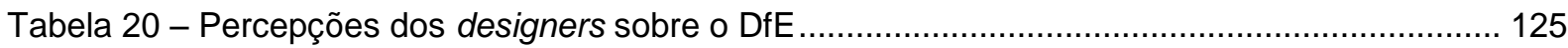

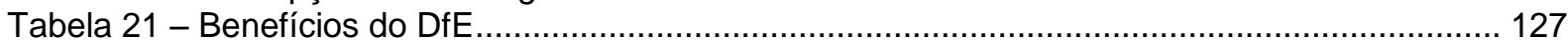




\title{
LISTA DE ABREVIATURAS E DE SIGLAS
}

\author{
ABINEE Associação Brasileira da Indústria Elétrica e Eletrônica \\ ACV Avaliação do Ciclo de Vida \\ AHP Analytic Hierarchy Process (Processo de Análise Hierárquica) \\ AM Agile Manufacturing (Manufatura Ágil) \\ ANP Analytical Network Process (Processo de Análise de Rede) \\ APQP Advanced Product Quality Planning (Planejamento Avançado da Qualidade do Produto) \\ BOM Bill of Materials (Lista de Materiais) \\ BSP Backcasting Sustainability Principles (Retrospectividade de Princípios de \\ Sustentabilidade) \\ C2C Cradle to Cradle (do berço-ao-berço) \\ C2Ga Cradle to Gate (do berço-ao-portão) \\ C2Gr Cradle to Grave (do berço-a-cova) \\ CAD Computer Aided Design (Projeto Assistido por Computador) \\ CAPES Coordenação de Aperfeiçoamento de Pessoal de Nível Superior \\ CBR Case Based Reasoning (Raciocínio Baseado em Casos) \\ CETESB Companhia Ambiental do Estado de São Paulo \\ CF Carbon Footprint (Pegada de Carbono) \\ CMFD Concurrent Multifunction Deployment (Desdobramento das Multifunções Concorrentes) \\ CSM Concept Selection Matrix (Matrix de Seleção de Conceito) \\ CV Contingent Valuation (Avaliação de Contingência) \\ DEMATEL Decision-Making Trial and Evaluation Laboratory (Laboratório de Ensaio e Avaliação de \\ Tomada de Decisão) \\ DfA Design for Assembly (Projeto para a Montagem) \\ DfD Design for Dissassembly (Projeto para a Desmontagem) \\ DfDI Design for Disassembly Index (Índice de Projeto para a Desmontagem) \\ DfE Design for Environment (Projeto para o Ambiente) \\ DfES Design for Energy Savings in the use phase (Projeto para a Economia de Energia na \\ fase de uso) \\ DfM Design for Manufacturing (Projeto para a Fabricação) \\ DfMS Design for Maintenance and Serviceability (Projeto para a Manutenção e \\ Operacionalidade) \\ DfR Design for Recyclability (Projeto para a Reciclabilidade) \\ DfRM Design for Remanufacturability (Projeto para a Remanufaturabilidade) \\ DfRU Design For Reusability (Projeto para a Reutilização) \\ DfX Design for " $X$ " (Projeto para "X") \\ DJSI Dow Jones Sustainability Indexes (Índice de Sustentabilidade Dow Jones) \\ DJSWI Dow Jones Sustainability World Index (Índice Dow Jones Mundial de Sustentabilidade) \\ D-L-N Dissassembly-Logic-Network (Rede Lógica de Desmontagem) \\ DM De-Manufacturing
}




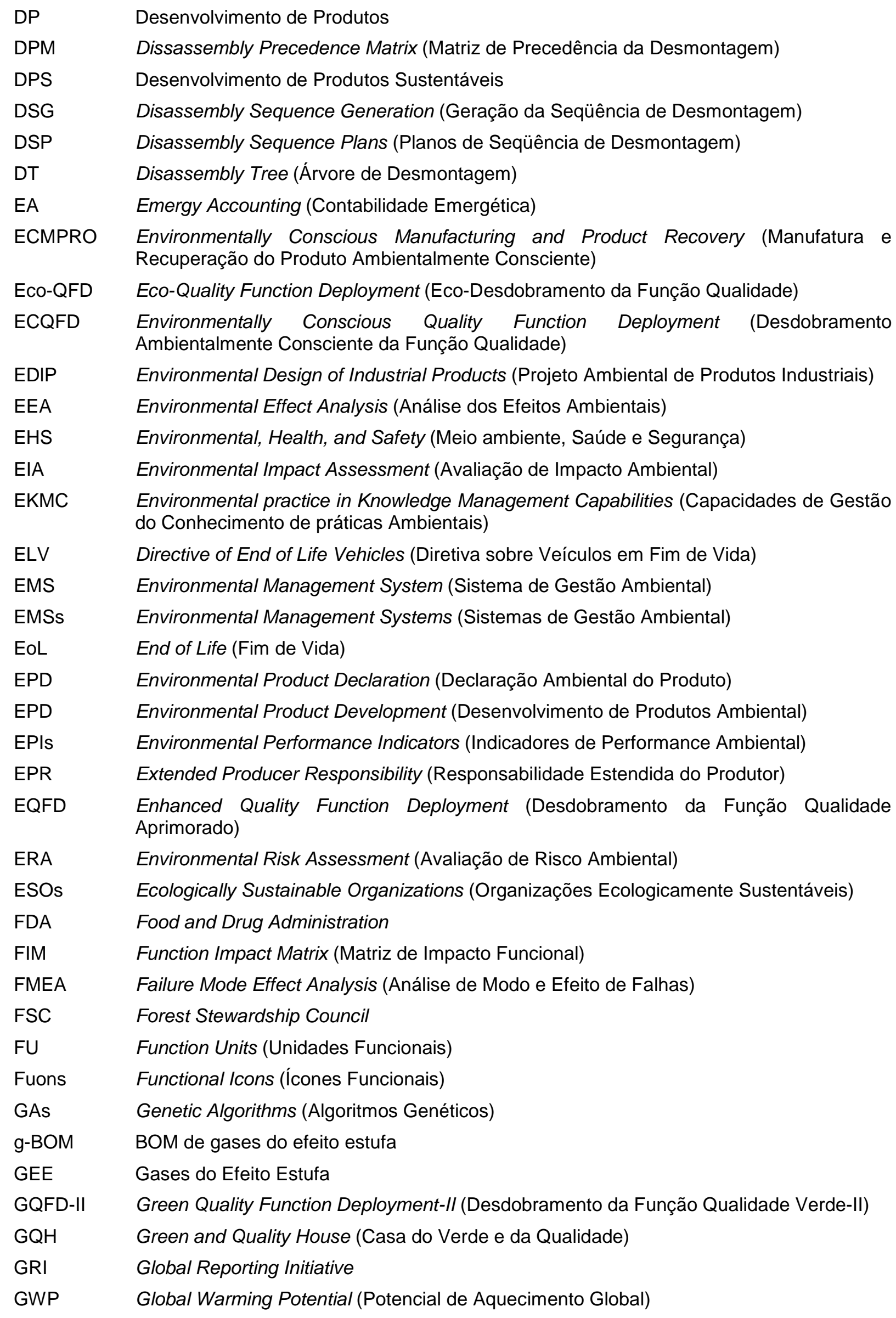




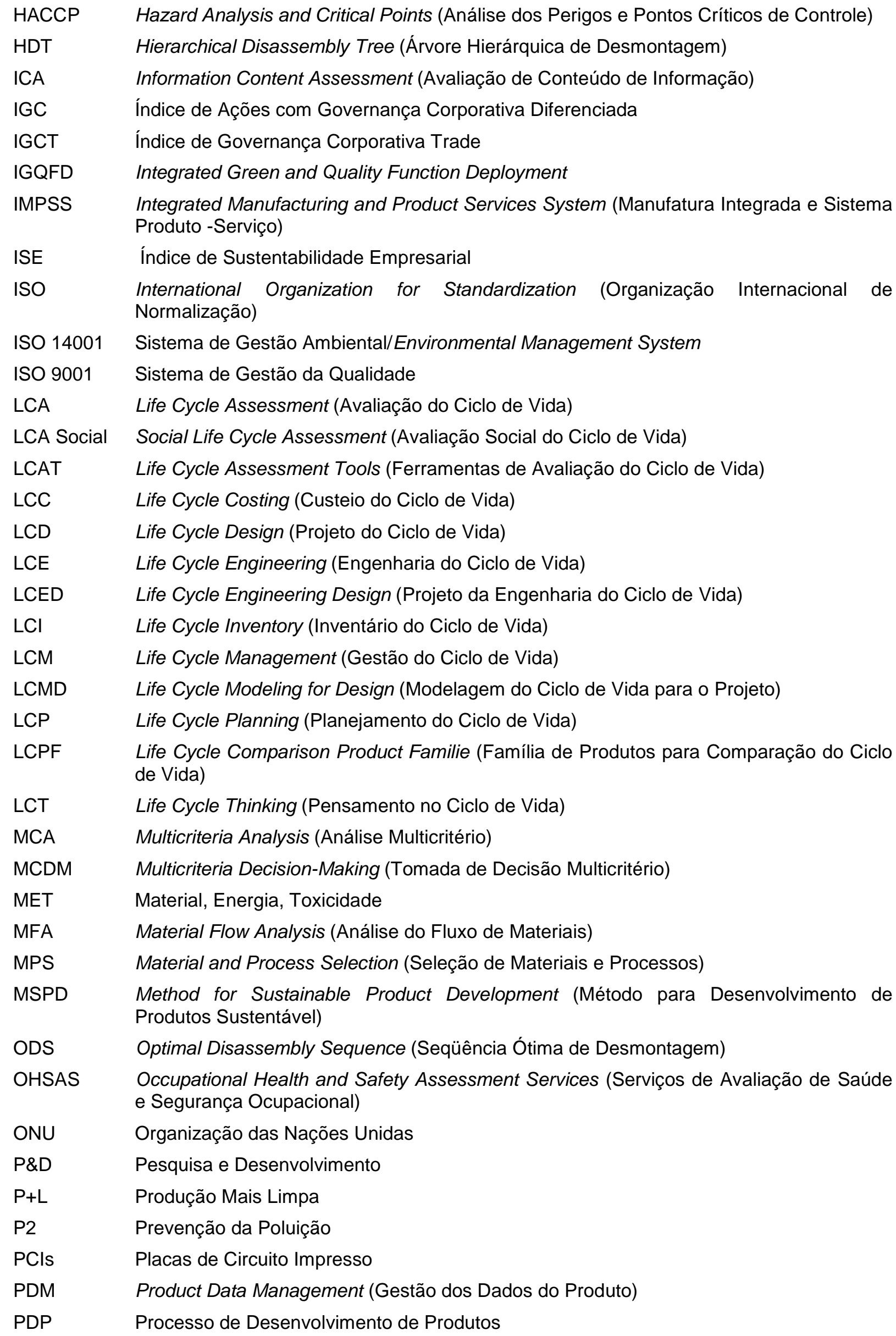


PFDR Product Family Design Re-use (Projeto para a Reutilização de Famílias de Produtos)

PLM Product Lifecycle Management (Gestão do Ciclo de Vida do Produto)

PNUD Programa das Nações Unidas para o Desenvolvimento

PNUMA Programa das Nações Unidas para o Meio Ambiente

PSI Product Sustainability Index (Índice de Sustentabilidade do Produto)

PSSs Product Service Systems (Sistemas Produto-Serviço)

QFD Quality Function Deployment (Desdobramento da Função Qualidade)

QFDE Quality Function Deployment for Environment (QFD para o Ambiente)

RFID Radio Frequency Identification Devices (Dispositivos de Identificação por Rádio Freqüência)

$\mathrm{RH} \quad$ Recursos Humanos

RIM Recycling Information Matrix (Matriz de Informação de Reciclagem)

RoHS Directive of Restriction on Hazardous Substances (Diretiva sobre Restrição de Substâncias Perigosas)

SCD Supply Chain Dynamics (Dinâmicas da Cadeia de Suprimentos)

SCM Supply Chain Management (Gestão da Cadeia de Suprimentos)

SETAC Society of Environmental Toxicology and Chemistry (Sociedade de Toxicologia e Química Ambiental)

SGA Sistema de Gestão Ambiental

SGQ Sistema de Gestão da Qualidade

SLCA Social Life Cycle Assessment (Avaliação Social do Ciclo de Vida)

SPD

Sustainable Product Development (Desenvolvimento de Produtos Sustentável)

SPSD Sustainable Product and/or Service Development (Desenvolvimento de Produtos e/ou Serviços Sustentáveis)

SRA Sustainability Risk Assessment (Avaliação de Risco da Sustentabilidade)

SRI Socially Responsible Investing (Investimentos Socialmente Responsáveis)

SRs Sustainability Risks (Riscos de Sustentabilidade)

TBL Triple Bottom Line (Tripé da Sustentabilidade)

TI Tecnologia da Informação

TRIZ Theory of Inventive Problem Solving (Teoria da Resolução Inventiva de Problemas)

TSPDs Templates for Sustainable Product Development ("Templates" de Desenvolvimento de Produtos Sustentável)

UE União Européia

UMA Unidade de Monte Alegre

UNEP United Nations Environment Programme (Programa das Nações Unidas para o Meio Ambiente)

UPK Unidade de Papéis Kraft

WEEE Directive of Waste Electrical and Electronic Equipment (Diretiva sobre Resíduos de Equipamentos Elétricos e Eletrônicos)

WTP Willingness-To-Pay (Disposição a Pagar dos clientes) 


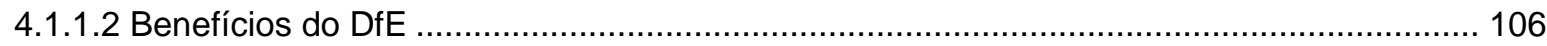

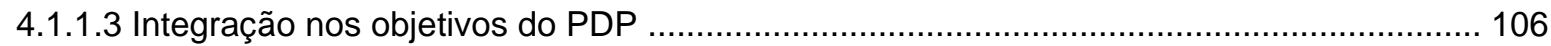

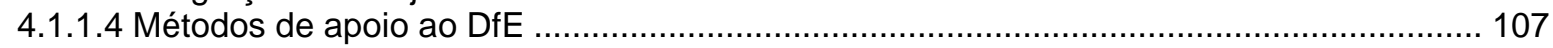

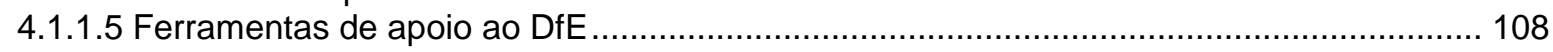

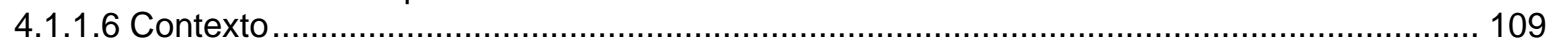

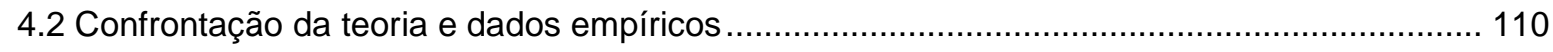

5 CONCLUSÕES E SUGESTÕES PARA TRABALHOS FUTUROS............................................ 130

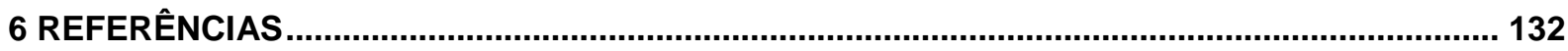

APÊNDICE A - Referências resultantes da Revisão da Literatura ............................................ 145

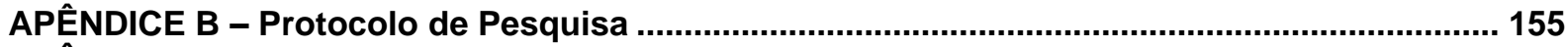

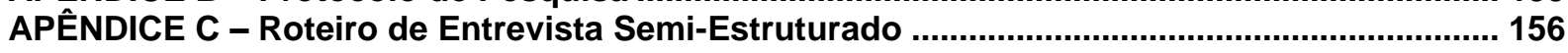

ANEXO A - Formulário de Planejamento das Atividades de Projetos (PAP) ............................. 165

ANEXO B - Formulário de Planejamento das Atividades de Projetos (PAP) - exemplo de

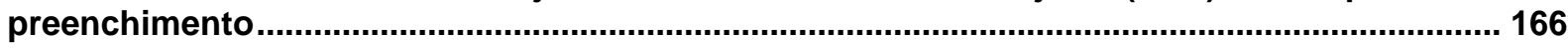




\section{INTRODUÇÃO}

Há alguns anos iniciou-se uma tendência mundial dos investidores procurarem empresas mais responsáveis, sustentáveis e rentáveis para aplicar seus recursos, como destacado pela Bovespa (2010). Tais aplicações, denominadas Investimentos Socialmente Responsáveis (Socially Responsible Investing - SRI), consideram que empresas sustentáveis geram valor para o acionista no longo prazo, pois estão mais preparadas para enfrentar riscos econômicos, sociais e ambientais (DOW JONES, 2010). Hoje essa demanda é atendida por vários instrumentos financeiros no mercado nacional e internacional como o Índice de Sustentabilidade Empresarial (ISE), lançado em 2005 (BOVESPA, 2010) e o Índice de Sustentabilidade Dow Jones (Dow Jones Sustainability Indexes DJSI), lançado em 1999, (DOW JONES, 2010). Bendavid-Val e Perine (2003) destacam que, para melhorar a competitividade das empresas, é fundamental incorporar o conceito de sustentabilidade, pois os investimentos nessa área podem atrair novos clientes em função de oferecer uma boa imagem corporativa.

Geralmente ligado ao conceito de sustentabilidade, é comum a utilização do termo "desenvolvimento sustentável" que, sob o ponto de vista corporativo, considera o tripé da sustentabilidade (Triple Bottom Line - TBL), ou seja, o alcance do equilíbrio entre a proteção ambiental, equidade social e prosperidade econômica (MAXWELL e VAN DER VORST, 2003). Este conceito, criado em 1987, pelo relatório das Nações Unidas, "Nosso Futuro Comum", marcou a década de 90 com o avanço de atitudes pró-ativas, voltadas à proteção ambiental, por parte das empresas, que começaram a vislumbrar oportunidades de mercado num primeiro momento, e barreiras à entrada num segundo momento (MAGRINI, 2001).

De modo geral, a proteção ambiental é reconhecida como um conceito importante pelas organizações modernas para a sobrevivência no mundo competitivo (BEVILACQUA, CIARAPICA e GIACCHETTA, 2007; VINODH e RATHOD, 2010b). No entanto, não há homogeneidade no tratamento da dimensão ambiental pelas empresas, e isto tem levado a literatura especializada a apresentar taxonomias de gestão ambiental empresarial constituídas por estágios evolutivos (JABBOUR e SANTOS, 2007). Dessa forma, diversos autores propõem, geralmente, três estágios evolutivos (conjuntos de razões estratégicas) para a análise e integração da gestão ambiental na empresa (HUNT e AUSTER, 1990; HART, 1995; DONAIRE, 1999; SANCHES, 2000; CORAZZA, 2003; SEIFFERT, 2005):

- Postura reativa: As questões ambientais são tratadas como geradoras de custo operacional extra e a empresa apenas reage às continuidades e descontinuidades da legislação ambiental, tentando gerir os efeitos da poluição, e não evitar que ela ocorra;

- Postura preventiva: A questão ambiental torna-se uma variável relevante para o sucesso empresarial, mas não é tida como determinante desse desempenho. Objetiva-se que a poluição não seja gerada, por meio do rearranjo dos processos produtivos, principalmente. A gestão ambiental tende a ser responsabilidade da área de gestão de produção, mas se inicia a expansão dessa responsabilidade para as demais áreas de gestão da empresa; 
- Gestão ambiental estratégica: A gestão ambiental é tomada como variável crítica do sucesso empresarial, passa a ser compartilhada pela totalidade das áreas da empresa e tende a ter o respaldo de certificações ambientais.

Caso as organizações não se adequem, voluntariamente, às modificações da postura reativa para a de além da conformidade, poderão enfrentar modificações legais e pressões de mercado, mais cedo do que o esperado (PORTER e LINDE, 1995; FURTADO, 2007; POMBO e MAGRINI, 2008). Porter e Linde (1995) propõem que os esforços de integração de aspectos ambientais nas empresas podem resultar em dois tipos de inovação que permitem reduzir os custos de entrada em conformidade com a regulamentação e construir vantagens absolutas sobre outras organizações: 1) de Produto: o desempenho ambiental do produto é melhorado e apresenta outros tipos de melhoria tais como: melhor desempenho técnico, preço, qualidade, segurança, redução de custos ou maior possibilidade de reaproveitamento e redução de custos para sua disposição final (substituição de materiais, redução de embalagens, facilidades de reciclagem ou desmanche); 2) de Processo: ao lado da redução da poluição, o novo processo leva a: melhor produtividade dos recursos; economia de materiais (devido à redução, substituição, reutilização ou reciclagem de insumos); utilização de subprodutos; menor consumo de energia; redução de estoques de materiais; conversão de resíduos em subprodutos com valor agregado; redução de custos com disposição de resíduos e maior segurança no ambiente de trabalho.

A visão estratégica requerer o engajamento das demais unidades da organização, como Finanças, Marketing, Jurídica, Recursos Humanos (RH), Logística, Suprimentos, Desenvolvimento de Produtos, entre outras (FURTADO, 2007). Esta última é o foco do presente estudo por estar em íntima conexão com todas as outras unidades, como destaca a literatura (ROZENFELD et al., 2006) e por permitir que os custos possam ser reduzidos desde o início das atividades, como pregam os princípios do Just In Time, eliminando desperdícios de retrabalho (readequação do processo produtivo e do produto com os requisitos, em constante evolução, relacionados à gestão de resíduos e impacto ambiental impostos pela legislação e pelo mercado).

Segundo Rozenfeld et al. (2006), o Processo de Desenvolvimento de Produtos (PDP) é considerado um processo de negócio cada vez mais crítico para a competitividade (rentabilidade, crescimento, fortalecimento da imagem e participação no mercado) das empresas, principalmente com a crescente internacionalização dos mercados, aumento da diversidade e variedade de produtos e redução do ciclo de vida dos produtos no mercado. O mesmo autor afirma que as empresas geralmente possuem um processo para desenvolver seus produtos, mesmo que este não seja claramente explicitado. Alguns autores, como Clark e Wheelwright (1993) e Cooper (1993), dissertam sobre a necessidade de otimização do PDP das empresas, gerenciando a sua carteira de desenvolvimento, alterando sua estrutura de trabalho, ou utilizando métodos e técnicas que facilitem o desenvolvimento de um novo produto.

As crescentes preocupações ambientais, notadamente na última década, juntamente com a pressão da opinião pública e regulamentos mais rigorosos, estão fundamentalmente impactando na forma como as empresas desenvolvem e lançam novos produtos em todo o mundo a fim de que estes permaneçam competitivos (SAVASKAN e VAN WASSENHOVE, 2006; GE e WANG, 2007; 
VACHON, 2007; VACHON e KLASSEN, 2007; CHOI, NIES e RAMANI, 2008). Afinal, o alcance da vantagem competitiva depende fortemente da capacidade da empresa em ser eco-eficiente, ou seja, de produzir bens que também satisfaçam as exigências ambientais (HUNT e AUSTER, 1990; PORTER e VAN DER LINDE, 1995; CAGNO e TRUCCO, 2007). Segundo Vinodh e Rathod (2010a), durante a última década, a integração de critérios ambientais no design de produtos e a questão de como comparar essas exigências com os requisitos de design tradicionais vêm ganhando importância vital.

Furtado (2007) afirma que iniciativas de mudança são representadas por legislação, sugestões ou códigos voluntários e a adoção de práticas ou ferramentas, como a Produção Mais Limpa (Cleaner Production ou $\mathrm{P}+\mathrm{L}$ ) que traz a visão do berço-a-cova (cradle to grave - $\mathrm{C} 2 \mathrm{Gr}$ ) (fonte de recursos materiais, métodos de extração, transporte, manufatura, uso e descarte) e aponta para aspectos tecnológicos como Ecodesign ou Design para o Ambiente (Design for Environment - DfE) e Avaliação do Ciclo de Vida (Life Cycle Assessment - LCA). O autor também se refere à Ecoefitividade (Ecoeffectiveness) que aponta para produtos desenhados para reciclabilidade (Design for Recyclability); Design para o renascimento (cradle to cradle design); uso de materiais biodegradáveis; formação de consórcio inteligente de materiais (Intelligent Materials Pooling) e para o modelo do berço-ao-berço (cradle to cradle - $\mathrm{C} 2 \mathrm{C}$ ), segundo o qual os não-produtos (resíduos) devem representar "nutrientes" para o mesmo ou para outros processos produtivos, e os materiais, retornados à natureza, devem representar nutrientes para os processos ecológicos.

A partir da conjuntura observada, percebe-se o surgimento de diversas demandas ambientais sobre o desenvolvimento de novos produtos nas últimas décadas, portanto, busca-se no presente trabalho investigar como ocorre a integração de aspectos ambientais no $\mathrm{PDP}^{1}$, como destacado a seguir.

Segundo Porter e Linde (1995), é possível verificar a gestão ambiental estratégica, principalmente, em empresas exportadoras e, quando nesse estágio, a empresa passa a desfrutar de diversos benefícios: i) Acesso a mercados de consumidores ambientalmente conscientes, com 0 marketing ambiental (GINSBERG e BLOOM, 2004); ii) Possibilidade de exportação para países com legislação ambiental mais severa (SEIFFERT, 2005); iii) Valorização das ações da empresa, conforme propõe o DJSI (PRESTON, 2001) e o ISE (BOVESPA, 2010); iv) Vantagens financeiras, por meio da exploração da imagem ambientalmente correta da empresa (MILES e COVIN, 2000); v) Redução de multas ambientais (HUNT e AUSTER, 1990); vi) Inovações em produtos e processos (PORTER e LINDE, 1995).

Segundo Senge et al. (2008), a percepção destes tipos de benefícios e as alterações climáticas, tem desencadeado uma série de iniciativas voltadas para a integração de aspectos ambientais no PDP, principalmente em empresas famosas: a DuPont, por exemplo, está alterando várias linhas de produtos, a fim de substituir o uso de petróleo e gás por um componente de origem biológica (como polímeros com base na soja e termoplásticos derivados do açúcar). Desde 1988, a Nike reduziu sua "pegada de carbono" em $75 \%$ - medida que exigiu a reavaliação do design, da

\footnotetext{
${ }^{1}$ A ISO TR 14062: Estabelece a integração de aspectos ambientais no projeto e desenvolvimento de produtos (criada em 2002 e revisada em 2004). Neste trabalho, utiliza-se a expressão "integração de aspectos ambientais (...)" "no PDP" ou "na empresa" devido à falta de nomenclatura padronizada para estes processos.
} 
produção e da distribuição dos produtos. Outros exemplos de inovações são apontados por Porter e Linde (1995). A fábrica da Rhône-Poulenc, na França, investiu 76 milhões de francos em um novo equipamento para recuperar e vender os resíduos de nylon (que costumavam ser incinerados) como corantes e aditivos para curtimento e como agentes de coagulação, gerando um retorno anual de aproximadamente 20,1 milhões de francos. A Hitachi investiu no design de seus produtos, reduzindo o tempo de desmanche e, conseqüentemente, os custos de montagem e do produto, após a implementação de uma lei de reciclagem no Japão. Segundo Senge et al. (2008), este tipo de inovação ambiental envolve uma série de práticas, modelos de negócio e mudanças no pensamento individual e organizacional, que se combinam para transformar o modo de fazer negócios, de usar a tecnologia e de envolver as pessoas.

Diversos métodos e ferramentas de apoio ${ }^{2}$ vêm sendo desenvolvidos para viabilizar a integração de aspectos ambientais no PDP (BAUMANN, BOONS e BRAGD, 2002; GE e WANG, 2007; PIGOSSO et al., 2010). No entanto, na maioria das empresas, prevalecem atitudes pontuais no fluxograma de processo de desenvolvimento de produto, com elevada tolerância para atitudes de redução ou minimização da poluição (FURTADO, 2007). Os consumidores estão se tornando mais sensíveis aos custos do ciclo de vida do produto (GINSBERG e BLOOM, 2004), mas consideram que existe um baixo número de produtos com apelo ambiental no mercado (MARX, DE PAULA e SUM, 2010). No link "Casos de Sucesso" do endereço eletrônico da Companhia Ambiental do Estado de São Paulo (CETESB) ${ }^{3}$ podem ser verificadas 111 iniciativas, de 32 empresas, voltadas para a Produção mais Limpa, classificadas em 6 tipos básicos: 1) Projeto do produto ("ecodesign", "design for environment - DfE" etc.); 2) Redução na fonte/Tecnologias mais limpas; 3) Reuso/Reciclagem de resíduos; 4) Substituição de matérias-primas/Insumos; 5) Uso racional de água; e 6) Uso racional de energia. Verifica-se que apenas $4 \%$ das iniciativas estão relacionadas a ações voltadas ao projeto de produtos e $16 \%$ à substituição de matérias primas/insumos. Estas posturas evidenciam que, apesar de os benefícios descritos acima, um número relativamente baixo de empresas vêm implementando estas práticas. Neste sentido, entende-se que esta resistência poderia residir nos custos ou na complexidade de implementação destes métodos e ferramentas de suporte a integração de aspectos ambientais no PDP.

\subsection{Objetivos e questões do trabalho}

O objetivo geral do presente trabalho é investigar como ocorre a integração de aspectos ambientais no PDP. Neste sentido, espera-se responder as seguintes questões: Como ocorre a escolha por determinado método e/ou ferramenta de apoio? Como os métodos e/ou ferramentas de

\footnotetext{
2 Segundo Furtado (2007), as iniciativas voltadas à proteção ambiental são representadas por legislação, sugestões ou códigos voluntários e a adoção de práticas ou ferramentas de apoio. Neste trabalho, são consideradas ferramentas, as técnicas, instrumentos e utensílios operacionais; e são considerados métodos, as práticas gerenciais, a aplicação de regras e princípios.

3 A Companhia Ambiental do Estado de São Paulo (CETESB) é a agência governamental responsável pelo controle, fiscalização, monitoramento e licenciamento de atividades geradoras de poluição. A CETESB é um dos 16 centros de referência da Organização das Nações Unidas - ONU para questões ambientais, atuando em estreita colaboração com os 184 países que integram esse organismo internacional. Também é órgão de referência e consultoria do Programa das Nações Unidas para o Desenvolvimento - PNUD, para questões ligadas a resíduos perigosos na América Latina.
} 
suporte escolhidos são incorporados ao PDP? Para consecução deste objetivo geral, os seguintes objetivos são considerados:

a. Identificar como ocorre a escolha por determinados métodos e/ou ferramentas de apoio a integração de aspectos ambientais no PDP.

b. Analisar como esses métodos e/ou ferramentas de apoio escolhidos são incorporados ao PDP.

\subsection{Justificativa de relevância do trabalho}

Segundo Brad (2009), a fim de competir com sucesso no mercado global, além da qualidade, alguns outros objetivos funcionais deverão ser levados em consideração no processo de otimização do design de produtos, relacionados ao design para $X$-habilidade (design for $X$-ability) nas formas de: custo, montagem, produção, meio ambiente, infraestrutura, tecnologia, serviço, reciclagem, testes, modularidade, etc. Segundo o mesmo autor, para a concepção de um produto de classe mundial, objetivos funcionais de suma importância sobre as fases do ciclo de vida do produto devem ser incluídos na equação do design e o "design para o ciclo de vida do produto" (design for product lifecycle) é o maior desafio, ou seja, design para a qualidade (design for quality); design para a conformidade (design for conformity); design para a manufatura (design for manufacturing); design para a montagem (design for assembly); design para testes (design for testing); design para fácil serviço e tele-serviços (design for easy service and tele-service); design para a fácil utilização (design for easy use); design para fácil manutenção e auto-manutenção (design for easy maintenance and self-maintenance); design para a confiabilidade (design for reliability); design para fácil substituição (design for easy replacement); design para o ambiente (design for environment); design para a desmontagem (design for de-assembly); design para a reciclagem (design for recycling); design para o reuso (design for reuse). Neste sentido, os aspectos ambientais se fazem cada vez mais presentes na realidade do desenvolvimento de novos produtos.

Apesar dos benefícios descritos por diversos autores (HUNT e AUSTER, 1990; PORTER e LINDE, 1995; MILES e COVIN, 2000; PRESTON, 2001; SEIFFERT, 2005; BOVESPA, 2010) e do crescente desenvolvimento de métodos e ferramentas de apoio à integração de aspectos ambientais no PDP (BAUMANN, BOONS e BRAGD, 2002; GE e WANG, 2007; PIGOSSO et al., 2010), a oferta de produtos com apelo ambiental, no mercado, continua restrita (CETESB, 2010; MARX, DE PAULA e SUM, 2010). Duas grandes diretivas da União Europeia (UE) orientam o fim de vida (End of Life EoL) dos produtos: a Diretiva 2000/53/EC sobre Veículos em Fim de Vida (Directive of End of Life Vehicles - ELV) e a Diretiva 2002/96/EC sobre Resíduos de Equipamentos Elétricos e Electrônicos (Waste Electrical and Electronic Equipment - WEEE). A ELV afirma que até 2015 os automóveis em fim de vida devem ser reciclados em 95\%. A WEEE, através da Responsabilidade Estendida do Produtor (Extended Producer Responsibility - EPR), torna a empresa ou organização, que coloca um determinado produto no mercado (inclusive varejistas), responsável pelos custos da coleta e reciclagem de seus produtos em fim de vida e estabelece requisitos para as operações de prétratamento e reciclagem. Existe, ainda, a Diretiva 2002/95/EC sobre Restrição de Substâncias 
Perigosas (Restriction on Hazardous Substances - RoHS), que estabelece limites para o teor de determinadas substâncias perigosas em produtos (coberto pela WEEE). Portanto, as empresas nacionais que desejarem exportar seus produtos para estes mercados, deverão se adequar a estes novos requisitos de mercado. A partir da conjuntura observada, verifica-se a necessidade de investigar como ocorre a integração de aspectos ambientais no desenvolvimento de novos produtos.

\subsection{Estrutura da dissertação}

Para o alcance dos objetivos propostos no presente trabalho, este é estruturado em 5 capítulos: Introdução, Métodos e técnicas de pesquisa, Referencial teórico, Resultados e Conclusões e sugestões para trabalhos futuros.

O capítulo 2, "Métodos e técnicas de pesquisa", apresenta as macro fases de condução do trabalho de pesquisa e a preparação para condução da parte empírica da pesquisa, no qual são discutidos e justificados os aspectos metodológicos adotados, os instrumentos de coleta e análise de dados, e os critérios para seleção das unidades de análise.

No capítulo 3, "Referencial teórico", busca-se descrever os principais conceitos relacionados a área de desenvolvimento de produtos e, em seguida, é realizada uma revisão da literatura sobre a integração de aspectos ambientais no PDP. Nesta revisão da literatura, propõe-se criar o alicerce conceitual do trabalho. As variáveis encontradas na literatura, sobre o tema, servem de base conceitual para a realização de uma investigação mais criteriosa a ser realizada sobre o tema. Neste sentido, as variáveis encontradas na literatura também servem de base para elaboração de um roteiro de entrevista utilizado na condução da parte empírica do trabalho, bem como para a análise dos resultados da pesquisa.

O capítulo 4, "Resultados", apresenta os achados na investigação empírica e está dividido em duas seções: i) Caracterização do processo de integração de aspectos ambientais no PDP, onde são descritos os casos individuais nas duas unidades de análise, mediante a caracterização dos processos de desenvolvimento de produtos e as formas de integração de aspectos ambientais particulares de cada empresa; e ii) Confrontação da teoria e dados empíricos, onde é realizada a análise cruzada dos casos confrontada aos postulados na literatura.

No capítulo 5, "Conclusões e sugestões para trabalhos futuros", são sintetizadas as principais conclusões do trabalho e algumas considerações finais. $O$ trabalho é finalizado com a apresentação das principais dificuldades encontradas durante a pesquisa, limitações do estudo e a proposição de temas a serem abordados em trabalhos futuros. 


\section{MÉTODOS E TÉCNICAS DE PESQUISA}

Este capítulo descreve as etapas utilizadas para construção e condução do presente trabalho. Além disso, trata da sustentação metodológica do trabalho de pesquisa, bem como as justificativas das escolhas dos métodos e técnicas adotados. Segundo Gil (1999), a abordagem metodológica de um trabalho de pesquisa é necessária para que as etapas de realização do trabalho sejam conduzidas com maior rigor e objetividade, com foco e limitações bem definidos, chegando-se a resultados finais confiáveis e válidos. Para consecução dos objetivos propostos na Introdução, o trabalho está subdividido nas seguintes partes:

I. Revisão da Literatura: delineamento dos limites da teoria revelando o que a literatura propõe para a integração de aspectos ambientais no PDP.

a. Varredura Horizontal ${ }^{4}$ : O tema ambiental conta com terminologia diversificada. Assim, realizou-se uma Varredura Horizontal para delinear, dentro do amplo tema "Sustentabilidade", o que se tem apresentado dentro da vertente ambiental.

b. Varredura Vertical: Partindo da Varredura Horizontal, parte-se para o estudo da área de interesse deste trabalho, ou seja, a integração de aspectos ambientais no PDP. Esta etapa, ainda, subsidia a consecução das seguintes etapas da pesquisa: Il.a. Seleção da unidade de análise; II.b. Procedimentos de coleta dos dados; e II.c. Desenvolvimento do protocolo de pesquisa.

II. Investigação Empírica: permite responder as questões, relacionadas a como ocorrem a escolha e a incorporação dos métodos e ferramentas de apoio ao PDP. Portanto, a Investigação Empírica auxilia na realização dos objetivos 1.a e 1.b, subdividida nas seguintes partes:

a. Seleção da unidade de análise

b. Procedimentos de coleta dos dados

c. Desenvolvimento do protocolo de pesquisa

III. Confrontação da teoria e dados empíricos: os resultados empíricos são confrontados com a literatura, mostrando a inserção de métodos e ferramentas de apoio no PDP das empresas investigadas.

A seguir, é realizada uma descrição detalhada dos métodos e técnicas de pesquisa, e a escolha destes é justificada com base na literatura e nos objetivos propostos.

\subsection{Revisão da Literatura}

Esta etapa do trabalho é de caráter teórico-conceitual, construída com base na literatura vigente. A revisão da literatura é dividida nas etapas apontadas anteriormente:

\footnotetext{
${ }^{4}$ Nesta pesquisa utiliza-se o conceito de Hart (2001), de procurar na literatura itens relevantes, utilizando-se a estratégia "Trawling and Mining for Information", para planejamento e preparação da pesquisa. Na primeira fase, é realizada uma busca bibliográfica ampla sobre determinado tema (varredura horizontal) e depois uma busca mais focada sobre determinado assunto de interesse (varredura vertical), selecionando itens relevantes e realizando uma análise crítica sobre os itens encontrados.
} 
a. Varredura Horizontal: A primeira fase buscou artigos por meio das palavras "sustentabilidade" e "desenvolvimento de produto" e os analisou no intuito de encontrar os termos mais gerais, relacionados à integração de aspectos ambientais no PDP;

b. Varredura Vertical: Os termos encontrados são utilizados para a busca por artigos mais específicos relacionados à integração de aspectos ambientais no PDP. A partir dos resultados obtidos é feita uma análise descritiva de conteúdo dos estudos relacionados à integração de aspectos ambientais no PDP.

\subsubsection{Varredura Horizontal}

A primeira etapa de busca foi realizada, por cerca de um mês, em bases científicas de dados disponíveis no portal de periódicos da CAPES e na biblioteca virtual da USP (SibiNet). Dentre as bases pesquisadas encontram-se: ISI Web of Knowledge; Ebsco; Scielo e Scopus.

Os trabalhos foram selecionados pelas seguintes palavras chave, em periódicos internacionais de língua inglesa: sustainability AND "product development" em todos os campos e, em segunda rodada, sustainable AND "product development". Nos periódicos nacionais as palavras chave foram: sustentabilidade AND "desenvolvimento de produto" em todos os campos e, em segunda rodada, sustentável AND "desenvolvimento de produto". Descartadas as ocorrências duplicadas, chegou-se ao número de publicações mostrado na Tabela 1.

Tabela 1 - Artigos sobre Sustentabilidade e DP - por tipo de documento

\begin{tabular}{lclc}
\hline \multicolumn{3}{c}{ Tipo de documento } \\
\hline Artigos em periódico & 616 & Patentes & 2 \\
Artigos em periódico No prelo & 3 & Notícias & 2 \\
Artigos em Conferência/Congressos & 417 & Revisão da Literatura & 225 \\
Editoriais & 7 & Short Surveys & 51 \\
Notas $^{*}$ & 39 & & \\
\hline Total & & & 1362 \\
\hline
\end{tabular}

* descrições curtas de descobertas em pesquisas atuais

Fonte: Elaborado pelo autor.

A busca bibliográfica filtrou as análises apenas em artigos publicados em periódicos, dado que esse tipo de publicação é submetida a critérios rigorosos de avaliação por pares. Portanto, foram excluídos os artigos em conferência, editoriais, notas, patentes e notícias, resultando em 895 artigos. A partir destes artigos, foi realizada uma busca pelas principais temáticas abordadas sobre sustentabilidade no Desenvolvimento de Produtos através de suas palavras-chave, resultando em 4.592 termos (fornecidos pelos autores e pelas bases de dados) com 11.434 ocorrências no banco de dados obtido, por exemplo: a palavra "recycling" apresentou 47 ocorrências. A seguir, os termos foram agrupados em grandes grupos, de acordo com a temática abordada. Na Tabela 3, verifica-se que as ocorrências de termos para os "aspectos ambientais" superam os termos relacionados a "Desenvolvimento de Produto" e os termos relacionado à "Sustentabilidade" em seu sentido geral. 
Tabela 2 - Palavras-chave agrupadas por assunto em Sustentabilidade e DP

\begin{tabular}{lcc}
\hline Palavras-chave agrupadas por Assunto & Ocorrências & $\%$ \\
\hline Aspectos ambientais & 1243 & $10,87 \%$ \\
Desenvolvimento de Produto & 1216 & $10,63 \%$ \\
Sustentabilidade & 732 & $6,40 \%$ \\
Industria & 377 & $3,30 \%$ \\
Aspectos Econômicos & 362 & $3,17 \%$ \\
Saúde & 322 & $2,82 \%$ \\
Produção e Operações & 286 & $2,50 \%$ \\
Marketing & 262 & $2,29 \%$ \\
Países e Regiões & 252 & $2,20 \%$ \\
Tecnologia & 244 & $2,13 \%$ \\
Química & 220 & $1,92 \%$ \\
Estratégia & 192 & $1,68 \%$ \\
Inovação & 186 & $1,63 \%$ \\
Tecnologia da Informação (TI) & 179 & $1,57 \%$ \\
Consumidor & 176 & $1,54 \%$ \\
Nomes de Empresas & 151 & $1,32 \%$ \\
Competitividade & 137 & $1,20 \%$ \\
Biologia & 130 & $1,14 \%$ \\
Aspectos Sociais & 122 & $1,07 \%$ \\
Têxteis & 114 & $1,00 \%$ \\
Cadeia de Suprimentos & 111 & $0,97 \%$ \\
Qualidade & 108 & $0,94 \%$ \\
Papel e Celulose & 106 & $0,93 \%$ \\
Tomada de Decisão & 91 & $0,80 \%$ \\
Conhecimento & 91 & $0,80 \%$ \\
Construção Civil & 84 & $0,73 \%$ \\
Legislação e normas & 83 & $0,73 \%$ \\
Automobilística & 78 & $0,68 \%$ \\
Embalagens & 41 & $0,36 \%$ \\
Outros & 3738 & $32,69 \%$ \\
\hline Total & 11434 & $100,00 \%$ \\
\hline
\end{tabular}

Fonte: Elaborado pelo autor.

Em seguida, deu-se inicio à análise das 1243 palavras relacionadas aos "aspectos ambientais", permitindo identificar, de uma forma mais abrangente, os principais termos utilizados nos estudos sobre a integração de aspectos ambientais no PDP. Assim, as palavras foram agrupadas, de acordo com a temática abordada, resultando nos 40 grandes grupos de palavras-chave apresentados na Tabela 3. A seguir, iniciou-se o agrupamento e seleção dos termos constantes em cada um dos grupos, sob os seguintes critérios apresentados em ordem de prioridade: 1) Relevância para a temática de Desenvolvimento de Produto; 2) Agrupamento e seleção conforme grafia e morfologia dos termos, por exemplo: a utilização ou não do hífen na palavra ecodesign ou eco-design; e 3) Número de ocorrências. A Tabela 4 mostra um exemplo deste processo para o termo Design for Environment. 
Tabela 3 - Palavras-chave agrupadas por assunto em Sustentabilidade Ambiental e DP

\begin{tabular}{|c|c|c|}
\hline Palavras-chave agrupadas por Assunto & Ocorrências & $\%$ \\
\hline Ciclo de Vida & 197 & $15,85 \%$ \\
\hline Impacto Ambiental & 109 & $8,77 \%$ \\
\hline Ecodesign & 93 & $7,48 \%$ \\
\hline Resíduos & 81 & $6,52 \%$ \\
\hline Reciclagem/Reuso/Reutilização & 71 & $5,71 \%$ \\
\hline Florestas & 70 & $5,63 \%$ \\
\hline Emissões & 52 & $4,18 \%$ \\
\hline Produtos e Materiais Sustentáveis & 49 & $3,94 \%$ \\
\hline Ecologia/Meio Ambiente & 44 & $3,54 \%$ \\
\hline Processo/Produção Sustentáveis & 41 & $3,30 \%$ \\
\hline Proteção Ambiental & 39 & $3,14 \%$ \\
\hline Poluição & 37 & $2,98 \%$ \\
\hline Práticas/Políticas/Estratégias Ambientais ou Sustentáveis & 36 & $2,90 \%$ \\
\hline Água & 25 & $2,01 \%$ \\
\hline Gestão/Consultoria & 25 & $2,01 \%$ \\
\hline Engenharia & 24 & $1,93 \%$ \\
\hline Biodiversidade & 23 & $1,85 \%$ \\
\hline Recursos Renováveis & 23 & $1,85 \%$ \\
\hline Design for environment (DfE) & 21 & $1,69 \%$ \\
\hline Recursos Naturais & 19 & $1,53 \%$ \\
\hline Ambiental (Aspecto/Conceito/Critério/Atributo/Fator) & 18 & $1,45 \%$ \\
\hline Responsabilidade/Sustentabilidade Ambiental & 14 & $1,13 \%$ \\
\hline Eco-Indicadores & 13 & $1,05 \%$ \\
\hline Ferramentas Diversas & 12 & $0,97 \%$ \\
\hline Análise/Avaliação Ambiental & 11 & $0,88 \%$ \\
\hline Certificação Ambiental & 11 & $0,88 \%$ \\
\hline Tecnologia Ambiental/Sustentável & 11 & $0,88 \%$ \\
\hline Energia & 9 & $0,72 \%$ \\
\hline Estado do Meio Ambiente & 9 & $0,72 \%$ \\
\hline Estratégias End-of-life (EoL) & 9 & $0,72 \%$ \\
\hline Legislação, Normas e Procedimentos & 9 & $0,72 \%$ \\
\hline Eco-eficiência & 8 & $0,64 \%$ \\
\hline Design for sustainability & 6 & $0,48 \%$ \\
\hline Benefícios Ambientais & 5 & $0,40 \%$ \\
\hline Construção Civil & 5 & $0,40 \%$ \\
\hline Organizações ligadas ao Meio Ambiente & 5 & $0,40 \%$ \\
\hline Química & 4 & $0,32 \%$ \\
\hline Design for recycling & 2 & $0,16 \%$ \\
\hline Design re-use & 2 & $0,16 \%$ \\
\hline Design for longevity & 1 & $0,08 \%$ \\
\hline Total & 1243 & $100,00 \%$ \\
\hline
\end{tabular}

Fonte: Elaborado pelo autor. 
Tabela 4 - Processo de Agrupamento e Seleção de Palavras-chave relacionadas a Design for Environment

\begin{tabular}{lcllc}
\hline \multicolumn{1}{c}{ Palavras Encontradas } & Ocor. & \multicolumn{1}{c}{ Agrupamento e Seleção } & Ocor. \\
\hline Design for environment & 11 & Design for environment & 15 \\
Design for environment (DfE) & 4 & & \\
Design for the environment & 4 & Design for the environment & 4 \\
Design for the environments & 1 & Design for the-environments & 1 \\
Design-for-the-environment & 1 & Design-for-the-environment & 1 \\
\hline Total & 21 & Total & 19 \\
\hline
\end{tabular}

Fonte: Elaborado pelo autor.

Em seguida, grupos que poderiam enveredar as buscas para estudos a respeito de práticas adversas ao desenvolvimento de produto, por exemplo: o grupo denominado "Água" (tratamento, poluição, filtragem, gestão da água, etc.), foram eliminados. A partir dos grupos remanescentes, uma nova etapa de eliminações e agrupamentos, foi realizada a partir de uma análise intergrupos, resultando nas 45 palavras apresentadas na Tabela 5 . Ao iniciar as buscas, verificou-se que destas, as 37 palavras assinaladas com um asterisco $\left(^{*}\right)$ só levariam a estudos voltados ao PDP se estivessem acompanhadas do termo "Desenvolvimento de Produto" (product development).

Tabela 5 - Quadro Resumo da segunda fase de triagem

\begin{tabular}{lcclcc}
\hline \multicolumn{1}{c}{ Palavras selecionadas } & & Ocor. & Palavras selecionadas & Ocor. \\
\hline Clean technology & $*$ & 1 & Responsible consumers & $*$ & 2 \\
Cleaner products & $*$ & 1 & Reusability & $*$ & 3 \\
Eco-Benchmark & $*$ & 1 & Reuse & $*$ & 1 \\
Eco-efficiency & $*$ & 5 & Reverse logistics & $*$ & 3 \\
Eco-efficient & $*$ & 2 & Source control & $*$ & 1 \\
Eco-innovation & $*$ & 3 & Sustainable design & $*$ & 3 \\
Ecologically intelligent designs & $*$ & 1 & Sustainable innovation & $*$ & 7 \\
End-of-life & $*$ & 4 & Sustainable product & $*$ & 27 \\
Environment Design & $*$ & 2 & Sustainable products & $*$ & 11 \\
Environmental & $*$ & 180 & Sustainable raw materials & $*$ & 1 \\
Environmentally & $*$ & 5 & Sustainable technologies & $*$ & 2 \\
EoL Strategies & $*$ & 3 & Sustainable technology & $*$ & 1 \\
Extended producer responsibility & $*$ & 2 & Sustainable use & $*$ & 2 \\
Green & $*$ & 7 & Ecodesign & 17 \\
Greening suppliers & $*$ & 2 & Eco-design & 11 \\
Impact assessment & $*$ & 7 & Environmental product design & & 2 \\
Inverse manufacturing & $*$ & 1 & Design for environment & 15 \\
Life Cycle & $*$ & 152 & Design for longevity & 1 \\
Material flow analysis (MFA) & $*$ & 2 & Design for recycling & 2 \\
Material safety data sheet (MSDS) & $*$ & 1 & Design for sustainability & 6 \\
Recyclability & $*$ & 1 & Design for the environment & 4 \\
Recyclable Materials & $*$ & 1 & Design re-use & 2 \\
Recycling & $*$ & 57 & & \\
\hline Total & Fonte: Elaborado pelo autor & 565 \\
\hline
\end{tabular}

Fonte: Elaborado pelo autor.

De posse das principais palavras chave relacionadas à integração de aspectos ambientais no PDP, partiu-se para a Varredura Vertical, descrita na seqüência. 


\subsubsection{Varredura Vertical}

Nesta fase, alguns critérios foram utilizados para orientar as buscas, com base em características observadas nos resultados da Varredura Horizontal: a) Artigos em periódicos: esse tipo de publicação é submetida a critérios mais rigorosos de avaliação por pares; b) Artigos completos em língua inglesa ou portuguesa: visto que neste caso, não será possível uma análise baseada apenas em Resumo e Palavras-Chave; c) Área de Gestão de Operações e Ciências Sociais e Ambientais: evitando estudos sobre materiais, estudos técnicos nas áreas químicas, biológicas, médicas, entre outras correlatas; e d) Uso de bases de dados importantes: ISI Web of Knowledge; Ebsco; Scielo e Scopus. Também optou-se por utilizar os termos obtidos na Varredura Horizontal acompanhados do termo "desenvolvimento de produto" (product development) em todos os casos.

Os artigos que retornaram das buscas foram, a princípio, contabilizados na integra de modo a viabilizar a identificação de termos análogos. Portanto, os primeiros resultados indicaram artigos que apareciam em duas ou mais buscas, repetidamente, totalizando 2.240 ocorrências. Um posterior agrupamento e seleção resultou nos 1401 artigos apresentados na Tabela 6, viabilizando uma redução e refinamento do grupo de palavras-chave que permitiu delinear os termos chave relativos à integração de aspectos ambientais no PDP. Os artigos encontrados em mais de uma categoria foram contabilizados apenas na categoria com maior número de artigos (por exemplo: um artigo que retornasse nas buscas para os termos "Environmental", "Impact assessment" e "Life Cycle", com 633, 28 e 829 artigos respectivamente, seria mantido nas buscas do termo "Life Cycle" e eliminado das demais). $O$ mesmo critério foi utilizado em relação às bases de dados.

Tabela 6 - Quadro Resumo de termos selecionados após a retirada de artigos duplicados

\begin{tabular}{|c|c|c|c|c|c|c|c|c|c|c|c|}
\hline Palavras selecionadas & $\begin{array}{l}E \\
B \\
S \\
C \\
O\end{array}$ & $\begin{array}{l}\mathrm{I} \\
\mathrm{S} \\
\mathrm{I}\end{array}$ & $\begin{array}{l}S \\
C \\
O \\
P \\
U \\
S\end{array}$ & $\begin{array}{c}S \\
C \\
\text { I } \\
E \\
L \\
O\end{array}$ & $\begin{array}{l}\mathrm{T} \\
\mathrm{O} \\
\mathrm{T} \\
\mathrm{A} \\
\mathrm{L}\end{array}$ & Palavras selecionadas & $\begin{array}{l}E \\
B \\
S \\
C \\
O\end{array}$ & $\begin{array}{l}\mathrm{I} \\
\mathrm{S} \\
\mathrm{I}\end{array}$ & $\begin{array}{l}S \\
C \\
O \\
P \\
U \\
S\end{array}$ & $\begin{array}{c}S \\
C \\
\text { I } \\
E \\
L \\
O\end{array}$ & $\begin{array}{l}\mathrm{T} \\
\mathrm{O} \\
\mathrm{T} \\
\mathrm{A} \\
\mathrm{L}\end{array}$ \\
\hline End-of-life & 0 & 3 & 8 & 0 & 11 & Reusability & 0 & 2 & 25 & 0 & 27 \\
\hline Environment Design & 0 & 1 & 3 & 0 & 4 & Reuse & 1 & 56 & 36 & 0 & 93 \\
\hline Environmental & 5 & 186 & 256 & 2 & 449 & Reverse logistics & 0 & 0 & 4 & 0 & 4 \\
\hline Environmentally & 0 & 2 & 1 & 0 & 3 & Sustainable innovation & 0 & 1 & 0 & 0 & 1 \\
\hline Extended producer responsibility & 0 & 0 & 1 & 0 & 1 & Sustainable product & 0 & 2 & 1 & 0 & 3 \\
\hline Green & 2 & 9 & 8 & 0 & 19 & Sustainable products & 0 & 1 & 0 & 0 & 1 \\
\hline Impact assessment & 0 & 0 & 1 & 0 & 1 & Sustainable technologies & 0 & 1 & 0 & 0 & 1 \\
\hline Life Cycle & 5 & 182 & 553 & 1 & 741 & Sustainable use & 2 & 0 & 0 & 0 & 2 \\
\hline Material safety data sheet & 0 & 0 & 1 & 0 & 1 & Design for environment & 0 & 3 & 1 & 0 & 4 \\
\hline Recycling & 0 & 0 & 29 & 0 & 29 & Design for the environment & 0 & 5 & 0 & 0 & 5 \\
\hline Responsible consumers & 0 & 1 & 0 & 0 & 1 & & & & & & \\
\hline Total & & & & & & 22 termos & 15 & 455 & 928 & 3 & 1401 \\
\hline
\end{tabular}

Fonte: Elaborado pelo autor.

Posteriormente, deu-se início à leitura dos resumos eliminando: (i) os artigos que não fossem veiculados em periódicos científicos (apesar da utilização dos filtros nas bases de dados, alguns 
artigos estavam classificados erroneamente) e (ii) os artigos que apenas citavam os termos, mas não tratavam efetivamente da integração de aspectos ambientais no PDP. A Tabela 7 apresenta os 346 artigos resultantes e a Figura 1 demonstra a sua distribuição cronológica. É possível perceber uma considerável redução no número de artigos (dos 1401 iniciais para 346 artigos), evidenciando que a falta de nomenclatura uniformizada dificulta o trabalho de pesquisa, tanto para a busca de literatura, quanto para orientar novas pesquisas para o desenvolvimento do tema de forma efetiva e eficaz.

Tabela 7 - Quadro Resumo de artigos após leitura dos resumos

\begin{tabular}{|c|c|c|c|c|c|c|c|c|c|c|c|}
\hline Palavras selecionadas & $\begin{array}{l}E \\
B \\
S \\
C \\
O\end{array}$ & $\begin{array}{l}\text { I } \\
\text { S } \\
1\end{array}$ & $\begin{array}{l}S \\
C \\
O \\
P \\
U \\
S\end{array}$ & $\begin{array}{l}S \\
C \\
I \\
E \\
L \\
O\end{array}$ & $\begin{array}{l}\mathrm{T} \\
\mathrm{O} \\
\mathrm{T} \\
\mathrm{A} \\
\mathrm{L}\end{array}$ & Palavras selecionadas & $\begin{array}{l}E \\
B \\
S \\
C \\
O\end{array}$ & $\begin{array}{l}\text { I } \\
\text { S } \\
\text { I }\end{array}$ & $\begin{array}{l}S \\
C \\
O \\
P \\
U \\
S\end{array}$ & $\begin{array}{l}S \\
C \\
I \\
E \\
L \\
O\end{array}$ & $\begin{array}{l}\mathrm{T} \\
\mathrm{O} \\
\mathrm{T} \\
\mathrm{A} \\
\mathrm{L}\end{array}$ \\
\hline End-of-life & 0 & 2 & 5 & 0 & 7 & Reuse & 0 & 2 & 1 & 0 & 3 \\
\hline Environmental & 3 & 49 & 80 & 1 & 133 & Reverse logistics & 0 & 0 & 4 & 0 & 4 \\
\hline Green & 1 & 1 & 1 & 0 & 3 & Sustainable product & 0 & 1 & 0 & 0 & 1 \\
\hline Life Cycle & 2 & 53 & 127 & 0 & 182 & Sustainable products & 0 & 1 & 0 & 0 & 1 \\
\hline Recycling & 0 & 0 & 7 & 0 & 7 & Sustainable technologies & 0 & 1 & 0 & 0 & 1 \\
\hline Responsible consumers & 0 & 1 & 0 & 0 & 1 & Design for environment & 0 & 2 & 0 & 0 & 2 \\
\hline Reusability & 0 & 0 & 1 & 0 & 1 & & & & & & \\
\hline Total & & & & & & & 6 & 113 & 226 & 1 & 346 \\
\hline
\end{tabular}

Fonte: Elaborado pelo autor.

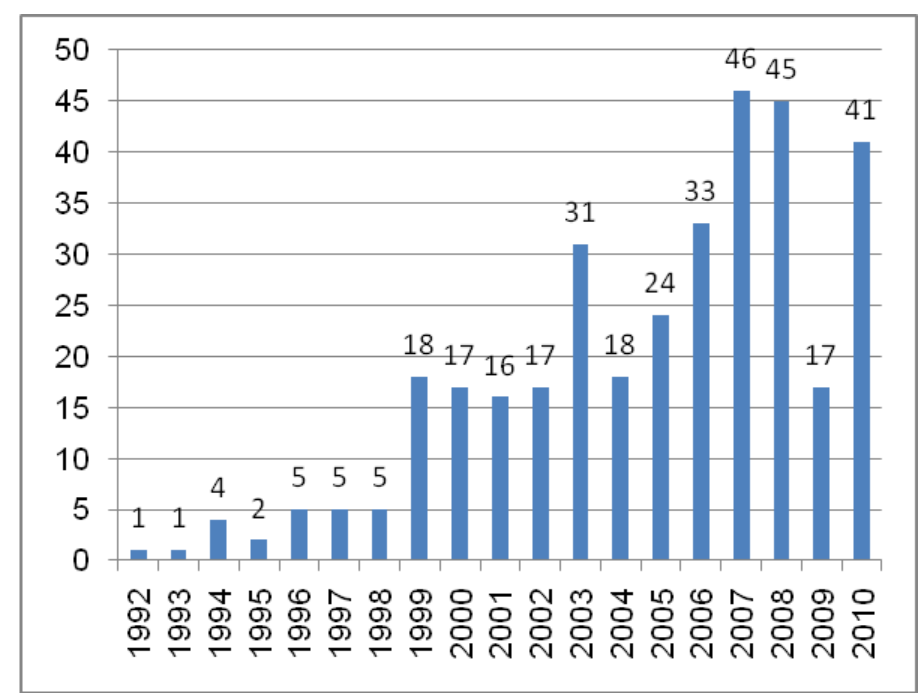

Figura 1 - Distribuição cronológica dos artigos

Fonte: Elaborado pelo autor.

Após estas etapas, deu-se início à revisão da literatura com base: (i) nos artigos mais citados (acima de 20 citações); (ii) nos artigos publicados nos últimos 5 anos e (iii) nos demais artigos que apareceram na busca e que foram citados pelos anteriores. Nesta etapa, também foram excluídos os artigos que se tratavam, apenas, da realização da LCA de determinado produto, o que resultou nos 185 artigos constantes no APÊNDICE A. Os resultados da revisão da literatura subsidiaram a estruturação da pesquisa empírica e integram a seção 3.2 do Referencial Teórico deste estudo.

É importante salientar que as terminologias encontradas na literatura foram mantidas conforme descrito pelos autores, já que a padronização ou definição destes termos não está entre os 
objetivos deste trabalho. Este trabalho restringe-se a investigar como ocorre a integração de aspectos ambientais no PDP, e para tanto, julgou-se relevante abarcar tudo o que vem sendo proposto na literatura nos últimos anos. Portanto, no decorrer da revisão, são encontrados termos como "produtos com apelo ambiental", "produtos verdes", "produtos ambientalmente amigáveis", "design para a reciclagem", "design para a reciclabilidade", etc.

\subsection{Investigação empírica}

Para responder as questões de pesquisa deste trabalho, verificou-se a necessidade de se realizar um estudo de caso múltiplo obtendo o consentimento de duas unidades de análise, com o objetivo de aprofundar o conhecimento acerca do problema, estimular a compreensão, sugerir hipóteses e questões conforme estabelecido por Mattar (1996). Esta escolha justifica-se, também, pois o presente estudo pretende esclarecer o motivo pelo qual uma ou um conjunto de decisões foram tomadas, como foram implementadas, bem como os seus resultados, conforme proposto por Yin (2001). Trata-se de uma análise aprofundada de um objeto (caso), para que permita o seu amplo e detalhado conhecimento (GIL, 1999; BERTO e NAKANO, 2000).

\subsubsection{Seleção da unidade de análise}

Uma das etapas mais importantes da pesquisa é a escolha da unidade de análise, pois esta subsidiará os resultados para o desenvolvimento do trabalho. Em primeiro lugar, é necessário definir a quantidade de casos a ser estudada, podendo ser um estudo de caso simples ou estudos de múltiplos casos (YIN, 2001). No presente estudo, optou-se pelo estudo de caso múltiplo com duas unidades de análise, no intuito de reunir as vantagens do estudo de caso simples, permitindo certo grau de aprofundamento conforme destaca a literatura (YIN, 2001; VOSS et al., 2002), e do estudo de caso múltiplo, verificando as particularidades de cada caso para aumentar a confiabilidade dos resultados, conforme Yin (2001) e Souza (2005).

Após a definição da quantidade de casos a ser estudada, é necessário a escolha das unidades de análise. Yin (2001) afirma que a definição da unidade de análise está relacionada com a forma como as questões de pesquisa foram elaboradas. Neste sentido, a pesquisa pretende investigar como ocorre a integração de aspectos ambientais no PDP, portanto, duas condições/premissas relacionadas às questões de pesquisa ajudam a limitar o universo a ser estudado: as unidades de análise devem ser desenvolvedoras de produtos e, deve haver evidência da integração de aspectos ambientais no PDP.

Ainda, segundo Yin (2001), nesta situação - de estudo de caso múltiplo - a análise deve seguir um experimento cruzado e cada caso deve ser selecionado de modo a prever resultados semelhantes ou, resultados contrastantes por razões previsíveis. Segundo Jabbour e Santos (2007), não há homogeneidade no tratamento da dimensão ambiental pelas empresas, e isto tem levado a literatura especializada a apresentar taxonomias de gestão ambiental empresarial constituídas por estágios evolutivos. As diferentes abordagens encontradas nas empresas podem ser consideradas 
estágios da gestão ambiental corporativa, o que tem sido objeto de diversos estudos importantes (HUNT e AUSTER,1990; HART, 1995; DONAIRE, 1999; SANCHES, 2000; CORAZZA, 2003; SEIFFERT, 2005). Segundo Jabbour (2010), o nível de maturidade da gestão ambiental das empresas tende a acompanhar o nível em que estas questões são introduzidas nas sub-áreas da função produção, principalmente no PDP. Na verdade, o PDP é a área mais pertinente para a avaliação do estágio em que as questões ambientais são inseridas na área de produção das empresas (JABBOUR, 2010; TINGSTRÖM e KARLSSON, 2006). Neste sentido, buscou-se por empresas que apresentassem diferentes posturas corporativas em relação à gestão ambiental.

Segundo Jabbour (2010), em geral, as empresas apresentam 3 tipos de comportamento em relação a implementação do DfE: 1) Empresas que, apesar da crescente integração de aspectos ambientais no PDP, não contam com metodologias e técnicas para a sua sistematização; 2) Empresas que vem, cada vez mais e, sistematicamente, implementando o DfE; 3) Empresas sem iniciativas no PDP, pois se beneficiam de melhorias ambientais em componentes produzidos por seus fornecedores. Neste trabalho, este último é desconsiderado devido à natureza das questões de pesquisa, onde não seria possível verificar a integração de aspectos ambientais no PDP. Portanto, empresas com diferentes tipos de comportamento em relação ao DfE foram escolhidas.

Segundo Azevedo e Nolasco (2009), os fatores econômicos ainda ditam a forma das empresas responderem às questões ambientais com o DfE, seja a adequação às leis e aos regulamentos ou a redução dos custos de produção. No entanto, segundo Savaskan e Van Wassenhove (2006), embora a legislação emitida pelos governos na Europa, América do Norte e Japão incentive essa consciência, a resposta das empresas à evolução das exigências de desempenho ambiental tem sido proativa em muitos casos. Neste trabalho, optou-se por uma empresa que atuasse em um mercado onde a legislação ambiental é severa e outra atuando em um mercado onde a legislação ambiental é mais branda.

Tien, Chung e Tsai (2005) afirmam que em empresas certificadas ou qualificadas para os EMSs, a motivação interna para o DfE tem um efeito significativo sobre a implementação do DfE. Segundo Gonzalez-Benito e Gonzalez-Benito (2008a), as empresas com uma função de operações mais pró-ativa são mais inclinadas a desenvolver capacidades que facilitam o desenvolvimento de um EMS e a adoção da norma ISO 14001 está associada com a implementação e desenvolvimento generalizado de diversas práticas de gestão ambiental no projeto de produtos e processos de produção. Portanto, uma das diferenças entre as empresas é a certificação ou não pela ISO 14001.

As empresas são mais propensas a investir em práticas ambientalmente responsáveis, quando os valores pessoais dos funcionários são a favor de fortes compromissos corporativos em responsabilidades ambientais (HART, 1995; HUANG, DING e KAO, 2009). Segundo Huang, Ding e Kao (2009), empresas familiares prestam muito mais atenção aos seus colaboradores internos do que as empresas não familiares, o que pode indicar uma maior influência destas questões em empresas familiares. Neste sentido, foram escolhidas empresas originalmente de controle familiar.

Dessa forma, buscou-se verificar como ocorre a integração de aspectos ambientais no PDP em empresas atuando em diferentes contextos, no intuito de verificar possíveis diferenças e 
similaridades no processo. Na Tabela 8 podem ser evidenciados os perfis das empresas selecionadas.

Tabela 8 - Diferenças e similaridades entre as unidades de análise

\begin{tabular}{|c|c|c|}
\hline & Empresa X & Empresa Y \\
\hline Ano de fundação & 1985 & 1899 \\
\hline Fundação & Nacional, de controle familiar & Nacional, de controle familiar \\
\hline Porte & Pequeno & Grande \\
\hline № de funcionários & 62 & 14.603 (diretos e indiretos) \\
\hline Tipo de negócio & Sensores Eletrônicos & Papel e Celulose \\
\hline $\begin{array}{l}\text { Legislação Ambiental brasileira } \\
\text { no setor }\end{array}$ & Branda & Severa \\
\hline Capital & Fechado & Aberto \\
\hline ISO 9001 & Possui & Possui \\
\hline ISO 14001 & Não possui & Possui \\
\hline Selos Ambientais & --- & FSC \\
\hline $\begin{array}{c}\text { Relacionamento com o mercado } \\
\text { externo }\end{array}$ & $\begin{array}{l}\text { Fornecedores e pretende } \\
\text { exportar }\end{array}$ & $\begin{array}{c}\text { Clientes e Entidades de } \\
\text { Pesquisa }\end{array}$ \\
\hline $\begin{array}{l}\text { Fase de integração dos aspectos } \\
\text { ambientais no PDP }\end{array}$ & Inicial & Avançada \\
\hline $\begin{array}{l}\text { Fases alvo do ciclo de vida do } \\
\text { produto para o DfE }\end{array}$ & Pré-Produção; Produção; e Uso & $\begin{array}{l}\text { Pré-Produção; Produção; } \\
\text { Transporte; Uso; e Descarte }\end{array}$ \\
\hline Principais parceirias para o DfE & Fornecedores e Certificadora & $\begin{array}{c}\text { Clientes e Entidades de } \\
\text { Pesquisa }\end{array}$ \\
\hline
\end{tabular}

Fonte: Elaborado pelo autor.

A literatura aponta para uma integração de aspectos ambientais no PDP abrangendo todas as fases do ciclo de vida dos produtos. No entanto, no presente estudo, buscou-se conhecer a realidade de uma empresa, de pequeno porte, em fase de integração de aspectos ambientais no PDP e a realidade de uma empresa de grande porte, em estágio mais avançado de implementação. Este fato permite verificar as dificuldades e expectativas de uma empresa ao integrar aspectos ambientais no PDP, bem como as formas de implementação. $O$ fato de as empresas atuarem em mercados e contextos diferentes permite verificar a influência do tipo de mercado, normalização e legislação nas abordagens adotadas. A seguir as unidades de análise são caracterizadas em mais detalhes.

\subsubsection{Empresa $X$}

A Empresa $X$, originalmente de controle familiar, foi incorporada ao grupo WEG Equipamentos Elétricos S/A em junho de 2010. Trata-se de uma empresa nacional, paulista, de pequeno porte, especializada na fabricação de sensores eletrônicos para automação industrial, comercial e de proteção humana, bem como na sua instalação e manutenção. Uma das justificativas para o presente estudo foi o baixo nível de integração de aspectos ambientais no PDP nas empresas, portanto a escolha de uma empresa nacional de pequeno porte, em fase inicial de integração de aspectos ambientais no PDP também se justifica pela possibilidade de verificação das possíveis dificuldades neste processo. 
A empresa é a única fabricante brasileira de equipamentos específicos para automação de segurança homem/máquina e o primeiro fabricante brasileiro de cortinas de luz a obter a certificação de produto de acordo com a norma EN 61.496/1-2 (categoria de segurança 4) e de seu Sistema de Gestão da Qualidade de acordo com a ISO 9001 pela Certificadora TÜV Rheinland Brasil (certificadora alemã). A Tabela 9 apresenta um maior detalhamento do perfil da empresa.

Tabela 9 - Perfil da Empresa X

\begin{tabular}{|c|c|}
\hline Aspectos & Dados/descrição \\
\hline Faturamento anual & $\mathrm{R} \$ 10$ milhões \\
\hline $\begin{array}{l}\text { Quantidade de } \\
\text { plantas/unidades }\end{array}$ & 1 \\
\hline Setor Industrial & automação industrial \\
\hline Certificações da Qualidade & ISO 9001 \\
\hline Certificações Ambientais & --- \\
\hline Outras Certificações & $\begin{array}{l}\text { Produtos da linha de segurança: norma EN } 61.496 / 1-2 \\
\text { (categoria de segurança 4); Sensores Indutivos e Fontes de } \\
\text { alimentação: norma DIN } 19234 \text { (NAMUR). }\end{array}$ \\
\hline Produtos & $\begin{array}{l}\text { Sensores, Fontes e Automação Rodovária: Cortinas de Luz, } \\
\text { Sensores Indutivos, Sensores Capacitivos, Sensores } \\
\text { Ópticos, Sensores Magnéticos para atuadores com Embolo } \\
\text { Magnético, Sensores Magneto Resistivos, Sensores } \\
\text { Eletrostáticos - Detectores de rupturas de fios, Conectores } \\
\text { para sensores, Fontes de Alimentação para Sensores, } \\
\text { Conversores de Corrente Contínua; e a Linha Safety: } \\
\text { Acessórios para Segurança, Barreiras ópticas de segurança, } \\
\text { Botoeiras eletrônicas de esforço zero, Cortinas de Luz de } \\
\text { segurança, Relés de segurança, Sensor indutivo de } \\
\text { segurança. }\end{array}$ \\
\hline Serviços & $\begin{array}{l}\text { Desenvolvimento de produtos; Nacionalização de produtos; } \\
\text { Desenvolvimento de sistemas de sensoreamentos; } \\
\text { Instalações; Consertos: eletrônica, usinagem e acabamento; } \\
\text { Manutenções: periódicas e preventivas; Orientações } \\
\text { técnicas; Treinamentos. }\end{array}$ \\
\hline
\end{tabular}

Fonte: Adaptado de Empresa X (2011)

A empresa mantém uma postura atenta em relação ao mercado e à legislação em sua área de atuação, se beneficiando da redução de impostos (IPI e ICMS) prevista na legislação brasileira de incentivo ao desenvolvimento de tecnologia no país, e do cadastro de seus produtos da linha de segurança para financiamento com juros reduzidos e prazos maiores pelo Banco Nacional do Desenvolvimento (BNDES). A empresa estudada atua junto a comitês e organizações não governamentais dedicadas a criar normas para regulamentar produtos de proteção humana e sua certificação no Brasil, é associada a ABINEE (Associação Brasileira da Indústria Elétrica e Eletrônica) e participa, como única fabricante nacional, no GTSafety ${ }^{5}$ da ABINEE, contribuindo para programas de prevenção e redução de acidentes nas indústrias. Na entrevista, o Coordenador de Qualidade

\footnotetext{
${ }^{5}$ Grupo de trabalho composto por fabricantes de Dispositivos Eletroeletrônicos de Segurança e Proteção em Máquinas e Equipamentos, que tem como intuito disseminar informações ligadas à prevenção de acidentes em máquinas e equipamentos.
} 
evidenciou que a empresa, há alguns anos, iniciou um projeto corporativo de reciclagem de materiais, no entanto, a iniciativa foi abortada devido à falta de espaço físico para acondicionamento e separação de materiais. Este tipo de experiência evidencia que determinadas iniciativas, algumas vezes, são abortadas e/ou descartadas devido a restrições ligadas à realidade de cada empresa. A partir de 2006, a empresa passou a eliminar o chumbo presente nos produtos da Linha de Segurança em obediência a Diretiva RoHS da União Européia, tornando-se pioneira no Brasil, na fabricação de produtos livres de chumbo.

A empresa possui setor de Ferramentaria próprio, auto-suficiente em injeção plástica e usinagem em máqinas de comando CNC. O setor de Produção conta com 28 colaboradores onde 5 se dedicam exclusivamente à fabricação de cortinas de luz, máquinas de inserção automática de componentes eletrônicos (Surface Mount Device - SMD/Montagens em Superfície Plana) e forno de refusão. O Departamento Comercial é constituído por uma equipe de 11 profissionais que garantem o atendimento, em todo o território nacional, na venda e pós venda de seus produtos e serviços. Outros departamentos, como Qualidade, Administração, TI (Tecnologia de Informação), Custos, Pessoal, Compras e Almoxarifado, são considerados pela empresa igualmente essenciais para a qualidade do produto, fornecendo as condições necessárias para o bom funcionamento da empresa.

O setor de Projeto e Desenvolvimento conta com uma equipe composta por 6 colaboradores e é o departamento dedicado a criação, nacionalização de produtos e suporte técnico ao cliente, coordenando todas as etapas de desenvolvimento de produtos desde os circuitos eletrônicos até a certificação dos produtos.

\subsubsection{Empresa $Y$}

Estruturada em três unidades de negócios - Florestal, Papéis (papelcartão e kraftliner) e Conversão (caixas de papelão ondulado e sacos industriais), a Empresa $Y$ é a maior produtora, exportadora e recicladora de papéis do Brasil. Atende as indústrias de alimentos, higiene e limpeza, eletroeletrônicos, bebidas, cimento, sementes e conversão de embalagens, entre outras, com grande aceitação na América do Norte, Europa e Ásia. A Tabela 10 apresenta um maior detalhamento do perfil da empresa.

A Unidade Florestal abastece a maior parte da madeira necessária à fabricação de seus produtos e outra parcela dessa matéria-prima é produzida em parceria com 18 mil produtores participantes do Programa de Fomento Florestal. A Política de Compra de Madeira da empresa evita a aquisição de produtos que integrem as seguintes categorias: madeira oriunda de exploração ilegal; madeira cuja exploração implicou a violação de direitos civis e tradicionais; madeira obtida de florestas cujo alto valor de conservação está ameaçado pelas atividades de manejo; madeira oriunda de florestas cujas terras estão sendo convertidas em plantações ou destinadas a outros usos que não o florestal; e madeira de árvores geneticamente modificadas. A empresa mantém 192 mil hectares de matas nativas preservadas possibilitando o desenvolvimento de programas de educação ambiental para colaboradores e comunidades dessas áreas. As plantações seguem o layout em mosaico, intercalando floresta plantada e nativa, permitindo uma maior preservação da mata e espécies nativas. 
A maior parte da madeira certificada produzida e comercializada pela empresa vai para o mercado externo, sobretudo Europa e Estados Unidos. Hoje a empresa possui Certificado de Manejo Florestal, de Manejo de Plantas Medicinais e da Cadeia de Custódia dos Produtos Florestais Não-Madeireiros, o que abriu oportunidades de comercialização de fitoterápicos e fitocosméticos com o selo do FSC (Forest Stewardship Council, ou Conselho de Manejo Florestal, em português).

Tabela 10 - Perfil da Empresa Y

\begin{tabular}{|c|c|}
\hline Aspectos & Dados/descrição \\
\hline Receita líquida anual & $\mathrm{R} \$ 3,7$ bilhões \\
\hline $\begin{array}{l}\text { Quantidade de } \\
\text { plantas/unidades }\end{array}$ & $\begin{array}{l}17 \text { fábricas no Brasil e uma na Argentina; Sede } \\
\text { administrativa em São Paulo-SP e escritórios comerciais em } \\
\text { nove estados no País, uma filial nos Estados Unidos e um } \\
\text { agente na Europa. }\end{array}$ \\
\hline Setor Industrial & Papel e celulose \\
\hline Certificações da Qualidade & ISO 9001 \\
\hline Certificações Ambientais & $\begin{array}{l}\text { ISO 14001; certificação de manejo florestal pelo Forest } \\
\text { Stewardship Council (FSC) e cadeia de custódia de todas as } \\
\text { fábricas de kraftliner, papelcartão e sacos industriais }\end{array}$ \\
\hline Outras Certificações & $\begin{array}{l}\text { OHSAS } 18001 \text { (Occupational Health and Safety Assessment } \\
\text { Services/Serviços de Avaliação de Saúde e Segurança } \\
\text { Ocupacional); ISO } 22000 \text { (Hazard Analysis and Critical } \\
\text { Points - HACCP/Análise dos Perigos e Pontos Críticos de } \\
\text { Controle): ISEGA - } 14130 \text { U* }^{*}\end{array}$ \\
\hline Produtos & $\begin{array}{l}\text { madeira em toras, papéis e cartões para embalagens, } \\
\text { embalagens de papelão ondulado e sacos industriais }\end{array}$ \\
\hline Serviços & $\begin{array}{l}\text { Consultoria em soluções de embalagem: Desenvolve } \\
\text { embalagens sob demanda de seus clientes; Cria processos } \\
\text { de montagem automática de embalagens na própria planta } \\
\text { do cliente, usando equipamentos que podem ser integrados } \\
\text { à sua linha de produção; Garante apoio na utilização das } \\
\text { suas embalagens: Visitas preventivas; Acompanhamento de } \\
\text { lotes-piloto e lotes comerciais dos envasadores; } \\
\text { Treinamentos em manuseio, armazenagem e transporte; } \\
\text { Capacitação das equipes que lidarão com a embalagem. }\end{array}$ \\
\hline
\end{tabular}

*certificado do Instituto independente alemão ISEGA: garantia de que o papel, utilizado nas embalagens de produtos alimentícios, pode entrar em contato direto com alimentos, de acordo normas da agência americana FDA (Food and Drug Administration) e do instituto federal alemão (Bundesinstitut für Risikobewertung - BfR).

Fonte: Adaptado de Empresa Y (2011)

Em relação à Unidade de Papéis, a Empresa Y é uma das maiores produtoras e exportadoras de cartões do país. A Unidade de Monte Alegre (UMA), em Telêmaco Borba, no Paraná é a maior fábrica de papéis do Brasil, uma das dez maiores fábricas de papel do mundo e a sexta maior fabricante global de papelcartão de fibras virgens, possuindo uma das máquinas mais modernas do mundo com capacidade de 350.000 toneladas/ano de papelcartão de diversos tipos. As principais aplicações do papelcartão são as embalagens de alimentos (líquidos, pastosos, sólidos e farináceos, inclusive congelados), bebidas engarrafadas e enlatadas, higiene e limpeza, fármacos, peças e utensílios, eletro-eletrônicos, brinquedos, calçados, utilidades domésticas, etc. A Empresa $Y$ é 
pioneira e líder na produção de papel Kraftliner (papel para embalagens) na América Latina e, além de abastecer suas fábricas de embalagens de papelão ondulado e sacos industriais, é a maior fornecedora desse papel, respondendo por aproximadamente $80 \%$ das exportações brasileiras, exportando para mais de 50 países. A companhia possui $6 \%$ do mercado interpaíses e 2,5\% do mercado intercontinentes (Europa, Ásia, América do Norte e América do Sul) de Kraftliner.

$\mathrm{Na}$ Unidade de Conversão, todos os produtos são 100\% recicláveis e biodegradáveis. A divisão de Sacos Industriais é lider sul-americana no segmento de sacos multifoliados e self opening sacks (SOS). A empresa desenvolve soluções para clientes de diversos setores, como a construção civil, as indústrias de alimentos e de produtos químicos e o agronegócio. A empresa também é líder brasileira do setor de embalagens de papelão ondulado, com a maior capacidade de produção do mercado nacional em nove unidades de conversão, entre caixas de carga pesada, displays para transporte e exposição no ponto de venda, caixas impressas de diferentes formatos, brinquedos e chapas, atendendo a todos os segmentos da economia. A produção de suas embalagens de papelão ondulado e papéis reciclados possui o selo FSC e recicladas, já substituem, com vantagens ambientais e de performance (automação), antigos materiais empregados na fabricação de embalagens, como containers para os setores têxtil (cones de fiação e tecelagem), metalúrgico (para 240 caixas de peças automotivas), agroindustrial (750 quilos de sementes) e alimentos (uma tonelada de líquidos ou pastosos), além de outras aplicações como as caixas de panelas de pressão desenvolvidas, recentemente, pela Empresa Y, para o grupo SEB (Panex).

Além de pioneira, no setor de papel e celulose das Américas, a obter a certificação FSC, a empresa possui Código de Conduta, vem se adequando para a SA8000, para criar um Sistema de Gestão padrão para todas as unidades e, recentemente, contratou a DuPont para implementar um Programa de Segurança nas fábricas. A empresa está classificada no Índice de Ações com Governança Corporativa Diferenciada - IGC e no Índice de Governança Corporativa Trade - IGCT da BM\&F Bovespa como Nível 1 desde 2002, e como elegível para o ISE 2012. Em 2010, publicaram o primeiro Relatório Anual de Sustentabilidade de acordo com as diretrizes da Global Reporting Initiative (GRI) e vêem realizando a contabilização da pegada de carbono de todas as unidades.

$\mathrm{Na}$ entrevista, realizada na Sede Administrativa, em São Paulo, o Diretor Comercial da Unidade de Papéis Kraft (UPK), evidenciou que a família fundadora da empresa é ambientalista desde a sua fundação e este fato pode ser evidenciado no histórico da empresa, com uma série de prêmios e certificações, além de iniciativas como o início das atividades fitoterápicas em 1984 e a inauguração da máquina de reciclagem de embalagem longa vida, na Unidade Piracicaba (SP) em 1999 (que resultou, em 2004, na joint venture com a Tetra Pak, Alcoa e TSL Ambiental inaugurando, em Piracicaba, a primeira planta do mundo do projeto Plasma para este fim).

A empresa investe constantemente na inovação de produtos e processos, o que inclui a reengenharia de materiais, canais de distribuição, sistemas de embalagem e prestação de serviços. Em 2010, foram aplicados $R \$ 386$ milhões em iniciativas visando o crescimento sustentável e a geração de valor para melhorar a produtividade nas fábricas e diminuir o impacto de suas atividades sobre o meio ambiente. $O$ investimento na Unidade Florestal incluiu o incremento do plantio com espécies de maior produtividade assegurando matéria-prima para o aumento da capacidade de 
produção de fibras e a aquisição de máquinas e equipamentos de colheita para acelerar o ritmo de corte de madeira. A companhia investiu na melhoria da matriz energética das unidades de Papéis com uma nova linha de transmissão de energia em alta-tensão $(230 \mathrm{kV})$ para a fábrica da Unidade Monte Alegre, Telêmaco Borba (PR) e novas caldeiras de biomassa nas unidades de Correia Pinto e Otacílio Costa (SC). A instalação do equipamento representou investimento de $R \$ 29$ milhões e agregou importantes avanços ao processo de preservação ambiental, com redução nas emissões de gases de efeito estufa e no consumo de óleo combustível da unidade.

A área de $\mathrm{P} \& \mathrm{D}$ da empresa tem avançado, nos últimos anos, visando à melhoria contínua e a inovação tecnológica na produção de celulose, papel e cartões, além da redução dos custos de desenvolvimento de produtos e processos industriais, contemplando aspectos ambientais, de qualidade, produtividade, saúde e segurança na execução dos projetos da empresa. A estrutura compreende uma área de P\&D e um Comitê de Inovação, que se reúne periodicamente para discutir novas estratégias. Os investimentos em P\&D focam em processos, produtos e parcerias com institutos de pesquisa e universidades. Com cerca de 25 pesquisadores, seis em nível de Mestrado e Doutorado, a empresa fornece assistência técnica a seus clientes diretos (convertedores) e indiretos, na solução de problemas comuns às embalagens de papel (kraft) e de papel cartão, no que diz respeito às suas propriedades físicas - barreiras (água, vapor, gordura, pragas), porosidade, permeabilidade, rugosidade - e conversão: corte, vincagem, colagem, fechamento e impressão.

Os laboratórios instalados em Monte Alegre, Correa Pinto, Otacílio Costa e Angatuba apoiam as unidades de produção. As atividades de P\&D da empresa dividem-se em: pesquisa florestal, preparo de madeira, polpação e branqueamento, química da parte úmida, propriedades físicas e óticas do papel, acabamento, processos de impressão, métodos analíticos, controle de processos; meio ambiente (contando com um Gestor Ambiental de P\&D voltado a projetos ambientais) e desenvolvimento de novos produtos. A área de P\&D ainda é responsável pela geração de conhecimentos e de tecnologias para o planejamento e desenvolvimento de sistemas de produção industrial. Os projetos de P\&D também respondem às necessidades apontadas pelas áreas de Atendimento a Clientes e Comercial, visando o planejamento estratégico da empresa, dentro de seus requisitos estatutários e regulamentares. A inovação tem como foco atender às necessidades dos clientes, que também são parceiros no desenvolvimento de produtos, processos e materiais. Nesse trabalho, a empresa conta com a participação de fornecedores de equipamentos e insumos e tem o apoio de centros de pesquisa que são sinônimos de excelência no setor.

Em todas as unidades da empresa, a área de P\&D segue a mesma metodologia, utilizando uma ferramenta de gerenciamento de projetos que contempla todas as etapas das atividades da área de pesquisa, de forma a assegurar a disponibilidade de informações ao longo dessas etapas, garantindo critérios de prioridade, execução e encerramento dos projetos.

Com o objetivo de melhorar a produção e produtividade da Unidade Monte Alegre, foi implantado o "Programa Superar". O Programa é baseado nos seguintes aspectos: tornar os recursos disponíveis, agir em pontos críticos, reconhecer e motivar as pessoas e definir metas de melhorias. Trata-se de um conjunto de projetos de melhoria realizados através da metodologia WCM (Manufatura de Classe Mundial ou World Class Manufacturing Management, em inglês). Nesse 
programa, são usados roteiros e ferramentas específicos para cada tipo de projeto de melhoria, sempre com o objetivo de potencializar as ações para eliminação de perdas - considerando-se como perdas todo processo que possa ser melhorado. A área de P\&D utiliza a metodologia WCM e é um dos pilares do "Programa Superar". A Gestão Antecipada do Produto trata da pesquisa e desenvolvimento de novas soluções. Com foco na antecipação dos problemas (de processo e produtos, internos e externos) que podem ser vivenciados pela produção e pelos clientes, a equipe desenvolve soluções prévias, garantindo a correta aplicação do produto e sua melhor performance. $O$ Programa Superar também é adotado nas unidades industriais, motivando os colaboradores a contribuírem com idéias e sugestões para o melhoramento contínuo das operações.

Utilizando tecnologia de ponta, a empresa tem garantido a constante evolução de suas soluções. Um exemplo da integração de aspectos ambientais no PDP é o Bag in Box (na Figura 2), um sistema híbrido, que combina papelão ondulado com uma bolsa plástica, para o acondicionamento e transporte de substâncias líquidas ou pastosas, com alta capacidade de contenção e sustentação. O sistema é leve, reciclável, resistente a impactos, ao manuseio, a baixas temperaturas e à umidade, pode ser empilhado, dispensa processos de higienização e oferece ganhos logísticos na movimentação de produtos em longas distâncias.

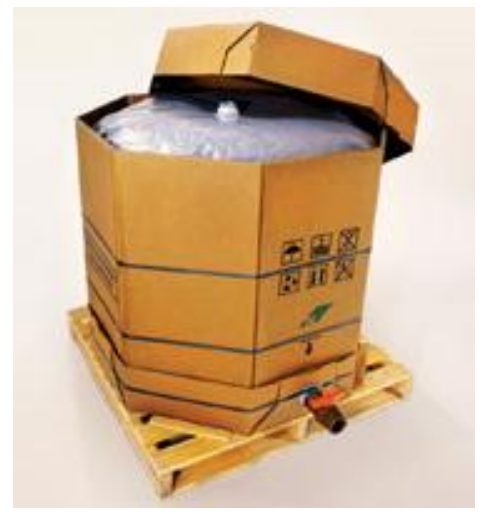

Figura 2 - Bag in Box

Fonte: Empresa Y (2011)

A empresa privilegia o desenvolvimento de tecnologias limpas e tem realizado altos investimentos no desenvolvimento tecnológico, que inclui a utilização de modernos recursos de informações geográficas, estudos de avaliação de impactos da silvicultura sobre recursos hídricos, solos e biodiversidade, além investir em equipamentos voltados à preservação do meio ambiente e ser uma das pioneiras no tratamento e aproveitamento de resíduos para geração de energia.

Em desenvolvimento de tecnologia, a empresa atua com as principais instituições de pesquisa no Brasil, como o Instituto de Pesquisas e Estudos Florestais (Ipef, da Universidade de São Paulo), a Sociedade de Investigações Florestais (SIF, da Universidade Federal de Viçosa), a Fundação Paranaense de Estudos Florestais (Fupef, da Universidade Federal do Paraná) e o Centro de Estudos e Pesquisas Florestais (Cepef, da Universidade Federal de Santa Maria). Também é associada à Central American and Mexico Coniferous Resources (Camcore - Recursos Coníferos da América Central e México), cooperativa com sede na Universidade da Carolina do Norte (EUA) que é 
referência internacional na conservação de pínus tropicais, e ao Innventia (ex-STFI-Packforsk). Outras parcerias com Associações, Universidades e Institutos de Pesquisa podem ser apontadas: ANPEI - Associação Nacional de Pesquisa, Desenvolvimento e Engenharia das Empresas Inovadoras; ABTCP - Associação Brasileira Técnica de Celulose e Papel; CETEA - Centro de Tecnologia de Embalagem Alimentícia; EMBRAPA - Empresa Brasileira de Pesquisa Agropecuária; USP Universidade de São Paulo (ESALQ - Escola Superior de Agricultura "Luiz de Queiroz"); UFPR Universidade Federal do Paraná; UFRJ - Universidade Federal do Rio de Janeiro; UEM Universidade Estadual de Maringá; UFV - Universidade Federal de Viçosa; UFSC - Universidade Federal de Santa Catarina; UNIPLAC - Universidade do Planalto Catarinense, entre outras. Com todas estas parcerias, a empresa tem dado continuidade ao desenvolvimento e à produção de papéis, cartões e embalagens de menor gramatura com o mesmo desempenho, reduzindo custos relacionados à fabricação, uso e transporte das embalagens - pela maior quantidade do produto na mesma tonelagem -, assim como vantagens ambientais, decorrentes do menor uso de fibras. Em Jundiaí (SP), a empresa conta com um Centro de Competência, onde uma equipe de profissionais se dedica à pesquisa e ao desenvolvimento de projetos de embalagens de papelão ondulado.

$\mathrm{Na}$ área florestal, a pesquisa desenvolvida nos últimos 25 anos permitiu dobrar a produtividade média anual das espécies cultivadas. Em melhoramento genético, participa do projeto internacional de estudo do genoma do eucalipto, desenvolvido pelo Joint Genome Institute (JGI), do Departamento de Energia dos Estados Unidos. O projeto de sequenciamento completo do genoma do eucalipto, liderado por pesquisadores do Brasil, da África do Sul e dos Estados Unidos, tem o objetivo de gerar importantes dados para a utilização na seleção e no melhoramento de árvores mais produtivas, resistentes a pragas e doenças e ao estresse ambiental (como seca e geada), com madeira tecnologicamente adequada aos diferentes usos aos quais se destina. A participação da empresa nesse estudo se dá por meio do Projeto Genolyptus, que realizou parte do sequenciamento no Brasil. O Projeto Genolyptus, tem como meta principal o aumento da produtividade brasileira no segmento de papel e celulose e, consequentemente, sua competitividade no mercado internacional. A pesquisa, uma das mais avançadas do mundo nessa área, conta no Brasil com uma rede integrada por 14 empresas florestais, 7 universidades e a Empresa Brasileira de Pesquisa Agropecuária (Embrapa), sendo financiada pelo Ministério de Ciência e Tecnologia e pelas empresas.

Em 2010, os principais projetos de P\&D envolveram: 1) Cartão Barreira Gordura - Destinado à fabricação de embalagens para fast-food, o produto tem como principal característica a aplicação de uma película que repele a gordura, melhorando a resistência da caixa quando em contato com o alimento. 2) Qualidade da polpa branqueada - O trabalho contou com a colaboração da Universidade de Viçosa, em Minas Gerais, e teve como objetivo melhorar a qualidade e a resistência da polpa produzida pela Unidade Monte Alegre, em Telêmaco Borba (PR). Para tanto, foram feitas alterações no processo de fabricação, como ajustes de temperatura, pressão, dosagens de produtos químicos. Houve incremento de $30 \%$ de fibras longas ao mix usado, o que representou melhora de $50 \%$ na capacidade de resistência ao rasgo dos produtos desenvolvidos com essa matéria-prima. 3) Consumo de óleo no forno de cal - A redução de $9 \%$ no consumo de óleo combustível foi possível graças a um avançado controle que emprega modelos matemáticos para antecipar pontos de 
oscilações e indica o melhor momento de ajuste da máquina para prevenir variações em seus processos. O trabalho foi finalista em um prêmio, na categoria Melhoria da Eficiência Energética, concedido pela Risi, empresa global de informações sobre o setor de papel e celulose. 4) Eficiência no processo de caustificação - A iniciativa teve como base o mesmo modelo usado para reduzir o consumo de óleo no forno de cal na Unidade Monte Alegre e proporcionou ganhos da ordem de $12 \%$ no processo de caustificação. O projeto foi premiado como o melhor trabalho do ano pela Associação Brasileira Técnica de Celulose e Papel (ABTCP).

\subsubsection{Procedimentos de coleta dos dados}

Segundo Yin (2001), as evidências para o estudo de caso podem ser obtidas com a utilização de documentos, registros, entrevistas, observação direta, observação participativa e artefatos físicos. Esses instrumentos podem ser utilizados isoladamente ou podem ser combinados, garantindo uma maior precisão e riqueza dos dados (YIN, 2001; MIGUEL, 2007). Os seguintes instrumentos foram escolhidos para a coleta de dados: entrevista semi-estruturada e análise de documentos públicos da empresa, tais como: página da empresa na internet, matérias em revistas especializadas e catálogo de produtos. Na Empresa X, foi possível ainda, a análise de documentos utilizados no PDP.

A realização da entrevista teve como principais objetivos identificar os passos ou etapas adotados pela empresa na integração de aspectos ambientais em seu PDP e levantar os principais elementos desse processo que permitam a sua caracterização. Este processo, nas duas empresas, pode ser verificado na Tabela 11.

Tabela 11 - Realização das entrevistas

\begin{tabular}{lcc}
\hline & Empresa X & Empresa Y \\
\hline Natureza do contato inicial & telefônico & e-mail \\
Profissional de contato & Coordenador de Qualidade & Diretor Comercial da UPK \\
Teste piloto & $26 / 9 / 2011$ & ---- \\
Data da entrevista & $30 / 9 / 2011$ & $4 / 10 / 2011$ \\
Duração da entrevista & Aprox. 3 horas & Aprox. 3 horas \\
Entrevis tados & Coordenador de Qualidade e & Coordenador de P\&D da Unidade de \\
& Supervisor de Projetos & Monte Alegre, em Telêmaco Borba - PR* \\
\hline *após a entrevista com o Diretor Comercial da UPK, um questionário com as questões 1, 10, 12, 15, 16, 19 e 22 do \\
roteiro de entrevista (mais específicas sobre projetos) foi enviado, via e-mail, ao Coordenador de P\&D da Unidade de \\
Monte Alegre, com posterior contato telefônico para esclarecimentos.
\end{tabular}

Fonte: Elaborado pelo autor

Na empresa X, foram entrevistados: 1) o Coordenador de Qualidade que gerencia os processos de certificação e auditoria por parte da certificadora, tanto em relação ao SGQ quanto à certificação dos produtos, também participa das atividades de Recursos Humanos relacionadas a Qualidade e Segurança do Trabalho e coordena a Prestação de Serviços de Intalação; e 2) o Supervisor de Projetos que também coordena a produção de Cortinas de Luz e a Prestação de Serviços de Manutenção. Na empresa Y, a entrevista foi realizada com o Diretor Comercial da UPK 
na sede administrativa da empresa, em São Paulo, e as questões relacionadas às Ferramentas utilizadas no PDP e às expectativas dos designers/projetistas em relação ao DfE foram enviadas (via e-mail) ao Coordenador de P\&D da Unidade de Monte Alegre (UMA), em Telêmaco Borba, no Paraná (dúvidas foram esclarecidas via contato telefônico).

O protocolo de pesquisa que orienta a busca por dados e informações na entrevista e na análise de documentos públicos das empresas está representado no APÊNDICE B. Como referência para a realização das entrevistas foi utilizado o roteiro apresentado no APÊNDICE C. No entanto, considerando a natureza da pesquisa, a entrevista não se limitou às questões do roteiro, pois a estrutura da entrevista seguiu um roteiro semi-estruturado não disfarçado (BOYD e WETFALL, 1964; MATTAR, 1996) composto por questões de múltpla escolha e questões abertas.

As questões foram formuladas de forma a fornecer subsídio aos objetivos propostos, e baseadas nos resultados obtidos na Varredura Vertical. Após a formulação do roteiro, foi realizado um teste piloto com um profissional da área de P\&D, visando o seu aprimoramento. A partir dessa aplicação, pôde-se verificar a qualidade dos dados obtidos e se contribuiam para o atendimento dos objetivos da pesquisa, conforme sugerido por Voss et al. (2002). A partir do teste piloto foram feitas as correções e ajustes necessários.

\subsection{Confrontação da teoria e dados empíricos}

Após a coleta dos dados, estes foram tabulados, em planilhas do Microsoft Excel, e reduzidos considerando aquilo que está relacionado com os objetivos de pesquisa, conforme recomendado por Miguel (2007). Através destes dados, identificaram-se as principais características do processo de integração de aspectos ambientais no PDP das empresas estudadas, as escolhas por determinados métodos e ferramentas de apoio, e a sua implementação. Essas informações foram enviadas aos entrevistados para análise e corroboração das evidências.

Posteriormente, os dados obtidos foram confrontados com a literatura. Com base nesses resultados, as descrições dos casos foram geradas contendo: 1) as etapas e características do processo de integração de aspectos ambientais no PDP na empresa estudada, e 2) as diferenças e similaridades entre os processos de integração de aspectos ambientais no PDP das empresas estudadas e os processos de integração de aspectos ambientais no PDP propostos na literatura.

Entenda-se que, considerando os objetivos de pesquisa, não houve a intenção de avaliar se as empresas desenvolvem ou não "produtos verdes", nem mesmo se elas integram, ou não, aspectos ambientais no PDP satisfatória ou suficientemente. Os objetivos do presente estudo limitam-se a investigar como ocorre a integração de aspectos ambientais no PDP, ou seja, verificar como isso ocorre na prática organizacional. Neste sentido, o presente capítulo descreveu os métodos e técnicas de pesquisa utilizados nesta investigação. A seguir, o referencial teórico elenca o que a literatura propõe para a integração de aspectos ambientais no PDP. 


\section{REFERENCIAL TEÓRICO}

Segundo Porter e Linde (1995), as empresas mais avançadas e os órgãos reguladores têm abraçado o conceito de redução na fonte, substituindo materiais e gerenciando do ciclo de vida do produto para limitar a poluição antes que ocorra, afinal quando sucata, substâncias nocivas, ou energia são lançadas ao meio ambiente sob a forma de poluição, é um sinal de que os recursos foram utilizados incompleta, ineficiente ou ineficazmente, caracterizando desperdício econômico. Senge et al. (2008) afirmam que na natureza não existe desperdício: todo subproduto de um sistema serve de alimento para outro e, num mundo pós-era-industrial, tudo (carros, celulares, eletrodomésticos) deve ser totalmente reciclável, remanufaturável ou passível de decomposição.

Porter e Linde (1995) afirmam que produtos concebidos adequadamente às normas ambientais podem desencadear inovações que reduzem o custo total de um produto ou agregam valor, permitindo às empresas compensar os custos da melhoria do impacto ambiental, tornando-as mais competitivas. Portanto, desenvolver produtos sustentáveis é o grande desafio das empresas, uma vez que esta estratégia demanda o desenvolvimento de diversas competências organizacionais (HART, 1995). Neste contexto, a seguir serão delineados os aspectos gerais e conceitos básicos sobre o Desenvolvimento de Produtos, e, posteriormente, os resultados da Revisão da Literatura sobre a integração de aspectos ambientais no PDP.

\subsection{O Processo de Desenvolvimento de Produtos}

O processo de desenvolvimento de produtos (PDP) é a seqüência de passos ou atividades que a empresa emprega para conceber, desenhar e comercializar um produto (ULRICH e EPPINGER, 1995). Wheelwright e Clark (1992) afirmam que a competitividade de longo prazo de qualquer empresa depende do sucesso de seu PDP, pois esta área abarca as esperanças de melhoria da posição que a empresa ocupa no mercado, da performance financeira da empresa, de renovação da empresa, de criação de novos padrões para a indústria e novos nichos de mercado.

Hayes, Wheelwright e Clark (1988) atentam para o alcance da vantagem competitiva por meio do desenvolvimento conjunto de produtos e processos, já que a vantagem proporcionada pelo desenvolvimento de produtos superiores é fortificada se estes só puderem ser feitos, com a tecnologia de processos próprios da organização. Os autores afirmam que novos produtos podem criar dinâmica de mercado, fidelizar distribuidores e clientes, enquanto novos processos podem reduzir custos, melhorar a qualidade, confiabilidade e a flexibilidade, portanto, este tipo de integração aumenta os retornos de ambos, constrói competências funcionais e a integração interfuncional.

Segundo Ulrich e Eppinger (1995), algumas empresas definem e seguem um preciso e detalhado PDP ao passo que outras mal podem descrever este processo. Além disso, os autores afirmam que cada empresa possui uma maneira peculiar de desenvolver seus produtos e, ainda, dentro de uma mesma empresa, podem ser encontradas maneiras diferentes de desenvolvimento para projetos diferentes. Neste sentido, os autores apontam 5 tipos básicos de projetos: Demanda de mercado (Market Pull), Desenvolvimento de Tecnologia (Technology-Push), Plataforma, Intensivo em 
Processo (Proces-Intensive, estes dependeriam fortemente do desenvolvimento conjunto de produto e processo de produção) e Produtos Customizados. Entretanto, Wheelwright e Clark (1992), os dividem em Pesquisa e Desenvolvimento (P\&D) e Alianças e Parcerias, dividindo-os, ainda, baseando-se no grau de mudança no processo e no produto, em Derivativos (pequenas alterações), de Ruptura (Breakthrough) e de Plataforma, conforme pode ser observado na Figura 3.

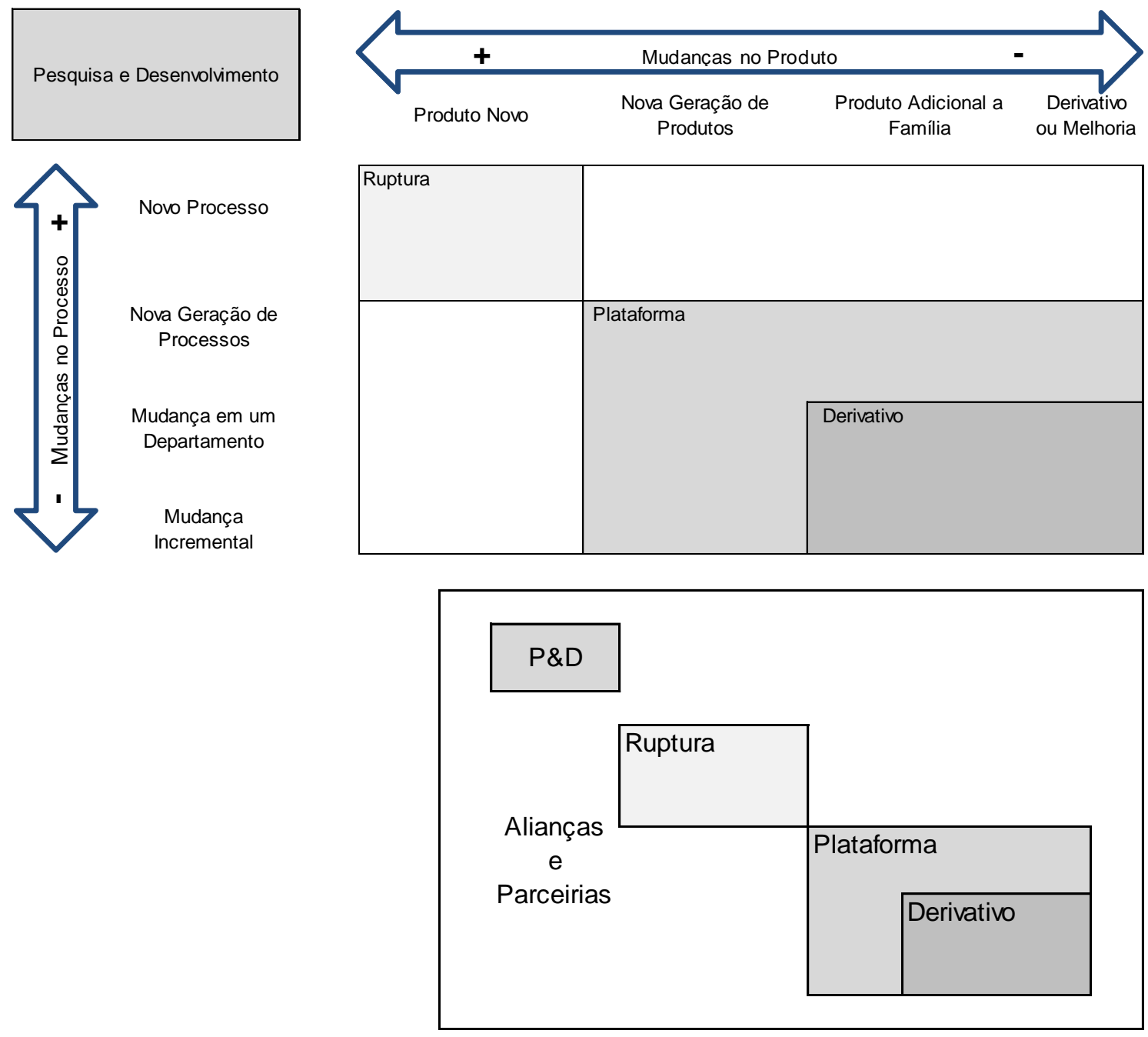

Figura 3 - Os cinco tipos de desenvolvimento de projetos

Fonte: Wheelwright e Clark (1992)

Cada um destes tipos de projetos, segundo os autores, requer diferentes formas de gestão e alocação de recursos, por exemplo: 1) Os indivíduos, poderiam ser alocados de acordo a sua experiência, gradativamente: mais experientes nos projetos de Ruptura, menos experientes, nos derivativos; 2) Os projetos de Alianças e Parcerias são classificados separadamente por exigirem um acompanhamento diferenciado, devido a interfaces intra e extra-organizacionais.

Para Ulrich e Eppinger (1995), a estruturação de um processo de desenvolvimento e suas fases é importante para garantir a qualidade do produto, melhorar a coordenação, o planejamento, o controle e ajudaria a identificar oportunidades de melhoria no processo, onde as principais fases seriam: 1) Desenvolvimento do Conceito (denominado pelos autores de processo front-end): com a 
Identificação das necessidades do consumidor, Estabelecimento de especificações, Benchmarking Competitivo (análise dos produtos da concorrência), Geração de conceitos, Seleção de conceitos, Refinamento das especificações, Análise econômica e Planejamento do Projeto; 2) Desenho do Sistema; 3) Detalhamento; 4) Testes e Refinamento e 5) Início da Produção.

Os autores também esclarescem que os principais atores do processo seriam Marketing, Desenvolvimento e Produção, mas outras áreas seriam de extrema importância auxiliando nas atividades de cada fase como a área jurídica, finanças, documentação, vendas, serviços, entre outras. Para desempenhar todas as atividades necessárias ao PDP, os autores afirmam que os indivíduos, muitas vezes, assumem duplo papel na organização, ocupando cargos funcionais dentro da organização (marketing, produção, finanças...) e sendo alocados aos projetos, acumulando responsabilidades de sua área funcional e do projeto, sendo cobrados por seu superior funcional e do projeto. Neste sentido, Wheelwright e Clark (1992) afirmam que a falta de coordenação entre atividades funcionais e de projeto poderia levar a priorização da resolução de problemas nas áreas funcionais (pressões de curto prazo) atrasando as atividades de projeto (atividades estratégicas). Hayes, Wheelwright e Clark (1988), afirmam que a fundação para o sucesso dos projetos é o entendimento compartilhado das estratégias das várias áreas funcionais envolvidas e uma direção estratégica clara da alta administração, complementadas por programas que garantam o talento e as competências necessárias para seguir esta direção. Para melhorar a coordenação nestes casos, segundo Ulrich e Eppinger (1995), é necessário escolher a estrutura organizacional que melhor se adéqüe a situação enfrentada pela organização, existindo dois tipos básicos de estrutura organizacional: Gerente de Projeto Peso-Pesado (quem mantém maior autoridade é o Gerente de Projeto) e Gerente de Projeto Peso-Leve (maior autoridade do Gerente Funcional).

Segundo Wheelwright e Clark (1992), a falta de um plano de projetos agregado (hoje chamado de gestão de portfólio), pode levar ao não atendimento das expectativas do PDP, devido a restrições financeiras, de tempo e de recursos humanos. As empresas, normalmente, desenvolvem diversos projetos em paralelo e a gestão de portfólio seria a responsável pela coordenação destes projetos, permitindo uma maior assertividade quanto ao que deve ser desenvolvido prioritariamente e ao que é mais estratégico para a empresa no momento, esclarescem os autores.

Hayes, Wheelwright e Clark (1988) acrescentam que a organização deve estar atenta aos trade-offs entre as três medidas primárias no PDP: utilização de recursos, qualidade do design e ciclo de tempo de desenvolvimento. Segundo os autores, ciclos de desenvolvimento mais curtos, normalmente, promovem uma melhoria na qualidade do design e reduzem os custos do projeto, por não permitirem que ocorram tantas mudanças no mercado, entre a concepção do projeto e o lançamento do produto, que demandaríam alterações no decorrer do projeto. Aliás, segundo os autores, quanto mais tarde surgir a necessidade de se alterar o projeto, mais difícil esta tarefa se tornará, conforme pode ser observado na Figura 4. 


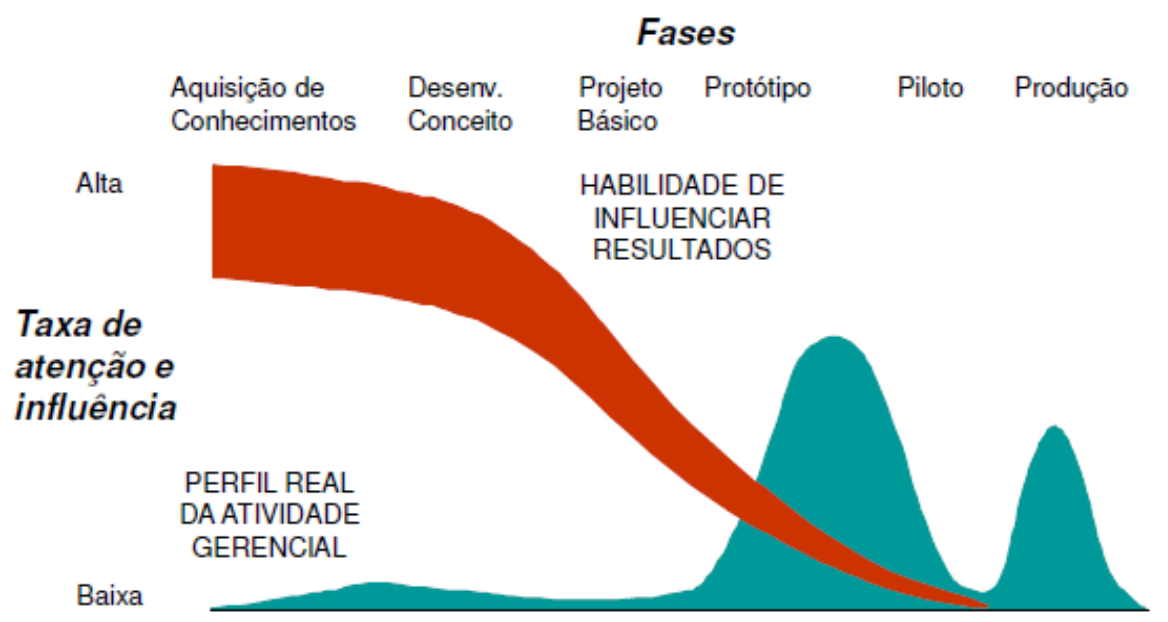

Figura 4 - Atenção e Influência da ação gerencial, impacto no tempo Fonte: Foster e Gluck (1979 appud HAYES; WHEELWRIGHT; CLARK, 1988)

Portanto, de acordo com Rozenfeld et al. (2006), o desenvolvimento de novos produtos e a melhoria da qualidade daqueles já existentes são atividades críticas para a empresa aumentar a sua competitividade por meio das seguintes estratégias: redução do tempo total de desenvolvimento, atender a segmentos específicos de mercado, incorporar tecnologias, integração a outros produtos e usos, menor tempo de resposta às evoluções do mercado, redução de custos, aumento da produtividade, manufaturabilidade (facilidade de produzir e montar) e adequação a novos padrões e restrições legais (principalmente quanto à saúde, meio ambiente e segurança). Portanto, os autores afirmam que este processo está diretamente ligado à interface entre mercado e empresa, tornando-se fatores críticos a identificação e a antecipação das necessidades do mercado, a proposição de novas soluções e a maneira como estas iniciativas são incorporadas ao processo. As principais características do PDP, segundo os autores, são:

a) Elevado grau de incertezas e riscos das atividades e resultados;

b) Decisões importantes, responsáveis por cerca de $85 \%$ dos custos do produto final, devem ser tomadas no início do processo quando as incertezas são ainda maiores;

c) Ciclo interativo: Projetar, Construir, Testar e Otimizar;

d) Manipulação e geração de alto volume de informações e atividades que estão relacionadas à diversas fontes e áreas da empresa e da cadeia de suprimentos (requisitos de mercado, legais, de homologação, as competências da empresa e de sua rede de fornecedores, etc.);

e) Multiplicidade de requisitos a serem atendidos pelo processo, considerando todas as fases do ciclo de vida do produto (produção, distribuição, uso, manutenção e descarte) e seus clientes (manufatura, distribuidores, usuários, pessoal de assistência técnica, reciclagem, etc.);

f) Necessidade de integração interfuncional na empresa (o produto será desenvolvido, produzido, vendido e controlado envolvendo todos os setores);

g) O custo de modificação de uma decisão anterior do projeto aumenta ao longo do ciclo de desenvolvimento.

Segundo os autores, estas características condicionam os modelos e práticas de gestão adequadas ao processo, além do perfil e das capacitações requeridas dos profissionais que atuam no 
PDP. Portanto, os autores concluem que a gestão do PDP é bastante complexa, incluindo a estratégia, a estrutura organizacional, a sistematização das atividades, as habilidades técnicas, as abordagens para resolução de problemas, os mecanismos de aprendizagem e o tipo de cultura dominante.

Segundo Rozenfeld et al. (2006), o PDP atrelado à gestão do impacto ambiental do produto e do processo costuma ser chamado de Design para o Ambiente (Design for Environment - DfE), apresentando aspectos relacionados ao domínio de estratégias de marketing e política de decisões, num nível operacional relacionado ao domínio de projeto de produtos (projetistas ou designers). De acordo com Pujari et al. (2003), a lógica do DfE assemelha-se a do PDP convencional, mas envolve a inserção de um novo nível de complexidade para este processo por meio de algumas iniciativas:

a) Exame mais amplo de satisfação do cliente: novas exigências dos clientes como qualidade, durabilidade, custos, forma como os produtos são feitos, utilizados e descartados;

b) Foco no ciclo de vida do produto: conseqüências da produção e do consumo, origem das matérias-primas, destinação dos produtos depois de descartados (SHARFMAN et al., 1997);

c) Foco na concepção de produtos para a reciclabilidade: atenção para o destino dos produtos por meio dos '5 R's': reparação, recondicionamento, reutilização, reciclagem e remanufatura (WHEELER, 1992);

d) Perspectiva ampliada da cadeia de abastecimento: a preocupação com os impactos ambientais dos fornecedores, citada na ISO 14000, aparece em muitas empresas que exigem que os seus fornecedores sofram auditorias ambientais (SINDING, 2000).

\subsection{Integração de aspectos ambientais no PDP}

Os resultados da revisão da literatura se mostraram bastante abrangentes e, com base no número de citações e nas citações inter-relacionadas dos artigos resultantes das buscas, pôde-se verificar que estes delineam as principais características do Design para o Ambiente (DfE - Design for Environment) e as implicações para a sua implementação através dos métodos e ferramentas de apoio ao DfE mais proeminentes na literatura. Esta seção está estruturada da seguinte forma: $\mathrm{Na}$ seção 3.2.1 é descrito o quadro geral do DfE, seguido das principais motivações para a sua implementação e características de integração com a cadeia de suprimentos. Na seção 3.2 .2 são descritas as estratégias de design do DfE, divididas entre as fases de vida do produto. Na seção 3.2.3 se encontram os métodos e ferramentas de apoio ao DfE.

\subsubsection{Design para o Ambiente (DfE - Design for Environment)}

A integração das considerações ambientais no PDP tem recebido diversas nomenclaturas como: Concepção Ecológica (Ecodesign), Desenvolvimento de Produtos Ambiental (Environmental Product Development - EPD), Desenvolvimento de Produtos Sustentável (Sustainable Product Development - SPD), Desenvolvimento de Produtos Verde (Green Product Development), Design Ambiental, Design Ambientalmente Consciente (Environmentally Concious Design), Design 
Ambientalmente Correto (Environmentally Sound Design), Design Ambientalmente Responsável (Environmentally Responsible Design), Design Ambientalmente Sensível (Environmentally Sensitive Design), Design de Produtos Sustentável, Design Ecológico (Ecological Design), Design limpo (Clean Design), Design para a Sustentabilidade (Design for Sustainability), Design para o Ambiente (Design for Environment ou Design for the Environment - DfE), Design Socialmente Responsável, Design Sustentável (Sustainable Design), Design Verde (Green Design), Engenharia Verde (Green Engineering), Manufatura e Recuperação do Produto Ambientalmente Consciente (ECMPRO Environmentally Conscious Manufacturing and Product Recovery), entre outros... (GUNGOR e GUPTA, 1999; BAUMANN, BOONS e BRAGD, 2002; WAAGE, 2007; ALMEIDA et al., 2010; COLLADO-RUIZ e OSTAD-AHMAD-GHORABI, 2010a; COLLADO-RUIZ e OSTAD-AHMADGHORABI, 2010b; DEVANATHAN et al., 2010).

Segundo Baumann, Boons e Bragd (2002), a transição de Design 'verde' para 'eco' e 'sustentável' representa uma ampliação do escopo, mas os termos são freqüentemente usados de forma intercambiável. No entanto, produtos sustentáveis devem ser produzidos considerando os aspectos ambientais, econômicos e sociais, abordando objetivos de negócios, éticos e técnicos (HAUSCHILD, WENZEL e ALTING, 1999) o que extrapola os limites do presente estudo que se atem à inserção de aspectos ambientais no PDP. Portanto, é interessante notar o uso de terminologias diferentes em diferentes continentes, onde o termo DfE parece ser o termo americano e ecodesign, o termo Europeu (PIGOSSO et al., 2010). Entretanto, o objetivo deste trabalho não é defender uma terminologia ou outra, portanto, no presente, será utilizado o termo DfE para identificar o: "processo onde o meio ambiente recebe o mesmo status dos valores industriais tradicionais do PDP, como durabilidade, funcionalidade, desempenho, custo, tempo para introdução no mercado, estética, ergonomia, qualidade, segurança, requisitos dos clientes, entre outros" (HUNT e AUSTER, 1990; PORTER e VAN DER LINDE, 1995; PUJARI e WRIGHT, 1999; BAUMANN, BOONS e BRAGD, 2002; NIELSEN e WENZEL, 2002; MAXWELL e VAN DER VORST, 2003; CAGNO e TRUCCO, 2007; LI et al., 2008; KUO, WU e SHIEH, 2009; MENGONI, GERMANI e MANDORLI, 2009; PIGOSSO et al., 2010), como pode ser verificado na Figura 5.

Design para o Ambiente (Design for Environment - DfE)

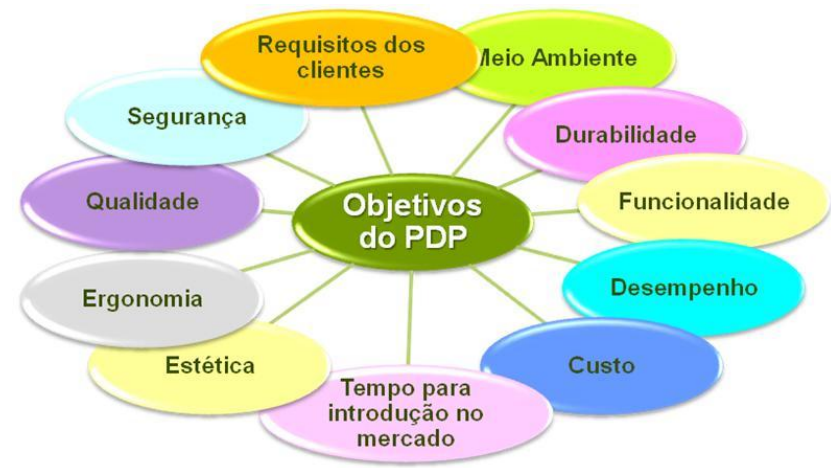

Figura 5 - Design para o Ambiente (Design for Environment - DfE) Fonte: Elaborado pelo Autor 
Esta definição se justifica, pois as pessoas adotam estilos de vida mais sustentáveis, não só por causa de uma consciência ecológica, mas também por fatores pessoais ou benefícios percebidos (PUJARI e WRIGHT, 1999; MARCHAND e WALKER, 2008; KUO, WU e SHIEH, 2009), e nenhuma melhoria ambiental será alcançada a menos que os novos produtos sejam competitivos e possam substituir os produtos com menor desempenho ambiental (PUJARI e WRIGHT, 1999; NIELSEN e WENZEL, 2002; KUO, WU e SHIEH, 2009).

Segundo Bovea e Wang (2007), redesenhar produtos com uma melhoria no seu desempenho ambiental sem comprometer outras necessidades do cliente é possível. No entanto, segundo Kuo, Wu e Shieh (2009), os eco-produtos não têem alcançado uma posição favorável no mercado conforme o esperado, embora pareçam mais econômicos e favoráveis ao ambiente. Segundo os autores, isto pode ser devido ao fato de que eles estão focados unicamente na análise de impacto ambiental sem levar em conta as necessidades dos clientes e as considerações de custo. Bovea e Wang (2007) argumentam que uma das principais causas para o fracasso de um produto no mercado pode ser que o aumento do custo para incorporar melhorias ambientais supere a disposição a pagar a mais que os clientes têm pelos benefícios ambientais percebidos. Nesse caso, o produto satisfaz todas as exigências do cliente, mas a um preço maior do que o acessível.

Um melhor desempenho ambiental pode ajudar a melhorar outros objetivos do PDP, podendo trazer outros benefícios para os negócios como a melhoria da funcionalidade dos produtos e/ou serviços, redução (ou manutenção) de custos, vantagem competitiva, novas oportunidades de negócios, desenvolvimento de capacidades em termos de conhecimentos e competências, melhora no relacionamento com os fornecedores e na reputação da empresa (MAXWELL e VAN DER VORST, 2003; TINGSTRÖM, SWANSTROM e KARLSSON, 2006; VAN BERKEL, 2007; NY et al., 2008; PALOUSIS, LUONG e ABHARY, 2010; VINODH e RATHOD, 2010a). No entanto, a implementação do DfE é uma questão complexa e, normalmente, consome demasiadamente custos, tempo e pessoal (MAXWELL e VAN DER VORST, 2003). A melhoria simultânea de custo, qualidade e impacto ambiental às vezes é possível, como no caso das lâmpadas fluorescentes, que muitas vezes resulta em economia de custos e de energia e iluminação com uma vida mais longa sobre a iluminação convencional (MANGUN e THUSSTON, 2002). Segundo Palousis, Luong e Abhary (2010), em alguns casos, produtos verdes podem custar até menos do que produtos tradicionais, e, segundo, Devanathan et al. (2010), as melhorias ambientais podem ser feitas sem afetar negativamente 0 desempenho funcional. Entretanto, normalmente, surgem problemas de tomada de decisão, onde já não é possível melhorar um objetivo sem piorar outro, constituindo trade-offs entre os objetivos do PDP, bem como nos do DfE e entre eles (ALTING, 1995; MANGUN e THUSSTON, 2002; CAGNO e TRUCCO, 2007; KURCZEWSKI e LEWANDOWSKA, 2010; LEWANDOWSKA e KURCZEWSKI, 2010; VINODH e RATHOD, 2010a). Se essas fronteiras não existissem, os fabricantes poderiam desenvolver produtos com custo zero, qualidade perfeita, e nenhum impacto ambiental (ALTING, 1995; MANGUN e THUSSTON, 2002; CAGNO e TRUCCO, 2007; VINODH e RATHOD, 2010a).

Segundo Bovea e Wang (2007), para a incorporação de melhorias ambientais serem viáveis do ponto de vista da empresa, um mercado para produtos "verdes" deve existir onde os clientes estejam dispostos a pagar por tais produtos. Entretanto, para um determinado produto, existem vários 
grupos de clientes exibindo diferentes níveis de consciência ambiental, onde uma abordagem de portfólio de produtos, com base na segmentação de mercado, criaria oportunidades para o engenheiro de projeto distribuir os custos, confiabilidade e impactos ambientais, de tal forma que o resultado final é uma maior satisfação do cliente do que o projeto de um produto para todos os grupos de clientes (MANGUN e THUSSTON, 2002). Luh, Chu e Pan (2010) e Xu, Ong e Nee (2007) também propuseram uma abordagem de portfólio para o DfE.

Segundo Vinodh e Rathod (2010a), o ciclo de desenvolvimento tradicional de produtos consiste no levantamento dos requisitos do cliente, identificação dos objetivos de design, design, análise de engenharia, produção, uso e descarte. Este processo se estende às atividades após o lançamento do produto para a obtenção de informações que podem melhorar o projeto de produtos e processos de produção em projetos futuros e estimula o aprendizado pós-projeto (CLARK e WHEELWRIGHT, 1993). Recentemente, uma abordagem denominada Gestão do Ciclo de Vida (Life Cycle Management - LCM), Design do Ciclo de Vida (Life Cycle Design - LCD) ou Design da Engenharia do Ciclo de vida (Life-cycle engineering design - LCED) se espalhou e recebeu atenção crescente (ALTING, 1993; WANYAMA et al., 2003; GIUDICE e FARGIONE, 2007). Esta abordagem considera o ciclo de vida do produto de uma forma holística com o objetivo da alcançar a máxima performance do produto: as escolhas de design não devem ser guiadas exclusivamente por requisitos funcionais, e por considerações de custo-eficácia, mas devem levar em consideração um espectro cada vez maior de características solicitadas aos produtos em relação a cada fase do seu ciclo de vida, como produção, distribuição, utilização, manutenção, descarte (RAMANI et al., 2010). Segundo Jianjun et al. (2008), o LCED deverá representar uma parte importante do design dos processos de fabricação, no futuro, principalmente como meio de minimizar o impacto ambiental.

A Engenharia do Ciclo de Vida (Life Cycle Engineering - LCE), Suporte Técnico, Avaliação do Ciclo de Vida (Life Cycle Assessment - LCA), Custeio do Ciclo de Vida (Life Cycle Costing - LCC) e a Gestão dos Dados do Produto (Product Data Management - PDM) ou Gestão do Ciclo de Vida do Produto (Product Lifecycle Management - PLM) são meios para alcançar a LCM (ALTING, 1993). Segundo Luttropp e Johansson (2010), a PLM ou PDM é um novo conceito, onde os dados do produto são reunidos e organizados, de tal forma que todas as informações necessárias sobre ele estejam disponíveis durante o seu ciclo de vida, facilitando a utilização, manutenção e processos de recuperação em seu fim de vida. Por tanto, o DfE seria uma decorrência natural da LCM, já que o sucesso do DfE é o resultado de uma coordenação sistêmica das ações e informações/necessidades de todo o ciclo de vida do produto (MAXWELL e VAN DER VORST, 2003).

O DfE consiste no desenvolvimento de produtos que são mais duráveis, eficientes no uso de recursos, evitam o uso de materiais poluentes ou perigosos, geram menos resíduos durante a produção e utilização e que podem ser facilmente desmontados para a reciclagem (LENOX, KING e EHRENFELD, 2000; BHAMRA, 2004; PUJARI, PEATTIE e WRIGHT, 2004). Portanto, o DfE envolve a integração de considerações ambientais no desenvolvimento de novos produtos e redesign dos produtos existentes, incluindo design, seleção de materiais, processos de produção (produção mais limpa - cleaner production), design e gerenciamento dos sistemas de produção e logística e entrega do produto aos consumidores, além da gestão do fim de vida (End of Life - EoL) após a vida útil do 
produto (GUNGOR e GUPTA, 1999; PUJARI, WRIGHT e PEATTIE, 2003; KJAERHEIM, 2005; TINGSTRÖM e KARLSSON, 2006; CAGNO e TRUCCO, 2007; VINODH e RATHOD, 2010a). Este processo integra questões de design de produtos e processos com o planejamento e controle da produção para identificar, quantificar, avaliar e gerenciar o fluxo de resíduos ambientais com o objetivo final de reduzir o impacto ambiental (AZZONE e a NOCI, 1996).

Byggeth e Hochschorner (2006) sugerem que o PDP deve visar o Conceito de Ciclo de Vida (Life Cycle Thinking - LCT) e não apenas uma seleção arbitrária de impactos dos fluxos e práticas atuais. Segundo Pigosso et al. (2010), o LCT é a integração das perspectivas do ciclo de vida nos processos de tomada de decisão, planejamento e estratégia das organizações, levando em consideração o TBL. O período de tempo a examinar não é só a vida útil do produto, mas também, e em particular, o processo de produção a montante (que inclui os tipos de matérias-primas e recursos energéticos usados) e as fases a jusante de descarte e reciclagem em várias formas (CAGNO e TRUCCO, 2007; PIGOSSO et al., 2010). Pujari, Wright e Peattie (2003) destacam os benefícios do envolvimento dos fornecedores no início do DfE. Pujari (2006) também argumentou que a inovação verde é amplamente determinada pelo impacto ambiental a montante. Segundo Ramani et al. (2010), a integração das questões a jusante no design é uma tarefa complexa. De qualquer forma, com o LCT as empresas começam a olhar mais para o desempenho ambiental de outros atores da cadeia do produto - os fornecedores de componentes e materiais, os atores responsáveis pela distribuição e venda do produto, o cliente e usuário do produto e os operadores do sistema de tratamento de resíduos que irão eventualmente descartar produto e, possivelmente, reciclar as peças do mesmo (WESTKÄMPER, ALTING e ARNDT, 2000).

A partir daí, a maioria dos estudos sobre o DfE se dividem em três categorias: design de produto, design de processos e design da cadeia de suprimentos (ELLRAM, TATE e CARTER, 2008). A forma mais eficaz de realizar o DfE é integrar o design de produtos, planejamento de produção, controle e gerenciamento da cadeia de suprimentos, de uma forma que permita identificar, quantificar, avaliar e gerenciar o fluxo de resíduos ambientais com o objetivo de reduzir e minimizar seu impacto sobre o meio ambiente na fase inicial de desenvolvimento (CHEN, 2001). Portanto, para alcançar a LCM, bem como o DfE existe a necessidade de colaboração com as outras partes interessadas internas, inclusive em nível estratégico (departamento de compras, produção, $\mathrm{RH}$, alta administração, etc...) e externas (fornecedores, clientes, e outros parceiros - como varejistas, instituições de pesquisa e órgãos governamentais) à organização (WESTKÄMPER, ALTING e ARNDT, 2000; FIKSEL, 2003; MAXWELL e VAN DER VORST, 2003; CHUNG e PENG, 2006; ABU BAKAR e RAHIMIFARD, 2007; JOHANSSON, LUTO e FLEISCHER; 2007; GEHIN, ZWOLINSKI e BRISSAUD, 2008). Pois, segundo Alting e Jogensen (1993), é necessário "Eliminar a lacuna" entre políticas ambientais isoladas, não operacionais na gestão de nível superior e métodos/ferramentas técnicoorientados para produtos/produção. Segundo os mesmos autores, as questões ambientais devem ser introduzidas, gerenciadas e monitoradas em todos os níveis e em todos os departamentos da empresa. Segundo Fiksel (2003), não é suficiente para uma empresa redesenhar apenas os sistemas que podem controlar completamente, pois na melhor das hipóteses, isso resultará em mudanças incrementais que não prejudicam, mas não criam benefícios significativos tanto para a empresa 
quanto para a sociedade. O DfE necessita de uma mudança mais radical, sistêmica, em detrimento de mudanças incrementais nos produtos através do pensamento no que o produto oferece (FIKSEL, 2003; WALKER, 2010). O projeto do sistema deve proceder com uma consciência constante dos sistemas relacionados, condições de fronteira, efeitos externos, e loops de feedback potenciais (FIKSEL, 2003). Entretanto, muitas vezes, percepções prévias detidas sobre os outros atores da cadeia impactam negativamente sobre a capacidade de cooperação dos participantes, evidenciando a necessidade de métodos que enfatizem aspectos de motivação e confiança entre os mesmos (EVANS, PARTIDARIO e LAMBERT, 2007). Na verdade, enquanto as equipes de design expandem continuamente o limite do sistema, elas precisarão enfrentar novos desafios técnicos de forma criativa (FIKSEL, 2003). Portanto, o PDP assume importância fundamental, através da integração de uma multiplicidade de requisitos na definição paralela do produto e o processo de produção/logística utilizando a engenharia simultânea (CAGNO e TRUCCO, 2007). Algumas empresas têm visto a propagação do LCT, do PDP para a maioria das outras atividades realizadas pela empresa, e várias indústrias estão agora trabalhando em uma integração do LCT em seu sistema de gestão ambiental (WESTKÄMPER, ALTING e ARNDT, 2000).

Segundo Maxwell e Van Der Vorst (2003) o DfE conta com algumas estratégias DfX, que normalmente são subconjuntos focados em áreas específicas, por exemplo, Design para a Desmontagem (Design for Dissassembly - DfD), Design para a Reciclagem (Design for Recycling), etc. A necessidade de integração aprofundada da eco-eficiência com outros objetivos da empresa no PDP demanda o desenvolvimento de ferramentas de apoio à decisão e análise oferecendo orientação na definição de ações específicas, fornecendo suporte válido em todas as principais áreas em que estratégias de eco-eficiência são desenvolvidas e implementadas (CAGNO e TRUCCO, 2007). Diversos métodos e ferramentas vêm sendo desenvolvidos para viabilizar a Estratégia DfE (BAUMANN, BOONS e BRAGD, 2002; PIGOSSO et al., 2010). Baumann, Boons e Bragd (2002) destacam o surgimento de diversos guias, catálogos e manuais que tratam da integração das questões ambientais no PDP, e que são freqüentemente utilizados como um material de referência no DfE, como o manual do Programa das Nações Unidas para o Meio Ambiente (PNUMA - em inglês: United Nations Environment Programme, UNEP). A ISO-TR 14062 (ISO/TR 14062, 2002) sugere a utilização de cerca de 30 instrumentos diferentes; Baumann, Boons e Bragd (2002) identificaram mais de 150 métodos e ferramentas de DfE existentes para implementar; e durante a última década, algumas das mais bem sucedidas empresas de desenvolvimento de produtos criaram seus próprios programas DfE (GE e WANG, 2007). Estes métodos podem servir para avaliar o impacto ambiental de produtos e serviços durante seu ciclo de vida e, assim, identificar seus pontos fracos ambientais, para melhorar o PDP e o desempenho ambiental do produto (PIGOSSO et al., 2010).

Estes métodos e ferramentas variam de acordo com a sua finalidade, por exemplo, em relação às fases do ciclo de vida dos produtos que devem ser otimizadas, ou a que fase do PDP se destinam, variam na apresentação dos dados e na forma de implementação no PDP (BAUMANN, BOONS e BRAGD, 2002; PIGOSSO et al., 2010). Segundo Pigosso et al. (2010), a decisão sobre qual método ou ferramenta utilizar depende principalmente do estágio do processo de desenvolvimento de produto, ou seja, qual nível de detalhamento de informações está disponível. 
Segundo Almeida et al. (2010), ainda existem problemas de mercado, tecnológicos e ambientais à frente e pouco consenso científico sobre a metodologia apropriada para comparar o desempenho ambiental dos produtos e as alternativas de processos.

A maioria dos parâmetros ambientais e o ciclo de vida do produto são definidos por decisões tomadas nas fases de definição do conceito e da estrutura do produto (ALTING e JOGENSEN, 1993; ALTING, 1995; MASCLE e ZHAO, 2008; RAMANI et al; 2010). Embora apenas 5-7\% do custo do produto sejam atribuíveis ao projeto inicial, as decisões tomadas durante essa fase são responsáveis por $70-80 \%$ dos impactos ambientais totais do produto (BOHM et al., 2010; RAMANI et al., 2010). Ou seja, se um produto é relativamente "verde" isto é em grande parte determinado durante a fase inicial do projeto (CAGNO e TRUCCO, 2007). Segundo Mascle e Zhao (2008), quanto mais cedo no ciclo de vida de design de produto, a equipe de projeto considerar os fatores ambientais, maior o potencial de benefícios ambientais e redução de custos. Segundo Ramani et al. (2010), estas decisões não se relacionam só com escolhas de material e de fabricação, elas têm um efeito de longo alcance sobre o ciclo de vida do produto, incluindo transporte, distribuição e logística do fim de vida. Segundo Wardak et al. (2008), a fim de realizar o potencial de mercado projetado para novas tecnologias, as incertezas do meio ambiente, saúde e segurança (environmental, health, and safety - EHS) precisam ser caracterizadas através da identificação de riscos e oportunidades nos estágios iniciais do PDP.

Devido aos elevados níveis de incerteza com relação ao projeto incorporado na fase inicial do projeto, novos métodos e ferramentas são essenciais para fornecer uma base para os designers verificarem o grau de sustentabilidade de um determinado produto ou processo (SOUSA e WALLACE, 2006). Excetuando as possibilidades no redesign, nas fases iniciais do PDP o conhecimento sobre materiais e processos é limitado e, conseqüentemente, também o conhecimento das cargas ambientais, mas os graus de liberdade são grandes e as decisões de longo alcance ao passo que, quando o nível de conhecimento aumenta, os graus de liberdade diminuem (ALTING e JOGENSEN, 1993). Segundo Pigosso et al. (2010), tempo e custo podem ser reduzidos e produtos mais ambientalmente corretos podem ser produzidos se as ferramentas de apoio ao DfE são utilizadas no início do processo de design. No entanto, grandes desafios devem ser superados para que os métodos e ferramentas DfE sejam aplicáveis nos estágios iniciais do projeto como: a falta de modelos de informação, interoperabilidade semântica, métodos para influenciar o pensamento no DfE nos estágios iniciais, ciência das medições e modelos de incerteza nas eco-decisões, e habilidade de equilibrar as decisões de negócios e a metodologia DfE (RAMANI et al., 2010). Segundo Alting e Jogensen (1993), os métodos de apoio devem ser capazes de lidar com as fases de desenvolvimento iniciais, onde as bases de avaliação são essencialmente qualitativas e com as fases posteriores, onde a avaliação é quantitativa.

Nesta seção foi definido o conceito de DfE, a importância das fases do ciclo de vida dos produtos e dos métodos e ferramentas do DfE. Portanto, dividimos este estudo em quatro seções principais: Design para o Ambiente (Design for Environment - DfE), Estratégias de Design do DfE, Métodos de Apoio ao DfE (métodos gerenciais e orientações gerais para avaliação qualitativa) e Ferramentas de Apoio ao DfE (ferramentas operacionais para avaliação quantitativa). 


\subsubsection{Motivações para o DfE}

Diversos fatores foram apontados na literatura como motivadores ou desencorajadores para o DfE. Segundo Jabbour (2010), as empresas possuem diferentes motivações para a adoção das práticas e certificação do sistema de gestão ambiental: sistematização para maior produtividade para produtos básicos; redução de multas ambientais; acesso a mercados externos; melhoria da imagem da empresa; atração de consumidores ambientalmente conscientes; exploração de oportunidades de inovações em produtos e processos; aumento do valor de suas ações através da inclusão da empresa no Indice Dow Jones de Sustentabilidade.

Segundo Westkämper, Alting e Arndt (2000), muitos países industrializados adotaram sua primeira legislação ambiental no início dos anos 1970 e nas primeiras duas décadas as autoridades concentraram a maior parte de sua atenção sobre a regulamentação dos processos produtivos e mais recentemente o foco tem sido os produtos e seu ciclo de vida completo. Segundo Kautto (2006), uma vez que o foco da política e gestão ambiental está mudando da produção mais limpa (cleaner production) no nível do processo para produtos mais verdes (greener products), há uma necessidade de novos tipos de instrumentos políticos, e iniciativas como os Sistemas de Gestão Ambiental (Environmental Management Systems - EMSs) de acordo com a série ISO 14000, e sistemas de Responsabilidade Estendida do Produtor (Extended Producer Responsibility - EPR) são esforços para superar as limitações da abordagem tradicional de regulamentação. Em 1996, Gupta e Wilemon (1996), já apresentavam os resultados de um survey com gestores de P\&D apontando os desafios que os mesmos esperavam encontrar durante os próximos anos na área como maior pressão para encontrar novos mercados, aumento da atenção sobre a gestão eficaz do pessoal técnico e aumento da regulamentação e sensibilidade para as questões ambientais.

Segundo Kuo, Wu e Shieh (2009), recentemente, as questões ambientais no contexto do ciclo de vida dos produtos são levadas muito a sério pelo público em geral e agências governamentais. Durante a última década, muita atenção tem sido dada a conceitos como o DfE, EPR e Gestão Responsável da Cadeia de Suprimentos (Responsable Chain Management) (DE BAKKER e NIJHOF, 2002; BYGGETH, BROMAN e ROBÈRT, 2007; WAAGE, 2007; GEHIN, ZWOLINSKI e BRISSAUD, 2008; KURK e EAGAN, 2008; ZACKRISSON et al., 2008; KNIGHT e JENKINS, 2009).

Segundo Westkämper, Alting e Arndt (2000), diversos países industriais, incluindo a União Européia estão discutindo ou já implementaram políticas ambientais orientadas a produtos, com o objetivo de reduzir os impactos dos produtos através de uma série de diferentes medidas:

- Rotulagem Ecológica ou Declarações Ambientais de produtos baseadas em uma avaliação do ciclo de vida, refletindo o impacto ambiental do produto.

- Contratos públicos ecológicos orientando os compradores públicos a levar em conta considerações ambientais.

- A responsabilização do Fabricante (Take-back responsibility) para determinados tipos de produtos (por exemplo, automóveis e produtos eletrônicos), tornando os fabricantes susceptíveis de coletar seus produtos de volta após a fase de uso, motivando-os a projetar e construir os produtos com o seu descarte em mente. 
Segundo Kautto (2006), os sistemas de EPR são impulsionadores do DfE. No entanto Gottberg et al. (2006) afirmam que em setores onde a demanda por produtos é relativamente inelástica aos preços e a regulamentação afeta todos os produtores da mesma maneira, a EPR não impulsiona o DfE, pelo menos no curto prazo (pois os fabricantes conseguem repassar os custos adicionais da EPR para os clientes com efeitos insignificantes sobre as vendas). $\mathrm{Na}$ verdade, as abordagens estratégicas para o DfE mais implementadas variam dependendo do setor econômico (ALBINO, BALICE e DANGELICO, 2009). Segundo Gottberg et al. (2006), a proibição de substâncias perigosas, declarações de produtos e pressões da cadeia de suprimentos, são muitas vezes mais eficazes impulsionadores do DfE. Assim, parece que uma mistura de medidas políticas é necessária, em vez da dependência de instrumentos econômicos sozinhos.

A ISO, com base na série ISO 14000, criou um enquadramento de diferentes tipos de rótulo ecológico: os rótulos de produtos verificados por terceiros (ISO tipo I) são eco-certificações de excelência ambiental dos produtos que estabelecem um alto padrão para diferentes tipos de produtos e tornam os produtos verdes (Green products) reconhecíveis; as Reivindicações Verdes - Green Claims - (ISO Tipo II) contêm uma grande quantidade de informações ambientais sobre os produtos na forma de auto-declarações; as Declarações Ambientais de Produtos - Product environmental declarations - (ISO Tipo III) consistem em dados ambientais quantificados sobre todos os impactos significativos do ciclo de vida do produto, apresentados de forma padronizada. Segundo Westkämper, Alting e Arndt (2000), na Europa existem vários sistemas de rotulagem ecológica nacional e um sistema comum da UE que cobre uma gama de diferentes tipos de produtos. Segundo Albino, Balice e Dangelico (2009), programas de eco-certificação foram desenvolvidos em diferentes países podendo abranger várias categorias de bens e cobrir uma vasta gama de impactos ambientais (como, por exemplo, o Anjo Azul (Blue Angel) alemão, o Selo Verde (Green Seal) dos EUA, o Cisne Branco (White Swan) do Conselho Nórdico, o Escolha Ambiental (Environmental Choice) do Canadá, o Rótulo Ecológico (Eco-Label) Europeu e o Eco Marca (Eco Mark) do Japão, ou ser dirigidos a uma categoria específica de produtos (por exemplo, certificações de madeira, produtos têxteis e alimentos) ou para um tipo específico de impacto ambiental (por exemplo, etiquetas de eficiência energética).

Wagner (2007) afirma que o nível de implementação de EMSs tem um efeito positivo no processo de inovação ambiental, e negativo no nível de inovação geral da empresa, visíveis nas atividades de patenteamento. Tien, Chung e Tsai (2005) afirmam que em empresas certificadas ou qualificadas para os EMSs, a motivação interna para o DfE tem um efeito significativo sobre a implementação do DfE. Segundo Gonzalez-Benito e Gonzalez-Benito (2008a), as empresas com uma função de operações mais pró-ativa são mais inclinadas a desenvolver capacidades que facilitam o desenvolvimento de um EMS e a adoção da norma ISO 14001 está associada com a implementação e desenvolvimento generalizado de diversas práticas de gestão ambiental no design de produtos e processos de produção. No entanto, Kautto (2006) afirma que a existência de um EMS dificilmente pode ser usada como um indicador convincente da implementação do DfE. Segundo Link e Naveh (2006), não existe uma relação comprovada entre a melhoria do desempenho ambiental e de negócios como resultado da implementação da ISO 14001. Assim, os laços estreitos entre o DfE e os EMSs que Simon et al. (2000) mencionaram podem indicar a sua ocorrência simultânea ao invés de 
uma conexão, fechada causal. Da mesma forma, o fato de a empresa possuir um departamento ambiental não significa que a questão ambiental seja considerada estratégica pela empresa (AMMENBERG e SUNDIN, 2005). Na verdade, somente se os requisitos da norma tornam-se parte das práticas cotidianas da organização então, esta prática leva um melhor desempenho organizacional ambiental (LINK e NAVEH, 2006). Quanto mais proativa a empresa na implementação de estratégias ambientais, melhores são os resultados obtidos na implementação do DfE (TIEN, CHUNG e TSAI, 2005).

Albino, Balice e Dangelico (2009) relatam um estudo com as 255 empresas incluídas no Índice Dow Jones Mundial de Sustentabilidade (Dow Jones Sustainability World Index - DJSWI), classificadas em diferentes setores (materiais básicos, consumo, energia, saúde, industrial, telecomunicações, tecnologia e utilitários) de 21 países. Os autores afirmam que mais de $50 \%$ das empresas desenvolvem produtos verdes (135 contra 120), tanto em nível setorial, com exceção dos setores da 'saúde' e 'de consumo', quanto em nível de área geográfica, onde não há área geográfica mais orientada para o DfE do que outra. Além disso, no estudo, os autores puderam evidenciar que mais de $70 \%$ das empresas no DJSWI adotam a um nível elevado a gestão verde, materiais ecoeficientes ou a eficiência energética. No estudo, a eficiência energética e a cadeia de suprimentos verde são as abordagens estratégicas mais e as menos adotadas respectivamente, e somente no setor de "tecnologia", a cadeia de suprimentos verde é a abordagem mais adotada. O principal resultado, apresentado pelos autores, é que as empresas com DfE são apoiadas pela adoção de abordagens estratégicas ambientais em maior grau do que as sem DfE independente de área geográfica ou setor da indústria.

Jabbour (2010) afirma que a proatividade com que a empresa introduz as questões ambientais na organização e implementa a norma ISO 14001 tem uma relação mais fechada com o DfE e, o nível de implementação do DfE fornece informações importantes a respeito das diferenças entre a gestão ambiental nas empresas. Segundo Hunt e Auster (1990) existem duas posições extremas na transformação ambiental das empresas: reatividade ambiental (empresas que implementam mudanças mínimas obrigatórias para cumprir regulamentações), versus a proatividade ambiental (empresas que voluntariamente tomam medidas para reduzir o seu impacto sobre o meio ambiente). As diferentes abordagens encontradas nas empresas podem ser consideradas estágios da gestão ambiental corporativa, o que tem sido objeto de diversos estudos importantes (HUNT e AUSTER,1990; HART, 1995). Segundo Jabbour (2010), o nível de maturidade da gestão ambiental das empresas tende a acompanhar o nível em que estas questões são introduzidas nas sub-áreas da função produção, principalmente no PDP. Na verdade o PDP é a área mais pertinente para a avaliação do estágio em que as questões ambientais são inseridas na área de produção das empresas (TINGSTRÖM e KARLSSON, 2006; JABBOUR, 2010). Segundo Jabbour (2010), em geral, as empresas apresentam 3 tipos de comportamento em relação a implementação do DfE:

- Empresas que, apesar da crescente integração dos Aspectos Ambientais no PDP, não contam com metodologias e técnicas para a sua sistematização, levando a melhorias para situações específicas. Neste caso é necessário persuadir a equipe de design para o DfE, no entanto os integrantes da equipe tendem a executar melhorias incrementais. 
- Empresas sem iniciativas no PDP, pois se beneficiam de melhorias ambientais em componentes produzidos por seus fornecedores e por que a principal melhoria no desempenho ambiental do produto foi motivada exclusivamente por imposição legal.

- Empresas que tem cada vez mais e, sistematicamente, implementado o DfE. Para estas empresas melhorar o desempenho ambiental dos produtos "é a meta mais ambiciosa na empresa. Deve ser alcançada, levando em consideração inúmeras variáveis como custo, qualidade, inovação... mas se alcançada, trará vantagens sobre a concorrência".

Segundo Huang, Ding e Kao, 2009, as empresas são mais propensas a investir em práticas ambientalmente responsáveis, quando os valores pessoais dos funcionários são a favor de fortes compromissos corporativos em responsabilidades ambientais. Além disso, o nível de conscientização ambiental entre os funcionários e disposição para se envolverem nesta questão são fundamentais para o sucesso de iniciativas ambientais corporativas (HART, 1995). A padronização dos EMSs aumenta seu efeito sobre o desempenho ambiental da organização através do seu impacto positivo no poder discricionário dos funcionários, que melhora ainda mais o desempenho ambiental (LINK e NAVEH, 2006). Neste sentido, Huang, Ding e Kao (2009) afirmam que as empresas familiares prestam muito mais atenção aos seus colaboradores internos do que as empresas não familiares, o que pode indicar uma maior influência destas questões em empresas familiares.

De qualquer forma, a implementação do DfE tem um efeito fundamentalmente significativo sobre as vantagens de negócios competitivas e quanto mais bem sucedida, maiores são as vantagens competitivas, independente de grupo da indústria ou escala empresarial (TIEN, CHUNG e TSAI, 2005). No entanto segundo Azevedo e Nolasco (2009), o modelo de gestão ambiental em muitas empresas ainda é quase inexistente, baseado na adoção tímida de requisitos ambientais, sendo esses identificados principalmente na etapa de descarte, caracterizando ações corretivas do processo. E segundo Gottberg et al. (2006), a escolha entre esquemas de recuperação de resíduos individuais ou centralizados repousa sobre as percepções dos custos relativos e praticidade.

Segundo Azevedo e Nolasco (2009), os fatores econômicos ainda ditam a forma das empresas responderem às questões ambientais com o DfE, seja a adequação às leis e aos regulamentos ou a redução dos custos de produção. Entretanto, Jabbour (2010) postula que as empresas apresentam diferentes expectativas quanto à introdução da dimensão ambiental nas prioridades competitivas da estratégia de produção: redução de custos, especialmente pelo aumento de produtividade e pela corte de despesas com possíveis multas ambientais, aumentar a qualidade em seus produtos, renovação do mix de produtos, gerando inovações em produtos com alto desempenho ambiental, acesso a novos mercados ou à exploração de novos nichos de consumidores em mercados onde a empresa está ativa. Neste sentido, Savaskan e Van Wassenhove (2006) afirmam que embora a legislação emitida pelos governos na Europa, América do Norte e Japão incentive essa consciência, a resposta das empresas à evolução das exigências de desempenho ambiental tem sido proativa em muitos casos. Segundo os autores, exemplos de posturas proativas são os fabricantes de automóveis, como a DaimlerChrysler e a BMW, que têm insistido que os seus fornecedores também respeitem as mesmas pautas ambientais que eles seguem. Os autores ainda citam joint ventures, recentemente criadas, para pesquisa e 
desenvolvimento de processos de recuperação, como a da BMW, Renault e Fiat, que concordaram em recuperar e processar os carros umas das outras. Outros exemplos de recuperação de produto são as câmeras descartáveis (Kodak), cartuchos de impressoras e copiadoras (Xerox, Canon e Accutone), copiadoras (Agfa Gevaert, Oce e Xerox), e telefones celulares (ReCellular) (SAVASKAN e VAN WASSENHOVE, 2006). Os autores afirmam que em todos estes casos, as atividades de recuperação de produtos são percebidas como parte integrante do PDP e dos processos de produção originais dos produtos.

A fonte desta proatividade pode estar na orientação das empresas ao mercado, pois, segundo Marx, de Paula e Sum (2010), no DfE, as necessidades dos consumidores finais e as necessidades de outros stakeholders devem ser consideradas para uma abordagem sistêmica e, González-Benito e González-Benito (2008b) afirmam que as reações das empresas às pressões dos stakeholders priorizam processos de produção internos enquanto que as empresas com elevada orientação para o mercado apresentam uma maior implementação de práticas ambientais relacionadas ao planejamento e organização, design de produto e logística em detrimento daqueles relacionados a processos de produção internos.

Wagner (2007) afirma que a inovação ambiental do produto e inovações ambientais patenteadas apresentam uma relação positiva com os stakeholders ambientalmente interessados e uma relação negativa com os ambientalmente neutros é encontrada. Segundo Marx, de Paula e Sum (2010), o sucesso do marketing de um produto sustentável é o resultado de uma coordenação adequada das ações da rede de fabricantes, varejistas, consumidores e governos.

Segundo Tingström e Karlsson (2006) consumidores ambientalmente conscientes e a demanda ambiental motivam a empresa a desenvolver conhecimento ambiental sobre as perspectivas de mercado, projeto de produtos e desenvolvimento de processos de produção e de lançamento de produtos. Em empresas proativas os fluxos de conhecimento e informação da sociedade e dos funcionários sobre determinada categoria de impacto ambiental levam ao desenvolvimento de produtos que visam a redução deste tipo de impacto (LEE, GEMBA e KODAMA, 2006). Nestes casos, a articulação da demanda social é um processo eficaz pelo qual os fluxos de conhecimento e informação mobilizam os requisitos necessários para uma inovação ambiental bemsucedida.

No entanto, segundo Huber (2008), a maioria das inovações tecnológicas ambientais (ou seja, novos produtos, processos e práticas que acompanham efeitos ambientais benignos) ocorre a montante e não a jusante, ou seja, a cima na cadeia, no início e não no final da cadeia de produtos, e nos estágios iniciais do desenvolvimento de tecnologias ou produtos ao invés de mais tarde, em estágios mais maduros. O comportamento de compra é um incentivo para o desenvolvimento de tecnologias sustentáveis (PUJARI e WRIGHT, 1999), mas segundo Huber (2008), novas tecnologias não ocorrem por meio de pressão pela demanda, originando-se do lado da oferta e, embora a demanda do consumidor seja de fato um fator importante de feedback no desenvolvimento e difusão destas inovações, seu efeito é seletivo. Marchand e Walker (2008) sugerem que os designers de produto podem apoiar e encorajar aqueles já ativos ou interessados em orientar os seus hábitos de consumo para soluções mais sustentáveis através da criação de alternativas de produtos adequadas 
ecologicamente e socialmente responsáveis. Entretanto, Huber (2008) afirma que os provedores básicos, principais fabricantes e grandes empresas de serviços e comércio, têm, ou podem ter, se assim o desejarem, uma influência decisiva sobre os fornecedores ao longo da cadeia do produto, e uma influência decisiva no DfE de bens de capital e de consumo.

\subsubsection{Integração da cadeia de suprimentos no DfE}

Segundo Alting (1995), no curto prazo, o fabricante do produto só pode influenciar o desempenho ambiental da pré-fabricação escolhendo os componentes e subconjuntos com menores encargos ambientais associados. Entretanto, o autor afirma que, no longo prazo, os principais interessados poderão colocar demandas sobre o desempenho ambiental dos fornecedores, e assim influenciar o desempenho ambiental de seus próprios produtos. Segundo Vachon e Klassen (2008), uma vez que as corporações tentam avançar em direção a sustentabilidade ambiental, a gestão deve estender seus esforços para melhorar as práticas ambientais em toda a sua cadeia de suprimentos. Segundo Lee et al. (2010), padrões estabelecidos pelos regulamentos desempenham um papel importante no impulsionamento de inovações tecnológicas ambientais e na determinação da direção das mudanças tecnológicas na indústria automobilística. Os autores afirmam que os fornecedores de componentes foram importantes fontes de inovação na década de 1970, mas no decorrer da evolução tecnológica, e, provavelmente, impulsionadas pelo desenvolvimento de novas normas e regulamentos ambientais, as montadoras gradualmente se transformaram na fonte da inovação (inclusive gerenciando estrategicamente o conhecimento de arquitetura e componentes na presença de incertezas sobre sua capacidade tecnológica para atender os novos padrões de controle de emissões de automóveis). Hart (1995) propôs que a cooperação entre os membros de uma cadeia de suprimentos leva a gestão ambiental mais avançada incluindo a gestão do produto (product stewardship). Segundo Cagno e Trucco (2007), a fase de design do produto é o momento em que todos os objetivos da empresa podem ser abordados, do ponto de vista do ciclo de vida, isto é, da maneira mais adequada para identificar soluções eficazes, enquanto também levando em consideração a cadeia cliente-fornecedor e estratégias de co-makership (parceria entre clientes e fornecedores de forma a gerenciar os produtos, processos, qualidade, pesquisas e desenvolvimento). Como tal, segundo Vachon (2007), várias organizações de manufatura tem se voltado para os seus fornecedores e clientes para encontrar soluções inovadoras para as questões ambientais. Questões ambientais na cadeia de suprimentos tem sido tema de diversos trabalhos (HART, 1995; ZHU e SARKIS, 2004; VACHON, 2007; VACHON e KLASSEN, 2008; etc.). Alguns estudos combinaram atividades a montante e a jusante em um construto unificado (ZHU e SARKIS, 2004). No entanto, segundo Vachon e Klassen (2008), práticas verdes de colaboração com os fornecedores trazem mais benefícios do que a colaboração com clientes. Segundo Vachon (2007), as práticas da cadeia de suprimentos verde com fornecedores (a montante) estão relacionadas à compra ambiental, ao DfD e DfE e, estas tendem a ser mais benéficas se realizadas em cooperação com os fornecedores.

Vachon e Klassen (2008) sugerem que uma ligação existiria entre a gestão ambiental na cadeia de suprimentos e as práticas de gestão da qualidade dentro de uma empresa. Outros estudos 
também sugerem que a gestão ambiental pode desenvolver capacidades que são semelhantes e complementares às que podem ser desenvolvidas pela gestão da qualidade (HART, 1995). A ligação entre a gestão ambiental interna e os sistemas de gestão da qualidade tem sido estabelecida na literatura (CHEN, 2001). Estudos mostram que empresas que possuem SGQ e/ou ferramentas da qualidade implementados, tais como ISO 9001:2000 (Sistema de Gestão da Qualidade), Manutenção Produtiva Total (Total Productive Maintenance - TPM), Kaizen e 5S, etc, muitas vezes implementam o DfE (VINODH, 2010; VINODH e RATHOD, 2010a; VINODH e RATHOD, 2010b).

De qualquer forma, a cadeia de suprimentos verde visa atenuar o impacto das atividades de desenvolvimento de produtos fora dos limites da empresa, como auditoria, avaliação e seleção de fornecedores, entrega do produto final para os consumidores, e gestão EoL do produto (ELLRAM, TATE e CARTER, 2008). Segundo Ge e Wang (2007), numerosos exemplos industriais revelam que a execução da legislação ambiental, muitas vezes depende de se o programa DfE utilizado na empresa consegue se associar de forma eficaz com outros stakeholders eco-conscientes chave do design, incluindo o grupo de design, gerenciamento de cadeia de suprimentos e fornecedores. As práticas de gestão ambiental mais avançadas, como o DfE, LCA e logística reversa, exigem a integração das diferentes partes interessadas na cadeia de suprimentos (VACHON e KLASSEN, 2008). As tecnologias de prevenção da poluição implicam mais conhecimentos tácitos através do desenvolvimento de habilidades e equipes "verdes", e este conhecimento tácito resulta em um recurso que é difícil de replicar (HART, 1995). A propriedade, conteúdo, extensão e métodos de informações trocadas e compartilhadas entre os diferentes atores no DfE são um dos principais fatores a afetar a eficácia de suas corporações (CHUNG e PENG, 2006; GE e WANG, 2007). Todas essas práticas, referidas geralmente como gerenciamento de produtos (product stewardship), criam uma teia de interações com troca de informações e de conhecimentos entre fornecedores e clientes, portanto, as estratégias ambientais com base no gerenciamento do produto são socialmente complexas (HART, 1995). Neste sentido, Tseng (2010a) apresenta uma abordagem integrada para a seleção multi-critérios do melhor fornecedor, de acordo com as suas capacidades de gestão do conhecimento de práticas ambientais (Environmental practice in Knowledge Management Capabilities - EKMC) com a incerteza e a falta de informação inerentes a este processo (TSENG, 2010b).

Segundo Savaskan e Van Wassenhove (2006), a organização do sistema de coleta dos produtos em fim de vida, bem como o seu reuso varia bastante dependendo das características e estrutura da cadeia de suprimentos do produto e da experiência na indústria. Segundo Jabbour (2010), as empresas apresentam dificuldades em estruturar a inserção da dimensão ambiental na área de logística. Em geral, segundo o mesmo autor, as empresas apresentam atividades de logística reversa (como retorno de embalagens aos fornecedores), mas a principal razão para esta prática não é a melhoria do desempenho ambiental. Segundo Savaskan e Van Wassenhove (2006), em algumas indústrias, os fabricantes de equipamentos gerenciam o processo de coleta em paralelo à distribuição de novos produtos: 1) A Xerox tem sido uma líder na reutilização de copiadoras ao fim de seus contratos de leasing na fabricação de novas copiadoras desde a década de 90; e 2) A Hewlett Packard (HP) reutiliza computadores e periféricos e a Xerox e a Canon reutilizam cartuchos de tinta e toner coletados diretamente dos consumidores utilizando caixas de correio pré-pagas pela fabricante. 
Os mesmos autores afirmam que, em alguns casos, os fabricantes atribuem as atividades de coleta de produtos para seus parceiros de distribuição: 1) A Kodak recolhe câmeras de volta por meio de grandes varejistas, e recupera $76 \%$ do peso de uma câmera na produção de uma nova (a cada câmera enviada à Kodak, o varejista é reembolsado com uma taxa fixa por câmera e com os custos de transporte); e 2) $\mathrm{Na}$ indústria eletrônica, varejistas/distribuidores também atuam como pontos de retorno dos produtos para os fabricantes.

\subsubsection{Estratégias de Design do DfE}

Todos os produtos causam algum tipo de impacto ao meio ambiente durante o seu ciclo de vida, desde a extração da matéria-prima até a produção, uso e descarte, e estes efeitos ambientais são o resultado de decisões inter-relacionadas, tomadas durante o ciclo de vida do produto (BAUMANN, BOONS e BRAGD, 2002). Persson (2001) resume que o DfE oferece oportunidades para minimizar o desperdício e melhorar a eficiência da utilização dos recursos através de modificações como tamanho do produto, vida útil, nas características de reciclagem e de uso. A utilização e conseqüente descarte do produto geram 2 fluxos: (a) de materiais a serem reutilizados ou reciclados na fase de produção; e (b) de análise das conseqüências ambientais de cada fase do ciclo de vida do produto, fornecendo mais conhecimento sobre como o produto pode se tornar mais verde (TINGSTRÖM e KARLSSON, 2006).

Segundo Alting (1995), somente quando escolhas ambientalmente conscientes sobre o conceito e a estrutura do produto são feitas, e a estratégia de design geral (DfE) é fixada, faz sentido implementar estratégias de design que tratam do desenvolvimento de materiais e processos de fabricação. Neste sentido, o autor afirma que esta é uma questão, definitivamente relevante, da adaptação do sistema, já que muitas das escolhas sobre materiais e processos já são feitas ao se escolher uma estratégia global de design. Segundo Persson (2001), o DfE deve considerar uma perspectiva completa do ciclo de vida dos produtos, considerando os trade-offs entre as fases do ciclo de vida (Por exemplo, a redução no tamanho do produto pode ser alcançada através da utilização de materiais menos pesados e volumosos, no entanto, materiais menos volumosos podem ser mais complexos e, portanto, desfavoráveis para a reciclagem).

Segundo Wong, Lee e Yung (2010), a maioria dos métodos e ferramentas do DfE abrangem todas as fases do ciclo de vida do produto $\mathrm{C} 2 \mathrm{Gr}$, ou seja, o âmbito da avaliação inclui os estágios de Pré-Produção, Produção, Transporte, Uso e Descarte. Por exemplo, Koehler e Wildbolz (2009) argumentam que para reduzir encargos ambientais de produtos de higiene, estes, por exemplo, devem ser produzidos em forma concentrada (reduzindo a demanda por embalagens e despesas de transporte), enquanto os consumidores devem aplicar dosagens de produtos corretas e utilizar baixas temperaturas da água durante a aplicação dos produtos (instruções de dosagem adequada fornecidas pelos fabricantes podem assim reduzir significativamente os efeitos ambientais adversos). $O$ estudo dos autores também mostra que a escolha por ingredientes químicos ambientalmente preferíveis e embalagens ecologicamente corretas, bem como estudos do Inventário do Ciclo de Vida (Life Cycle Inventory - LCl) dos novos materiais, também são eminentemente importantes. Além 
disso, segundo os autores, o uso de embalagens recarregáveis prova ser ambientalmente benéfico, e, portanto, devem ser considerados no portfólio de produtos dos fabricantes e varejistas.

No entanto, segundo Alting (1995), as Estratégias de Design utilizadas, na maioria das vezes, no design do ciclo de vida podem ser classificadas de acordo com a fase do ciclo de vida a que se reportam (Figura 6). O autor afirma que "Estratégia de Design" no sentido amplo do termo inclui estratégias ambientalmente benéficas relacionadas, mas não necessariamente diretamente voltadas ao projeto do produto.

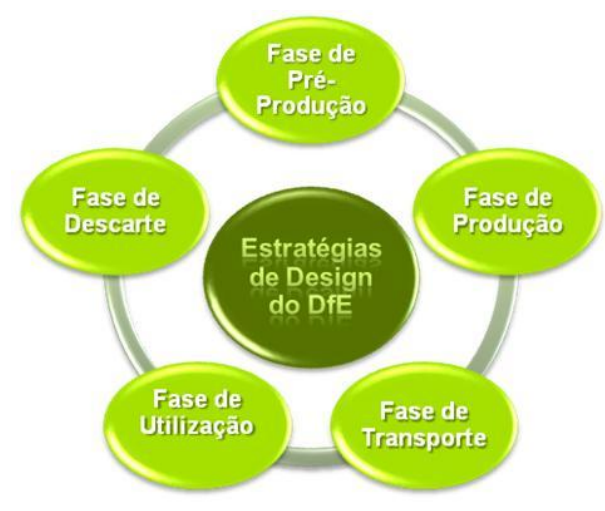

Figura 6 - Estratégias de Design do DfE

Fonte: Elaborado pelo Autor

Segundo Mascle e Zhao (2008), a principal implicação ambiental que um designer procura controlar em um produto vai ditar qual a estratégia de DfE apropriada, no entanto, a reutilização, remanufatura e reciclagem de componentes, por exemplo, podem ter um impacto positivo e/ou negativo sobre o custo, a confiabilidade do produto, e no impacto ambiental. Como resultado, os trade-offs entre os custos, confiabilidade e impacto ambiental devem ser analisados (MANGUN e THUSSTON, 2002).

\subsubsection{Estratégias de Design voltadas à Fase de Pré-Produção}

Segundo Alting (1995), as estratégias de design que se referem à fase de pré-produção lidam com a seleção ambientalmente consciente dos materiais e componentes, englobando as Compras verdes, Rotulagem Ambiental de materiais e componentes, a Diretiva Européia RoHS e Estratégias de cooperação com fornecedores. A seleção de materiais tem sido reconhecida como um dos processos mais eficazes na redução do impacto ambiental dos produtos (LJUNGBERG, 2007; YUAN e DORNFELD, 2010). Segundo Alting (1995), os materiais são divididos em materiais renováveis, não sujeitos ao esgotamento, e materiais não-renováveis, sujeitos ao esgotamento, neste caso, é necessário avaliar os trade-offs sobre os impactos no ambiente externo.

\subsubsection{Estratégias de Design voltadas à Fase de Produção}

Segundo Fitzgerald, Herrmann e Schmidt (2010), o DfE nem sempre aumenta a lucratividade, portanto as práticas DfE como o Design para a Reciclagem e a utilização de recursos renováveis 
historicamente não fazem parte da cultura da maioria das empresas de engenharia. Assim, segundo os autores, uma barreira para a incorporação efetiva de programas DfE é a baixa prioridade que as organizações muitas vezes atribuem às questões ambientais. No entanto, segundo Alting (1995), as estratégias de design DfE ligadas a fase de produção tratam de assuntos voltados à melhoria da performance dos processos, como melhorar o tempo de atravessamento (muitos dos processos poluentes funcionam ininterruptamente e o encargo ambiental total é proporcional ao tempo em que o processo funciona) e projetar para a utilização de processos que economizam materiais, ou à redução de despesas gerais (não é uma estratégia de desenvolvimento de produtos, mas se as despesas gerais são rateadas em cima do número total de unidades produzidas, uma redução nas despesas gerais significa que o produto é mais verde).

Neste sentido, segundo Fitzgerald, Herrmann e Schmidt (2010), os programas e as práticas Design para "X" (Design for "X" - DfX), como o Design para a Fabricação (Design for Manufacturing DfM) e o Design para a Montagem (Design for Assembly - DfA), se desenvolveram ao longo do tempo como uma resposta natural para melhorar a lucratividade, pois reduzem o tempo para trazer os produtos ao mercado, os custos dos produtos e melhoram a qualidade dos produtos. Portanto, segundo os autores, diretrizes, como a redução do número de peças e exploração da simetria das peças agora estão embutidas na cultura de engenharia. A observância destas estratégias confirma que é possível reduzir o impacto ambiental do produto, aumentar a eficiência do processo e reduzir custos (SINGH, GOODYER e POPPLEWELL, 2007).

\subsubsection{Estratégias de Design voltadas à Fase de Transporte}

Segundo Alting (1995), estratégias de design voltadas à fase de transporte também podem resultar em substanciais economias de materiais e custos e englobam o design para baixo volume ou peso (reduzindo o consumo de energia dos processos de transporte), a melhoria da logística de transportes ou a área de Embalagens (escolha de materiais mais verdes e tornar o produto menos frágil). Segundo o mesmo autor, a Digital® realizou um estudo onde a fragilidade dos elementos internos dos computadores foi reduzida, permitindo uma redução de $54 \%$ nos materiais necessários para a embalagem e de $62 \%$ nos custos de embalagem.

\subsubsection{Estratégias de Design voltadas à Fase de Utilização}

As estratégias de design voltadas à fase de utilização tratam do aumento da eficiência funcional, adaptação aos padrões de uso individual, e redução do consumo, principalmente de energia (ALTING, 1995). A principal estratégia é aumentar o tempo de vida útil do produto, diminuindo os encargos ambientais por unidade envolvendo o Design para a Manutenção e Operacionalidade (Design for Maintenance and Serviceability - DfMS), ex. por um principio modular (ALTING, 1995; MASCLE e ZHAO, 2008). No entanto, segundo Kara et al. (2008), os produtos a devem ser desenvolvidos com uma vida útil pré-determinada, minimizando o uso de recursos e impacto ambiental com base na sua estratégia EoL pretendida, pois se os produtos são projetados para uma 
vida útil maior do que a sua vida média de utilização, isto irá se traduzir em desperdício de recursos a menos que exista uma "estratégia de reutilização" posicionada para utilizar a vida estendida dos produtos. Segundo Hakkinen (2007), o Design para a Vida Útil e Sustentabilidade (Design for service life and sustainability) requer novas informações, incluindo, por exemplo, informações sobre a vida útil, os dados LCA e informações sobre substâncias químicas nocivas e emissões, bem como informações detalhadas sobre o desempenho técnico dos produtos. Segundo Lee et al. (2007), o feedback de informação dos estágios posteriores do ciclo de vida de volta para os estágios iniciais do PDP é importante para projetar a fase de serviços dos produtos e se a empresa possui uma rede de serviços bem estabelecida, é mais fácil incorporar e estabelecer uma gestão EoL para o produto e a mesma será capaz de colher os benefícios tanto do ponto de vista comercial quanto do ambiental.

Segundo Alting (1995), estudos de produtos que consomem combustíveis fósseis ou eletricidade durante a operação, como produtos eletrônicos e automotivos, têm demonstrado que grande parte das contribuições para o impacto ambiental global total decorre do consumo de energia na fase de uso. O consumo de um determinado produto pode ser altamente individual, e progressos podem ser feitos com a análise e a identificação dos padrões de uso individual no Design para a Economia de Energia na fase de uso (Design for Energy Savings in the use phase - DfES) (ALTING, 1995; MASCLE e ZHAO, 2008). Hoje é comum, por exemplo, os fabricantes de produtos de linha branca reduzirem o consumo de seus produtos devido a pressões de mercado, no entanto, segundo Alting (1995), necessidades puramente tecnológicas também podem levar ao mesmo resultado.

\subsubsection{Estratégias de Design voltadas à Fase de Descarte}

Segundo Kim et al. (2006), cada vez mais, as empresas têm dado considerável atenção a vários processos de recuperação de materiais e produtos devido a motivações econômicas e ambientais, bem como as crescentes pressões da legislação para coletar e reprocessar os seus produtos em fim de vida de forma adequada. Maxwell e Van der Vorst (2003) afirmam que mesmo quando orientados pelas exigências dos consumidores, os requisitos ambientais do produto suscitados pela força de marketing são muitas vezes focados na fase de utilização do ciclo de vida do produto e não consideram as necessidades dos consumidores nas fases de aquisição ou descarte. Por exemplo, a sustentabilidade de um produto pode estar mais relacionada com a sua fase de descarte do que à sua fase de utilização, como acontece com os alimentos, o descarte da embalagem causa um impacto ambiental maior do que o descarte do próprio alimento (LEE e XU, 2005).

Pigosso et al. (2010) define o "fim de vida" de um produto como o momento em que o produto já não satisfaz o seu usuário, já que as preferências do usuário mudam mais rapidamente do que o produto se desgasta. Toffel (2003) defende a reavaliação das prioridades de design dos produtos com vistas às diretivas européias ELV e WEE. Segundo Alting (1995), nas estratégias voltadas à fase de descarte, dois princípios se destacam: a adaptação a sistemas de descarte atuais e futuros, envolvendo a disciplina de Design para a Desmontagem (Design for Dissassembly - DfD), que aumenta a eficiência de recuperação; e a questão da preservação da qualidade dos materiais, pois a 
remoção de impurezas na recuperação de metais está associada com a maior parte dos encargos ambientais e a pureza é essencial para a reciclagem direta.

Devido a variabilidade na complexidade dos produtos, para alguns componentes, sistemas ou sub-sistemas, a destinação mais apropriada pode ser a reciclagem, reuso ou remanufatura, geralmente incluindo mais de uma estratégia EoL (STAIKOS e RAHIMIFARD, 2007; PIGOSSO et al., 2010). Ao criar uma hierarquia entre as alternativas EoL, de acordo com o impacto ambiental, a reutilização direta e/ou aumento da vida útil do produto seriam as primeiras no ranking, seguidas dos Sistemas de Serviço do Produto (Product Service Systems - PSSs), reforma, recondicionamento ou remanufatura, reciclagem e o descarte (COLLADO-RUIZ e CAPUZ-RIZO, 2010; PIGOSSO et al., 2010) pois exigem um processo de desmontagem (COLLADO-RUIZ e CAPUZ-RIZO, 2010).

Entre as estratégias EoL estão o Design para a Reciclabilidade (Design for Recyclability DfR), Design para a Remanufaturabilidade (Design for Remanufacturability - DfRM), Design para a Reutilização (Design For Reusability - DfRU), Design para a Desmontagem (Design For Dissassembly - DfD), etc (MASCLE e ZHAO, 2008). O sistema de gestão EoL adequado deve ajustar os processos de desmontagem e separação de peças para a obtenção de maiores lucros, melhor desempenho e resultado ambiental, otimizando o fechamento do ciclo de materiais (PIGOSSO et al., 2010).

\subsection{Design para o Reuso ou Reutilização (Design for Reuse)}

O Reuso ou Reutilização direta implica que o componente, peça ou material pode ser utilizado novamente como ele próprio, sem modificação ou atualização que não seja a limpeza (MASCLE e ZHAO, 2008; PIGOSSO et al., 2010). Por este motivo, Pigosso et al. (2010) afirma que a reutilização é uma solução ideal para a abordagem EoL do produto, a fim de minimizar o impacto ambiental. Segundo Xu, Ong e Nee (2007), o Design para a Reutilização ou Reuso (Design Re-use) é essencial para o desenvolvimento de produtos competitivos e sustentáveis, permitindo economizar recursos. No entanto, esta abordagem, como uma estratégia única, não seria viável, pois não considera as necessidades do usuário ou a qualidade do produto (PIGOSSO et al., 2010).

Segundo Pigosso et al. (2010) a Reforma consiste na coleta de produtos ou componentes, avaliação de suas condições, e troca de peças danificadas, quebradas ou obsoletas por peças novas ou reformadas. Neste caso, a identidade ou funcionalidade original do produto é mantida, embora com uma possível perda de qualidade.

\subsection{Design para a Reciclagem (Design for Recycling)}

Segundo Pigosso et al. (2010) a Reciclagem caracteriza-se pelo recolhimento ou coleta e reprocessamento de materiais, tanto dos resíduos dos processos de fabricação quanto dos produtos em fim de vida e deve ser considerada apenas quando todas as outras alternativas não são economicamente viáveis. Os mesmos autores afirmam que o processamento destes materiais, muitas vezes altera as suas características básicas, por exemplo, a resistência material, densidade e elasticidade, o que implica no seu uso para fins menos nobres, após processados. Os maiores 
problemas quanto à reciclagem são a falta de infra-estrutura de coleta, de identificação, triagem e compactação de materiais, e ineficiência econômica (BHANDER, HAUSCHILD e MCALOONE, 2003). Portanto, a reciclagem ajuda a reduzir a poluição, aproveitar melhor os espaços dos aterros, e conservar os recursos naturais, mas não pode ser a principal estratégia EoL de uma empresa, um governo ou da sociedade (PIGOSSO et al., 2010). Segundo Luttropp e Johansson (2010), uma possibilidade é a de identificar individualmente cada produto através de Dispositivos de Identificação por Rádio Freqüência (Radio Frequency Identification Devices - RFID) oferecendo a possibilidade de procurar informações sobre reciclagem relevantes em bancos de dados e, ainda, de adicionar informações sobre tratamento de resíduos depois que o produto tenha entrado no mercado. Segundo Paska (2010), a Sony Ericsson tem trabalhado com a eliminação progressiva de substâncias indesejáveis através da introdução de um sistema de declaração de materiais que mantém o controle de todas as substâncias em componentes usados em produtos da empresa, melhorando os impactos ambientais na fase de reciclagem de seus produtos. O autor também descreve sistemas de informação para a cadeia de suprimentos e como eles são utilizados para facilitar a eliminação progressiva de substâncias na indústria eletrônica.

\subsection{Design para a Remanufatura (Design for Remanufacturing)}

Segundo Pigosso et al. (2010) a meta de recuperação é recuperar componentes, conjuntos ou módulos inteiros do produto com a intenção de reutilizar-los em outros produtos e processo, redirecionando-os para um segundo período de vida. A recuperação do valor dos produtos pode ser obtida por meio da remanufatura e desmanufatura (WESTKAMPER, 2003). O Recondicionamento ou Remanufatura preserva a identidade do produto e procura trazer o produto de volta para a condição de "produto novo" realizando a desmontagem, testes, reparos, limpeza, inspeção de peças, atualização, substituição de peças e remontagem (GUNGOR e GUPTA, 1999; MASCLE e ZHAO, 2008; PIGOSSO et al., 2010). É, portanto, necessário levar em consideração aspectos de design e engenharia do ciclo de vida, ou seja, a capacidade dos sistemas para a montagem, desmontagem e diagnóstico em todas as fases do ciclo de vida (PIGOSSO et al., 2010). Neste sentido, surge o Design para a Capacidade de Atualização (Design for Upgradability) (UMEDA et al., 2005; XING et al., 2007).

Segundo Mascle e Zhao (2008) a indústria de remanufatura enfrenta três problemas no planejamento de remanufatura: (1) componentes que falham, tipos de falhas, e as distribuições dos tempos de falha são muitas vezes desconhecidos e/ou apresentam uma grande variação, (2) falta de um incentivo para os clientes comprarem produtos remanufaturados, bem como a percepção de que eles são de "segunda" mão e, portanto, têm baixa qualidade, e (3) as barreiras tecnológicas para a remanufatura que decorrem da diferenciação dos produtos. Além disso, Shu e Flowers (1999) afirmam que o Design para Remanufatura entra em conflito com outras metodologias como o DfA e o Design para Reciclagem, pois também depende de outros domínios do ciclo de vida, especificamente fabricação e montagem, manutenção e reciclagem de materiais de sucata e questões de fixação. 


\subsection{Design para a Desmontagem (DfD - Design for Dissassembly)}

Numa perspectiva de melhorar o comportamento dos produtos em seu ciclo de vida, o planejamento eficiente dos processos de desmontagem adquire importância estratégica, melhorando tanto a fase de utilização do produto, facilitando as operações de serviços (manutenção, atualização e reparos) (MILDENBERGER e KHARE, 2000; GIUDICE e FARGIONE, 2007), quanto a fase EoL, favorecendo a reciclagem de materiais e a recuperação e reutilização de componentes (ALTING, 1995; GUNGOR e GUPTA, 1999; MILDENBERGER e KHARE, 2000; HULA et al., 2003; KARA, PORNPRASITPOL e KAEBERNICK, 2006; KONGAR e GUPTA, 2006; DONG, GIBSON e ARNDT, 2007; GIUDICE e FARGIONE, 2007). Além disso, outras considerações também estão conectadas a desmontagem, por exemplo: produtos projetados para a desmontagem são de fácil manuseio e não constituem um perigo para a saúde ocupacional (ALTING, 1995). Aliás, a montagem e desmontagem são processos críticos e necessários para o DfE, pois elas interferem em todas as etapas do ciclo de vida do produto (MILDENBERGER e KHARE, 2000).

A Desmontagem ou De-Manufatura (De-Manufacturing - DM) é um processo para separar um produto em componentes e materiais que serão reparados, substituídos, reutilizados ou reciclados e pode ser definida como a remoção sistemática de componentes desejáveis de uma montagem, assegurando que nenhuma peça seja danificada no processo de desmontagem (CHUNG e PENG, 2006; GIUDICE e FARGIONE, 2007), com as operações de classificação necessárias (GUNGOR e GUPTA, 1999). As principais barreiras à desmontagem estão relacionadas ao fato de que a maioria dos produtos não é projetada para a "desmontabilidade": além da dificuldade de obtenção de todas as informações necessárias para planejar a desmontagem, eles possuem inúmeras etapas de desmontagem; as técnicas de montagem não levam em consideração a necessidade de posterior desmontagem; diversidade de materiais e complexos subconjuntos, onde os componentes ambientalmente problemáticos estão dispersos por todo o produto, muitas vezes, a uma profundidade considerável; e as configurações dos produtos não levam em conta os efeitos de, por exemplo, a corrosão (durante seu tempo de vida, um produto está sujeito a reparação, contaminação e a corrosão), que são altamente problemáticos para uma operação de desmontagem (ALTING, 1995; MASCLE e ZHAO, 2008; COLLADO-RUIZ e CAPUZ-RIZO, 2010). Segundo Kongar e Gupta (2006), a complexidade da determinação da melhor seqüência de desmontagem aumenta com o aumento do número de peças do produto. Segundo Dong, Gibson e Arndt (2007), a expectativa de vida diferente, dos componentes reutilizáveis, afeta a ordem da desmontagem.

Diversos estudos se concentraram em melhorar a "desmontabilidade" dos produtos e nos vários problemas de desmontagem, como o DfD, planejamento do processo de desmontagem, a programação da desmontagem, etc (ALTING, 1995; GUNGOR e GUPTA, 1999; FELDMANN et al., 2000; CHU et al., 2009). Avaliar a desmontabilidade (eficiência do processo de desmontagem) é uma tarefa difícil, principalmente no processo de design (GÜNGÖR e GUPTA, 2001). Os principais aspectos do planejamento e programação do processo de desmontagem são:

- Análise das características do sistema (geometria e relações de montagem dos componentes) (KUO, 2000; GIUDICE e FARGIONE, 2007); 
- Geração de uma Árvore de Desmontagem (Disassembly Tree - DT) ou Árvore Hierárquica de Desmontagem (Hierarchical Disassembly Tree - HDT): grupo de possíveis seqüências de desmontagem (KUO, 2000; VEERAKAMOLMAL e GUPTA, 2000; GUNGOR e GUPTA, 2001);

- Geração da Seqüência de Desmontagem (Disassembly Sequence Generation - DSG) ótima (ou quase ótima) ou Seqüência Ótima de Desmontagem (Optimal Disassembly Sequence ODS), mais rápida (KROLL e CARVER, 1999; HULA et al., 2003; KIM et al., 2006; GIUDICE e FARGIONE, 2007), eficiente e rentável (ALTING, 1995; GUNGOR e GUPTA, 1999; KUO, 2000; HULA et al., 2003; KARA, PORNPRASITPOL e KAEBERNICK, 2006; KIM et al., 2006; KONGAR e GUPTA, 2006; DONG, GIBSON e ARNDT, 2007; GIUDICE e FARGIONE, 2007), tanto do ponto de vista econômico como ambiental (ALTING, 1995; GUNGOR e GUPTA, 1999; HULA et al., 2003; KARA, PORNPRASITPOL e KAEBERNICK, 2006; DONG, GIBSON e ARNDT, 2007; GIUDICE e FARGIONE, 2007);

- Determinação do nível ótimo de desmontagem (KIM et al., 2006; GIUDICE e FARGIONE, 2007).

O resultado desta análise deve fornecer feedback à fase de design para melhorar as decisões no início do PDP para permitir o DfE (por exemplo, mudanças em materiais das peças e métodos de montagem) (FELDMANN et al., 2000; CHUNG e PENG, 2006; GIUDICE e FARGIONE, 2007; CHU et al., 2009). No entanto, a análise de produtos relacionada à desmontagem é geralmente considerada como um pós-processo no desenvolvimento de produtos (CHUNG e PENG, 2006). Segundo Alting (1995), os métodos e ferramentas DfD devem catalisar esse processo.

Segundo Alting (1995), o DfD envolve o uso de regras gerais de design e diversas ferramentas e as suas diretrizes mais importantes se referem à consolidação de peças, por exemplo: redução do número de peças e subconjuntos do produto; limitação da variabilidade de materiais (subconjuntos com número reduzido de materiais e materiais compatíveis, evitando a combinação de materiais que podem dar origem a corrosão ou envelhecimento), por exemplo, o agrupamento de componentes nocivos, valiosos ou reutilizáveis para o mesmo subconjunto facilitando o acesso à estas peças ou componentes, e protegendo as peças contra a sujeira, facilitando a drenagem de fluidos do produto; utilização de técnicas de fixação mais simples (fácil acesso, redução da necessidade de força para desmontagem, não utilização de adesivos, número mínimo de elementos de fixação, fixando diversas peças com um mesmo elemento), projetar para a desmontagem por meio de movimentos simples, por exemplo, a não utilização de rotações, e projetar para o reconhecimento de material, seja por meio de etiquetas, códigos, tecnologias de informação ou de outras formas.

Existem, ao menos, dois problemas básicos nas Estratégias EoL (ALTING, 1995; LI et al., 2008): (1) trata-se de uma tarefa de múltiplos objetivos e; (2) o produto é projetado para um cenário futuro de descarte, dos quais só existem indicações. Este pode ser o motivo da discussão sobre se a modularidade auxilia (KUO, 2000; SAND, GU e WATSON, 2002; LI et al., 2008; SELIGER e ZETTL, 2008) ou não o DfE e o DfD (COLLADO-RUIZ e CAPUZ-RIZO, 2010). Sand, Gu e Watson (2002) e Seliger e Zettl (2008) buscaram projetar módulos, considerando vários atributos do ciclo de vida, como a compatibilidade dos materiais, semelhanças quanto ao tempo de vida útil, ciclo de manutenção e facilidade de desmontagem. 
Segundo Gunther, Sebastian e Marco (2007), os facilitadores tecnológicos para a adaptação como a modularidade, tecnologias de informação e de comunicação são necessários para o DfE. Mengoni, Germani e Mandorli (2009) e Li et al. (2008), também advogam pela modularidade para auxiliar no alcance dos objetivos tradicionais e ambientais do PDP. No entanto, somente se os produtos tem a sua destinação EoL correta é que faz sentido pensar em um design modular, pois, em alguns casos, todo o produto pode ser picado, ou apenas parte do produto é desmontada, tornando o design modular desnecessário (LI et al., 2008). Segundo Collado-Ruiz e Capuz-Rizo (2010), o desempenho da modularidade e da desmontagem são avaliados por indicadores diferentes, e não existe uma correlação comprovada entre estes dois conceitos (em alguns dos casos, até mesmo a correlação inversa é encontrada). Segundo os autores, fatores como a estrutura do produto ou Estratégia EoL selecionada são mais importantes que a modularidade e apenas em módulos com propriedades muito específicas é que o desempenho EoL pode ser garantido.

Segundo Alting (1995), considerando que as ferramentas DfD se concentram na estrutura do produto, para facilitar a desmontagem e unir partes do produto que exigem a mesma rota de descarte, e que as escolhas sobre materiais e processos são definidas na aplicação da Avaliação do Ciclo de Vida (Life Cycle Assessment - LCA), a LCA e o DfD se complementam no que diz respeito ao planejamento da fase de descarte do ciclo de vida.

\subsubsection{Métodos e Ferramentas de Apoio ao DfE}

Neste trabalho, serão consideradas ferramentas, as técnicas, instrumentos e utensílios operacionais de avaliação; e métodos, a aplicação de regras, princípios e práticas gerenciais. Uma série de métodos e ferramentas são propostos a fim de apoiar a tomada de decisões no DfE (BYGGETH e HOCHSCHORNER, 2006). A maioria das obras sobre DfE oferece diretrizes, listas de verificação e outras ferramentas que têm sido utilizadas no PDP durante muito tempo (LUTTROPP e LAGERSTEDT, 2006). Baumann, Boons e Bragd (2002), em um estudo que examinou 650 artigos sobre métodos e ferramentas para o DfE, descreveram que a maioria das referências era conceitual, com poucas referências que descreviam a sua difusão e a experiência de como eles funcionam no PDP e que a maioria das publicações com conteúdo empírico relatavam testes de novos métodos e ferramentas. Neste sentido, segundo os autores, os envolvidos no campo estão mais interessados no desenvolvimento de novos métodos e ferramentas ao invés de estudar a utilização dos já existentes, a fim de avaliá-los e melhorá-los. Este trabalho também não se presta a esta avaliação, no entanto, são levantados os principais requisitos para estes métodos e ferramentas efetivamente apoiarem o DfE. Os métodos e ferramentas de apoio ao DfE podem ser divididos em dois grupos:

1. Métodos de Apoio ao DfE: O DfE restrito ao uso de ferramentas operacionais de avaliação, muitas vezes é prejudicado, pois os designers, geralmente, estão à procura de orientação geral ao invés de uma direção específica (LINDAHL, 2006). Portanto, procedimentos gerenciais ativos continuamente garantindo que as preocupações ambientais são avaliadas durante todo o PDP são necessários para apoiar o processo (ALTING e JOGENSEN, 1993).

É necessário que o método forneça suporte a utilização das Ferramentas de Apoio ao DfE 
(NY et al., 2006; BYGGETH, BROMAN e ROBÈRT, 2007). Pois uma visão bem-estruturada não é uma alternativa para o conhecimento e ferramentas detalhadas, tais como a pegada ecológica, ou a LCA, mas sim uma maneira de fazer melhor uso destas (NY et al., 2006). Na verdade, para utilizar estas ferramentas ambientais, é necessário um extensivo treinamento e educação da força de trabalho do PDP sobre os efeitos ambientais, de onde vem e como impactam no meio ambiente, pois a equipe deverá tomar decisões a respeito de trade-offs entre os impactos ambientais no perfil do produto, precisando conhecer as conseqüências ambientais destas escolhas (ALTING e JOGENSEN, 1993; ALTING, 1995).

2. Ferramentas de Apoio ao DfE: Ferramentas operacionais para a análise/avaliação freqüente das conseqüências e benefícios ambientais durante o PDP (ALTING e JOGENSEN, 1993). As Ferramentas de Apoio ao DfE não podem substituir as decisões de um designer, pois o PDP, muitas vezes, envolve complexas tomadas de decisões baseadas no conhecimento e exigem expertise ( $\mathrm{LI}$ et al., 2008). O elemento mais importante nestas ferramentas é o método de avaliação que quantifica a carga ambiental para remeter ao público, às agências e outros, as cargas ambientais em todas as fases do ciclo de vida (ALTING e JOGENSEN, 1993). A melhor maneira de utilizar essas ferramentas é considerá-las como uma sugestão de design (LI et al., 2008).

Segundo Almeida et al. (2010), os designers estão sendo forçados a considerar as técnicas mais holísticas para projetar e avaliar produtos e processos e diversos métodos e ferramentas são descritos na literatura, no intuito de integrar aspectos ambientais no PDP, de diversas formas diferentes (dos mais abrangentes e detalhados aos mais simplificados e focados em determinado objetivo ou fase do ciclo de vida). Neste sentido, é necessário definir requisitos para os métodos e ferramentas DfE (LINDAHL, 2006). Portanto, a seguir são listados os métodos e ferramentas, seguidos dos requisitos identificados na literatura para que possam auxiliar o DfE.

\subsubsection{Métodos de Apoio ao DfE}

A literatura sobre gestão ambiental corporativa têm explorado as conexões entre os sistemas de gestão ambiental e o DfE (AMMENBERG e SUNDIN, 2005), os determinantes para o DfE (BERCHICCI e BODEWES, 2005), e como as questões ambientais afetam o trabalho de P\&D na produção (BLOMQUIST e SANDSTROM, 2004). Por exemplo, Fryxell e Vryza (1999) examinaram a integração de considerações ambientais nas múltiplas funções das principais empresas dos EUA em meados dos anos 1990, mostrando que a integração com o desenvolvimento de produtos foi a função onde os departamentos ambientais corporativos tiveram as maiores aspirações e onde a melhoria mais foi procurada. Blomquist e Sandstrom (2004), depois de uma breve exploração da integração de considerações ambientais nas atividades de P\&D de duas grandes empresas de manufatura suecas, argumentam que o teste final do visível "esverdeamento" é fazer as considerações ambientais evidentes no trabalho de P\&D. Apesar do fato de as considerações ambientais terem recebido alguma atenção nos estudos de desenvolvimento de produtos (por exemplo, BAUMANN, BOONS e BRAGD, 2002; AMMENBERG e SUNDIN, 2005; BERCHICCI e BODEWES, 2005), o conceito da 
integração da dimensão ambiental neste processo não foi discutido nestes estudos. Neste sentido, Handfield et al. (2001), desenvolveram um estudo para verificar as barreiras na integração de aspectos ambientais no PDP, por meio de entrevistas com os especialistas ambientais e os designers (usuários das ferramentas DfE), em uma amostra de dez empresas consideradas best-in-class em práticas ambientais (Organizações Ecologicamente Sustentáveis/Ecologically Sustainable Organizations - ESOs), a respeito das metas e objetivos de cada grupo e Lindahl (2006) desenvolveu um estudo baseado na literatura e em entrevistas semi-estruturadas em uma empresa de equipamentos industriais para identificar as exigências dos designers para os métodos e ferramentas de apoio ao DfE.

A maioria das organizações não está disposta a comprometer a funcionalidade, custo unitário, ou o tempo para introdução do produto no mercado, a fim de criar produtos que tenham menor impacto ambiental do que o exigido pela legislação (HANDFIELD et al., 2001; FITZGERALD, HERRMANN e SCHMIDT, 2010; LENOX, KING e EHRENFELD, 2010). Neste sentido, segundo Fitzgerald, Herrmann e Schmidt (2010), os designers podem enfrentar um conflito entre a melhoria da funcionalidade do produto e a redução do impacto ambiental, caracterizando a necessidade de métodos e ferramentas de apoio ao DfE. No entanto, os requisitos para os métodos e ferramentas de apoio ao DfE são quase inexistentes ou são muito vagos e escondidos dos usuários primários, ou seja, os deisgners (LINDAHL, 2006).

Normalmente se a empresa implementa o DfE, a avaliação ambiental do produto é geralmente realizada por especialistas ambientais e os resultados não são levados de volta para o PDP de forma eficiente (BAUMANN, BOONS e BRAGD, 2002). Neste sentido, o DfE é, freqüentemente, limitado a utilização de checkpoints e requisitos de saída (se o projeto não violar nenhuma regulamentação ambiental, o projeto passa pelo ponto de verificação) (HANDFIELD et al., 2001). Segundo Cagno e Trucco (2007), excluindo as configurações intermediárias possíveis, existem basicamente duas formas de integrar os requisitos ambientais no PDP: integração em série (10 requisitos tradicionais, $2^{\circ}$ requisitos ambientais) e integração paralela (desenvolvimento simultâneo das duas fases básicas). Segundo os autores, na integração em série, a segunda fase de design será capaz de analisar apenas um número limitado de soluções, já que a alternativa mais favorável pode ser selecionada somente daqueles que satisfaçam plenamente as demandas primárias, e embora fácil de acionar e implementar, este tipo de integração apresenta limitações em relação ao valor dos resultados obtidos. Neste caso, os autores afirmam que ao invés de um caso global ideal, casos locais ideais são apresentados. Alting e Jogensen (1993) apresentaram o projeto Design Ambiental de Produtos Industriais (Environmental Design of Industrial Products - EDIP) que foi realizado na Universidade Técnica da Dinamarca, em colaboração com cinco grandes empresas industriais dinamarquesas, a Confederação das Indústrias Dinamarquesas e a Agência de Proteção Ambiental. O projeto EDIP (1991 - 1996) combinava o desenvolvimento da metodologia LCA com a adaptação para uso no PDP dentro do campo eletromecânico (ALTING e JOGENSEN, 1993; WESTKÄMPER, ALTING e ARNDT, 2000). Segundo os autores, a conclusão geral é que o sucesso do DfE exige a participação de dois tipos de qualificações:1) Experiência em desenvolvimento de produtos gerenciando o PDP e integrando as prioridades ambientais, às outras prioridades; e 2) Experiência 
em LCA identificando e quantificando os impactos ambientais durante todo o ciclo de vida do produto e avaliando as melhorias obtidas através de soluções de design diferentes. Estas competências podem trabalhar em conjunto de forma interativa ou o trabalho do especialista em meio ambiente pode ser feito off-line em relação ao processo de desenvolvimento, dependendo do escopo e das ambições do projeto (ALTING e JOGENSEN, 1993).

Os designers acreditam que o DfE afetaria negativamente o desempenho empresarial, medido em termos de custo, prazo, qualidade e flexibilidade (HANDFIELD et al., 2001) e mesmo quando motivados para o $\mathrm{DfE}$, os designers de produto não tem certeza exatamente de como proceder enfrentando um problema em aberto de escassez de informações (LENOX, KING e EHRENFELD, 2010). Com o amplo conjunto de dados necessários para apoiar o DfE, os designers simplesmente não têm recursos adequados disponíveis (DUFLOU, DEWULF e SAS, 2003). Portanto, os designers acabam enxergando as questões ambientais como restrições a serem vencidas para se poder dar continuidade à próxima etapa do projeto (HANDFIELD et al., 2001). Segundo Alting (1995), um estudo piloto é essencial para a familiarização com as possibilidades e limitações das ferramentas ambientais, tendo em vista também superar as barreiras e medos, como a possibilidade de aumento de custos do produto e o prolongamento do tempo de desenvolvimento do produto. Os designers têm uma função chave na integração das questões ambientais e têm sido muitas vezes negligenciados em favor de opiniões dos gestores sobre a utilização e benefícios dos métodos e ferramentas DfE (BAUMANN, BOONS e BRAGD, 2002). Estes fatores tornam quase impossível para os designers responder aos gestores se os métodos ou ferramentas estão cumprindo os requisitos estabelecidos (LINDAHL, 2006).

Portanto, os designers contemporâneos precisam de abordagens para a implementação do DfE e são necessários Métodos de Apoio que orientem os designers e os outros atores da organização sobre como proceder à integração de aspectos ambientais no PDP, bem como nas demais atividades relacionadas a este processo, inclusive sobre a utilização das Ferramentas de Apoio ao DfE (VINODH, 2010). Segundo Alting (1995), o DfE requer o desenvolvimento de normas e diretrizes para apoiar o uso eficiente das ferramentas ambientais. No entanto, há uma necessidade de uma melhor definição de requisitos para os métodos e ferramentas que são utilizados (LINDAHL, 2006). Pois os Métodos de Apoio ao DfE devem ser integrados no PDP existente e em seu processo de tomada de decisão, garantindo que os responsáveis pelo processo de tomada de decisões sejam os usuários diretos das Ferramentas de Apoio ao DfE, pois o entendimento do resultado destas é melhorado (SCHMIDT e BUTT, 2006). Diversos autores se preocuparam em desenvolver ou descrever Métodos de Apoio ao DfE, alguns inclusive, desenvolvendo ferramentas para serem implementadas juntamente com os métodos. A seguir são listados os métodos verificados neste estudo, e em seguida, são listadas as principais conclusões derivadas da literatura.

Gunther, Sebastian e Marco (2007), apresentam um modelo de referência para a sustentabilidade na produção baseado em facilitadores tecnológicos para a adaptação de produtos e componentes, como a modularidade, tecnologias de informação e de comunicação e em abordagens para a disseminação do conhecimento em sustentabilidade, ilustrando abordagens sustentáveis no que diz respeito à gestão, tecnologia, processo e produto. 
Fiksel (2003) apresenta um protocolo de design que envolve as seguintes etapas: identificação das fronteiras e da função do sistema, estabelecimento dos requisitos, seleção das tecnologias apropriadas, desenvolvimento de um design do sistema, avaliação do desempenho esperado, e elaboração de um meio prático para a implantação do sistema, incentivando a consideração da resiliência nos sistemas de engenharia e nos sistemas em que estão inseridos. Mangun e Thusston (2002) desenvolvem um modelo, para incorporar o planejamento de longo prazo para o reuso de componentes no PDP, que utiliza uma abordagem de portfólio de produtos com base na segmentação de mercado, considerando os efeitos do desenvolvimento de PSSs e é incorporado em uma ferramenta de decisão que auxilia na determinação de quando um produto deve ser tomado de volta, e quais componentes devem ser reutilizados, reciclados ou descartados.

Segundo Johansson (2006), as características dos projetos de desenvolvimento de produtos diferem em relação às dimensões "nível de experiência em DfE" e "complexidade ambiental". Portanto o autor sugere um modelo bidimensional de contingência para o posicionamento de diferentes organizações. Collado-Ruiz e Ostad-Ahmad-Ghorabi (2010b) desenvolveram um estudo onde diferentes tipos e níveis de informação - geralmente disponíveis para os designers - foram fornecidos a 56 estudantes (engenheiros mecânicos, arquitetos, cientistas ambientais, etc.), e todos foram convidados a gerar idéias de design diferentes. Segundo os autores, os resultados apontam que o fornecimento de informações detalhadas (de modelos anteriores ou de produtos concorrentes, normalmente, um produto de referência) reduz significativamente a criatividade das idéias de design, enquanto informações suaves, não apresentam este efeito. Portanto, os autores apontam que os métodos e ferramentas devem fornecer informações relevantes evitando este efeito de fixação, já que os designers necessitam de informações sobre os impactos ambientais de seus produtos para se concentrar em aspectos relevantes. Van Berkel (2007) realiza uma revisão da literatura e classifica as abordagens DfE encontradas em práticas de eficiência, estratégias de design e modelos de criatividade. As práticas de eficiência, e, em menor medida, as estratégias de design têm demonstrado a sua utilidade em uma variedade de processos e produtos a nível mundial, muitas vezes com benefícios ambientais e econômicos. Segundo o autor, a escassez de exemplos em que a sua aplicação resultou em produtos altamente inovadores e eficientes com recursos ou processos sugere que um nicho permanece, potencialmente podendo ser cumprido com modelos de criatividade.

Gotzsch (2008) deriva da literatura sobre práticas e recomendações DfE, um modelo para identificação dos principais pontos de atração do produto, que fornece uma visão geral dos aspectos desejáveis do produto a partir de uma perspectiva de design, implicando em qualidade, funcionalidade, ergonomia, estética, aspectos ecológicos e simbolismo do produto; e que pode ser aplicado nas fases iniciais do PDP, ajudando a estruturar a discussão entre os parceiros no PDP. Rausand e Utne (2009) descrevem um modelo de ciclo de vida do produto que pode ser usado pelos fabricantes para melhorar a segurança e impedir que produtos de consumo e industriais defeituosos sejam colocados no mercado, de acordo com os principais requisitos de segurança dos produtos com foco na legislação européia de segurança do produto e normas ISO. Segundo Tseng (2010a), a integração das capacidades de gestão do conhecimento de práticas ambientais (Environmental practice in Knowledge Management Capabilities - EKMC) nas empresas é uma atividade importante 
que ajuda as empresas a sobreviver e fazer melhorias contínuas (TSENG, 2010a; TSENG, 2010b). Portanto, Tseng (2010b) apresenta um framework para medir a EKMC com um conjunto de medidas qualitativas e quantitativas utilizando o modelo híbrido de Tomada de Decisão Multicritério (Multicriteria Decision-Making - MCDM), o Processo de Análise de Rede (Analytical Network Process ANP), o Laboratório de Ensaio e Avaliação de Tomada de Decisão (Decision-Making Trial and Evaluation Laboratory - DEMATEL) e a teoria dos conjuntos fuzzy.

Johansson e Magnusson (2006) apresentam os resultados de um estudo de caso de um projeto $\mathrm{DfE}$, onde o foco é definido sobre como o projeto foi organizado de modo a assegurar que os requisitos de desempenho ambiental fossem considerados. Segundo os autores, um específico subprojeto "verde" foi incluído na organização do projeto e a análise mostra que este pode: (1) servir como um meio de colocar as considerações ambientais na agenda, (2) ajudar a solucionar a confusão sobre quem é responsável pelo cumprimento dos requisitos de desempenho ambiental, (3) atuar como uma arena para a comunicação sobre os requisitos de desempenho ambiental, (4) servir como uma plataforma para os campeões ambientais se tornarem ativos, e (5) servir como um meio para especialistas em meio ambiente se tornarem parte das redes de contatos estabelecidas na organização de desenvolvimento de produto.

Maxwell e Van Der Vorst (2003) apresentam o modelo Desenvolvimento de Produtos e/ou Serviços Sustentáveis (Sustainable Product and/or Service Development - SPSD) que leva o foco do projeto de "um produto" para o fornecimento de uma funcionalidade e determina se esta funcionalidade será fornecida através de um serviço, produto ou alguma combinação de PSS. O método, segundo as autoras, utiliza listas de verificação considerando todo o ciclo de vida, dentro do contexto TBL, além dos requisitos tradicionais do PDP. As autoras afirmam que trata-se de uma abordagem qualitativa, simples, flexível, pragmática, de acordo com as realidades da empresa (personalizada de acordo com a cultura organizacional, abordagens de gestão ambiental e do PDP), integrada aos sistemas existentes na empresa, e que pode ser apoiada por ferramentas quantitativas, como por exemplo, a LCA. A implementação do SPSD, segundo as autoras, inclui o uso de uma abordagem em nível estratégico, integrada aos negócios da empresa, sistemas de gestão sustentável/ambiental, sistemas de desenvolvimento de produtos existentes e o uso das Dinâmicas da Cadeia de Suprimentos (Supply Chain Dynamics - SCD) para determinar as "empresas meta" mais eficazes da cadeia de suprimentos para a implementação do SPSD e efetiva Gestão da Cadeia de Suprimentos (Supply Chain Management - SCM) a montante e a jusante.

Schmidt e Taylor (2008) descrevem o Índice de Sustentabilidade do Produto (Product Sustainability Index - PSI) da Ford da Europa, uma ferramenta de gestão da sustentabilidade diretamente utilizada e desenvolvida pelos próprios engenheiros da empresa (e não por especialistas em sustentabilidade ou ciclo de vida) que considera aspectos TBL com base em aspectos do ciclo de vida (LCA, Custo de propriedade - Cost of Ownership e LCC) externamente revistos de acordo com a ISO 14040, aspectos certificados externamente (Interior testado contra alergias) e os aspectos relacionados a materiais sustentáveis, segurança, capacidade de mobilidade e de ruído (SCHMIDT e BUTT, 2006). O PSI suporta o processo de tomada de decisão do PDP e fornece as informações necessárias para algumas decisões de trade-off (SCHMIDT e BUTT, 2006) tratando oito indicadores: 
Potencial de Aquecimento Global (Global Warming Potential - GWP), potencial de impacto na qualidade do ar, materiais sustentáveis, substâncias restritas e unidades de ruído exterior, capacidade de mobilidade e segurança e custo de propriedade (SCHMIDT e TAYLOR, 2008). O método se traduz em uma ferramenta fácil de planilha na qual engenheiros foram treinados em uma hora, seguindo o princípio de reduzir a necessidade de qualquer tempo incremental ou dados adicionais ao mínimo, com uma necessidade mínima de recursos, sem burocracia (abordagem voluntária integrada as ferramentas de gerenciamento específicas do PDP existentes na empresa), mas com alta precisão (SCHMIDT e BUTT, 2006).

Vinodh (2010) descreve um estudo de caso baseado na integração da Manufatura Àgil (Agile Manufacturing - AM) no DfE com o auxilio de equipes cross-funcionais e do Design Assistido por Computador (Computer Aided Design - CAD) para a concepção de novos modelos de um produto em discussão com os executivos da empresa e também reunindo as preferências dos clientes. $A$ análise da sustentabilidade, segundo o autor, é realizada para determinar o impacto ambiental dos modelos por meio de um pacote de software que é incorporado com algoritmos que analisam os modelos CAD dos produtos, para materiais, processo de fabricação, locais de fabricação e distribuição.

Tingström, Swanstrom e Karlsson (2006), descrevem modelo GATE da ABB que integra as prioridades de desenvolvimento sustentável no seu principal modelo de PDP de utilização obrigatória. O modelo ABB GATE, segundo os autores, fornece a estrutura para o processo de trabalho e define os papéis e responsabilidades das diversas pessoas dentro da $A B B$, que são responsáveis por assegurar que as metas para o design, desenvolvimento, uso e gestão EoL são alcançadas. Cada líder de projeto tem a plena responsabilidade de tomar ações de sustentabilidade em seu projeto e a organização de apoio auxilia com ferramentas relevantes e competência, conforme selecionado no projeto (TINGSTRÖM, SWANSTROM e KARLSSON, 2006). Segundo os autores, o fator de sucesso e a parte mais crítica é que os processos de identificação dos aspectos e requisitos de sustentabilidade, de definição de metas e criação de um plano de sustentabilidade são incluídos como um componente obrigatório do Modelo ABB GATE, garantindo um alto grau de flexibilidade mediante a combinação de um conjunto de ferramentas de apoio. Schiavone, Pierini e Eckert (2008) descrevem a abordagem metodológica desenvolvida para integrar a inovação de produtos e a visão estratégica da Rieter Automotive, como ponto de partida para o desenvolvimento de uma ferramenta de avaliação. Os autores afirmam que os resultados mostram oportunidades promissoras para o DfE de componentes automotivos, com a validação da tomada de decisões, apoiando os engenheiros durante as tarefas de inovação e desenvolvimento de produtos, por meio de métodos de fácil utilização.

Lewandowska e Kurczewski (2010) apresentaram uma ferramenta DfE desenvolvida com base nas diretrizes da norma ISO 14062. O artigo foi dividido em duas partes. A parte 1 apresenta a descrição da estrutura do procedimento e dos seus elementos mais importantes. A parte 2 (KURCZEWSKI e LEWANDOWSKA, 2010) se concentra nos aspectos práticos e apresenta um exemplo da aplicação da metodologia sugerida em relação a um frigorífico. O exemplo apresentado pelos autores utiliza a LCA, o LCC, o benchmarking ambiental e a Análise Multicritério (Multicriteria Analysis - MCA), no entanto, segundo os autores, o uso de outras técnicas, por exemplo, os métodos 
de matriz, LCA Social, ou listas de verificação, também é possível. Segundo os autores, uma inovação é o desenvolvimento de critérios de avaliação relativos às partes interessadas e suas necessidades e da utilização de análise comparativa multidimensional na avaliação das variantes de design, que permitem a representação de uma solução de compromisso entre vários, muitas vezes contraditórios, requisitos identificados em diferentes estágios do ciclo de vida. O método proposto pelos autores prevê a nomeação dentro da organização de uma equipe interdisciplinar, incluindo pessoas dos departamentos-chave da empresa. Os autores afirmam que é importante que esta equipe possua conhecimento da estratégia da empresa e suficiente poder de decisão a fim de realizar os estágios particulares no âmbito do processo de DfE, bem como o conhecimento das questões relacionadas com os produtos em todas as fases do seu ciclo de vida. Segundo os autores, o método leva à resultados consistentes, claros e compreensíveis, no entanto, não está entre as ferramentas simples e requer conhecimento e experiência do pesquisador.

$\mathrm{Ny}$ et al. (2006) desenvolveram o modelo de Retrospectividade de Princípios de Sustentabilidade (Backcasting Sustainability Principles - BSP) implementado na Matsushita, que conta com um facilitador externo que leva um grupo interdisciplinar de representantes da empresa: a discutir o quadro DfE, para alcançar um modelo mental compartilhado; a iniciar um processo brainstorming, descrevendo as práticas correntes; a identificar soluções e futuras alternativas e; avaliar e priorizar ações estratégicas iniciais (investimentos). Para esta priorização, segundo os autores, é necessário escolher "plataformas flexíveis" ou investimentos para alcançar as metas definidas pela organização e considerar os princípios de sustentabilidade definidos em consenso e a busca pelo retorno sobre o investimento para continuamente reforçar o processo.

Byggeth, Broman e Robèrt (2007) desenvolveram o Método para Desenvolvimento de Produtos Sustentável (Method for Sustainable Product Development - MSPD), também implementado na Matsushita, que se baseia na BSP e apóia a prevenção e a proatividade, integrando a sustentabilidade com a engenharia simultânea (ULRICH e EPPINGER, 2003) no PDP. O objetivo geral do MSPD, segundo os autores, é: 1) fornecer conhecimentos básicos sobre a sustentabilidade sob a perspectiva de sistemas completos e ciclo de vida; 2) fornecer uma abordagem estratégica para o DfE; 3) fornecer conhecimentos básicos sobre a metodologia de desenvolvimento de produtos; 4) sensibilização para as questões sobre a sustentabilidade do produto e apontar para fontes de informação mais detalhadas, sobre sustentabilidade e meio ambiente; 5) iniciar investigações relevantes e vincular considerações de design tradicional com considerações de sustentabilidade para estimular a criatividade; 6 ) ajudar na identificação e esclarecimento dos trade-offs e priorizações de ações de curto e médio prazo; e 7) ajudar na documentação. Os autores descrevem que o MSPD conta com um manual de introdução, um sistema modular que investiga perguntas para estimular a brainstorming, e uma matriz de priorização das decisões sobre as soluções. Os autores afirmam que ao testar o MSPD, algumas empresas suecas manifestaram o desejo de algum tipo de orientação para categorias específicas de produtos e para uma melhor interação com outros métodos e ferramentas, tais como EMSs, a LCA, e CAD. Portanto, Ny et al. (2008) desenvolveram o conceito de "Templates" de Desenvolvimento de Produtos Sustentável ("Templates" for Sustainable Product Development - TSPDs) como um complemento ao MSPD para ajudar as equipes de PDP a chegar 
mais rápido e mais facilmente a uma visão geral dos principais desafios e oportunidades da sustentabilidade de uma categoria de produtos nas fases iniciais de desenvolvimento. A idéia, segundo os autores, é fomentar a comunicação criativa entre alta administração, stakeholders, e designers. Segundo os autores o TSPD capta os aspectos de sustentabilidade gerais do ciclo de vida das categorias de produtos e tem a capacidade de (1) ajudar a tirar o foco de melhorias graduais, (2) facilitar a consenso entre os níveis organizacionais, e (3) facilitar o diálogo contínuo com especialistas em sustentabilidade externos, identificando as melhorias que são relevantes para o desenvolvimento sustentável estratégico. Em um estudo de caso os autores identificaram os seguintes pontos centrais como facilitadores do DfE: Comprometimento da alta direção; Um especialista em sustentabilidade; Comunicação entre a alta administração e os níveis de desenvolvimento de produtos; Treinamentos e diálogos escritos e orais facilitados pelos templates; Sensibilização social e cooperação entre os níveis organizacionais; Base funcional para 0 diálogo sobre questões relacionadas com sustentabilidade e, assim, facilitar a tomada de decisões. Segundo Byggeth, Broman e Robèrt (2007), desde a implementação do MSPD novos modelos, abordagens e ferramentas de avaliação técnica e relacionadas com a sustentabilidade (incluindo a abordagem de templates) foram integradas e/ou desenvolvidas em um novo procedimento de otimização, o design iterativo.

\subsection{Requisitos dos Métodos de Apoio ao DfE}

A maioria dos métodos DfE se concentram no nível operacional e muitas abordagens existentes não estão integradas no PDP, muito menos nas estratégias das empresas e funções de negócios (MAXWELL e VAN DER VORST, 2003). Segundo Alting e Jogensen (1993), é necessário "Eliminar a lacuna" entre políticas ambientais isoladas, não operacionais na gestão de nível superior e métodos/ferramentas técnico-orientados para produtos/produção. Para realmente fazer uma mudança, o interesse na sustentabilidade deve ser defendido pela gestão e ser apoiado e atualizado no âmbito da gestão de cada grupo de projeto (TINGSTRÖM, SWANSTROM e KARLSSON, 2006). O papel decisivo do comprometimento da Alta Administração (NY et al., 2008; VINODH, 2010) e da comunicação entre a alta administração e os designers, stakeholders, especialistas em sustentabilidade externos e internos (NY et al., 2008) é bastante frisado na literatura, pois freqüentemente, não existe nenhum procedimento formal que garanta que as diretrizes ambientais da alta gerência são disseminadas no PDP (HANDFIELD et al., 2001). É extremamente importante que as empresas abordem a questão da sustentabilidade de forma sistêmica na organização, ou seja, em nível estratégico, principalmente em relação às funções de interface com o PDP (MAXWELL e VAN DER VORST, 2003; NY et al., 2006; BYGGETH, BROMAN e ROBÈRT, 2007). Isso contribuiria para um maior comprometimento da empresa e ajudaria na inserção do conceito nas atividades organizacionais (MAXWELL e VAN DER VORST, 2003) garantindo a sensibilização para estas questões no produto (NY et al., 2006; BYGGETH, BROMAN e ROBÈRT, 2007) e a cooperação entre os níveis organizacionais (NY et al., 2008) importantes para o DfE.

Empresas com alto desempenho inovador têm uma maior capacidade de investir em práticas de recursos humanos que visam melhorar o desempenho de uma empresa nas áreas social e 
ambiental e estudos mostram que em empresas sustentáveis, a maioria das inovações sugeridas é uma conseqüência da conscientização ambiental dos funcionários (JABBOUR e SANTOS, 2008). Segundo Handfield et al. (2001), é importante que os designers sejam avaliados quanto ao desempenho ambiental de seus projetos na mesma medida que os objetivos de custo, prazo e qualidade. Portanto, inclusive as práticas de gestão de $\mathrm{RH}$ têm que ser um moderador entre a diversidade cultural e a gestão ambiental, a fim de melhorar o desempenho inovador da empresa (JABBOUR e SANTOS, 2008).

No DfE considerações sobre diversos aspectos sobre o ciclo de vida dos produtos devem ser levados em consideração, portanto diversos atores internos e externos à organização devem estar envolvidos neste processo (WESTKÄMPER, ALTING e ARNDT, 2000; FIKSEL, 2003; MAXWELL e VAN DER VORST, 2003; CHUNG e PENG, 2006; ABU BAKAR e RAHIMIFARD, 2007; JOHANSSON, LUTO e FLEISCHER; 2007; GEHIN, ZWOLINSKI e BRISSAUD, 2008). Segundo Alting e Jogensen (1993), as questões ambientais e de recursos devem ser introduzidas, gerenciadas e monitoradas em todos os níveis e em todos os departamentos da empresa. Segundo Lindahl (2006), do ponto de vista dos designers, métodos e ferramentas são utilizados para facilitar a comunicação dentro do PDP com o objetivo de economizar tempo, a fim de se poder fazer mais. E, segundo o autor, o meio para alcançar este objetivo é utilizar métodos e ferramentas que forneçam uma estrutura definida que proporcione benefícios como troca de informações mais fácil e acompanhamento e controle mais simples. O método de apoio ao DfE deve fornecer a estrutura para o processo de trabalho e também definir os papéis e responsabilidades das diversas pessoas dentro da empresa, que são responsáveis por assegurar que as metas para o design, desenvolvimento, uso e gestão EoL são alcançadas (TINGSTRÖM, SWANSTROM e KARLSSON, 2006). No entanto, o nível de experiência de DfE que a empresa possui reflete em como as questões ambientais são abordadas e geridas (DE CALUWE, 2004; JOHANSSON, 2006), bem com a complexidade do projeto (JOHANSSON, 2006). Neste sentido, os especialistas que são responsáveis pela gestão de pessoas em empresas sustentáveis têm de participar ativamente quando os objetivos estão sendo definidos, a fim de apoiá-los satisfatoriamente com um conjunto de práticas a fim de apoiar a gestão da inovação, a diversidade cultural e gestão ambiental de uma forma igual (JABBOUR e SANTOS, 2008). Pois, é necessário um processo de estabelecimento de metas em consenso com o grupo interdisciplinar de representantes da empresa (NY et al., 2006; BYGGETH, BROMAN e ROBÈRT, 2007). Portanto, os métodos de apoio ao DfE devem abordar as fases iniciais do PDP (JOHANSSON, 2006; GOTZSCH, 2008) e fornecer suporte à engenharia simultânea (NY et al., 2006; BYGGETH, BROMAN e ROBÈRT, 2007).

Forças-tarefa e mecanismos de grupo ad hoc são uma parte de mecanismos de coordenação organizacional menos convencionais (FRYXELL e VRYZA, 1999) que podem ser usados no DfE nos casos em que surgem novas idéias que precisam ou se beneficiam de respostas específicas, surgindo a partir do compromisso da alta administração ou de iniciativas de baixo para cima (KIVIMAA, 2008). Na verdade, a utilização de equipes multifuncionais se faz necessária (HANDFIELD et al., 2001; KIVIMAA, 2008; KURCZEWSKI e LEWANDOWSKA, 2010; LEWANDOWSKA e KURCZEWSKI, 2010; VINODH, 2010) embora com o risco de tornar a comunicação interpessoal em equipes mais difícil (BERCHICCI e BODEWES, 2005). 
Principalmente em empresas com baixo nível de experiência em DfE, muito esforço deve ser feito para tornar os requisitos de desempenho ambiental explícitos dentro do projeto, e como os membros da equipe do projeto são novatos a considerar tais exigências, parece vital atrair a atenção e criar um foco (JOHANSSON, 2006). Portanto é necessário que os métodos de apoio também contem com mecanismos que promovam a comunicação elevada entre os diversos atores no DfE, ajudando a estruturar a discussão entre os parceiros (GUNTHER, SEBASTIAN e MARCO, 2007; GOTZSCH, 2008; KIVIMAA, 2008) e oferecendo suporte à análise de trade-offs e ao processo de tomada de decisão (NY et al., 2006; SCHMIDT e BUTT, 2006; BYGGETH, BROMAN e ROBÈRT, 2007; VINODH, 2010). Trade-offs entre as diferentes questões ambientais devem ser monitorados durante todo o projeto, a fim de alcançar o mínimo impacto ambiental possível (JOHANSSON, 2006). Isso pode ser alcançado com exemplos de casos de sucesso ambientais de negócios (SCHMIDT, 2003), um sub-projeto "verde" (JOHANSSON e MAGNUSSON, 2006), ferramentas que espelham as conseqüências das decisões de design impulsionadas por um atributo sobre os outros (SCHMIDT e BUTT, 2006), reuniões em equipes multifuncionais (VINODH, 2010), treinamentos e diálogos orais e escritos facilitados por templates (NY et al., 2008), definição de metas em grupo por meio de sessões brainstorming (NY et al., 2006; BYGGETH, BROMAN e ROBÈRT, 2007), base funcional para o diálogo sobre questões relacionadas com sustentabilidade dentro da empresa (NY et al., 2008). Também é necessário fornecer conhecimentos básicos sobre a metodologia de desenvolvimento de produtos aos outros integrantes do grupo interdisciplinar (NY et al., 2006; BYGGETH, BROMAN e ROBÈRT, 2007). Em empresas que possuem um alto nível de experiência em DfE, há uma menor necessidade de comunicação sobre as questões ambientais no projeto, porque os membros do projeto estão bem cientes das questões e como elas devem ser tratadas (JOHANSSON, 2006).

Indivíduos como integradores e guardiões em equipes de PDP têm sido apontados como um importante meio de coordenação em tarefas organizacionais de sucesso (FRYXELL e VRYZA, 1999). É importante contar com um facilitador externo para orientar o grupo interdisciplinar de representantes da empresa (NY et al., 2006; BYGGETH, BROMAN e ROBÈRT, 2007). A integração multifuncional dentro do PDP pode significar que os especialistas ambientais são incluídos como membros destas equipes, pois são cruciais como recursos de conhecimento ambiental da organização (NY et al., 2008; KIVIMAA, 2008) e no estabelecimento de ligações de comunicação entre os membros da equipe de PDP, podendo funcionar como guardiões ou integradores facilitando a integração entre os designers e o pessoal ambiental na organização (KIVIMAA, 2008). No entanto, o setor ambiental, muitas vezes, é limitado aos programas de educação e conscientização da empresa e os especialistas ambientais servem apenas como "consultores" para conscientizar os designers sobre os custos e benefícios do DfE, desempenhando um papel limitado no processo, restrito a palestras e listas de materiais publicadas, que dificulta a efetiva integração de aspectos ambientais no PDP (HANDFIELD et al., 2001). Schmidt e Butt (2006) recomendam fazer as funções principais da empresa diretamente responsáveis pelo gerenciamento de sua própria parte dos aspectos TBL com o auxilio das funções de staff (especialistas em sustentabilidade ou ciclo de vida) limitadas a iniciar o processo com o apoio metodológico e treinamento, certificando-se que as contribuições das diferentes funções principais se 
encaixam. Portanto é importante dispor de mecanismos para a integração entre os designers e os especialistas ambientais (HANDFIELD et al., 2001).

Projetos em empresas que possuem um alto nível de experiência em DfE, são mais propensos a objetivos ambiciosos de desempenho ambiental para os produtos, por vezes, necessitando de novas tecnologias a serem introduzidas (JOHANSSON, 2006). Segundo Tseng (2010a) a captação, compartilhamento e a exploração do conhecimento ambiental existente na organização ou a distribuição de novos conhecimentos é fundamental para o DfE a longo prazo. Segundo o autor, a organização eficaz das informações disponíveis e do conhecimento é a chave para a correta aplicação das metodologias DfE. Para este tipo de gestão também é necessário manter uma documentação dos projetos desenvolvidos (NY et al., 2006; BYGGETH, BROMAN e ROBÈRT, 2007). Azevedo e Nolasco (2009), afirmam que a ausência de profissionais capacitados na área de DfE propicia o aumento das dificuldades em estruturar este processo. Neste sentido, muitas universidades de engenharia na Escandinávia e no resto da Europa vêm repensando, reorganizando, e relançando seus currículos escolares e programas de pesquisa para a inserção da sustentabilidade (MCALOONE, 2007). No entanto, as empresas precisam de métodos de apoio para o fornecimento de conhecimentos básicos sobre a sustentabilidade, sob a perspectiva de sistemas completos e do ciclo de vida, aos atores responsáveis pelo DfE (NY et al., 2006; BYGGETH, BROMAN e ROBÈRT, 2007; KURCZEWSKI e LEWANDOWSKA, 2010; LEWANDOWSKA e KURCZEWSKI, 2010). Pois segundo Tien, Chung e Tsai (2005), quanto mais alto o índice de comunicação com grupos de interesse relacionados, educação continuada e inovação persistente mais bem sucedida é a implementação do DfE. Os métodos de apoio ao DfE devem fornecer acesso aos designers à competência de sustentabilidade, tanto no grupo de projeto ou tê-la fornecida por algum tipo de organização de apoio (TINGSTRÖM, SWANSTROM e KARLSSON, 2006) e conter abordagens para a disseminação do conhecimento em sustentabilidade (GUNTHER, SEBASTIAN e MARCO, 2007). No entanto, em projetos realizados em organizações que possuem alto nível de experiência em DfE, a necessidade de comunicação sobre as questões ambientais é menor, pois os membros do projeto estão bem cientes das questões e como elas devem ser tratadas (JOHANSSON, 2006).

Também é necessário iniciar investigações relevantes e vincular considerações de design tradicional com considerações ambientais para estimular a criatividade, como em um sub-projeto "verde" (JOHANSSON e MAGNUSSON, 2006; NY et al., 2006; BYGGETH, BROMAN e ROBÈRT, 2007) pois o DfE necessita de soluções criativas e inovadoras (VAN BERKEL, 2007; COLLADO-RUIZ e OSTAD-AHMAD-GHORABI, 2010B). Portanto, é necessário contar com métodos de apoio para estimular a criatividade (NY et al., 2006; BYGGETH, BROMAN e ROBÈRT, 2007). Em muitos métodos o uso de informações sobre o meio ambiente é uma etapa preliminar muito encorajada (NIELSEN e WENZEL, 2002). No entanto, segundo Collado-Ruiz e Ostad-Ahmad-Ghorabi (2010b), a exposição a exemplos pode provocar fixação e redução da criatividade global do processo de geração de idéias.

Outro fator importante é que os designers não tem tempo para passar pelos diversos treinamentos das ferramentas DfE (HANDFIELD et al., 2001). Portanto, a integração de uma Abordagem Ágil no DfE oferece benefícios de negócios, como a variedade de produtos melhorada 
com o mínimo impacto ambiental; geração de produtos robustos; melhoria no PDP; compressão do tempo juntamente com eficácia de custos; e sobrevivência no ambiente de negócios competitivo (VINODH, 2010). Neste sentido, os método de apoio ao DfE devem ser traduzidos em ferramentas fáceis nas quais os engenheiros possam ser treinados em pouco tempo (HANDFIELD et al., 2001; MAXWELL e VAN DER VORST, 2003; LINDAHL, 2006; TINGSTRÖM, SWANSTROM e KARLSSON, 2006), seguindo o princípio de reduzir a necessidade de qualquer tempo incremental ou dados adicionais ao mínimo, com necessidade mínima de recursos e sem burocracia (abordagem voluntária integrada as ferramentas de gerenciamento específicas do PDP existentes na empresa), mas com alta precisão (SCHMIDT e BUTT, 2006).

Segundo Schmidt e Butt (2006), cada fabricante automotivo tem o seu próprio PDP, específico da empresa. Apesar de as considerações ambientais no PDP serem uma prática padrão em algum nível, a prática ainda varia muito entre as empresas (KIVIMAA, 2008). Neste sentido, as empresas deveriam criar os seus próprios métodos DfE ou personalizar os já existentes, pois não se pode sugerir que qualquer metodologia ou abordagem irá se adequar a cultura ou mercado das empresas, já que não podem ser generalizadas (QUELLA e SCHMIDT, 2003). Exemplos são a Nike e a IKEA que integraram o DfE em sua abordagem TNS (The Natural Step), a Electrolux e a Philips que incluiriam o DfE em seu Sistema de Gestão Ambiental Orientado aos Produtos (Product Orientated Environmental Management System - POEMS) (MAXWELL e VAN DER VORST, 2003), a abordagem para criação do PSI da Ford da Europa (SCHMIDT e BUTT, 2006), o modelo GATE da ABB, incluindo as considerações de sustentabilidade no PDP (TINGSTRÖM, SWANSTROM e KARLSSON, 2006), o MSPD, implementado na Matsushita (BYGGETH, BROMAN e ROBÈRT, 2007; NY et al., 2006), a abordagem DfE da Rieter Automotive (SCHIAVONE, PIERINI e ECKERT, 2008), a ferramenta CUMPAN desenvolvida pela Daimler-Benz na Alemanha, que possui uma função de banco de dados e avaliação de impacto (ALTING, 1995), a Abordagem Matricial sugerida pela AT\&T, o método para quantificar a eco-eficiência usando o QFD e a LCA utilizado na Toshiba (KOBAYASHI et al., 2005), a chamada "Pré-LCA" sugerida pela Battelle \& Digital (ALTING, 1995) e a Xerox Corp, a Bayer AG, a General Electric, a IBM, a Procter \& Gamble e a Whirlpool que também desenvolveram seus programas DfE (BAUMANN, BOONS e BRAGD, 2002).

As organizações também devem trabalhar na melhoria contínua de seus Métodos de Apoio ao DfE (NY et al., 2006; SCHMIDT e BUTT, 2006; BYGGETH, BROMAN e ROBÈRT, 2007), bem como no desenvolvimento de novas abordagens e procedimentos (NY et al., 2006; BYGGETH, BROMAN e ROBÈRT, 2007). Schmidt e Butt (2006) recomendam deixar as decisões de 'se' e 'como', a melhoria contínua nos métodos será realizada, com as funções responsáveis dentro das corporações. Pois parece haver uma lacuna entre os desenvolvedores e os usuários dos métodos e ferramentas de apoio ao DfE (BAUMANN, BOONS e BRAGD, 2002).

Os métodos e ferramentas do DfE são pouco conhecidos e raramente utilizados (BAUMANN, HANDFIELD et al., 2001; BOONS e BRAGD, 2002; LINDAHL, 2006). Isto também implica que a integração do DfE dentro do trabalho do dia-a-dia do PDP é baixa (BAUMANN, BOONS e BRAGD, 2002). Outro problema é a forma existente de seleção e implementação de métodos e ferramentas que não considera as necessidades dos designers (LINDAHL, 2006). No entanto, as considerações 
ambientais devem ser levadas em consideração de acordo com uma estrutura do dia-a-dia do PDP (TINGSTRÖM, SWANSTROM e KARLSSON, 2006). Portanto, identificar as exigências dos designers é uma maneira útil para aumentar a utilização dos métodos e ferramentas DfE (LINDAHL, 2006).

O Método de Apoio ao DfE deve proporcionar o diálogo entre os usuários das Ferramentas de Apoio ao DfE, os usuários dos resultados destas ferramentas e os responsáveis pela seleção e implementação das ferramentas para garantir a utilização correta do método ou ferramenta (LINDAHL, 2006), identificar os objetivos do projeto (JOHANSSON e MAGNUSSON, 2006; LINDAHL, 2006) e selecionar a ferramenta e/ou método mais adequado de acordo com as características do produto ou com a estratégia da empresa (LINDAHL, 2006; PIGOSSO et al., 2010).

Ainda assim, segundo Lindahl (2006), se o designer experiencia a satisfação com o método ou ferramenta, irá alcançar um resultado positivo, caso contrário não trabalhará de forma eficaz, nem eficiente, com um grande risco de utilizar o método ou ferramenta de apoio ao DfE sem realmente utilizar os resultados (considerados, não confiáveis ou desnecessariamente complexos, por exemplo) para os passos seguintes no PDP; ou de irá pular partes dos métodos sem o conhecimento do gerente, a fim de produzir um resultado mais rápido. Isso, muitas vezes, ocorre, pois a maioria dos métodos e ferramentas DfE têm sido principalmente desenvolvidos por especialistas em meio ambiente com as questões ambientais como o seu principal, e às vezes, único, foco e sem contato real ou idéia sobre os usuários que os utilizarão (BAUMANN, BOONS e BRAGD, 2002). Portanto, é de extrema importância levantar as necessidades do PDP. Os principais requisitos para que os Métodos de Apoio ao DfE possam efetivamente melhorar o desempenho dos produtos encontram-se na Tabela 12 e na Tabela 13:

Tabela 12 - Requisitos para os Métodos de Apoio ao DfE - parte 1

\begin{tabular}{|c|c|}
\hline Requisitos & Refs. \\
\hline $\begin{array}{l}\text { Os Métodos de Apoio ao DfE não devem consumir demasiadamente } \\
\text { custos, tempo e pessoal }\end{array}$ & Maxwell e Van Der Vorst (2003) \\
\hline $\begin{array}{l}\text { É necessário que o método auxilie a tomada de decisão, ajudando na } \\
\text { identificação e esclarecimento dos trade-offs e priorizações de ações }\end{array}$ & $\begin{array}{l}\text { Ny et al. (2006); Byggeth, Broman e } \\
\text { Robèrt (2007) }\end{array}$ \\
\hline $\begin{array}{l}\text { Os objetivos ambientais devem estar refletidos nos objetivos } \\
\text { corporativos estratégicos das empresas }\end{array}$ & Handfield et al. (2001) \\
\hline \multicolumn{2}{|l|}{ Os Métodos de Apoio ao DfE devem... } \\
\hline$\rightarrow$ oferecer resultados relevantes e confiáveis & Lindahl (2006) \\
\hline $\begin{aligned} & \text { apoiar a comunicação criativa entre alta administração, } \\
& \rightarrow \text { stakeholders, especialistas em sustentabilidade externos e } \\
& \text { internos e os designers }\end{aligned}$ & Ny et al. (2008) \\
\hline $\begin{array}{l}\text { incentivar o comprometimento da Administração da Empresa e } \\
\rightarrow \text { do Projeto para o acompanhamento da utilização dos métodos e } \\
\text { ferramentas }\end{array}$ & $\begin{array}{l}\text { Lindahl (2006); Tingström, Swanstrom e } \\
\text { Karlsson (2006) }\end{array}$ \\
\hline$\rightarrow \begin{array}{l}\text { definir claramente os papéis e responsabilidades em relação aos } \\
\text { objetivos do projeto }\end{array}$ & $\begin{array}{l}\text { Tingström, Swanstrom e Karlsson } \\
\text { (2006); Johansson e Magnusson (2006) }\end{array}$ \\
\hline$\rightarrow$ impulsionar a interação do PDP com especialistas ambientais & $\begin{array}{l}\text { Handfield et al. (2001); Johansson e } \\
\text { Magnusson (2006) }\end{array}$ \\
\hline
\end{tabular}

Fonte: Elaborado pelo autor. 
Tabela 13 - Requisitos para os Métodos de Apoio ao DfE - parte 2

\begin{tabular}{|c|c|c|}
\hline \multicolumn{2}{|r|}{ Requisitos } & Refs. \\
\hline \multicolumn{3}{|c|}{ O Método de Apoio ao DfE deve ser... } \\
\hline$\rightarrow$ & Simples/fácil de usar & $\begin{array}{l}\text { Handfield et al. (2001); Maxwell e Van Der Vorst } \\
\text { (2003); Lindahl (2006); Tingström, Swanstrom e } \\
\text { Karlsson (2006) }\end{array}$ \\
\hline$\rightarrow$ & Flexível & Maxwell e Van Der Vorst (2003) \\
\hline$\rightarrow$ & Pragmático & $\begin{array}{l}\text { Maxwell e Van Der Vorst (2003); Lindahl (2006); } \\
\text { Tingström, Swanstrom e Karlsson (2006) }\end{array}$ \\
\hline & $\begin{array}{l}\text { desenvolvido ou adaptado para a realidade da } \\
\text { empresa (personalizado de acordo com as tarefas do } \\
\text { dia-a-dia do PDP, a cultura organizacional e as } \\
\text { abordagens de gestão ambiental) }\end{array}$ & $\begin{array}{l}\text { Handfield et al. (2001); Baumann, Boons e Bragd } \\
\text { (2002); Maxwell e Van Der Vorst (2003); Lindahl } \\
\text { (2006); Schmidt e Butt (2006); Tingström, } \\
\text { Swanstrom e Karlsson (2006); Schmidt e Taylor } \\
\text { (2008) }\end{array}$ \\
\hline & $\begin{array}{l}\text { integrado aos sistemas existentes na empresa } \\
\text { (podendo ser apoiado por ferramentas de apoio } \\
\text { quantitativas, como por exemplo, a LCA) }\end{array}$ & $\begin{array}{l}\text { Maxwell e Van Der Vorst (2003); Ny et al. (2006); } \\
\text { Tingström, Swanstrom e Karlsson (2006); Byggeth, } \\
\text { Broman e Robèrt (2007) }\end{array}$ \\
\hline & $\begin{array}{l}\text { constantemente melhorados e atualizados pela } \\
\text { organização, bem como novas abordagens e } \\
\text { procedimentos desenvolvidos }\end{array}$ & $\begin{array}{l}\text { Ny et al. (2006); Schmidt e Butt (2006); Byggeth, } \\
\text { Broman e Robèrt (2007) }\end{array}$ \\
\hline
\end{tabular}

Fonte: Elaborado pelo autor.

Com base nestas conclusões parece claro que as Ferramentas de Apoio ao DfE necessitam de suporte metodológico de Métodos de Apoio ao DfE já que a sua aplicação isolada em determinada etapa do PDP traria apenas benefícios ambientais incrementais como a substituição de materiais.

\subsubsection{Ferramentas de Apoio ao DfE}

Segundo Almeida et al. (2010), ainda há uma forte necessidade de uma ferramenta para facilitar o DfE. As Ferramentas de Apoio ao DfE, segundo os mesmos autores, são ferramentas operacionais que auxiliam os atores envolvidos no DfE a gerir as informações inerentes a este processo, muitas vezes, se traduzindo em sistemas de software. Segundo Alting e Jogensen (1993) a análise ou avaliação em si não proporcionam melhorias ambientais, mas elas revelam que as melhorias podem ser feitas. Segundo os autores, estas ferramentas ajudam a quantificar os possíveis impactos ambientais dos produtos, bem como a avaliar os diversos trade-offs envolvendo os objetivos do DfE e as fases do ciclo de vida dos produtos. Segundo Almeida et al. (2010), técnicas como a Avaliação do Ciclo de Vida (Life Cycle Assessment - LCA) e a Análise do Fluxo de Materiais (Material Flow Analysis - MFA) são cada vez mais populares, para quantificar as variáveis ambientais críticas, buscando avaliar cientificamente o impacto ambiental e o consumo de recursos. A LCA, por exemplo, contribui para o DfE através da identificação de fatores dominantes do impacto ambiental (todas as categorias de impacto podem ser selecionadas) do ciclo de vida completo do produto (ALTING, 1995; WESTKÄMPER, ALTING e ARNDT, 2000; KOEHLER e WILDBOLZ, 2009; ALMEIDA et al., 2010; DEVANATHAN et al., 2010). A seguir são listadas as Ferramentas de Apoio ao DfE resultantes desta revisão da literatura e em seguida os requisitos identificados na literatura para as mesmas.

A LCA é a única ferramenta de avaliação ambiental padronizada internacionalmente (KLOEPFFER, 2008) e sua estrutura bem conhecida de Definição de metas e escopo, Análise de 
inventário (LCl), Avaliação de impacto e Interpretação foi desenvolvida durante o trabalho de harmonização/normalização pela Sociedade de Toxicologia e Química Ambiental (Society of Environmental Toxicology and Chemistry - SETAC) e pela ISO (ALTING, 1995; WESTKÄMPER, ALTING e ARNDT, 2000; KLOEPFFER, 2008). No entanto, a LCA consiste em um processo interativo, onde a experiência reunida em uma fase posterior pode servir como um feedback levando a modificação de uma ou mais fases anteriores (ALTING, 1995; WESTKÄMPER, ALTING e ARNDT, 2000). A ISO 14040 forneceu um quadro geral para a LCA, e normas mais detalhadas para as diferentes fases da LCA estão em processo de constante revisão (WESTKÄMPER, ALTING e ARNDT, 2000; KLOEPFFER, 2008). Neste sentido, a LCA representa a principal Ferramenta de Apoio ao DfE, sendo considerada em muitas metodologias como o padrão para medir o desempenho ambiental e alguns chegam a defini-la como o núcleo do DfE (NIELSEN e WENZEL, 2002; BALA et al., 2010). Mesmo em avaliações alternativas que pretendem ter um melhor desempenho em alguns aspectos, seus princípios são incluídos, de alguma forma (ERNZER e WIMMER, 2002). Segundo Bala et al. (2010), o guia 64:2008 da ISO aponta a LCA como a segunda fonte de informações em ordem de preferência, depois de guias setoriais importantes, para ajudar a identificar relevantes aspectos e impactos ambientais relacionados ao ciclo de vida do produto.

Segundo Devanathan et al. (2010), a LCA foi desenvolvida para identificar as conseqüências ambientais de um produto ou processo ao longo de cada uma das etapas do seu ciclo de vida. Sua principal aplicação tem sido como uma ferramenta de apoio à decisão no PDP (WESTKÄMPER, ALTING e ARNDT, 2000; ALMEIDA et al., 2010; RAMANI et al., 2010), para avaliar os impactos ambientais e o consumo de recursos associados à existência de produtos durante todo o seu ciclo de vida - $\mathrm{C} 2 \mathrm{Gr}$ - considerando todas as categorias de impacto ambiental como: o aquecimento global, destruição do ozônio estratosférico, a acidificação dos ecossistemas terrestres e aquáticos, a formação fotoquímica de ozônio (smog), o enriquecimento de nutrientes nos ecossistemas de água doce e marinhos, a toxicidade para seres humanos e para os ecossistemas e a geração de resíduos sólidos (WESTKÄMPER, ALTING e ARNDT, 2000; KLOEPFFER, 2008; RAMANI et al., 2010). A LCA oferece uma abordagem holística e, portanto, apresenta uma estimativa precisa dos trade-offs ambientais dos produtos (DEVANATHAN et al., 2010). Portanto, ela difere de outros sistemas de avaliação ambiental como Avaliação de Risco Ambiental de Produtos Químicos (Environmental Risk Assessment - ERA) ou Avaliação de Impacto Ambiental das Principais Atividades Humanas como as obras de construção (Environmental Impact Assessment - EIA) que incidem sobre os processos individuais ou grupos de processos confinados em espaço e tempo (WESTKÄMPER, ALTING e ARNDT, 2000). Neste sentido, para reduzir o tempo destinado aos cálculos, é necessária uma extensa base de dados (sobre o consumo de energia e materiais, sobre as emissões dos fornecedores, sobre os padrões de uso individual dos consumidores e, sobre processos de descarte/reciclagem para o produto) e uma base de dados customizada deve ser mantida e atualizada, para garantir uma LCA atual e real, o que requer certo treinamento sobre conhecimentos básicos sobre o meio ambiente e manipulação de dados (ALTING e JOGENSEN, 1993; ALTING, 1995). Alting (1995) apresenta uma visão geral das várias ferramentas utilizadas no mundo para estudos de LCA na década de 90, classificadas de acordo com as suas principais características: 
possibilidade de utilização em produtos complexos, quantitativa ou semi-quantitativa (Pré-LCAs), avaliação de impacto e disponibilidade de banco de dados.

Segundo Collado-Ruiz e Ostad-Ahmad-Ghorabi (2010b) as ferramentas LCA proporcionam conjuntos complexos de dados que podem não ser adequados para utilização direta no design, embora adaptáveis a esta finalidade. Ao avaliar as cargas ambientais de um produto os números "absolutos" finais não são um "bom ou utilizável" pano de fundo para a tomada de decisões no PDP (ALTING e JOGENSEN, 1993). Os resultados de uma LCA são difíceis de interpretar em termos absolutos, portanto, a LCA é desenvolvida e utilizada para a análise comparativa de alternativas e para fazer simulações do tipo "e se" para ajudar a decidir quais as mudanças no produto são preferíveis de um ponto de vista ambiental, exigindo um produto de referência (ALTING, 1995; ALTING e JOGENSEN, 1993; WESTKÄMPER, ALTING e ARNDT, 2000). Este produto pode ser uma referência funcional (produtos com a mesma função) ou tecnológica (tecnologias similares ou substitutas) e esta referência utilizada deve ser constantemente atualizada para que uma nova plataforma sempre exista como base para a otimização de produtos novos (ALTING e JOGENSEN, 1993). Aqui é absolutamente necessário definir as fases do ciclo de vida de forma clara e assegurar o controle de qualidade de todos os dados, pois se dois produtos no mercado são comparados, a discussão habitual sobre dados, qualidade e delimitação aparece (ALTING e JOGENSEN, 1993; CULLEN e ALLWOOD, 2009). Segundo Alting (1995), este desenvolvimento inicial na LCA aplicado nas fases de análise e de definição de metas revela as características ambientais boas e ruins do produto de referência e é possível identificar possíveis melhorias, pontos focais e, posteriormente, as estratégias de design. Existem inúmeros estudos que oferecem suporte a seleção de Estratégias DfE usando a LCA, devido a sua capacidade de demonstrar as fases do ciclo de vida de onde provem os maiores impactos ambientais (RAMANI et al., 2010).

No entanto a LCA totalmente exaustiva é muito onerosa (ALMEIDA et al., 2010), demorada (NIELSEN e WENZEL, 2002; SOUSA e WALLACE, 2006; ALMEIDA et al., 2010; BALA et al., 2010) e complexa (NIELSEN e WENZEL, 2002; SOUSA e WALLACE, 2006; BALA et al., 2010), difícil de encaixar no PDP (NIELSEN e WENZEL, 2002; SOUSA e WALLACE, 2006) e geralmente requer treinamento especial (SOUSA e WALLACE, 2006). A LCA envolve modelagem complexa, que não necessariamente caminha lado a lado com os modelos utilizados durante o PDP (SOUSA e WALLACE, 2006). Segundo Bohm et al. (2010), os esforços de avaliação do ciclo de vida são muitas vezes assolados por deficiências de dados, incluindo a falta de dados relevantes e má qualidade dos dados. Em geral, a coleta de dados de um ciclo de vida do produto é o maior obstáculo para a realização da LCA (RAMANI et al., 2010). Segundo Bala et al. (2010), como resultado, tais abordagens abrangentes podem acabar sendo descartadas já que são impraticáveis em muitos casos, devido a restrições de tempo e/ou financeiras.

A LCA requer muita informação, que geralmente não está disponível nos estágios iniciais (ALMEIDA et al., 2010; BALA et al., 2010; BOHM et al., 2010; DEVANATHAN et al., 2010). Portanto as LCAs são normalmente realizadas na fase posterior ao projeto detalhado e ao planejamento da produção (ALMEIDA et al., 2010; BOHM et al., 2010) quando essa informação está disponível, mas, nesta fase, os resultados da LCA já não são tão úteis (SOUSA e WALLACE, 2006). Além disso, 
segundo Almeida et al. (2010), a necessidade de um produto de referência inviabiliza a sua utilização em novos produtos ou tecnologias. Segundo Collado-Ruiz e Ostad-Ahmad-Ghorabi (2010b), esta referência também pode levar um estado de fixação, limitando a criatividade de soluções, em alguns casos. Segundo Nielsen e Wenzel (2002) possíveis soluções para o problema são LCAs simplificadas e modelagem do LCl com cenários e com informações secundárias, não específicas de produtos, e dados de $\mathrm{LCl}$ sobre materiais de referência e processos.

Tem havido alguns esforços de abordar estas questões através do desenvolvimento de uma LCA simplificada ou racionalizada para fins de triagem (LUTTROPP e LAGERSTEDT, 2006). Neste sentido, a LCA pode ser restrita à escolhas de projeto especificadas, o que economiza tempo e esforço (NIELSEN e WENZEL, 2002). Segundo Bala et al. (2010), a análise da Pegada de Carbono (Carbon Footprint - CF) também pode ser considerada um subconjunto da LCA, limitada a uma única categoria de impacto, o GWP. Segundo Song e Lee (2010), a prática normal de limitação das fronteiras do sistema, é incluir apenas as etapas de matérias-primas e produção da peça, também conhecida como do Berço ao Portão (Cradle to Gate - C2Ga). Segundo Bala et al. (2010), um grande número de métodos simplificados da LCA (qualitativos, quantitativos ou semi-quantitativos) têm sido desenvolvidos nos últimos anos para aplicações tais como o DfE e compras verdes. No entanto, estes métodos tendem a ignorar os impactos ambientais de certas fases do ciclo de vida, fluxos de materiais/energia, ou categorias de impacto, constituindo ferramentas semi-quantitativas (ALTING, 1995; LUTTROPP e LAGERSTEDT, 2006). Segundo Bala et al. (2010), é aconselhável escolher as categorias de impacto mais relevantes a serem incluídas no modelo em uma base caso a caso.

Segundo Alting (1995), as ferramentas semi-quantitativas são rápidas, mas incipientes, e em grande parte dependem da avaliação subjetiva dos parâmetros ambientais do produto, fornecendo um ponto de partida para o DfE, mas elas não permitem a concepção mais complexa de ciclos de vida do produto. No entanto, segundo Bala et al. (2010), ferramentas de reduzido escopo, abordando uma única categoria de impacto da LCA podem ser extremamente úteis para rápidas aplicações de rotina, e para uso por profissionais inexperientes com acesso limitado aos softwares e bancos de dados da LCA. A conclusão é que a simplificação da LCA não pode ser evitada no desenvolvimento de novos produtos (NIELSEN e WENZEL, 2002; BALA et al., 2010). Segundo Collado-Ruiz e OstadAhmad-Ghorabi (2010b) avaliações simplificadas também devem garantir que a entrega de simplificadas informações suaves que não limitem a criatividade e nos esforços para integrar a avaliação ambiental no CAD, a apresentação dos resultados também deve prestar atenção nos efeitos de fixação, para evitar a mera otimização incremental. Eventualmente, a LCA pode ser atualizada e tornada mais detalhada conforme as informações necessárias se tornam disponíveis com o desenvolvimento e uma utilização mais ampla da tecnologia (NIELSEN e WENZEL, 2002). No entanto, segundo Bala et al. (2010), as decisões políticas em termos de compras verdes que visam melhorar os bens e serviços só devem ser tomadas com base na avaliação conjunta de uma série de tipos de impacto, pois a ISO 14044:2006 explicitamente pede para não usar apenas uma categoria de impacto em comparações públicas.

Além disso, há sempre algum nível de incerteza nos resultados, embora a exatidão aparente possa ser uma fonte de excesso de confiança (SOUSA e WALLACE, 2006). Segundo Almeida et al. 
(2010), os profissionais da LCA têm uma série de métodos de ponderação diferentes, e os resultados dos diferentes métodos geralmente não coincidem devido à falta de padronização nas metodologias convencionais. Neste ponto, em um estudo de LCA, ao utilizar métodos de ponderação diferentes pode ser desejável conduzir uma análise de sensibilidade para avaliar as conseqüências que podem ter sobre os resultados da LCA (ALTING, 1995; WESTKÄMPER, ALTING e ARNDT, 2000). Neste sentido o resultado da interpretação destas análises serve como recomendação para os tomadores de decisão, que, normalmente, irão ponderá-lo contra outros critérios de decisão (ALTING e JOGENSEN, 1993; ALTING, 1995; WESTKÄMPER, ALTING e ARNDT, 2000).

Cullen e Allwood (2009) descrevem outro problema na aplicação da LCA, o "efeito da máquina de lavar roupa". Segundo os autores, a utilização da LCA para respostas de priorização por fase do ciclo de vida deve ser abordada com cautela, pois quando as fronteiras do sistema de um produto não estão definidas corretamente, atividades na fase de uso, por exemplo, podem ser contabilizadas para diversos produtos (em estudos separados de roupas, detergentes e máquinas de lavar, o uso de energia é determinado pelo funcionamento da máquina de lavar) ou para nenhum deles (por exemplo, a energia gasta pelo automóvel do consumidor no ato da compra). Portanto, segundo os autores, o usuário devem considerar se os limites do sistema escolhidos coincidiriam com LCAs de outros produtos e estar ciente de outros fatores importantes que podem nunca ser registrados dentro dos limites escolhidos para a LCA. Portanto, também é necessária a Apresentação de relatórios e revisão crítica: uma apresentação transparente e suficientemente detalhada dos resultados, dados, métodos utilizados, as suposições feitas e limitações inerentes ao estudo para permitir a compreensão da complexidade e trade-offs inerentes ao estudo (ALTING, 1995; WESTKÄMPER, ALTING e ARNDT, 2000).

Segundo Palousis, Luong e Abhary (2010), questões relacionadas com Sustentabilidade representam significativos riscos financeiros, de cumprimento, estratégicos e operacionais para os fabricantes. Segundo os autores, gerenciar os custos associados a estes riscos na fase de design é importante antes que estes custos estejam comprometidos em todo o ciclo de vida. Segundo Cagno e Trucco (2007), os custos do ciclo de vida continuam a ser um fator competitivo fundamental para garantir a capacidade de produzir e vender um produto. Segundo Kloepffer (2008), o LCC é a contrapartida lógica da LCA para a avaliação econômica e uma diretriz está sendo desenvolvida pela SETAC como base para a padronização futura. Segundo o mesmo autor o LCC supera o cálculo do custo puramente econômico levando em consideração as fases de utilização e fim de vida e além dos custos ocultos.

Segundo Gotzsch (2008), para o uso efetivo pelos designers de produtos, as ferramentas, deveriam permanecer "inspiradoras e simples" para dar a criatividade o lugar merecido na fase de projeto, ao invés da rigidez das ferramentas DfE tradicionais $(\mathrm{GOTZSCH}, 2008)$. Neste sentido o autor, defende o uso de listas de verificação no DfE, não só permitindo melhorias incrementais em produtos já existentes, mas também permitindo a criação de soluções radicais em novos produtos. Segundo Almeida et al. (2010), as Listas de Verificação ou Checklists foram adaptadas com a inclusão de preocupações ambientais, tais como recomendações contra o uso de materiais tóxicos e de matérias-primas desnecessárias ou sugestões sobre a minimização do consumo de energia em 
diferentes fases de produção. Em particular, seu uso no DfE é bastante popular (VEZZOLI e SCIAMA, 2006). Estas listas consistem em uma série de perguntas para ajudar os designers a gerenciar os produtos de forma sistemática (WONG, LEE e YUNG, 2010). Segundo Kishita et al. (2010), os fabricantes freqüentemente usam checklists de DfE destinadas à obtenção de rótulos ecológicos, como o Eco Mark no Japão. No entanto, estas listas têm dois problemas na avaliação do desempenho ambiental de um produto: Uma delas é que os requisitos das listas dos rótulos ecológicos são avaliados qualitativamente - "Sim" ou "Não", e esta avaliação é insuficiente para oferecer soluções concretas como melhorias no design (DEVANATHAN et al., 2010). A outra é que uma lista de verificação lista uma série de requisitos a partir de vários aspectos ambientais e as relações entre estes requisitos e o impacto ambiental, por exemplo, as emissões de CO2 e de substâncias perigosas, são indeterminados (KISHITA et al., 2010). As listas de verificação e orientações também diferem em complexidade e estrutura (ALMEIDA et al., 2010). Portanto, o tempo necessário para completar este tipo de avaliação normalmente depende da complexidade do produto, disponibilidade de dados e conhecimento dos usuários sobre o produto (ERNZER e WIMMER, 2002). Vezzoli e Sciama (2006) propuseram um procedimento para o enquadramento de diretrizes, que consiste em requisitos específicos para um determinado produto a partir de critérios que incluem "redução do consumo de material", "toxicidade e redução de nocividade", e "DfD". Neste procedimento, segundo os autores, um conjunto de requisitos são agrupados por critérios e a prioridade de um critério é determinada com base no potencial de melhoria ambiental, que é avaliada pela LCA do produto, no entanto, a prioridade relativa entre os requisitos individuais da diretriz é indeterminada e, além disso, cada requisito ainda é avaliado qualitativamente (sim, em parte, ou não). Kishita et al. (2010) propõem um método para apoiar a avaliação de DfE através do desenvolvimento de uma lista ponderada a partir de uma lista de verificação de rótulo ecológico convencional. Esta lista ponderada, segundo os autores, avalia o desempenho ambiental de um produto com base na melhoria ambiental potencial de cada requisito, obtido por simulação do ciclo de vida, esclarecendo os pontos de design a serem melhorados através da extração de requisitos da lista de verificação, e em um exemplo, as melhorias ambientais alcançaram $67 \%$.

Ferramentas mais complexas também têm sido desenvolvidas: Choi, Nies e Ramani (2008) propuseram um quadro para a priorização de estratégias de DfE apropriadas e rentáveis, integrando resultados da LCA no processo de tomada de decisão multicritério. Wong, Lee e Yung (2010) propõem uma ferramenta de avaliação ambiental de produtos composta por quatro módulos: parte geral, análise do tipo de avaliação, análise das fases do ciclo de vida envolvidas, e apresentação dos resultados. Segundo os autores, a ferramenta oferece idéias para os usuários sobre o nível de impacto do produto avaliado mesmo se um produto de referência não for identificado, comparando-o com o índice ambiental de materiais de outros produtos da mesma categoria de produto. Houe e Grabot (2007) descrevem um protótipo de software de um sistema para verificar a conformidade de um produto com normas e padrões que traduz o conhecimento, contido nas normas e padrões em forma textual, em restrições que podem ser propagadas através da estrutura do produto, a fim de identificar as inconsistências entre o projeto atual e uma dada norma. Fitch e Cooper (2005a) apresentam a Modelagem do Ciclo de Vida para o Design (Life-cycle modeling for design - LCMD), 
para avaliar os impactos do ciclo de vida de produtos complexos a partir da fase de design inicial, quando algumas especificações de design já foram feitas. A LCMD, segundo os autores, combina a LCA com métodos de design probabilísticos de forma que as previsões de possíveis atributos do design final reduzem as necessidades de informação e gera matrizes de cenários de design que comunicam a gama de designs sendo considerados pela equipe. A parte 2 do artigo (FITCH e COOPER, 2005b) desenvolve um estudo de caso automotivo (redesign do sedã Ford C-class) com a LCMD focado na substituição de materiais com o objetivo de reduzir o consumo de recursos, reduzir as emissões do Ciclo de Vida do ar e aumentar a massa reciclável do veículo. Leibrecht (2005) descreve uma tecnologia para integrar a LCA em modelos tridimensionais do produto, como os usados nos sistemas CAD que permite a reutilização de dados existentes de CAD. Assim, segundo o autor, avaliações ecológicas podem ser realizadas durante o desenvolvimento do produto e os efeitos globais das alterações nos materiais ou outras propriedades do produto podem ser avaliados instantaneamente. Segundo Singh, Goodyer e Popplewell (2007), o Planejamento Avançado da Qualidade do Produto (Advanced Product Quality Planning - APQP) é amplamente utilizado pelos fabricantes para o design e fabricação de componentes automotivos. Portanto os autores desenvolvem um método, compatível com o APQP, para lidar com uma variedade de características do produto e impactos ambientais através de uma seleção de Indicadores de Performance Ambiental (Environmental Performance Indicators - EPIs) para uma configuração final do produto, onde as mudanças no design do produto ou processo de seleção podem reduzir o impacto ambiental do produto, aumentar a eficiência do processo e reduzir custos. O resultado desta pesquisa, segundo os autores, permite que fornecedores de componentes automotivos modifiquem o seu design de produtos (ou configurações de produtos) e alterem as suas técnicas de produção favorecendo a qualidade dos produtos e o DfE.

Em relação à seleção de materiais, Yuan e Dornfeld (2010) apresentam um método para a caracterização e avaliação comparativa (benchmarking) do impacto na saúde humana de substâncias químicas tóxicas, como uma ajuda visual para facilitar a tomada de decisão no processo de seleção de materiais. Djassemi (2009) fornece uma perspectiva das ferramentas de software para a Seleção de Materiais e Processos (Material and Process Selection - MPS) para fins de desenvolvimento de produtos. Segundo o autor, os sistemas MPS podem auxiliar os tomadores de decisão na resolução de muitos problemas, inclusive nos estágios iniciais de desenvolvimento de produto e planejamento de negócios, no entanto essas ferramentas contam com as seguintes limitações: 1) A sua aplicação à produtos complexos não é uma tarefa simples; 2) Embora haja alguma sobreposição de informações em seletores de material, a maioria se concentra em determinados tipos e classes de materiais; 3) $O$ uso da ferramenta deve ser conjugado com a experiência do usuário para as efetivas funções de busca e triagem; 4) Embora os seletores de processo possam ser utilizados como ferramenta de busca, eles não são seletores de equipamentos, necessitando ser complementados com técnicas e análises de custo-benefício antes de decisões sobre a aquisição de equipamentos.

Song e Lee (2010) propõem um sistema que permite o cálculo rápido das emissões de GEE (Gases do Efeito Estufa) de um produto com base na Lista de Materiais (Bill of Materials - BOM) usando os dados de emissões de GEE incorporadas das peças (definidas como a soma de dois 
conjuntos de emissões de GEE: o primeiro sobre a utilização de matérias-primas, fabricação e transporte da peça, e o segundo a partir das emissões atribuídas à peça durante as fases de fabricação do produto, distribuição, utilização e fim da vida) permitindo a avaliação de peças alternativas para a concepção do produto. Almeida et al. (2010), propõem a introdução da Contabilidade Emergética (Emergy Accounting - EA) como uma ferramenta para ajudar no design de produto, fornecendo indicadores quantitativos, com base em uma unidade comum (joules de energia solar), que podem ser comparados com aqueles calculados para outros processos e outros produtos, independentemente do método de ponderação, para facilitar na seleção de materiais e processos orientando a tomada de decisão. Para tanto o método, segundo os autores, integra a LCA com a MFA, para estudar como os materiais e energia fluem para dentro, pelo e para fora de um sistema, e a EA, para calcular o investimento emergético necessário para eliminar ou reciclar alguns dos resíduos e poluentes. Os autores afirmam que esta ferramenta permitiria responder a algumas questões fundamentais relativas à seleção de materiais, a taxa adequada de reciclagem a ser utilizada e os benefícios alcançados para cada taxa de reciclagem. Khan, Sadiq e Veitch (2004) propuseram um sistema de indexação do ciclo de vida, que é útil para a aplicação da LCA na avaliação de processos e produtos e tomada de decisão, onde os índices são compostos por fatores de custo, meio ambiente, tecnologia, e sócio-políticos, e são ponderados com base em um AHP.

Andersson et al. (1998) combinaram o conceito de sustentabilidade e a LCA para obter uma ferramenta operacional que incorpora a sustentabilidade no PDP e no planejamento estratégico. Eles delinearam a estrutura da LCA para enfatizar os aspectos e parâmetros, muitas vezes omitidos nas LCA tradicionais e concluíram que a LCA é bem adequada para a análise de triagem. Strazza et al. (2010), mostram a aplicação da LCA para o desenvolvimento de uma Declaração Ambiental do Produto (Environmental Product Declaration - EPD/rótulo ambiental Tipo III) para o setor de cimento. Bakker et al. (2010), analisaram a compatibilidade do conceito C2C e a LCA no dia-a-dia do PDP. Segundo os autores, as duas ferramentas podem e devem ser utilizadas como ferramentas complementares, onde os designers podem projetar pilotos de acordo com o conceito $\mathrm{C} 2 \mathrm{C}$ e utilizar a LCA para avaliar os aspectos ambientais destes pilotos. Bala et al. (2010), apresentam dois modelos baseados no LCT, seguindo as orientações das normas ISO para a LCA, respectivamente, abordando a avaliação do GWP no desenvolvimento de novas normas de produtos e as economias de GWP alcançáveis através do uso de materiais reciclados. Segundo os autores, os modelos dispensam a implantação de um software LCA específico, dependendo de algoritmos simples, complementados por tabelas de dados para os processos de fundo associados, provenientes de bases de dados de inventário padrão de ciclo de vida. Ainda assim, segundo os autores, ao final do estudo, o algoritmo simplificado foi percebido como muito complicado e pouco prático por um grupo de fabricantes espanhóis de sacos plásticos (CICLOPLAST), que decidiram simplificá-lo ainda mais, levando a uma fórmula única para emissões de $\mathrm{CO} 2 \mathrm{com}$ uma explicação adicional em anexo. Neste sentido, os autores afirmam que a possibilidade de exigir uma LCA plenamente desenvolvida, exigindo um LCl completo e abordando várias outras categorias de impacto, teria sido descartada ainda mais rapidamente. 
Alguns esforços foram realizados no sentido de avaliar aspectos ambientais de novas tecnologias. Nielsen e Wenzel (2002) introduziram um procedimento de LCA passo a passo para ser utilizado em paralelo com o PDP, onde o ponto de partida da ferramenta é a LCA de um produto de referência ou cenário de produtos fictícios e o modelo $\mathrm{LCl}$ do produto é definido gradualmente durante o PDP, já que a qualidade da informação aumenta em paralelo com o PDP. Na primeira fase, segundo os autores, as idéias do projeto conceitual são comparadas, e conforme o design procede, as comparações de alternativas de projeto mais detalhadas podem ser feitas. Os autores afirmam que o método poderia ser usado para a avaliação de uma nova tecnologia, utilizando uma tecnologia convencional como referência e os diferentes elementos e alternativas da nova tecnologia e as conseqüências indiretas de usá-la podem ser avaliados separadamente e com mais precisão, se necessário. Neste sentido, Kunnari et al. (2009) desenvolveram um estudo para avaliar as questões ambientais relacionadas a uma tecnologia nova, a eletrônica impressa (processo aditivo, sem necessidade de material extra e produtos químicos corrosivos). Com base em estudos anteriores sobre a LCA simplificada, os autores concluíram que os métodos de LCA simplificada e outras ferramentas de avaliação baseadas no LCT são pontos de partida adequados na avaliação da eletrônica impressa. Os autores também concluíram que existe a necessidade do desenvolvimento de cenário baseado na experiência adquirida com os produtos-piloto durante a pesquisa de tecnologia e que este desenvolvimento poderia ser alcançado pela modelagem de cenários futuros do ciclo de vida de produtos, instalações fabris, e sistemas de produto e tecnologia. Segundo os autores, a avaliação poderia começar usando uma matriz MET (Material, Energia, Toxicidade), que é uma ferramenta de avaliação qualitativa adequada para um estudo ambiental preliminar de um cenário de ciclo de vida do produto e que deve ser utilizada antes da LCA (HUR et al., 2005). Collado-Ruiz e Ostad-Ahmad-Ghorabi (2010a) apresentam uma abordagem para definir Unidades Funcionais (Function Units - FU) padronizadas: o conceito de Ícones Funcionais (Functional Icons - Fuons), definidos como uma abstração de um produto, com base na sua função essencial ajudando a obter uma Família de Produtos para Comparação do Ciclo de Vida (Life cycle Comparison Product Familie LCPF) cuja LCA compartilha um comportamento comum, permitindo o desempenho ambiental de um novo produto ou tecnologia com os produtos desta família.

Diversos autores descreveram seus esforços para desenvolver ferramentas de apoio ao DfE voltadas à fase de design conceitual, como pode ser verificado a seguir. Fitzgerald, Herrmann e Schmidt (2010) apresentam o Design por Analogia, uma ferramenta de design conceitual para inspirar designers com exemplos de produtos que, simultaneamente, reduzem o impacto ambiental e melhoram a funcionalidade do produto. Wu, Lo e Hsu (2008), apresentam uma técnica fuzzy CBR (case based reasoning - raciocínio baseado em casos) para gerar idéias a partir de um banco de dados de produtos para melhorar as funções de um determinado produto (chamado de produto de referência). No banco de dados, segundo os autores, um produto é modelado por um vetor de 100 atributos, dos quais 87 são usados para modelar o cenário de uso e 13 são usados para descrever as características de produção/reciclagem. Com base nos atributos do cenário de uso e seus pesos relativos - determinados por uma técnica de Processo de Análise Hierárquica (Analytic Hierarchy Process - AHP) fuzzy, um mecanismo de recuperação CBR fuzzy é desenvolvido para recuperar 
idéias de produtos que tendem a melhorar as funções do produto de referência (WU, LO e HSU, 2008). Com base nas características de produção/reciclagem, segundo os autores, um mecanismo fuzzy CBR filtra as idéias de produtos obtidas, a fim de obter uma maior proporção de idéias de produtos valiosas, a fim de economizar tempo na posterior avaliação das idéias de produtos por especialistas. Bohm et al. (2010) descrevem os esforços adotados para promover a transição das técnicas de LCA das fases mais detalhadas do projeto para a etapa conceitual do PDP (após a determinação das necessidades dos clientes e da funcionalidade global), onde conceitos virtuais são criados e especificados por meio da geração de conceito automatizada e um arquivo de conhecimentos de design de produtos, conhecido como Repositório do Design (Design Repository), e técnicas simplificadas de LCA são utilizadas para determinar os impactos ambientais dos conceitos virtuais. Além de informações sobre a conexão funcional e de componentes, o Repositório de Design captura informações de design para materiais, geometrias e processos de fabricação para a maioria dos artefatos. No estudo de Devanathan et al. (2010), é desenvolvida a Matriz de Impacto Funcional (Function Impact Matrix - FIM), uma ferramenta de design visual, semi-quantitativa, que integra aspectos ambientais nas fases iniciais do PDP, combinando a LCA, o Desdobramento da Função Qualidade (Quality Function Deployment - QFD), a Matriz de Componentes Funcionais (functionalcomponent matrix) e o Gráfico de Pugh (Pugh chart) para apoiar o design conceitual e a seleção de conceito. A ferramenta, segundo os autores, correlaciona os impactos ambientais com as funções do produto, identificando o nível de importância de cada função e determinando as que devem ser reexaminadas, no entanto, sem identificar como elas podem ser melhoradas.

Nesta direção, esforços recentes no desenvolvimento de ferramentas DfE têm se concentrado na integração da LCA no QFD (ZHANG, WANG e ZHANG, 1999; CAGNO e TRUCCO, 2007; DEVANATHAN et al., 2010; VINODH e RATHOD, 2010a; etc.), comprovando as suas boas características de integração (CAGNO e TRUCCO, 2007). Segundo Devanathan et al. (2010) as ferramentas baseadas no QFD são as mais adequadas para os estágios iniciais do PDP quando as especificações ainda estão sendo estabelecidas e os conceitos estão sendo gerados. $O$ Desdobramento da Função Qualidade Verde-II (Green Quality Function Deployment-II - GQFD-II) (ZHANG, WANG e ZHANG, 1999) avalia requisitos tradicionais e ambientais com a mesma ferramenta, a Casa da Qualidade (House of Quality) típica do QFD adaptada para avaliar os problemas da eco-eficiência, onde o conceito do produto que melhor satisfaz os requisitos verdes e de qualidade é selecionado. A ferramenta, segundo os autores, inclui a integração da LCA e do LCC no QFD e sugere o desdobramento da qualidade, as exigências ambientais e de custos durante todo o PDP para avaliar conceitos de produtos diferentes. Cagno e Trucco (2007) desenvolveram uma ferramenta de denominada Desdobramento das Funções Verde e Qualidade Integrado (Integrated Green and Quality Function Deployment - IGQFD) utilizando uma "Abordagem de Matriz" com a LCA Simplificada e o Desdobramento da Função Qualidade Aprimorado (Enhanced Quality Function Deployment - EQFD). Os autores alegam que a falta de integração no GQFD-II de Zhang, Wang e Zhang (1999) é superada no IGQFD por meio da "Casa do Verde e da Qualidade" (Green and Quality House - GQH); que trata as correlações técnicas entre as especificações de design de qualidade e eco-eficiência por meio da introdução de uma seção para identificar sinergias e trade-offs. Segundo 
os autores, na ferramenta, uma "Matrix de Seleção de Conceito" (Concept Selection Matrix - CSM) identifica a alternativa de design que melhor combina as necessidades das partes interessadas. $O$ conjunto de características do produto é tal que cada elemento não representa, necessariamente, a satisfação de um requisito único ou uma única categoria de exigências, mas cumpre as especificações de design integradas indistintamente, no entanto, o problema da integração dos custos é negligenciado no IGQFD (CAGNO e TRUCCO, 2007). Kobayashi et al. (2005), apresentam uma ferramenta, utilizada na Toshiba Corporation, que quantifica a eco-eficiência usando o QFD e a LCA. Segundo os autores, um índice do valor do produto é calculado como a média ponderada das taxas de melhoria das características de qualidade; ao aplicar o método LCA do tipo endpoint, o dano endpoint causado por vários inventários do ciclo de vida é calculado; e a Disposição a Pagar dos clientes (Willingness-To-Pay - WTP) é aplicada para integrá-los em um único índice. O valor do produto, segundo os autores, é calculado com base em dados do QFD armazenados na ferramenta LCPlanner (Planejamento do Ciclo de Vida/LCP - Life-Cycle Planning) desenvolvida por Kobayashi (2005). O LCPlanner foi descrito por Kobayashi (2005) como uma ferramenta de design conceitual para auxiliar o designer a criar um conceito DfE, que implica em uma combinação adequada, analisando os trade-offs entre os aspectos ambientais, de qualidade e de custo nas fases iniciais do PDP, respeitando as exigências dos clientes como custo e desempenho. A ferramenta, segundo o autor, também suporta a seleção de opções EoL, tais como extensão do tempo de vida útil, atualização, manutenção, reutilização e reciclagem, aplicáveis a cada componente de um produto. $\mathrm{O}$ autor afirma que a ferramenta assegura o feedback em todas as etapas, permitindo a otimização do design do produto, é baseada no Microsoft Excel e desenvolve diversas matrizes e gráficos de análise automaticamente utilizando dados fornecidos pelo designer e dados importados de outras ferramentas DfE. Bovea e Wang (2007) apresentam uma ferramenta de redesign que estabelece uma relação entre as técnicas de QFD, LCA, LCC e Avaliação de Contingência (Contingent Valuation - CV) para avaliar os requisitos de clientes, ambientais, de custos e WTP, respectivamente. A ferramenta, segundo os autores, permite a identificação de opções de melhoria ambiental e o estudo do efeito que a incorporação destas tem sobre os outros requisitos tradicionais do produto, comparando o aumento de custos que a incorporação das melhorias ambientais produz com os montantes suplementares que o cliente está disposto a pagar pelos benefícios ambientais percebidos. Kuo, Wu e Shieh (2009), desenvolvem o Eco-Desdobramento da Função Qualidade (Eco-Quality Function Deployment - Eco-QFD) para integrar as preocupações ambientais, de qualidade, custo e as necessidades do cliente, onde um método dos conjuntos fuzzy é aplicado ao Eco-QFD para para reduzir a imprecisão e incerteza do processo de tomada de decisão em grupo, constituindo um modelo multi-objetivo fuzzy. O Eco-QFD, segundo os autores, fornece uma estrutura para o DfE através da integração da LCA no QFD, onde os atributos técnicos e preocupações ambientais podem ser priorizados. Vinodh e Rathod (2010a) integram a LCA Simplificada no Desdobramento Ambientalmente Consciente da Função Qualidade (Environmentally Conscious Quality Function Deployment - ECQFD) para levar em consideração os custos do produto e as estratégias EoL. Os autores realizaram um estudo de caso em uma empresa de interruptores eletrônicos localizada em Coimbatore, na Índia, que tem implementado estratégias tais como ISO 9001:2000 (Sistema de 
Gestão da Qualidade), 5S, Kaizen, TQM, a ISO 14001 (EMS), etc. Em outro artigo publicado no mesmo ano, Vinodh e Rathod (2010b), apresentam um projeto na mesma empresa no qual o QFD para o Ambiente (Quality Function Deployment for Environment - QFDE) foi aplicado no estágio inicial do PDP. Segundo os autores, o QFDE consiste em quatro fases: As fases I e II se concentram na identificação das peças do interruptor rotativo que são ambientalmente críticas e as fases III e IV avaliam o efeito da melhoria do projeto em requisitos de qualidade ambiental.

Outros autores propuseram ferramentas para o design modular no intuito de auxiliar o DfE como pode-se verificar a seguir. Mengoni, Germani e Mandorli (2009) propõem uma abordagem ágil baseada na modularidade do produto e na integração de ferramentas baseadas em CAD que permite a gestão simultânea de possíveis mudanças em plataformas de produtos e processos através da adoção de protótipos virtuais para a realização de simulações. O protótipo virtual, segundo os autores, é definido como um conjunto de informações geométricas, funcionais, de produção, estruturais, ambientais, contidas nos módulos das plataformas de produtos e processos. Li et al. (2008) também desenvolveram uma ferramenta de projeto modular com base em um gráfico fuzzy para implementar estratégias DfE, considerando múltiplos objetivos do ciclo de vida do produto. Segundo os autores, uma abordagem gráfica fuzzy é utilizada para apresentar a estrutura do produto, segundo a qual os valores de relacionamento fuzzy são determinados aplicando o AHP aos objetivos ambientais do ciclo de vida, juntamente com outras preocupações funcionais e de produção.

Muitos autores defenderam o uso de ferramentas que viabilizam a engenharia simultânea para o DfE, como Hara et al. (2009), que demonstraram uma ferramenta DfE que fornece um ambiente para atividades de design, baseado em CAD, que analisa clientes e desenvolve soluções de produtos/serviços, fornecendo uma linguagem comum para as atividades de marketing $\mathrm{e}$ engenharia. A ferramenta, segundo os autores, permite que gestores, profissionais de marketing e engenheiros trabalhem juntos para melhorar os serviços existentes ou para criar novos serviços. Lee et al. (2007), desenvolvem o modelo Manufatura Integrada e Sistema de Serviços do Produto (Integrated Manufacturing and Product Services System - IMPSS), uma abordagem holística para integrar a produção e os serviços com as considerações ambientais, permitindo o design de serviços durante a fase de conceitualização do produto. Os autores propõem um quadro de infra-estrutura de software que incorpora ferramentas ambientais e o fechamento do circuito do ciclo de vida do produto através da adição das fases de serviço e EoL, fornecendo feedback de informação dos estágios posteriores aos estágios iniciais do ciclo de vida do produto em uma plataforma de intercâmbio de informações e conhecimentos entre os diferentes sub-estágios da rede de serviços. Riou e Mascle (2009) apresentam uma solução $C A D$, desenvolvida em $C++\hat{A}$ com o núcleo geométrico OpenCASCADE, que avalia fatores de eficiência e as incompatibilidades entre as características de desenvolvimento, a fim de otimizar o projeto de produtos para vários domínios, permitindo que o designer obtenha feedback sobre a viabilidade de suas escolhas de design, e possa coletar dados das partes interessadas para o planejamento de processos e tarefas, planejamento estratégico de manutenção e fim de vida. Segundo os autores, a ferramenta facilita a acessibilidade da informação para cada parte interessada em todo o ciclo de vida do produto, tornando-as capazes de inserir dados diversos e de adaptar as suas escolhas futuras de acordo com implicações sobre o ciclo de vida do 
produto. Os autores afirmam que o quadro desta solução $\mathrm{DfX}$, com base na estrutura de dados do produto, consiste em impor restrições de integração sobre o PDP durante todo o processo. Chalal e Ghomari (2008) descrevem um software, que utiliza a LCA, e se propõe a concentrar a avaliação e facilitar a cooperação entre as partes intervenientes (engenharia, ecologia, logística e gestão de risco) no âmbito da concepção simultânea do produto durável. Segundo os autores a atividade de design de produtos duráveis satisfazendo as necessidades dos clientes implícitas e explícitas prevê a parte mais importante da avaliação e da necessidade de ter gradualmente uma representação precisa do design. Segundo Jianjun et al. (2008), na maioria das atuais Ferramentas de Avaliação do Ciclo de Vida (Life Cycle Assessment Tools - LCAT), os conjuntos de dados e informações dentro das diversas ferramentas utilizadas em vários estágios do PDP não estão sendo devidamente trocados, resultando em uma falta de intercâmbio de informações disponíveis para os diferentes atores ao longo da cadeia de valor e, portanto, conduzindo à adoção ineficaz e ineficiente de práticas DfE. Neste sentido, os autores desenvolveram uma LCAT, usando o Microsoft Visual $\mathrm{C}++$, estendendo o modelo de núcleo do produto NIST (National Institute of Science and Technology - USA) para servir como modelo de informação de produtos apoiando o LCED do produto, facilitando a avaliação do DfA, DfD, Design para a Reciclagem e quase todas as outras fases do LCED. Os autores propõem a Rede Lógica de Desmontagem (Dissassembly-Logic-Network - D-L-N) para mapear o produto e as atividades do ciclo de vida para o modelo abstrato. Brad (2009) apresenta o Desdobramento das Multifunções Concorrentes (Concurrent Multifunction Deployment - CMFD) que integra conceitos de engenharia simultânea para o planejamento do PDP com relação a funções multi-objetivo. Segundo o autor, o método TRIZ (Teoria da Resolução Inventiva de Problemas/Theory of Inventive Problem Solving) foi explorado para determinar os vetores apropriados de intervenção na formulação da ferramenta e um algoritmo sistemático suporta o processo de desdobramento do CMFD.

Segundo Almeida et al. (2010), há uma necessidade urgente de uma ferramenta para facilitar a integração e avaliação das demandas ambientais e econômicas no PDP. E diversos autores tentaram criar ferramentas para esta tarefa. Xu, Chen e Xie (2006), apresentam um quadro do sistema LCC do produto para apoiar a tomada de decisão, especialmente em fases muito iniciais do ciclo de vida de um produto. Neste modelo, segundo os autores, o método de raciocínio baseado em caso é utilizado para construir rapidamente um modelo novo do produto e os custos dos processos de desenvolvimento de produtos relacionados com o novo produto, são calculados usando métodos de custeio baseado em atividade. Palousis, Luong e Abhary (2010) descrevem o primeiro passo da metodologia de Avaliação de Risco da Sustentabilidade (Sustainability Risk Assessment - SRA), que é um processo de identificação dos Riscos de Sustentabilidade (Sustainability Risks - SR) inerentes ao ciclo de vida do produto. Após a identificação dos principais riscos, segundo os autores, as etapas subseqüentes da SRA os avaliam e priorizam para o tratamento através de modificações no design de produto e composição dos materiais, fornecendo uma abordagem para comparar o custo financeiro de um eco-produto versus um produto tradicional. Segundo Rudenauer et al. (2005), o método de análise de eco-eficiência desenvolvido e utilizado pelo Oko-Instituto analisa diferentes alternativas que satisfaçam as necessidades dos consumidores a partir das perspectivas econômica e ambiental. A análise de eco-eficiência, segundo os autores, baseia-se em dois métodos: LCA, de 
acordo com a ISO 14040 (para avaliar os aspectos ambientais de produtos e processos), e o LCC. Segundo os autores, os resultados podem ser plotados em gráficos bidimensionais que mostram a eficácia de determinadas medidas em termos ambientais e econômicos. Devido ao fato de na análise da eco-eficiência o lado ambiental já ser considerado separadamente, incluir esses no lado econômico significaria uma dupla contagem dos aspectos ambientais (KLOPFFER, 2003).

Segundo Pigosso et al. (2010), existem diversos métodos e ferramentas para o DfE que podem ser aplicados com eficácia às primeiras fases do PDP no intuito de aumentar a realização das estratégias EoL, normalmente incluindo mais de uma estratégia EoL, já que todas as estratégias EoL estão relacionadas e nem todos os componentes do produto podem seguir o mesmo destino EoL. Segundo Almeida et al. (2010), algumas publicações se concentram sobre um tipo especial de produto, outros incorporam uma LCA, enfatizando a desmontagem e a reciclagem como questões centrais no DfE. Neste sentido, diversos autores enfatizaram aspectos do DfD como pode ser verificado a seguir. Kara, Pornprasitpol e Kaebernick (2006), desenvolveram uma metodologia de desmontagem seletiva de produtos em fim de vida por inversão e modificação da metodologia desenvolvida por Nevins e Whitney (1989 - apud KARA, PORNPRASITPOL e KAEBERNICK, 2006) para a montagem. Veerakamolmal e Gupta (1998) propuseram uma técnica para analisar a eficiência do design de produtos eletrônicos, a fim de estudar o efeito da desmontagem e descarte no meio ambiente. A eficiência do projeto, segundo os autores, é medida utilizando um Índice de Design para a Desmontagem (Design for Disassembly Index - DfDI) que usa uma DT para identificar as relações precedentes, que definem a hierarquia da estrutura do produto (que representa a ordem na qual os componentes podem ser recuperados). Segundo os autores, o DfDI pode ser usado para analisar as vantagens e desvantagens de diferentes projetos. Kuo (2000) fornece a seqüência de desmontagem e análise de custos para os produtos eletromecânicos durante a fase de concepção, onde o planejamento da desmontagem é dividido em quatro etapas: representação geométrica da montagem, análise de pesquisa de corte de vértices, análise da Matriz de Precedência da Desmontagem (Dissassembly Precedence Matrix - DPM), e geração da seqüência e do plano de desmontagem. Gungor e Gupta (2001) desenvolveram uma abordagem para gerar Planos de Seqüência de Desmontagem (Disassembly Sequence Plans - DSP) automaticamente para a reciclagem e remanufatura de produtos, onde, primeiramente é definido um algoritmo, que gera uma DPM, a partir de um desenho CAD do produto, e esta é então utilizada para gerar uma HDT, que representa o DSP viável. Segundo os autores, o usuário pode inserir duas variáveis para manter o tamanho da HDT gerenciável. A função de avaliação, segundo os autores, incorpora mudanças de ferramentas, mudanças na direção do movimento durante a desmontagem da peça, juntamente com as características individuais (por exemplo, peças de elevado-valor, peças com conteúdos perigosos, etc.). Feldmann et al. (2000) estimaram a taxa de reciclagem com base nos resultados da análise de uma ferramenta de software proprietário (proprietary software tool) e, em seguida, sugeriram alterações e/ou modificações no método de montagem dos materiais da peça, resultando em menores custos de reciclagem. Chu et al. (2009) propõem uma abordagem baseada em CAD e Algoritmos Genéticos (Genetic Algorithms - GAs) que altera a estrutura do produto para o DfD, onde três mecanismos de variação são fornecidos para atingir esse objetivo: alterações na combinação das 
peças, seqüência de montagem e método de montagem, levando em consideração os requisitos funcionais e ambientais do produto e as restrições de montagem para os componentes. Giudice e Fargione (2007) propõem uma ferramenta para o planejamento do processo de desmontagem adequado ao serviço do produto e a recuperação EoL (combinando as considerações econômicas e ambientais), desenvolvendo dois algoritmos diferentes (que partilham a tipologia de modelagem e a estrutura lógica e também podem ser usados como ferramentas de suporte durante as fases de design de produtos, inclusive com a capacidade de decisão autônoma para um deles, em nível da desmontagem a ser alcançado, e na definição do plano de recuperação ideal). Kim et al. (2006), desenvolvem um modelo computacional de programação inteira, baseado em um algoritmo, enfocando o caso do produto de tipo único sem comunalidade de peças, considerando as restrições de capacidade de recursos, com o objetivo de minimizar o número de produtos desmontados, gerando as melhores soluções em um curto período de tempo de computação. Dong, Gibson e Arndt (2007), descrevem uma ferramenta usando o Microsoft $C++$, para gerar uma ODS baseando-se em modelagem Petri net, com base em acessibilidade, expectativas de vida diferente dos componentes e estratégias EoL, onde gráficos e/ou são usados para gerar todas as seqüências viáveis de desmontagem, e, em seguida, gráficos e/ou são transferidos para gráficos Petri net enquanto os valores de acessibilidade e de tempo de vida dos componentes são levados em conta para obter a ODS. Kongar e Gupta (2006) apresentam um GA para a DSG de produtos em fim de vida. Chung e Peng (2006) apresentam uma abordagem híbrida para DSG de um conjunto selecionado de peças em um produto, baseada na desmontabilidade topológica e na acessibilidade da ferramenta e um aplicativo baseado em um ambiente de Internet de três camadas para a análise global concorrente pela cadeia de suprimentos durante o PDP. Mascle e Zhao (2008) descrevem uma metodologia geral de DfE, e uma parte de uma pesquisa com uma aplicação específica utilizando minimização de entropia (entropy minimization). Segundo os autores, a avaliação de entropia oferece a geração de uma DSG na qual a eficiência de desmontagem, o valor material e o valor específico são grandes e a responsabilidade é pequena. Os autores destacam que a lógica fuzzy e a modelagem de recursos são utilizados durante a avaliação DfE de peças, montagem e análise de operações.

Outros autores se concentraram em outras estratégias EoL como Luttropp e Johansson (2010) que sugerem a Matriz de Informação de Reciclagem (Recycling Information Matrix - RIM) concentrando-se sobre os WEEE, a fim de facilitar e melhorar a reciclagem de materiais, onde cada RIM se concentra em uma meta de reciclagem, e para cada tipo de produto um vetor WEEE é construído com nove números hexadecimais para armazenagem das principais informações de reciclagem. Shu e Flowers (1999) desenvolveram um quadro que avalia o efeito de design conjunto em cada uma das fases do ciclo de vida englobando o custo de remanufatura em relação a outros custos do ciclo de vida determinado pelo desenho da junta, que foi aplicado a estudos de caso de juntas que não facilitam a remanufatura. Kara et al. (2008) apresentam uma metodologia para avaliar o tempo de vida útil de um produto durante a fase de projeto com base em mecanismos de falha do produto e seus parâmetros de previsão de vida útil críticos associados. Segundo Tingström e Karlsson (2006), a Análise dos Efeitos Ambientais (Environmental Effect Analysis - EEA) é uma variável da Análise de Modo e Efeito de Falhas (Failure Mode Effect Analysis - FMEA) que considera 
a variável ambiental para estimar situações em que o produto gera impactos ambientais não previstas antes, e buscar opções para superar estes impactos. Okumura, Morikuni e Okino (2003) desenvolveram uma ferramenta que utiliza o método de simulação do comportamento da função para avaliar a qualidade do produto, a FMEA para examinar o efeito da deformação na deterioração dos componentes, e uma análise de tendência dos dados de monitoramento do tempo de vida para estimar o potencial de reutilização de componentes. Mangun e Thurston (2002) utilizaram uma função de utilidade multi-atributo que combina custo, confiabilidade e impacto ambiental para avaliar a significância da reutilização de componentes sobre o design do portfólio de produtos. Wardak et al. (2008) apresentam uma ferramenta para identificar riscos de nano-produtos (quais produtos apresentam maiores riscos, onde estes riscos ocorrem no ciclo de vida do produto, e os impactos destes riscos ambientais para a sociedade) utilizando uma abordagem de análise de cenário que permite a elicitação especialista em um conjunto de cenários pré-identificados de utilização e descarte e o que os autores rotularam de "gatilhos de risco" (risk triggers) para obter pontuações em sua probabilidade de ocorrência e gravidade. Staikos e Rahimifard (2007) desenvolveram uma ferramenta de software para suportar a tomada de decisões para determinar a forma mais conveniente (em termos ambientais, econômicos e sócio-técnicos), na qual tratar resíduos de calçados. Essa metodologia, segundo os autores, além de apoiar processos de design e seleção de materiais, também pode fornecer informações de referência para a seleção das melhores práticas EoL para um intervalo selecionado de tipos de sapatos diferentes.

Outros autores desenvolveram ferramentas para uma abordagem DfE de portfólio de produtos, como Luh, Chu e Pan (2010) apresentam uma ferramenta que facilita o gerenciamento de dados do desenvolvimento de produtos verdes e não verdes. Os autores propõem uma arquitetura genérica de produto modularizado, que funciona como uma representação de produtos unificada, permitindo o desenvolvimento de produtos verdes e não verdes, ao mesmo tempo. Xu, Ong e Nee (2007) que apresentaram uma metodologia de Design para a Reutilização de Famílias de Produtos (Product Family Design Re-use - PFDR) em um modelo de processo em três etapas para gerir os processos de design. O método de Avaliação de Conteúdo de Informação (Information Content Assessment - ICA) que é proposto para avaliação de desempenho do produto, segundo os autores, define os passos lógicos para computar o conteúdo de informação que é utilizado como uma métrica, uniforme e adimensional de desempenho do produto.

Embora o escopo deste trabalho seja o DfE, é importante observar que existem esforços para a padronização de futuras normas internacionais integradas e/ou compatíveis com a LCA. Segundo Hauschild, Dreyer e Jorgensen (2008) no âmbito da Iniciativa conjunta do PNUMA e da SETAC para "desenvolver e disseminar ferramentas práticas para avaliar as oportunidades, riscos e trade-offs associados aos produtos e serviços através do seu ciclo de vida", uma força tarefa tem se dedicado à discussão sobre a metodologia da Avaliação Social do Ciclo de Vida (Social Life Cycle Assessment LCA Social ou SLCA). A metodologia de LCA Social complementa a LCA e o LCC para apoiar o TBL (HAUSCHILD, DREYER e JORGENSEN, 2008; KLOEPFFER, 2008). Segundo Hauschild, Dreyer e Jorgensen (2008) é um ponto muito importante, que os diferentes métodos baseados no ciclo de vida para a avaliação de sustentabilidade utilizem consistentes - de preferência idênticas - fronteiras do 
sistema. Kloepffer (2008) afirma que na comunidade LCA/LCM, a possível extensão da série ISO 14040 ou uma nova norma internacional de eco-eficiência, desempenham um papel essencial na discussão, podendo resultar na unificação das 3 normas ou na sua compatibilização.

Como se pode verificar, Ferramentas de Apoio ao DfE das mais simples às mais complexas tem sido desenvolvidas para apoiar a tomada de decisão neste processo. Na seção a seguir são derivados os requisitos para este tipo de ferramentas.

\subsubsection{Requisitos das Ferramentas de Apoio ao DfE}

Segundo Brad (2009), as atuais necessidades e desafios no desenvolvimento de produtos radicalmente inovadores e com ciclo de vida otimizado exigem uma abordagem simultânea de planejamento de produto contra um complexo conjunto de objetivos funcionais (por exemplo, custo, qualidade, montagem, produção, meio ambiente, tecnologia, serviço, descarte, etc.). E, segundo Almeida et al. (2010), as ferramentas devem ser integradas às atividades do PDP, portanto, muitas Ferramentas de Apoio ao DfE, se concentram em otimizar estes outros objetivos também. As ferramentas para o DfE devem, portanto, ao mesmo tempo incluir várias bases de dados e orientações (ALTING e JOGENSEN, 1993). Por exemplo, Luh, Chu e Pan (2010) afirmam que as ferramentas devem ser simples, e práticas para o gerenciamento do PDP em conformidade com várias diretivas verdes a um custo competitivo. Segundo Kloepffer (2008), costuma-se dizer que as ferramentas de avaliação utilizadas no DfE devem ser simples e nem sempre quantitativas. Mas segundo o autor, isso pode ser verdade para encontrar pontos de acesso, mas certamente não para a tomada de decisão, pois se diferentes soluções são propostas, métodos quantitativos são necessários e a força da LCA é que a quantificação é possível.

Durante a última década, um bom número de Ferramentas de Apoio ao DfE tem sido desenvolvido (DEVANATHAN et al., 2010) e escolher uma delas é uma tarefa difícil, mas uma boa ferramenta é essencial para garantir que os cálculos possam ser realizados em um nível aceitável de tempo (ALTING, 1995). No entanto, a maior parte das ferramentas no mercado são excessivamente qualitativas ou subjetivas, exigindo que o designer conte com uma vasta experiência, ou são quantitativamente complexas e não podem ser aplicadas durante o projeto inicial, quando as especificações do produto ainda são desconhecidas (BOKS, 2006). Segundo Fitzgerald, Herrmann e Schmidt (2010), as ferramentas de apoio ao DfE atualmente disponíveis são inadequadas no que diz respeito a ajudar os designers a determinar como resolver conflitos durante a fase de projeto conceitual. Segundo Devanathan et al. (2010), a falta de ferramentas DfE eficazes tem feito da sustentabilidade um pensamento posterior e não um parâmetro crítico no processo de design.

$\mathrm{Na}$ verdade, segundo Johansson (2006), em organizações para as quais as inter-relações com o ambiente são muito claras ou onde exista uma forte concordância entre os vários atores em relação à quais questões são essenciais, parece haver uma menor necessidade para realização de avaliações dos impactos ambientais. Em tais casos, objetivos ambientais específicos para os produtos podem ser muito facilmente definidos e o projeto pode, então, se esforçar para alcançar esses objetivos sem a necessidade de fazer intrincados trade-offs com outras questões ambientais 
(JOHANSSON, 2006). Mas se a complexidade das questões ambientais abordadas é alta, uma quantidade substancial de esforços precisa ser investida em avaliações ambientais durante o PDP, inclusive na fase inicial do projeto, quando a especificação do produto é estabelecida (JOHANSSON, 2006). Uma boa ferramenta auxilia na modelagem dos ciclos de vida, bem como na elaboração do inventário e avaliação do impacto, oferecendo uma ou uma seleção de opções de impacto ambiental, pois a equipe do PDP não consegue facilmente elaborar o resultado para um inventário, que é basicamente uma lista de materiais, consumo de energia e emissões (ALTING, 1995).

No entanto, os designers descrevem que a utilização das Ferramentas DfE é difícil, demorada, exige trabalho adicional e os resultados não justificam o tempo e o esforço despendidos (HANDFIELD et al., 2001). Segundo Song e Lee (2010), as ferramentas devem ser fáceis e rápidas. Portanto, é necessário um conjunto de ferramentas de apoio ao DfE desenvolvido de forma sólida e prontamente disponíveis com ferramentas de software fáceis de usar (TINGSTRÖM, SWANSTROM e KARLSSON, 2006). Segundo Riou e Mascle (2009), as ferramentas devem facilitar a acessibilidade da informação para cada parte interessada em todo o ciclo de vida do produto. Segundo Vinodh (2010), a integração da Manufatura Àgil (Agile Manufacturing - AM) no DfE, por exemplo, por meio de ferramentas $C A D$ traz bons resultados. Além disso, os designers desejam basicamente com o uso destas ferramentas é que elas devem facilitar o seu trabalho (BAUMANN, BOONS e BRAGD, 2002). Portanto, as ferramentas também devem permitir a inserção de dados por parte das partes interessadas (RIOU e MASCLE, 2009). É necessária, ainda, uma melhoria contínua nas ferramentas e indicadores utilizados no DfE (NY et al., 2006; SCHMIDT e BUTT, 2006; BYGGETH, BROMAN e ROBÈRT, 2007) bem como o desenvolvimento de novas ferramentas e indicadores (NY et al., 2006; BYGGETH, BROMAN e ROBÈRT, 2007). No entanto, Schmidt e Butt (2006) recomendam deixar as decisões de 'se' e 'como', a melhoria contínua nas ferramentas e indicadores será realizada, com as funções responsáveis dentro das corporações. Como pôde-se verificar, uma série de requisitos são apontados para que as Ferramentas DfE possam efetivamente melhorar o desempenho dos produtos. A Tabela 14 e a Tabela 15 listam os principais requisitos, encontrados nesta revisão da literatura.

Tabela 14 - Requisitos para as Ferramentas de Apoio ao DfE - parte 1

\begin{tabular}{|c|c|}
\hline Requisitos & Refs. \\
\hline \multicolumn{2}{|l|}{ As Ferramentas de Apoio ao DfE devem ser... } \\
\hline$\rightarrow$ simples & $\begin{array}{l}\text { Kobayashi (2005); Kobayashi et al. (2005); Vezzoli e Sciama (2006); Gotzsch } \\
\text { (2008); Bala et al. (2010); Bohm et al. (2010); Collado-Ruiz e Ostad-Ahmad- } \\
\text { Ghorabi (2010b); Kishita et al. (2010); Luh, Chu e Pan (2010); Song e Lee (2010) }\end{array}$ \\
\hline$\rightarrow$ fáceis de usar & $\begin{array}{l}\text { Handfield et al. (2001); Lindahl (2006); Tingström, Swanstrom e Karlsson (2006); } \\
\text { Luh, Chu e Pan (2010); Song e Lee (2010) }\end{array}$ \\
\hline$\rightarrow$ rápidas & $\begin{array}{l}\text { Gungor e Gupta (2001); Handfield et al. (2001); Nielsen e Wenzel (2002); } \\
\text { Kobayashi (2005); Kobayashi et al. (2005); Lindahl (2006); Tingström, Swanstrom } \\
\text { e Karlsson (2006); Wu, Lo e Hsu (2008); Bala et al. (2010); Bohm et al. (2010); } \\
\text { Song e Lee (2010) }\end{array}$ \\
\hline $\begin{array}{l}\text { adaptáveis as tarefas do dia-a-dia do } \\
\text { PDP }\end{array}$ & $\begin{array}{l}\text { Handfield et al. (2001); Nielsen e Wenzel (2002); Lindahl (2006); Tingström, } \\
\text { Swanstrom e Karlsson (2006); Almeida et al. (2010); Bala et al. (2010) }\end{array}$ \\
\hline $\begin{array}{l}\text { integradas às outras ferramentas do } \\
\rightarrow \text { PDP, inclusive permitindo a } \\
\text { transferência de dados }\end{array}$ & $\begin{array}{l}\text { Zhang, Wang e Zhang (1999); Kobayashi (2005); Kobayashi et al. (2005); Xu, } \\
\text { Chen e Xie (2006); Cagno e Trucco (2007); Lee et al. (2007); Singh, Goodyer e } \\
\text { Popplewell (2007); Li et al. (2008); Jianjun et al. (2008); Brad (2009); Mengoni, } \\
\text { Germani e Mandorli (2009); Riou e Mascle (2009); Devanathan et al. (2010); } \\
\text { Vinodh (2010); Vinodh e Rathod (2010a) }\end{array}$ \\
\hline
\end{tabular}

Fonte: Elaborado pelo autor. 
Tabela 15 - Requisitos para as Ferramentas de Apoio ao DfE - parte 2

\begin{tabular}{|c|c|}
\hline Requisitos & Refs. \\
\hline $\begin{array}{l}\text { É importante que a própria empresa } \\
\text { desenvolva as suas ferramentas }\end{array}$ & $\begin{array}{l}\text { Baumann, Boons e Bragd (2002); Schmidt e Butt (2006); Tingström, Swanstrom e } \\
\text { Karlsson (2006); Schmidt e Taylor (2008) }\end{array}$ \\
\hline $\begin{array}{l}\text { É importante que a empresa torne } \\
\text { obrigatória a utilização das ferramentas }\end{array}$ & Tingström, Swanstrom e Karlsson (2006) \\
\hline $\begin{array}{l}\text { É necessária a melhoria contínua das } \\
\text { ferramentas e indicadores utilizados }\end{array}$ & Ny et al. (2006); Schmidt e Butt (2006); Byggeth, Broman e Robèrt (2007) \\
\hline $\begin{array}{l}\text { É necessário o desenvolvimento de } \\
\text { novas ferramentas e indicadores }\end{array}$ & Ny et al. (2006); Byggeth, Broman e Robèrt (2007) \\
\hline $\begin{array}{l}\text { Em projetos complexos, existe uma maior } \\
\text { necessidade de utilização dos métodos e } \\
\text { ferramentas do DfE do que em projetos } \\
\text { mais simples }\end{array}$ & Johansson (2006) \\
\hline \multicolumn{2}{|l|}{ As Ferramentas de Apoio ao DfE devem... } \\
\hline$\rightarrow$ abordar as fases iniciais do PDP & $\begin{array}{l}\text { Zhang, Wang e Zhang (1999); Nielsen e Wenzel (2002); Fitch e Cooper (2005a); } \\
\text { Kobayashi et al. (2005); Cagno e Trucco (2007); Lee et al. (2007); Wu, Lo e Hsu } \\
\text { (2008); Riou e Mascle (2009); Bohm et al. (2010); Devanathan et al. (2010); } \\
\text { Fitzgerald, Herrmann e Schmidt (2010); Pigosso et al. (2010); Vinodh e Rathod } \\
\text { (2010a); Vinodh e Rathod (2010b) }\end{array}$ \\
\hline $\begin{array}{l}\text { auxiliar no desenvolvimento de novas } \\
\text { tecnologias }\end{array}$ & $\begin{array}{l}\text { Nielsen e Wenzel (2002); Kunnari et al. (2009); Collado-Ruiz e Ostad-Ahmad- } \\
\text { Ghorabi (2010a) }\end{array}$ \\
\hline$\rightarrow$ fornecer suporte à resolução de & $\begin{array}{l}\text { Zhang, Wang e Zhang (1999); Khan, Sadiq e Veitch (2004); Kobayashi (2005); } \\
\text { Kobayashi et al. (2005); Leibrecht (2005); Rudenauer et al. (2005); Xu, Chen e } \\
\text { Xie (2006); Cagno e Trucco (2007); Staikos e Rahimifard (2007); Choi, Nies e } \\
\text { Ramani (2008); Li et al. (2008); Wu, Lo e Hsu (2008); Hara et al. (2009); Kuo, Wu } \\
\text { e Shieh (2009); Almeida et al. (2010); Bohm et al. (2010); Devanathan et al. } \\
\text { (2010); Palousis, Luong e Abhary (2010) }\end{array}$ \\
\hline$\rightarrow$ facilitar a Abordagem Ágil & $\begin{array}{l}\text { Gungor e Gupta (2001); Leibrecht (2005); Kara, Pornprasitpol e Kaebernick } \\
\text { (2006); Giudice e Fargione (2007); Chu et al. (2009); Hara et al. (2009); Mengoni, } \\
\text { Germani e Mandorli (2009); Riou e Mascle (2009); Bohm et al. (2010); Vinodh } \\
\text { (2010) }\end{array}$ \\
\hline$\rightarrow \begin{array}{l}\text { auxiliar na otimização de outros } \\
\text { objetivos do PDP }\end{array}$ & $\begin{array}{l}\text { Shu e Flowers (1999); Zhang, Wang e Zhang (1999); Mangun e Thurston (2002); } \\
\text { Okumura, Morikuni e Okino (2003); Khan, Sadiq e Veitch (2004); Kobayashi } \\
\text { (2005); Kobayashi et al. (2005); Rudenauer et al. (2005); Xu, Chen e Xie (2006); } \\
\text { Bovea e Wang (2007); Cagno e Trucco (2007); Giudice e Fargione (2007); } \\
\text { Staikos e Rahimifard (2007); Singh, Goodyer e Popplewell (2007); Chalal e } \\
\text { Ghomari (2008); Choi, Nies e Ramani (2008); Jianjun et al. (2008); Li et al. } \\
\text { (2008); Wu, Lo e Hsu (2008); Brad (2009); Hara et al. (2009); Kuo, Wu e Shieh } \\
\text { (2009); Mengoni, Germani e Mandorli (2009); Riou e Mascle (2009); Devanathan } \\
\text { et al. (2010); Luh, Chu e Pan (2010); Palousis, Luong e Abhary (2010); Vinodh e } \\
\text { Rathod (2010a) }\end{array}$ \\
\hline$\rightarrow$ auxiliar diversas estratégias DfE & $\begin{array}{l}\text { Veerakamolmal e Gupta (1998); Shu e Flowers (1999); Gungor e Gupta (2001); } \\
\text { Kobayashi (2005); Kobayashi et al. (2005); Lee et al. (2007); Staikos e Rahimifard } \\
\text { (2007); Singh, Goodyer e Popplewell (2007); Choi, Nies e Ramani (2008); Jianjun } \\
\text { et al. (2008); Li et al. (2008); Wu, Lo e Hsu (2008); Riou e Mascle (2009); Almeida } \\
\text { et al. (2010); Bakker et al. (2010); Bohm et al. (2010); Pigosso et al. (2010); Song } \\
\text { e Lee (2010); Vinodh e Rathod (2010a) }\end{array}$ \\
\hline$\rightarrow$ facilitar a engenharia simultânea & $\begin{array}{l}\text { Ny et al. (2006); Byggeth, Broman e Robèrt (2007); Cagno e Trucco (2007); Lee } \\
\text { et al. (2007); Chalal e Ghomari (2008); Jianjun et al. (2008); Brad (2009); Hara et } \\
\text { al. (2009); Riou e Mascle (2009) }\end{array}$ \\
\hline$\rightarrow$ auxiliar na & $\begin{array}{l}\text { Xu, Ong e Nee (2007); Mengoni, Germani e Mandorli (2009); Luh, Chu e Pan } \\
(2010)\end{array}$ \\
\hline
\end{tabular}

Fonte: Elaborado pelo autor.

A revisão da literatura subsidiou a formulação do roteiro de entrevista presente no Apêndice $C$ e nas seções a seguir, os resultados do estudo empírico são delineados. 


\section{RESULTADOS}

Este capítulo apresenta os resultados empíricos do presente estudo, e busca demonstrar uma análise dos dados coletados nas unidades de análise, por meio da aplicação do protocolo de pesquisa. Nesse sentido, o capítulo analisa o processo de integração de aspectos ambientais no PDP nas unidades de análise e está dividido em 2 seções permitindo a caracterização deste processo na Empresa $\mathrm{X}$ e na Empresa $\mathrm{Y}$, bem como a confrontação da teoria e dados empíricos, respectivamente.

\subsection{Caracterização do processo de integração de aspectos ambientais no PDP}

Esta seção busca através das principais variáveis identificadas nos resultados da Varredura Vertical, compreender como as unidades de análise conduzem a integração de aspectos ambientais no PDP e verificar o entendimento das áreas envolvidas neste processo sobre a importância das principais variáveis do DfE.

\subsubsection{Empresa $X$}

Segundo os entrevistados, as empresa se preocupa em estar constantemente atualizada quanto às normas e regulamentos no setor, participando de Grupos de Trabalho e Entidades de Classe, mantendo relações estreitas com fornecedores e Órgãos de Normalização e Certificação, viabilizando a constante atualização de seus produtos e serviços, bem como a participação de seus colaboradores em palestras, cursos, seminários, feiras e convenções. Um exemplo é a participação da empresa no GTSafety da ABINEE onde o Coordenador de Qualidade representava a empresa e a pouco tempo transferiu esta responsabilidade ao Consultor de Aplicações, devido ao acúmulo de trabalhos demandados devido a recente incorporação da Empresa X pela WEG, o que quintuplicou as metas de produção.

Os entrevistados afirmam que a preocupação com a aceitação dos produtos no mercado é uma constante no dia-a-dia da empresa, o que motivou a certificação de seus produtos da linha de segurança, onde a certificação é voluntária pela legislação brasileira, mas mandatória devido a pressões dos clientes. Existem, ainda, clientes que exigem a certificação CEPEL-EX-1780/09 para sensores ópticos de nível. No entanto, em relação às preocupações ambientais, os entrevistados afirmam que seus clientes no mercado interno, na maioria das vezes, sequer compreendem o que vem a ser um produto livre de chumbo. Portanto, pode-se afirmar que os direcionadores da estratégia DfE teriam uma ligação com os fluxos de informação e conhecimentos de funcionários na interação com a Certficadora e com os fluxos de informação e conhecimentos da sociedade que motivou a criação das Diretivas da União Européia. No entanto, quando questionados se o fato de possuírem $S G Q$, Certificações de Segurança e utilizarem as ferramentas da qualidade, seria um impulsionador para a preocupação ambiental, os entrevistados afirmaram, que na verdade este fator teria o efeito oposto devido a necessidade de cumprimento de diversos procedimentos extras, inerentes à Gestão da Qualidade e Certificação. Quanto ao relacionamento com os fornecedores, a empresa exige 
produtos certificados e os entrevistados afirmam que a certificação de seu SGQ gera a responsabilidade de uma avaliação acurada dos mesmos, inclusive com a realização de auditorias.

\subsubsection{Motivações para o DfE}

Quanto às motivações para implementar o DfE, os entrevistados afirmaram que a Melhoria da Imagem da Empresa e Acesso a Mercados Externos foram os fatores determinantes, enquanto outras motivações foram: a possibilidade de aumento da Vantagem competitiva devido ao Marketing, a Pressão da Opinião Pública dos mercados externos e a possibilidade de descarte mais simples no futuro (devido a regulamentação em alguns países já abordar esta fase do ciclo de vida dos produtos). $\mathrm{Na}$ opinião dos entrevistados, devido à participação em grupos de trabalho para normalização, a possibilidade de futura regulamentação não parece uma ameaça veemente, mas a regulamentação externa vem fazendo com que clientes e fornecedores do mercado externo estejam mais atentos a este tipo de preocupação.

Segundo os entrevistados, a iniciativa de eliminar o chumbo dos equipamentos da linha de segurança originou-se de uma das visitas de auditoria da TÜV Rheinland, certificadora de seu SGQ e dos certificados de segurança dos produtos da linha. $O$ auditor da certificadora mencionou as Diretivas da União Européia RoHS e WEE, alertando os colaboradores da Empresa X quanto às dificuldades que viriam a sofrer caso desejassem exportar seus produtos para o mercado europeu no futuro. Ao consultar a TÜV sobre o que era necessário para obter a certificação RoHS, uma das exigências seria o procedimento para descarte de resíduos de produtos eletrônicos e descarte para equipamentos que retornam dos clientes com defeito. Neste sentido, a empresa buscou uma empresa especializada na reciclagem de produtos eletrônicos para tentar estabelecer uma parceria, no entanto, não conseguiram encontrar uma empresa que pudesse apresentar uma proposta viável para reciclagem. Entretanto, segundo os entrevistados, esta iniciativa também demandou uma série de questões relacionadas aos produtos e processos. O processo de soldagem, por exemplo, fica mais difícil e o resultado da solda Lead Free (livre de chumbo) fica mais poroso e opaco. Isto demandou modificações do processo de fabricação das Placas de Circuito Impresso (PCls) que, passaram a receber tratamento em ouro nas regiões de soldagem. Além disso, a soldagem manual tornava-se ainda mais demorada e sujeita a refugo. O produto sofreu um aumento nos custos de matéria prima em torno de $14 \%$, no entanto, isso não se refletiu no valor final do produto. Na verdade, após a incorporação pela WEG, os produtos sofreram uma redução de preços como diretriz estratégica da WEG. Segundo os entrevistados, o desempenho funcional e de mercado dos produtos Lead Free, não sofreu alterações em relação à antiga linha em estanho-chumbo.

Algum tempo após a implementação do Lead Free uma máquina de solda foi adquirida para aumentar a produção e melhorar a qualidade do processo de soldagem de componentes. Devido à maior dificuldade de solda nas linhas de produtos Lead Free e à intenção da empresa em, no futuro, migrar todos os produtos para o Lead Free optou-se pela utilização da máquina para os produtos da linha Lead Free. A alteração no processo, por sua vez, demandou alterações nos produtos. As PCls passaram a receber componentes somente de um lado para viabilizar a soldagem automatizada. $A$ 
aquisição da máquina de soldagem incorreu na melhoria da qualidade dos produtos e dos processos, com uma redução significativa no desperdício com refugo, melhorias em relação à Segurança no Trabalho e às Emissões no processo de soldagem, melhoria na qualidade da solda e na rapidez dos processos comparados com os de estanho-chumbo que ainda são realizados manualmente para evitar a contaminação da máquina. Aliás, seria possível a aquisição de mais um tanque de solda para permitir a utilização da solda com estanho-chumbo na mesma máquina, apesar de caracterizar um alto investimento financeiro.

O fato de a empresa trabalhar com uma estratégia de portfólio, produzindo os produtos da linha de segurança Lead Free e os demais produtos no processo tradicional, gera uma aumento na complexidade do gerenciamento de processos e produtos devido a possibilidade de contaminação, demandando, por exemplo, a separação dos processos em salas diferentes, o que ainda não é implementado na empresa. Portanto, a Empresa $X$ optou por investir no redesign dos produtos que ainda utilizam estanho-chumbo para readequá-los ao Lead Free no futuro.

\subsubsection{Benefícios do DfE}

Outros benefícios para a organização após a introdução do Lead Free podem ser apontados como Melhoria na Reputação da Empresa, Novas Oportunidades de Mercado (externo), Vantagem Competitiva (devido ao Marketing), Desenvolvimento de Capacidades em termos de Conhecimentos e Competências (para todos os funcionários), Melhoria no Relacionamento com os Fornecedores, Exploração de Oportunidades de Inovações em Processos.

Quanto ao impacto para o setor de compras no relacionamento com fornecedores, pouca coisa mudou, pois os componentes SMD (em sua maior parte, importados) já eram livres de chumbo (Lead Free) e a maioria dos fornecedores de matéria prima já oferecia materiais Lead Free, no entanto, a empresa recusava, pois não os conhecia. Este fato incorreu na melhoria do relacionamento com os fornecedores, pois a Empresa $X$ passou a conhecer melhor os produtos de seus fornecedores. Hoje a empresa exige a certificação de produto pela RoHS de seus fornecedores para os componentes da linha de segurança.

\subsubsection{Integração nos objetivos do PDP}

Quando questionados a respeito dos objetivos do PDP, os entrevistados apontaram a Lucratividade como o principal objetivo. Mesmo quando os clientes demandam o desenvolvimento de um novo produto (a empresa também desenvolve sob encomenda), uma análise de investimento é realizada e esta definirá se a demanda pelo novo produto será ou não encaminhada ao setor de projetos. Outros objetivos do PDP foram apontados, como a Ergonomia, Estética, Custo, Qualidade, Tecnologia/Inovação, Necessidades dos clientes e Tempo para introdução no mercado (apesar deste processo ser demorado para os produtos que passarão por auditoria de certificação). O Impacto Ambiental é apontado como mais um objetivo na linha de segurança. Em relação à priorização entre 
os objetivos, os entrevistados afirmaram que não existe nenhum tipo de priorização, mas que esta pode ser realizada nos projetos sob demanda dos clientes.

Apesar de os objetivos ambientais não estarem expressos no planejamento estratégico, estes estão expressos na política de qualidade da empresa. Na realidade, a empresa chegou a iniciar um processo de separação de materiais para reciclagem em nível estratégico, no entanto, devido a restrições de espaço físico para este fim, a iniciativa foi abortada. Portanto, quanto às estratégias do PDP, a empresa aborda as fases de: Pré-Produção, com a seleção de materiais; Produção, com o Design para a montagem; e Uso, com o Design para a facilidade manutenção, instruções de uso nas etiquetas e visando a Segurança do Produto. Quando questionados a fase do ciclo de vida do produto onde os entrevistados acreditavam residir os maiores impactos ambientais, ambos apontaram a Extração de Matérias-Primas.

\subsubsection{Métodos de apoio ao DfE}

O processo de integração de aspectos ambientais no PDP e nos processos, mencionado pela empresa simplesmente como Lead Free, demandou uma série de cursos e treinamentos para os colaboradores, principalmente do PDP e de Processos. Neste sentido, a empresa contou com a colaboração dos fornecedores que auxiliaram no processo, muitas vezes fornecendo ou indicando cursos, treinamentos e palestras. Outras fontes de colaboração podem ser apontadas como o relacionamento com a Certificadora e as interações nos grupos de trabalho, seminários, feiras e workshops.

Quando questionados a respeito dos facilitadores do DfE, os entrevistados afirmaram que uma Ferramenta de Apoio seria extremamente interessante, no entanto, a empresa não conta com ferramentas para este fim. Quanto aos facilitadores ao DfE que a empresa utiliza, foram citados: a integração do PDP com os departamentos de Marketing, Produção e Processos; a integração com Fornecedores e o GTSafety; a integração com a Alta Administração; os treinamentos sobre DfE (fornecidos pelos fornecedores aos colaboradores de projetos e produção); Discussões sobre o DfE; Clara definição de papéis e Responsabilidades; a realização de um Estudo Piloto; o Estímulo a cooperação entre os diversos atores; Compras Verdes; o Benchmarking Ambiental; a Engenharia Simultânea; Comunicação com grupos de interesse relacionados ou organizações de apoio (Auditor da Certificadora); Mecanismos de Gestão do Conhecimento Ambiental, a Criação de Diretrizes organizacionais, Equipe de Projetos composta por profissionais dos setores de produtos e processos; que a equipe de projeto possua conhecimento das questões relacionadas com os produtos em todas as fases do ciclo de vida e possua conhecimento da estratégia da empresa, bem como suficiente poder de decisão a fim de realizar os estágios particulares no âmbito do DfE.

Os entrevistados concordaram com a hipótese de que a exposição a exemplos pode provocar fixação e redução da criatividade. Quando questionados, afirmaram que: as ferramentas do DfE são pouco conhecidas e raramente utilizadas; os designers estão à procura de orientação geral ao invés de uma direção específica; a visão inicial dos designers é que o DfE consome demasiadamente custos, tempo e pessoal; é importante que o método de apoio utilizado seja simples, flexível, 
pragmático; além das ferramentas é necessário um procedimento metodológico que apóie o DfE para se fazer um melhor uso destas; devido ao comprometimento com a meta os designers tem tempo e disposição para passar pelos diversos treinamentos do DfE; os designers vêem as questões ambientais como uma característca do projeto e não como restrições a serem vencidas para se poder dar continuidade à próxima etapa do projeto.

Em relação às expectativas iniciais dos designers, os entrevistados afirmaram que no início os projetistas sentiram que o prazo para conclusão do projeto seria um pouco mais demorado (devido a necessidade de maior cuidado), também existia o receio, um pouco maior, quanto a qualidade final do produto e maior ainda quanto aos custos finais do produto. No entanto, após a finalização dos projetos essas preocupações foram quase que totalmente neutralizadas, visto que estas preocupações não se materializaram.

Quanto ao PDP, a equipe de projeto, composta por 6 projetistas, desenvolve as suas atividades de forma contingencial, adequando as atividades a serem realizadas de acordo com as características particulares de cada projeto. O estudo de viabilidade dos projetos sempre é feito em uma etapa anterior, pela equipe comercial e a direção. A cada projeto aprovado para desenvolvimento, um formulário de Planejamento das Atividades de Projetos (PAP), que pode ser visualizado no ANEXO A, é utilizado para orientar as atividades de projeto, bem como para a programação das atividades e reuniões necessárias para conclusão do projeto (uma versão preenchida e adaptada do PAP pode ser verificada, como exemplo, no ANEXO B). Os produtos que sofrerão auditoria de certificação devem passar por todas as fases. Durante os projetos, uma interação com os demandantes pelo projeto é realizada durante as fases iniciais do projeto, para garantir que o produto atende as necessidades do demandante. O levantamento de materiais é realizado paralelamente ao PDP, pelos próprios projetistas, mas não é realizado nas etapas iniciais do projeto, nem conta com ferramentas especificas para este processo a não ser o próprio Know How dos projetistas. Segundo os entrevistados, o Lead Free não impõe restrições às opções de projeto em nenhuma das etapas de desenvolvimento a não ser na própria seleção de materiais e nem demanda a contratação ou consulta a algum tipo de especialista ambiental.

\subsubsection{Ferramentas de apoio ao DfE}

A empresa não utiliza ferramentas para o DfE, mas com um estudo mais aprofundado sobre as ferramentas do PDP, pode-se verificar se as exigências impostas as ferramentas do DfE, pela literatura, são equivalentes as das ferramentas tradicionais. Na empresa, o PDP conta com a utilização de 4 ferramentas, também de forma contingencial: I) Estudo em PC Board: Ferramenta utlizada para estudos iniciais do projeto de produtos eletrônicos; II) Software para o Design Assistido por Computador (CAD): SolidWorks; III) Software para projeto de Placas de Circuito Impresso (PCls): Altiun; e IV) Desenvolvimento de FMEA. Todas as ferramentas foram consideradas rápidas, adaptáveis as tarefas do dia-a-dia do PDP, integradas ao processo de tomada de decisão e obtentoras de resultados adequados, mas exigem conhecimento e experiência do usuário. Em contrapartida, todas reduzem custos e podem ser utilizadas em projetos simples ou complexos. 
Segundo os entrevistados, somente as ferramentas (II) e (III) são de utilização obrigatória, facilitam a troca de informações entre as fases do PDP, estão integradas aos parceiros da cadeia de suprimentos, podem ser abastecidas com restrições como as necessidades dos clientes, abordam diversos objetivos do PDP e reduzem tempo. Ambas são constantemente atualizadas pelo Responsável de $\mathrm{TI}$ da empresa. Ambas possuem banco de dados que é customizado e constantemente atualizado pelos usuários em conjunto com o pessoal de $\mathrm{TI}$.

A implementação da ferramenta (II), substituindo o software utilizado anteriormente, foi demandada por clientes e pela WEG após a incorporação. A ferramenta (III) foi escolhida pelos próprios usuários (projetistas). Somente a ferramenta III fornece informações para decisões de tradeoffs tradicionais e está integrada a outras ferramentas da empresa, pois permite a transferência dos dados diretamente ao equipamento que fabrica as PCls. Nenhuma das ferramentas demandou extensos treinamentos. No entanto, nenhuma delas é considerada simples ou de fácil utilização.

\subsubsection{Contexto}

Quanto ao DfE, os entrevistados afirmam que a empresa deseja adequar ainda mais seus projetos e processos à Diretiva RoHS (o que demandaria a separação dos processos de estanhochumbo para salas diferentes, devido a possibilidade de contaminação) com a transição dos outros produtos da empresa para o projeto Lead Free, a eliminação de outras substâncias utilizadas nos produtos e processos como o clorofórmio, éter, etc. (de acordo com as sugestões do auditor da TÜV) e a retomada do processo de planejamento do descarte de produtos eletrônicos para viabilizar a obtenção do selo da comunidade européia.

Os entrevistados acrescentaram que um dos maiores obstáculos no DfE seria a falta de informações, citando o exemplo de um fornecedor de dissipadores de calor: ao ser questionado quanto a presença de chumbo no acabamento dos dissapadores (processo realizado por uma terceira empresa), não sabia responder. Isto demandou o contato da Empresa $X$ com a terceira empresa, que na verdade confirmou que seus processos já eram Lead Free.

Devido ao pequeno porte da empresa, os diversos departamentos conseguem trabalhar de forma integrada, pois muitas vezes os colaboradores desempenham mais de uma função na organização e em setores diferentes. Outra característica é que a empresa também oferece serviços aos seus clientes, como a instalação, manutenção, etc. Dessa forma, e com base no fato de que 3 dos projetistas, acumulam funções como serviços de instalação, assistência técnica e apoio a produção quando a demanda está alta, a equipe de projeto conta com a possibilidade de visualizar os impactos de suas escolhas na área de produção, manutenção, instalação, utilização pelo usuário, etc.

\subsubsection{Empresa $Y$}

$\mathrm{Na}$ entrevista, o Diretor Comercial da UPK evidenciou que a família fundadora da empresa é ambientalista desde a sua fundação e este fato pode ser evidenciado no histórico da empresa, hoje a empresa também conta com acionistas ambientalistas. Além disso, o entrevistado relata que a 
empresa, periodicamente, recebe questionários de diversos clientes (somente este ano uns 7 clientes, como Avon, fornecedores do MC Donald's, etc...) a respeito de políticas socio-ambientais na empresa.

A integração de aspectos ambientais na empresa e no PDP estão evidenciados nos objetivos estratégicos da empresa e nos objetivos do PDP, bem como no Código de Conduta da empresa. No mercado de atuação da empresa existem diversos tipos de rótulos ambientais como o CERFLOR (Sistema Brasileiro de Certificação Florestal) e o FSC. A empresa possui o FSC devido a sua aceitação internacional e também possui a certificação ISO 14000. Segundo dados da empresa, durante e depois da crise de 2008, o mercado de madeira certificada comportou-se melhor do que o dos produtos não-certificados e a parcela de clientes que buscam madeira certificada têm aumentado consistentemente ano após ano. A empresa também possui outros tipos de certificação como a ISO 9000,22000 , OHSAS 18001. Quanto à certificação do ISEGA, a empresa declara que recebe de 4 a 5 questionários/mês, de clientes internacionais, solicitando informações sobre a composição de seus papéis (substâncias químicas), o que demandou a certificação de seus produtos. Existem clientes para os quais a certificação de contato alimentar já é uma exigência, e também os que ainda solicitam que o papel seja composto $100 \%$ de fibra virgem devido ao contato com alimentos. Este tipo de contato acaba gerando trocas de informações com clientes e subsdiando o benchmarking ambiental e social realizado pela empresa, complementando a busca por informações do mercado.

Além disso, todos os funcionários são ouvidos quanto a sugestões e informações relevantes para a empresa. Portanto, pode-se afirmar que os direcionadores da estratégia DfE teriam uma ligação com os Fluxos de informação e conhecimentos de funcionários e com os Fluxos de informação e conhecimentos da sociedade que motivaram a criação das normas ISO 14000 e da certificação FSC. O entrevistado ainda acrescentou que os Fluxos de informação e conhecimentos da concorrência também são constantemente monitorados, através do benchmarking ambiental. No entanto, quando questionado se o fato de possuírem as demais certificações, seria um impulsionador para a preocupação ambiental, o entrevistado afirma que, a preocupação ambiental já esta arraigada na cultura organizacional da empresa e que seria difícil tentar estabelecer este tipo de relação.

Quanto ao relacionamento com os fornecedores, o entrevistado afirma que quanto aos fornecedores de produtos químicos, a maioria já é certificado, no entanto, a empresa ainda não exige a certificação. Em contrapartida, a empresa já envia questionários a respeito dos produtos e boas práticas aos seus fornecedores. Quanto à compra de "aparas" (papel usado para reciclagem), o setor de suprimentos, normalmente analisa os processos dos fornecedores e auxilia na otimização dos mesmos. Em relação aos 18 mil produtores participantes do Programa de Fomento Florestal (com compromisso de compra da empresa), é realizado um trabalho de orientação e educação aos fomentados. Neste sentido, a empresa trabalha com uma estratégia de orientação e parceria, mas no futuro, pretende começar a exigir as certificações.

\subsubsection{Motivações para o DfE}

Quanto às motivações para implementar o DfE, além da própria cultura de sustentabilidade da empresa, foram apontados a Melhoria da Imagem da Empresa, Pressão da Opinião Pública 
(segundo o entrevistado, a indústria papeleira é muito vigiada), Acesso a novos mercados, Regulamentos mais rigorosos, Maior produtividade, Renovação do Mix de Produtos, Redução de custos, Redução de multas ambientais, Acesso a Mercados Externos, Proibição de Substâncias Perigosas, Aumento do Valor de suas Ações através da inclusão da empresa no ISE (a empresa está classificada como elegível para o ISE 2012), Atração de consumidores ambientalmente conscientes, Vantagem Competitiva ("dificil visualizar em valores inicialmente, mais garante vantagens no Marketing na comparação com as concorrentes e ganhos de produtividade"), o entrevistado acrescentou ainda, a maior facilidade de obtenção e renovação de licenças de operação, o fato de o Cliente fazer analogia entre solidez da empresa e sustentabilidade, que alguns clientes (empresas) podem exercer certo tipo de pressão, mas que o consumidor final ainda parece estar pouco atento as questões ambientais.

Outra motivação apontada pela empresa como importante, é a Exploração de Oportunidades de Inovações em Processos, onde o entrevistado citou alguns exemplos. Para a empresa, que possui cerca de $8 \mathrm{mil} \mathrm{km}$ de estradas (entre casacalho, terra e asfalto) nas florestas, existem esforços para a melhoria da logística de transportes, visando a redução de emissões, economia de combustíveis e horas de trabalho, o que justificou o investimento aproximado de 80 milhões de reais na recente aquisição de um software para traços mais eficientes das rotas entre as florestas. Ainda no setor logístico, antes do transporte, as toras de madeira são descascadas e, quando possível, picadas (devido a dificuldade de transporte do talhão - equipamento utilizado para picar a madeira e abastecer os caminhões). Na produção de papéis, um software de conjugação de produtos, para programação da produção traz reduções de desperdícios de 2 a 3\%. O investimento nas caldeiras de biomassa para geração de energia elétrica traz economia e ajuda numa melhor destinação das cascas e galhos de árvores.

A Exploração de Oportunidades de Inovações em Produtos também pode ser apontada como uma das motivações, já que a empresa desenvolve o Programa de Fitoterapia com apoio de universidades do Paraná, estudando a floresta da Fazenda Monte Alegre (PR) e produzindo produtos de beleza e saúde, bem como medicamentos fitoterapicos para seus colaboradores e familiares. A empresa estuda projetos para inicializar a comercialização destes produtos. Também são reveladas inovações em produtos como o papel para embalagens na cor creme, TCF (Total Chlorine Free totalmente livre de cloro), e que permite uma maior aderência e definição de estampas do que os papéis marrons, além de ser adequado ao contato alimentar. A empresa investiu em Marketing e Vendas e hoje vende mais do que vendia com o papel branco. Outra iniciativa é a redução da gramatura dos papéis, mantendo o mesmo desempenho. Este tipo de iniciativa reduz custos de matéria-prima e logísticos, reduzindo o peso em até $28,5 \%$, no entanto, demanda a utilização de máquinas e equipamentos mais novos e sofisticados (para evitar o rompimento do papel durante os processos) ou uma desaceleração dos processos. Este tipo de trade-off pode ocasionar resistência em por parte de alguns clientes. A empresa vem tentando substituir os papéis de 110 gramas $/ \mathrm{m}^{2}$ para a padronização em 100 gramas $/ \mathrm{m}^{2}$. Durante a entrevista, o Diretor Comercial da UPK, recebeu o telefonema de um cliente, a respeito desta questão (110 para 100 gramas $\left./ \mathrm{m}^{2}\right)$. O interessante é que a empresa ainda comercializa o 110 gramas (que em metros quadrados ao mesmo preço do 100 
gramas, fica mais caro para o cliente), mas já inicia uma política de conscientização dos clientes no intuito de persuadi-los a passar ao padrão 100 gramas compartilhando com os mesmos o ganho de área (mesmo mais barato para o cliente).

Neste sentido, a empresa afirma que não adota uma estratégia de portfólio para a comercialização de produtos com apelo ambiental e sem apelo ambiental. Todos os produtos da empresa possuem apelo ambiental. A empresa ainda afirma que este tipo de produto tem alcançado uma posição favorável no mercado, sendo mais competitivos, mais lucrativos, custando menos e que a única "desvantagem" no seu desempenho seria em relação aos processos produtivos, para empresas acostumadas com papéis de maior gramatura, onde é necessário um cuidado um pouco maior para evitar a ruptura dos papéis.

\subsubsection{Benefícios do DfE}

Outros benefícios para a organização podem ser apontados como Maior Satisfação dos Clientes, Melhoria na Reputação da Empresa, Maior Atratividade para Diversos Investidores, Novas Oportunidades de Mercado, Redução de Custos, Vantagem Competitiva, Novas Oportunidades de Negócios, Desenvolvimento de Capacidades em termos de Conhecimentos e Competências, Aumento do Valor de suas Ações através da inclusão da empresa no ISE, Acesso mais fácil às fontes de recursos que podem financiar os seus projetos (a empresa conta com apoio do BNDES devido aos seus projetos de educação e meio ambiente), e a maior facilidade de obtenção e renovação de licenças de operação.

\subsubsection{Integração nos objetivos do PDP}

Quando questionados a respeito dos objetivos do PDP, os entrevistados apontaram a Qualidade, o Custo, a Estética, a Ergonomia, Tecnologia / Inovação, Funcionalidade, Impacto Ambiental, as Necessidades dos Clientes, além da produtividade, padronização, saúde e segurança, bem como a solução de problemas comuns às embalagens de papel, no que diz respeito às suas propriedades físicas - barreiras (água, vapor, gordura, pragas), porosidade, permeabilidade, rugosidade - e conversão: corte, vincagem, colagem, fechamento e impressão. Em relação a estes objetivos, os trade-offs são analisados objetivando o melhor resultado global, sem qualquer priorização pré-definida entre eles (que, no entanto, pode ser demandada por clientes). Dessa forma, a integração dos aspectos ambientais no PDP ocorre de forma paralela, já que os objetivos ambientais estão presentes na empresa como diretriz organizacional em todos os processos, mas também é caracterizada na forma de check-points, visto que os projetos passam por avaliação do setor ambiental. Já na primeira fase dos projetos (Análise de Viabilidade e Planejamento) é realizado um procedimento qualitativo estabelecido para avaliação de aspectos ambientais nos projetos de P\&D por meio do preenchimento de um Formulário sobre os Aspectos Ambientais. Os projetos do setor de P\&D podem ser demandados pelos clientes ou fruto das iniciativas de pesquisa da empresa 
(da análise de problemas, dos times internos de melhoria, do planejamento estratégico, qualidade, assistência técnica, etc.).

Dessa forma, de um modo geral, normalmente os projetos se baseiam no melhoramento e em alterações dos produtos existentes, e são realizados em 4 fases principais: 1) Análise de Viabilidade e Planejamento: é realizada uma análise do que deve ser melhorado/alterado; 2) Desenvolvimento do Conceito e Protótipo: os trade-offs são analisados, são realizadas reuniões entre os diversos setores envolvidos de forma a se chegar a um consenso, toda a empresa é envolvida no desenvolvimento do produto piloto e; 3) Testes e Aperfeiçoamento: onde são realizados os testes laboratoriais; 4) Produção.

\subsubsection{Métodos de apoio ao DfE}

Com relação aos facilitadores do DfE, o Diretor Comercial da UPK afirmou que a empresa possui softwares para o redesenho de estradas entre as plantações de eucalipto, de roteirização logística e para a conjugação dos pedidos no sistema de produção. No entanto, a empresa aponta a utilização de ferramentas de apoio como complementar à cultura organizacional, à vigilância do sistema e à parceria do pessoal de Qualidade e Meio Ambiente. A empresa apontou a integração do PDP com outros setores da empresa como muito importante, principalmente com os setores de Marketing, Produção, Logística, Compras, Processos e Meio Ambiente. A integração do PDP com outras entidades também foi apontada como muito importante, como a colaboração com clientes, aparistas (fornecem papel para reciclagem), Universidades e entidades de pesquisa. Também foram apontados como muito importantes a Integração com a Alta Administração; Exposição a exemplos de casos de sucesso; a Clara definição de papéis e responsabilidades; as Políticas de RH voltadas a dimensão ambiental (O Setor de RH é que promove o jornal interno da empresa, com casos de sucesso e outras políticas de Endomarketing. Também é no $\mathrm{RH}$ onde os novos funcionários recebem os treinamentos sobre as políticas ambientais da Empresa Y); Discussões sobre o DfE (estimuladas pelo jornal interno); Compras Verdes; Tecnologias de Comunicação; Benchmarking Ambiental (Toda a área comercial, além disso, a empresa faz comparação de Demanda Bioquímica de Oxigênio (DBO), pegada de carbono (CO2) e relatórios ambientais de concorrentes); Comunicação com grupos de interesse relacionados ou organizações de apoio (A empresa possui contatos e parcerias com acionistas ambientalistas, Instituto Ethos, Universidades, faz parte da joint venture com a Tetra Pak, Alcoa e TSL Ambiental para reciclagem de embalagens longa vida, etc.); Disseminação do Conhecimento em sustentabilidade; Normas e diretrizes para o DfE para apoiar o uso eficiente dos métodos e/ou ferramentas ambientais; Um Especialista Ambiental na empresa (Em todas as fábricas existe o pessoal de processos, especialistas ambientais e de mercado. Os especialistas ambientais são utilizados como fonte de informação.); Um Especialista Ambiental cooperando com PDP; Equipes multifuncionais com membros das áreas de mercado, processos e desenvolvimento; Que a equipe possua conhecimento da estratégia da empresa; Que a equipe possua conhecimento das questões relacionadas com os produtos em todas as fases do ciclo de vida, e; a necessidade de integração entre os gerentes de produto e as outras áreas da empresa. A empresa também apontou como 
importante Que a equipe possua suficiente poder de decisão a fim de realizar os estágios particulares no âmbito do DfE; Estimular a cooperação entre os diversos atores, e; Mecanismos de Gestão do Conhecimento Ambiental. A empresa também apontou que os Gerentes e Diretores são avaliados por 6 competências nas quais estão refletidos os objetivos ambientais, no entanto, segundo a empresa, a cultura organizacional exerceria um maior impacto sobre os projetos. Quanto ao setor ambiental, a empresa vem medindo a sua pegada de carbono, bem como a de seus produtos, C2Gr, além de funcionar como fonte de informação na empresa.

O Coordenador de P\&D concordou moderadamente com a hipótese de que a exposição a exemplos pode provocar fixação e redução da criatividade e com a hipótese de que os designers estão à procura de orientação geral ao invés de uma direção específica. Quando questionado, afirmou que: as ferramentas do DfE são pouco conhecidas e raramente utilizadas; é importante que o método de apoio ao DfE utilizado seja simples, flexível, pragmático; além das ferramentas é necessário um procedimento metodológico que apóie o DfE para se fazer um melhor uso destas; os designers vêem as questões ambientais como restrições a serem vencidas para se poder dar continuidade à próxima etapa do projeto; os designers tem tempo e disposição para passar pelos diversos treinamentos do DfE; e o DfE não consome demasiadamente custos, tempo e pessoal. Em relação às expectativas iniciais dos designers, o entrevistado afirmou que é comum a visão entre os projetistas de que o DfE afetaria negativamente o desempenho empresarial, medido em termos de prazo, custo, qualidade e flexibilidade.

\subsubsection{Ferramentas de apoio ao DfE}

Quanto às ferramentas utilizadas no PDP, a empresa utiliza uma ferramenta de apoio ao DfE (Formulário sobre Aspectos Ambientais) acompanhada de outras 6 ferramentas: I) Formulário de Abertura Projetos: utilizado na primeira fase dos projetos (Análise de Viabilidade e Planejamento); II) FMEA: também realizada na primeira fase; III) QFD: realizado na primeira fase; IV) Formulário sobre Aspectos de Segurança: primeira fase dos projetos; V) Formulário sobre Aspectos Ambientais: primeira fase dos projetos; VI) Check List Tarefas: utilizadas em todas as fases dos projetos; e VII) Software Gerenciador de Projetos: integrando todas as fases dos projetos, todos os projetos e todas as ferramentas do PDP.

Todas as ferramentas são de utilização obrigatória e foram consideradas simples, rápidas, fáceis de usar, adaptáveis as tarefas do dia-a-dia do PDP, integradas ao processo de tomada de decisão e obtentoras de bons resultados, mas exigem extensos treinamentos, conhecimento e experiência do usuário. Em contrapartida, todas reduzem tempo e custos e podem ser utilizadas em projetos simples ou complexos, tornando o DfE mais ágil, abordam as necessidades dos clientes, a disposição a pagar do consumidor, os custos do ciclo de vida e os outros objetivos do PDP. Os gestores de P\&D são os responsáveis pela constante atualização de todas as ferramentas e de seus bancos de dados, bem como da customização das mesmas. As ferramentas são desenvolvidas em parceria entre o fornecedor, equipe de P\&D, setor de suprimentos e o setor de TI da empresa. 
A ferramenta (III) fornece informações para decisões de trade-offs tradicionais. Em relação às outras ferramentas, estes são analisados pela equipe de P\&D. Além da ferramenta (IV), as ferramentas (II) e (III) também abordam aspectos sociais do ciclo de vida dos produtos. A ferramenta (VI) é uma lista de verificação. A ferramenta (V) é qualitativa, baseada em uma planilha do Microsoft Excel, aborda os aspectos ambientais do ciclo de vida, onde os dados a respeito dos impactos ambientais do projeto são listados e enviados ao setor de meio ambiente. No entanto, não é destinada a obtenção de rótulos ecológicos.

Por meio da ferramenta (VII), todas as ferramentas estão integradas entre si, a ferramentas de outros setores da empresa, ao Design Assistido por Computador (CAD), com outros setores da empresa e aos parceiros da cadeia de suprimentos, facilitando a troca de informações. A ferramenta possui acesso controlado por meio de senha individual, devido à confidencialidade dos dados. principal usuário das ferramentas é a equipe de P\&D, no entanto, a ferramenta (VII) está disponível para todos os outros setores da Empresa $\mathrm{Y}$ em todas as unidades. A ferramenta ainda disponibiliza fóruns para idéias, sucessos e insucessos, funcionando como uma ferramenta de gestão do conhecimento.

Quanto às estratégias do PDP, pode-se afirmar que a empresa aborda as fases de: PréProdução, com a seleção de materiais; Transporte, com a Melhoria da Logística de Transportes, Design para Baixo Volume, Design para Baixo Peso; Produção, com a Melhoria da Performance dos Processos de Produção, Redução de Despesas Gerais de Produção; e Uso, com o Aumento da Eficiência Funcional e Segurança do Produto; e Descarte, com o Design para a Reciclabilidade. A fase do ciclo de vida do produto onde residem os maiores impactos ambientais é a Extração de Matérias-Primas.

\subsubsection{Contexto}

A empresa afirma que apesar do porte, trabalha de forma bastante integrada viabilizando o melhor desempenho de seus projetos. Isto ficou visível durante a entrevista, que foi realizada em uma sala de reuniões, no entanto, o Diretor Comercial da UPK apresentou a sala da Diretoria, onde todos os Diretores trabalham em mesas lado a lado.

Quanto à presença da preocupação ambiental na cultura organizacional da empresa, pôde-se observar fisicamente no escritório comercial da empresa impressões com menções voltadas ao meio ambiente, quadros mencionando os prêmios ambientais da empresa, publicações em revistas, dicas para economia de recursos, em todos os ambientes visitados, desde a recepção, à sala de café, nos lavabos, salas de reuniões e sala da diretoria. Também pôde-se observar durante a entrevista com o Diretor Comercial da UPK e o contato telefônico com o Coordenador de P\&D da UMA que a preocupação ambiental se reflete diretamente em seus trabalhos devido às políticas da empresa. Além disso, existem diversas políticas de $\mathrm{RH}$ voltadas a este tipo de preocupação conforme exposto acima, e no histórico da empresa são visíveis ações voltadas à preocupação ambiental desde a década de 80. 


\subsection{Confrontação da teoria e dados empíricos}

Esta seção visa traçar um paralelo entre a literatura e a realidade encontrada nas unidades de análise selecionadas. Quanto aos impulsionadores do DfE, ambas as empresa possuem certificação ISO 9001 (conforme proposto por HART, 1995; VACHON e KLASSEN, 2008) e utilizam as ferramentas da qualidade (ver VINODH, 2010; VINODH e RATHOD, 2010a; VINODH e RATHOD, 2010b), bem como outras certificações voltadas à área de atuação das empresas. Em relação à influência de normas e regulamentos ambientais na área de atuação em que a empresa atua (ver PORTER e LINDE, 1995; WESTKÄMPER, ALTING e ARNDT, 2000; HANDFIELD et al., 2001; DE BAKKER e NIJHOF, 2002; KIM et al., 2006; SAVASKAN e VAN WASSENHOVE, 2006; BYGGETH, BROMAN e ROBÈRT, 2007; FURTADO, 2007; GE e WANG, 2007; WAAGE, 2007; CHOI, NIES e RAMANI, 2008; GEHIN, ZWOLINSKI e BRISSAUD, 2008; KURK e EAGAN, 2008; ZACKRISSON et al., 2008; ALBINO, BALICE e DANGELICO, 2009; KNIGHT e JENKINS, 2009; ALMEIDA et al., 2010; FITZGERALD, HERRMANN e SCHMIDT, 2010; JABBOUR, 2010; LEE et al., 2010; LENOX, KING e EHRENFELD, 2010), pode-se afirmar que em ambas as áreas de atuação existem certificações ambientais, mas apenas na área de papel e celulose a legislação ambiental brasileira é mais severa. Apenas a Empresa $Y$ possui certificação pela ISO 14001 (conforme proposto por HART, 1995; WAGNER, 2007; VACHON e KLASSEN, 2008). No entanto, não foi verificada nenhuma relação causal entre o fato de a empresa possuir certificação do sistema de gestão da empresa (ambiental ou de qualidade) e o DfE, como a literatura aponta (HART, 1995; WAGNER, 2007; VACHON e KLASSEN, 2008). Entretanto, em empresas de pequeno porte, em fase inicial de implementação do DfE (Empresa X), a certificação do Sistema de Gestão da Qualidade, foi apontada até mesmo como geradora de mais obstáculos à implementação do DfE devido a necessidade de cumprimento de diversos procedimentos.

A hipótese de que as empresas podem influenciar o desempenho ambiental de seus fornecedores por meio da exigência de Certificações/Declarações Ambientais de Produtos (defendida por WESTKÄMPER, ALTING e ARNDT, 2000; SAVASKAN e VAN WASSENHOVE, 2006; PASKA, 2010; STRAZZA et al., 2010) parece ser verificável independentemente de porte, tipo de negócio ou fase/estágio de implementação do DfE. A Empresa $X$ afirma não sofrer este tipo de pressão de seus clientes quanto à certificação ambiental. No entanto, a consciência de que no mercado externo este tipo de certificação já é exigido impulsionou a implementação do DfE e a exigência para com os seus fornecedores de Certificações/Declarações Ambientais de Produtos, devido à intenção de exportação de seus produtos no futuro. A empresa também relata que este tipo de pressão já existe em relação às certificações voltadas à segurança (EN 61.496/1-2), onde seus produtos já são certificados. A Empresa $Y$ relata que seus clientes enviam, periodicamente, questionários a respeito das políticas da empresa e das características de seus produtos, tanto quanto a assuntos voltados a segurança quanto aos aspectos ambientais e sociais (o que acaba se tornando mais uma fonte de benchmarking para a empresa), apesar de a empresa já possuir estas iniciativas anteriormente ao inicio deste tipo de preocupação por parte de seus clientes. A empresa também adota este tipo de iniciativa 
(questionários) em relação aos seus fornecedores e atua com uma postura de orientação e educação de seus fornecedores, mas já visualiza a futura exigência deste tipo de certificação.

Devido aos resultados obtidos, pode-se concluir que os mesmos fatores que motivam as empresas a buscar a certificação, impulsionam as empresas a se engajar em práticas como o DfE. Ou seja, as empresas com elevada orientação para o mercado e com uma função de operações mais pró-ativa são mais inclinadas a desenvolver capacidades que facilitam o desenvolvimento generalizado de diversas práticas de gestão ambiental no design de produtos e processos de produção, confirmando as conclusões de Gonzalez-Benito e Gonzalez-Benito (2008b). Esta similaridade, em relação à orientação para o mercado, pode ser verificada mediante a análise das motivações para o DfE (propostas por HUNT e AUSTER, 1990; PORTER e VAN DER LINDE, 1995; GOTTBERG et al., 2006; KIM et al., 2006; TINGSTRÖM e KARLSSON, 2006; BEVILACQUA, CIARAPICA e GIACCHETTA, 2007; CAGNO e TRUCCO, 2007; GE e WANG, 2007; CHOI, NIES e RAMANI, 2008; FITZGERALD, HERRMANN e SCHMIDT, 2010; JABBOUR, 2010) apontadas pelas empresas, que apesar de atuarem em mercados e contextos diferentes, apresentaram respostas bastante similares, considerando as diferenças relacionadas ao contexto mercadológico e legal, porte e nível de implementação do DfE, conforme o observado na Tabela 16.

Tabela 16 - Motivações para o DfE

\begin{tabular}{|c|c|c|}
\hline & Empresa $\mathrm{X}$ & Empresa Y \\
\hline \multirow{3}{*}{ Principais motivações } & $\begin{array}{c}\text { Intenção futura de } \\
\text { certificação pela RoHS }\end{array}$ & $\begin{array}{l}\text { A família fundadora da empresa é } \\
\text { ambientalista }\end{array}$ \\
\hline & Intenção de exportar & $\begin{array}{l}\text { Os clientes fazem analogia entre } \\
\text { sustentabilidade e empresa solidez }\end{array}$ \\
\hline & & Acionistas ambientalistas \\
\hline Pressão da Opinião Pública & $\begin{array}{l}\text { Por ter originado as } \\
\text { Diretivas Européias }\end{array}$ & A indústria papeleira é bastante visada \\
\hline Vantagem Competitiva & Devido ao Marketing & Devido ao Marketing \\
\hline Produtividade & Apesar dos trade-offs & Apesar dos trade-offs \\
\hline Melhoria da Imagem da Empresa & $\mathrm{O}$ & $\mathrm{O}$ \\
\hline Renovação do Mix de Produtos & $\mathrm{O}$ & $\mathrm{O}$ \\
\hline Acesso a Mercados Externos & $\mathrm{O}$ & $\mathrm{O}$ \\
\hline \multirow{2}{*}{$\begin{array}{l}\text { Atração de consumidores verdes } \\
\text { Aumento do Valor das Ações através da } \\
\text { inclusão da empresa no ISE }\end{array}$} & $\mathrm{O}$ & $\mathrm{O}$ \\
\hline & $x$ & $\mathrm{O}$ \\
\hline $\begin{array}{l}\text { Aumento do Valor das Ações através da } \\
\text { inclusão da empresa no DJSI }\end{array}$ & $x$ & $x$ \\
\hline Regulamentos mais rigorosos & $\mathrm{X}$ & $\mathrm{O}$ \\
\hline Redução de Multas Ambientais & $\mathrm{X}$ & $\mathrm{O}$ \\
\hline Proibição de Substâncias Perigosas & $\mathrm{X}$ & $\mathrm{O}$ \\
\hline Acesso a Novos Mercados & $x$ & Fitoterápicos \\
\hline $\begin{array}{l}\text { Exploração de Oportunidades de } \\
\text { Inovações em Produtos }\end{array}$ & $x$ & $\begin{array}{l}\text { Programa de Fitoterapia, papel para } \\
\text { embalagens TCF, Bag in Box, etc. }\end{array}$ \\
\hline Redução de Custos & $x$ & $\mathrm{O}$ \\
\hline Inovações em Processos & $x$ & $\begin{array}{c}\text { Especial destaque para os processos } \\
\text { de Produção e Logísticos }\end{array}$ \\
\hline Pressões dos consumidores & $\mathrm{X}$ & Clientes industriais \\
\hline \multirow{2}{*}{$\begin{array}{c}\text { Pressões da Cadeia de Suprimentos } \\
\text { Aumento da Qualidade em seus } \\
\text { Produtos }\end{array}$} & $\mathrm{X}$ & $\mathrm{X}$ \\
\hline & $x$ & $x$ \\
\hline
\end{tabular}

*Legenda: X - Não concorda; O - Concorda; o - Concorda moderadamente

Fonte: Elaborado pelo autor. 
Esta análise evidenciou que na empresa de grande porte, em estágio mais avançado de implementação do DfE, a própria cultura organizacional e a necessidade de transmitir uma imagem sólida aos seus clientes seriam as principais motivações. Já na empresa de pequeno porte em fase inicial de implementação do DfE, a certificação ambiental, no intuito de permitir uma maior facilidade de exportação de seus produtos seria a principal motivação.

Provavelmente devido a natureza da legislação ambiental brasileira, em relação aos Regulamentos mais rigorosos, apenas a Empresa $Y$ considera que esta seria uma motivação, enquanto a Empresa $X$ acredita que o mercado nacional ainda deve demorar a implementar tais normas. Neste sentido, a possibilidade de Regulamentos mais rigorosos no futuro, a Redução de Multas Ambientais e a Proibição de Substâncias Perigosas seriam motivações apenas para empresas que atuam em mercados onde a legislação ambiental é mais severa, pois foram apontados como motivações para o DfE apenas pela Empresa Y.

O ganho de Vantagem Competitiva (devido ao Marketing), a Produtividade (apesar dos tradeoffs de Produtividade), a Melhoria da Imagem da Empresa, a Renovação do Mix de Produtos, o Acesso a Mercados Externos e a Atração de consumidores ambientalmente conscientes estariam entre as motivações menos contingenciáveis, sendo apresentadas pelas duas empresas que atuam em mercados e contextos diferentes e apresentam diferentes níveis de implementação do DfE.

Da mesma forma, a Pressão da Opinião Pública também seria uma motivação menos contingencial, presente em mais de um contexto, apontada por ambas as empresas, ainda que por motivos diferentes (no caso da Empresa X, por ter originado as Diretivas Européias, e no caso da Empresa $\mathrm{Y}$, devido a indústria papeleira ser bastante vigiada).

O Aumento do Valor das Ações da empresa através da inclusão da empresa no ISE, bem como no DJSI, apontados apenas pela Empresa Y, parecem estar mais relacionados ao porte e tipo de constituição da empresa (capital aberto $X$ capital fechado), mas também pode-se afirmar que estejam relacionados a níveis mais altos de integração de aspectos ambientais nas empresas, visto que este tipo de índice costuma levar em consideração aspectos mais estratégicos, não se restringindo ao DfE.

O Acesso a Novos Mercados foi apontado como motivação apenas pela Empresa Y, devido a suas iniciativas com os Fitoterápicos. Neste sentido, a Empresa $Y$ também apresentou como motivação para o DfE a Exploração de Oportunidades de Inovações em Produtos, devido a diversos exemplos como o Programa de Fitoterapia, produtos como o papel para embalagens na cor creme, totalmente livre de cloro, o Bag in Box, etc. No entanto, pode-se concluir que fatores como porte e nível de integração de aspectos ambientais na empresa podem constituir diferenças importantes neste sentido, permitindo maiores investimentos nesta área. $O$ mesmo pode-se inferir ao fato de a Empresa $Y$ ter sido a única a apresentar a Redução de Custos como uma motivação para o DfE, já que a mesma implementa um número maior de estratégias do DfE, muito provavelmente, devido ao seu estágio de implementação do DfE.

Quanto às pressões dos consumidores, ambas afirmam que o consumidor final ainda não parece ter este tipo de visão, no entanto, a Empresa $Y$ apontou que clientes industriais como Avon, 
Natura e Tetra Pak, além do envio de questionários a respeito de suas práticas socioambientais, também estabelecem parcerias, como no caso da Planta de reciclagem de embalagens longa vida, em Piracicaba. Portanto, apenas a Empresa $Y$ apontou Pressões da Cadeia de Suprimentos como possíveis motivações para o DfE. Portanto, o Acesso a Novos Mercados, a Exploração de Oportunidades de Inovações em Produtos e Pressões da Cadeia de Suprimentos parecem ser motivações para o DfE contingenciáveis a fatores como porte e a níveis mais altos de integração de aspectos ambientais na empresa, bem como do DfE, permitindo maiores investimentos, inclusive em parcerias, e implementação de Estratégias do DfE nesta área.

O fato de implementar um número maior de estratégias do DfE também parece explicar o fato de a Exploração de Oportunidades de Inovações em Processos também ter sido apontada como motivação para o DfE pela Empresa $\mathrm{Y}$, com especial destaque para os processos de Produção e Logísticos. Já a Empresa X, apesar de não apontar a Exploração de Oportunidades de Inovações em Processos como motivação para o DfE, a inicial queda na produtividade dos processos com a implementação do Lead Free pode ter sido um dos gatilhos na aquisição da máquina de soldagem (que otimizou o processo e superou os processos em estanho-chumbo que ainda são feitos manualmente). Portanto, a Redução de Custos e, em menor medida, a Exploração de Oportunidades de Inovações em Processos seriam motivações para o DfE, para empresas em estágios mais avançados de implementação do DfE, pois implementam um número maior de estratégias do DfE.

A Pressão dos Consumidores e o Aumento da Qualidade em seus Produtos seriam motivações contingenciáveis em relação a diferentes tipos de mercado, ou Estratégias do DfE implementadas, visto que nenhuma das empresas a apontaram como motivação para o DfE. No entanto, seria interessante estender a pesquisa para mais empresas em setores de atuação diferentes para verificar a influência deste tipo de motivação. Esta pode ser apontada como uma das limitações do presente trabalho.

Interessante notar que nenhuma das empresas apresentou o Aumento da Qualidade em seus Produtos como motivação para o DfE, apesar de a automatização do processo de soldagem Lead Free na Empresa $X$ ter melhorado a qualidade do resultado final da soldagem. Ambas as empresas parecem fazer uma clara distinção entre os objetivos ambientais e os outros objetivos do PDP, incluindo-os como mais um requisito no processo, sem substituir os outros objetivos ou restringir as suas possibilidades de otimização (da mesma forma com que ocorre com os objetivos tradicionais). No entanto, além de estarem presentes entre os objetivos do PDP como apontado pela literatura (HUNT e AUSTER, 1990; PORTER e VAN DER LINDE, 1995; PUJARI e WRIGHT, 1999; BAUMANN, BOONS e BRAGD, 2002; NIELSEN e WENZEL, 2002; MAXWELL e VAN DER VORST, 2003; CAGNO e TRUCCO, 2007; LI et al., 2008; KUO, WU e SHIEH, 2009; MENGONI, GERMANI e MANDORLI, 2009; PIGOSSO et al., 2010) em ambas as empresas, na Empresa Y, os objetivos ambientais estão expressos no planejamento estratégico da empresa conforme defendido por diversos autores (ALTING e JOGENSEN, 1993; ANDERSSON et al., 1998; HANDFIELD et al., 2001; MAXWELL e VAN DER VORST, 2003) inclusive em seu código de conduta, enquanto que na Empresa $X$, estes objetivos não são expressos no planejamento estratégico da empresa, mas se encontram entre os objetivos da política de qualidade da empresa. 
Quanto à hipótese de que os objetivos ambientais devem ser integrados nas fases iniciais do PDP, defendida em diversos estudos (ALTING e JOGENSEN, 1993; ALTING, 1995; ZHANG, WANG e ZHANG, 1999; NIELSEN e WENZEL, 2002; FITCH e COOPER, 2005a; KOBAYASHI, 2005; KOBAYASHI et al., 2005; JOHANSSON, 2006; CAGNO e TRUCCO, 2007; LEE et al., 2007; GOTZCH, 2008; MASCLE e ZHAO, 2008; NY et al., 2008; WARDAK et al., 2008; WU, LO e HSU, 2008; RIOU e MASCLE, 2009; BOHM et al., 2010; DEVANATHAN et al., 2010; FITZGERALD, HERRMANN e SCHMIDT, 2010; PIGOSSO et al., 2010; RAMANI et al., 2010; VINODH e RATHOD, 2010a; VINODH e RATHOD, 2010b), a Empresa $Y$ afirma que os objetivos ambientais estão presentes na cultura organizacional, portanto, estão presentes em todos os processos de tomada de decisão. Portanto, em estágios mais avançados de implementação do DfE, estes objetivos já estariam integrados em todas as fases do PDP. Já a Empresa X, afirma que esta integração é feita antes da seleção de materiais e não impõe restrições às outras fases. Em relação a forma de integração de aspectos ambientais no PDP, é interessante notar que a Empresa $X$ classificou esse processo como Integração Paralela (ver ALTING e JOGENSEN, 1993; CAGNO e TRUCCO, 2007), já que os próprios projetistas realizam esta tarefa e os objetivos tradicionais não impõem restrições aos objetivos ambientais. A Empresa $\mathrm{Y}$, no entanto, verificou que este processo pode ser classificado como Integração em Série (ver ALTING e JOGENSEN, 1993; CAGNO e TRUCCO, 2007), já que os estudos ambientais também são realizados no setor ambiental da empresa; Integração Paralela, já que o pessoal de desenvolvimento está atento aos objetivos ambientais, e; Integração na forma de Check-points (ver HANDFIELD et al., 2001), já que após o desenvolvimento os produtos são avaliados ambientalmente.

Quanto aos fatores que impulsionam o direcionamento das estratégias do DfE, os Fluxos de informação e conhecimentos da sociedade (LEE, GEMBA e KODAMA, 2006) e dos funcionários (LEE, GEMBA e KODAMA, 2006; JABBOUR e SANTOS, 2008) parecem ser identificáveis independente de contexto mercadológico e nível de implementação do DfE. Aliás, em ambas as empresas, todos os funcionários são incentivados a trazer informações e sugestões de melhoria, tanto em relação aos aspectos ambientais quanto tradicionais nas empresas. Isto está em conformidade com as conclusões de Huang, Ding e Kao (2009), de que as empresas familiares são mais propensas a investir em práticas ambientalmente responsáveis, pois prestam muito mais atenção aos seus colaboradores internos do que as empresas não familiares. Em empresas de grande porte, em estágios mais avançados de implementação do DfE, ainda podem ser apontados os Fluxos de informação e conhecimentos de consumidores (conforme PUJARI e WRIGHT, 1999; TINGSTRÖM e KARLSSON, 2006), apontados somente pela Empresa $Y$, pois parcerias como a joint venture para reciclagem de embalagens longa vida, deixam visíveis estratégias como a troca de conhecimentos com os clientes industriais. A Empresa $Y$ também acrescentou os Fluxos de informação e conhecimentos da concorrência, obtidos através do Benchmarking Ambiental.

Em relação aos Métodos de Apoio ao DfE (apresentados na Tabela 17 e na Tabela 18), interessante notar que ambas as empresas, apesar de atuarem em contextos diferentes, não apontaram como Métodos de Apoio ao DfE o Estímulo à Criatividade (propostos por JOHANSSON e MAGNUSSON, 2006; NY et al., 2006; BYGGETH, BROMAN e ROBÈRT, 2007; VAN BERKEL, 2007; 
GOTZSCH, 2008; COLLADO-RUIZ e OSTAD-AHMAD-GHORABI, 2010b), a realização de Brainstormings (propostas por BYGGETH, BROMAN e ROBÈRT, 2007; NY et al., 2006) e Mudanças radicais nos produtos (propostas por FIKSEL, 2003; VACHON, 2007; VAN BERKEL, 2007; GOTZSCH, 2008; JABBOUR e SANTOS, 2008; BRAD, 2009; COLLADO-RUIZ e OSTAD-AHMADGHORABI, 2010B; JABBOUR, 2010; WALKER, 2010). Talvez a natureza dos mercados de atuação das empresas, papel e celulose e sensores eletrônicos, não permitam revelar este tipo de preocupação, já que são mercados onde as inovações radicais não fazem parte do cotidiano das empresas, já que ambas estão voltadas a produtos destinados a clientes industriais e grande parte da demanda por P\&D está voltada às solicitações destes clientes. No caso da Empresa $\mathrm{Y}$, ainda se verifica um índice mais alto de inovação nos produtos, devido à constante atividade de pesquisa em seus laboratórios e ao número de produtos lançados, ainda assim, a empresa não apontou os Métodos voltados a criatividade como importantes para o DfE. Portanto, os Métodos de Apoio ao DfE voltados a criatividade como o Estímulo à Criatividade, a realização de Brainstormings e Mudanças radicais nos produtos, parecem ser contingenciáveis a fatores como mercados de atuação, nível de implementação do DfE ou cultura organizacional, visto que nenhuma das empresas os apontou como importantes.

Tabela 17 - Métodos de apoio ao DfE - parte1

\begin{tabular}{|c|c|c|}
\hline & Empresa X & Empresa Y \\
\hline Estímulo à Criatividade & $\mathrm{X}$ & $\mathrm{X}$ \\
\hline Brainstormings & $\mathrm{X}$ & $\mathrm{X}$ \\
\hline Mudanças radicais nos produtos & $x$ & $\mathrm{X}$ \\
\hline Acesso a Guias Setoriais & $X$ & $X$ \\
\hline Acesso a informações ambientais no grupo & $X$ & $X$ \\
\hline Designers capacitados em DfE & $x$ & $\mathrm{X}$ \\
\hline $\begin{array}{l}\text { Um facilitador externo que leva a equipe multifuncional a considerar a } \\
\text { sustentabilidade }\end{array}$ & $\mathrm{X}$ & $\mathrm{X}$ \\
\hline Tecnologias de Informação & $\mathrm{X}$ & $\mathrm{X}$ \\
\hline Abordagem Ágil & $\mathrm{X}$ & $X$ \\
\hline Modularidade & $X$ & $X$ \\
\hline Integração com a Alta Administração & $\mathrm{O}$ & $\mathrm{O}$ \\
\hline Clara definição de papéis e responsabilidades & $\mathrm{O}$ & $\mathrm{O}$ \\
\hline Compras Verdes & $\mathrm{O}$ & $\mathrm{O}$ \\
\hline Mecanismos de Gestão do Conhecimento Ambiental & $\mathrm{O}$ & $\mathrm{O}$ \\
\hline Um Especialista Ambiental no PDP & $\mathrm{X}$ & $X$ \\
\hline Um Especialista Ambiental na empresa & $\mathrm{X}$ & $\mathrm{O}$ \\
\hline Integração do PDP com Especialistas Ambientais & $X$ & $\mathrm{O}$ \\
\hline $\begin{array}{c}\text { Mecanismos para a integração entre o pessoal de P\&D e os } \\
\text { especialistas ambientais }\end{array}$ & $\mathrm{X}$ & $\mathrm{O}$ \\
\hline Normas e diretrizes para o DfE & Diretrizes & $\mathrm{O}$ \\
\hline Treinamentos sobre o DfE & $\mathrm{O}$ & $X$ \\
\hline Estudos Piloto & $\mathrm{O}$ & $\mathrm{X}$ \\
\hline Estímulo à cooperação entre os diversos atores & $\mathrm{O}$ & 0 \\
\hline Engenharia Simultânea & $\mathrm{O}$ & $X$ \\
\hline Exposição a exemplos de casos de sucesso & $\mathrm{X}$ & $\mathrm{O}$ \\
\hline Tecnologias de Comunicação & $\mathrm{X}$ & $\mathrm{O}$ \\
\hline Disseminação do Conhecimento em sustentabilidade & $X$ & $\mathrm{O}$ \\
\hline Políticas de $\mathrm{RH}$ voltadas a dimensão ambiental & $\mathrm{X}$ & $\mathrm{O}$ \\
\hline
\end{tabular}

*Legenda: X - Não concorda; O - Concorda; o - Concorda moderadamente

Fonte: Elaborado pelo autor. 
Tabela 18 - Métodos de apoio ao DfE - parte 2

\begin{tabular}{|c|c|c|}
\hline & Empresa $\mathrm{X}$ & Empresa $Y$ \\
\hline $\begin{array}{l}\text { Integração do PDP com outros } \\
\text { departamento da empresa }\end{array}$ & $\begin{array}{l}\text { Marketing, Produção e } \\
\text { Processos }\end{array}$ & $\begin{array}{l}\text { Marketing, Produção, Logística, } \\
\text { Compras, Processos e Meio Ambiente }\end{array}$ \\
\hline $\begin{array}{c}\text { Integração do PDP com outras } \\
\text { entidades }\end{array}$ & $\begin{array}{c}\text { Fornecedores, } \\
\text { Certificadora e o GT Safety }\end{array}$ & $\begin{array}{c}\text { Clientes, Universidades e Entidades de } \\
\text { Pesquisa e os Aparistas }\end{array}$ \\
\hline Discussões sobre o DfE & Reuniões e treinamentos & $\begin{array}{c}\text { Casos de sucesso da empresa no } \\
\text { jornal interno }\end{array}$ \\
\hline $\begin{array}{c}\text { Comunicação com grupos de } \\
\text { interesse ou organizações de } \\
\text { apoio }\end{array}$ & $\begin{array}{l}\text { Colaboração com } \\
\text { fornecedores e o auditor da } \\
\text { certificadora }\end{array}$ & $\begin{array}{l}\text { Acionistas ambientalistas, Instituições e } \\
\text { pesquisa, joint venture com clientes, etc }\end{array}$ \\
\hline Benchmarking Ambiental & $\mathrm{O}$ & $\begin{array}{c}\text { Comparações de DBO, pegada de } \\
\text { carbono, relatórios ambientais de } \\
\text { concorrentes, etc. }\end{array}$ \\
\hline Equipes multifuncionais... & Projetos e processos & Projetos, processos e mercado \\
\hline $\begin{array}{l}\text {... com conhecimento da } \\
\text { estratégia da empresa } \\
\text {... com conhecimento das }\end{array}$ & $\mathrm{O}$ & $\mathrm{O}$ \\
\hline $\begin{array}{c}\text { questões relacionadas aos } \\
\text { produtos em todas as fases do } \\
\text { seu ciclo de vida }\end{array}$ & $\mathrm{O}$ & $\mathrm{O}$ \\
\hline $\begin{array}{c}\text {... com suficiente poder de } \\
\text { decisão a fim de realizar os } \\
\text { estágios particulares no âmbito } \\
\text { do DfE }\end{array}$ & 0 & 0 \\
\hline $\begin{array}{l}\text {... que membros alheios ao PDP } \\
\text { recebam informações sobre } \\
\text { como ocorre este processo }\end{array}$ & $x$ & $x$ \\
\hline $\begin{array}{c}\text { Avaliação de Desempenho dos } \\
\text { Designers/Projetistas atrelada ao } \\
\text { desempenho ambiental de seus } \\
\text { projetos }\end{array}$ & $\begin{array}{l}\text { Comprometimento com a } \\
\text { meta exerceria maior } \\
\text { impacto sobre os projetos }\end{array}$ & $\begin{array}{c}\text { Presente na Avaliação dos Gerentes e } \\
\text { Diretores (Cultura organizacional } \\
\text { exerceria um maior impacto sobre os } \\
\text { projetos) }\end{array}$ \\
\hline Ferramentas de Apoio ao DfE & Ainda não as possui & Complementar à cultura organizacional \\
\hline
\end{tabular}

Fonte: Elaborado pelo autor.

Outros Métodos de Apoio como o Acesso a Guias Setoriais, destacado por Bala et al. (2010), o Acesso a informações ambientais no grupo (conforme TINGSTRÖM, SWANSTROM e KARLSSON, 2006), Designers capacitados em DfE (conforme estabelecido por JOHANSSON, 2006; AZEVEDO e NOLASCO, 2009; DJASSEMI, 2009), a figura de um facilitador externo que leva a equipe multifuncional de representantes da empresa através de um procedimento para que os membros considerem a sustentabilidade (ver NY et al., 2006), Tecnologias de Informação (ver ALTING, 1995; GUNTHER, SEBASTIAN e MARCO, 2007; RIOU e MASCLE, 2009), a Abordagem Ágil (ver GUNGOR e GUPTA, 2001; LEIBRECHT, 2005; KARA, PORNPRASITPOL e KAEBERNICK, 2006; GIUDICE e FARGIONE, 2007; CHU et al., 2009; HARA et al., 2009; MENGONI, GERMANI e MANDORLI, 2009; RIOU e MASCLE, 2009; BOHM et al., 2010; VINODH, 2010) e a Modularidade (ver KUO, 2000; SAND, GU e WATSON, 2002; GUNTHER, SEBASTIAN e MARCO, 2007; LI et al., 2008; SELIGER e ZETTL, 2008; MENGONI, GERMANI e MANDORLI, 2009) também não foram apontados como importantes para o DfE nas empresas estudadas. Talvez o comprometimento com a meta (apontado pela Empresa X) e a cultura organizacional (apontada pela Empresa Y) impulsionem a equipe de $P \& D$ a suprir as necessidades por informações e a superar os obstáculos da integração 
dos aspectos ambientais de outras formas. Outra possibilidade é que em outros mercados de atuação ou em outros estágios de implementação do DfE, estes métodos venham a se tornar cruciais. Isto poderia indicar a necessidade de criação de um modelo contingencial de implementação do DfE levando em consideração, ao menos, estas duas variáveis (nível/estágio de implementação e mercado de atuação).

Os Mecanismos de Gestão do Conhecimento Ambiental, apontados por diversos estudos (ALTING e JOGENSEN, 1993; ALTING, 1995; HART, 1995; TIEN, CHUNG e TSAI, 2005; JOHANSSON, 2006; NY et al., 2006; TINGSTRÖM, SWANSTROM e KARLSSON, 2006; BYGGETH, BROMAN e ROBÈRT, 2007; GUNTHER, SEBASTIAN e MARCO, 2007; HOUE e GRABOT, 2007; KIVIMAA, 2008; NY et al., 2008; BOHM et al., 2010; FITZGERALD, HERMANN e SCHMIDT, 2010; KURCZEWSKI e LEWANDOWSKA, 2010; LEWANDOWSKA e KURCZEWSKI, 2010; TSENG, 2010a; TSENG, 2010b) foram apontados como, moderadamente, importantes por ambas as empresas. Neste sentido, também houve consenso em relação à grande importância da Integração do PDP com outros departamentos da empresa (conforme WESTKÄMPER, ALTING e ARNDT, 2000; FIKSEL, 2003; MAXWELL e VAN DER VORST, 2003; CHUNG e PENG, 2006; ABU BAKAR e RAHIMIFARD; 2007; EVANS, PARTIDARIO e LAMBERT, 2007; JOHANSSON, LUTO e FLEISCHER; 2007; GEHIN, ZWOLINSKI e BRISSAUD, 2008), com especial atenção na Empresa X para Marketing, Produção e Processos e, na Empresa Y, para Marketing, Produção, Logística, Compras, Processos e Meio Ambiente; da Integração do PDP com outras entidades conforme destaca a literatura (WESTKÄMPER, ALTING e ARNDT, 2000; FIKSEL, 2003; MAXWELL e VAN DER VORST, 2003; CHUNG e PENG, 2006; ABU BAKAR e RAHIMIFARD; 2007; EVANS, PARTIDARIO e LAMBERT, 2007; JOHANSSON, LUTO e FLEISCHER; 2007; GEHIN, ZWOLINSKI e BRISSAUD, 2008; MARX, DE PAULA e SUM, 2010), para a Empresa $Y$ os principais parceiros seriam Clientes, Universidades e Entidades de Pesquisa e os Aparistas, enquanto que na Empresa $X$ as principais fontes de colaboração seriam o relacionamento com fornecedores e com a Certificadora e a participação no GT Safety; das Discussões sobre o DfE (ver JOHANSSON e MAGNUSSON, 2006; LINDAHL, 2006; NY et al., 2006; BYGGETH, BROMAN e ROBÈRT, 2007; GUNTHER, SEBASTIAN e MARCO, 2007; GOTZSCH, 2008; KIVIMAA, 2008; NY et al., 2008; PIGOSSO et al., 2010) promovidas, na Empresa $Y$ através da publicação dos casos de sucesso da empresa no jornal interno, e na Empresa $X$, através de reuniões e treinamentos; da Comunicação com grupos de interesse relacionados ou organizações de apoio (conforme TIEN, CHUNG e TSAI, 2005; TINGSTRÖM, SWANSTROM e KARLSSON, 2006), na Empresa X, exemplos são a colaboração com fornecedores e o auditor da TÜV Rheinland, e na Empresa $Y$, exemplos são os contatos e parcerias com acionistas ambientalistas, Instituto Ethos, Universidades, joint venture com a Tetra Pak, Alcoa e TSL Ambiental para reciclagem de embalagens longa vida, etc.; e do Benchmarking Ambiental (proposto por KURCZEWSKI e LEWANDOWSKA, 2010; LEWANDOWSKA e KURCZEWSKI, 2010) onde a Empresa $Y$ já faz comparação de Demanda Bioquímica de Oxigênio (DBO), pegada de carbono (CO2) e relatórios ambientais de concorrentes, além de outras iniciativas. Estes parecem ser mais contingenciáveis em relação ao nível de implementação do DfE, visto que as estratégias envolvidas em cada Método mudam de empresa para empresa. No entanto, questões como porte e cultura organizacional também podem ser os 
condicionantes destas estratégias. Neste sentido, pesquisas voltadas a esta distinção seriam interessantes.

Também houve consenso em relação à grande importância da Integração com a Alta Administração conforme destaca a literatura (LINDAHL, 2006; TINGSTRÖM, SWANSTROM e KARLSSON, 2006; NY et al., 2008; VINODH, 2010); da Clara definição de papéis e responsabilidades (conforme JOHANSSON e MAGNUSSON, 2006; TINGSTRÖM, SWANSTROM e KARLSSON, 2006) e; das Compras Verdes (destacadas por ALTING, 1995; MAXWELL e VAN DER VORST, 2003; EVANS, PARTIDARIO e LAMBERT, 2007; LJUNGBERG, 2007; VACHON e KLASSEN, 2008; MARX, DE PAULA e SUM, 2010; YUAN e DORNFELD, 2010). O que pode indicar que estes métodos deveriam estar presentes em todos os níveis de implementação do DfE, independente de contexto industrial ou mercadológico, onde também não foram verificados indícios de influências como porte ou cultura.

Em relação às equipes multifuncionais utilizadas como um Método de Apoio ao DfE, as respostas também foram quase unanimes, já que ambas as empresas afirmaram a importância deste tipo de iniciativa. A única discrepância foi quanto aos integrantes destas equipes, onde ambas apontaram integrantes das áreas de projetos e processos, no entanto a Empresa $\mathrm{Y}$ incluiu a necessidade da presença de membros ligados a área de mercado. Houve consenso quanto a extrema importância de a equipe possuir conhecimento da estratégia da empresa (conforme KURCZEWSKI e LEWANDOWSKA, 2010; LEWANDOWSKA e KURCZEWSKI, 2010) e conhecimento das questões relacionadas com os produtos em todas as fases do seu ciclo de vida (destacado por KURCZEWSKI e LEWANDOWSKA, 2010; LEWANDOWSKA e KURCZEWSKI, 2010). Ambas as empresas apontaram uma importância moderada em relação a afirmação de que a equipe designada deve possuir suficiente poder de decisão a fim de realizar os estágios particulares no âmbito do DfE (proposta por KURCZEWSKI e LEWANDOWSKA, 2010; LEWANDOWSKA e KURCZEWSKI, 2010) e descartaram a necessidade de que os membros de equipe multifuncionais alheios ao PDP recebam informações sobre como ocorre este processo (ver BYGGETH, BROMAN e ROBÈRT, 2007).

As empresas também descartaram a necessidade de um Especialista Ambiental dentro da equipe do PDP (proposta por NY et al., 2008; KIVIMAA, 2008), o que pode indicar uma contingência para outros setores de atuação. No entanto, a Empresa $X$ não visualiza a necessidade de um Especialista Ambiental na empresa, enquanto que a Empresa $Y$ afirma a extrema importância de Especialistas Ambientais (conforme ALTING e JOGENSEN, 1993; HANDFIELD et al., 2001; BAUMANN, BOONS e BRAGD, 2002; JOHANSSON e MAGNUSSON, 2006; SCHMIDT e BUTT, 2006; NY et al., 2008; KIVIMAA, 2008) em todas as suas fábricas, bem como do pessoal de mercado e de processos. A Empresa $Y$ ainda aponta a extrema importância da Integração do PDP com Especialistas Ambientais (ver ALTING e JOGENSEN, 1993; HANDFIELD et al., 2001; BAUMANN, BOONS e BRAGD, 2002; JOHANSSON e MAGNUSSON, 2006; SCHMIDT e BUTT, 2006; NY et al., 2008; KIVIMAA, 2008) e acrescenta a extrema necessidade de integração dos gerentes de produtos com todas as áreas da empresa, afirmando também a necessidade de Mecanismos para a integração entre 0 pessoal de P\&D e os especialistas ambientais (proposta por HANDFIELD et al., 2001; KIVIMAA, 2008). Esta diferença entre as empresas pode ser auferida ao estágio de implementação 
do DfE e também ao porte das empresas, onde a Empresa $X$ supri as suas necessidades de informações com os parceiros da cadeia de suprimentos e não visualiza a necessidade de um setor ambiental (o investimento não se justificaria devido ao porte e estágio de implementação do DfE, onde a empresa ainda não realiza estudos ambientais como análises DBO, pegada de carbono, etc.). Portanto, a extrema importância de um Especialista Ambiental na empresa, da Integração do PDP com Especialistas Ambientais e de Mecanismos para a integração entre o pessoal de P\&D e os Especialistas Ambientais, parece ser verificável em empresas de grande porte, em estágios mais avançados de implementação do DfE e/ou da integração de aspectos ambientais na empresa. Neste contexto, na conjuntura observada, empresas de pequeno porte supririam as suas necessidades de informações ambientais com os parceiros da cadeia de suprimentos.

Em relação à necessidade de Normas e diretrizes para apoiar o uso eficiente dos métodos e/ou ferramentas ambientais (proposta por ALTING, 1995), a Empresa $Y$ apontou como de extrema importância, enquanto que a Empresa $X$ aponta uma importância moderada para a criação de Diretrizes neste sentido. Se a cultura organizacional da Empresa $Y$ já possui os aspectos ambientais, então mais uma vez, parece que as diferenças entre o porte e o nível de implementação do DfE das organizações estejam contingenciando as respostas.

A extrema importância atribuída pela Empresa $X$ aos Treinamentos sobre o DfE (propostos por ALTING e JOGENSEN, 1993; ALTING, 1995; SCHMIDT e BUTT, 2006; NY et al., 2008) e a realização de Estudos Piloto (conforme ALTING, 1995; JOHANSSON e MAGNUSSON, 2006; NY et al., 2006; BYGGETH, BROMAN e ROBÈRT, 2007), parece estar atrelada ao seu estágio inicial de implementação do DfE, visto que a Empresa $Y$ sequer os apontou como importantes, mesmo que moderadamente. Neste sentido, a Empresa $X$ também revelou considerar de extrema importância o Estímulo à cooperação entre os diversos atores (proposto por HART, 1995; BYGGETH, BROMAN e ROBÈRT, 2007; EVANS, PARTIDARIO e LAMBERT, 2007; CHALAL e GHOMARI, 2008; NY et al., 2008) enquanto a Empresa $Y$ atribui importância moderada a este tipo de prática. Portanto, pode-se concluir que determinados Métodos de Apoio ao DfE seriam mais importantes em estágios iniciais, e, conforme a empresa e o PDP vão absorvendo os aspectos ambientais, estes vão sendo substituídos por outros Métodos voltados a reafirmação destes aspectos na cultura organizacional.

Neste sentido, a Exposição a exemplos de casos de sucesso (conforme SCHMIDT, 2003; FITZGERALD, HERMANN e SCHMIDT, 2010), as Tecnologias de Comunicação (ver GUNTHER, SEBASTIAN e MARCO, 2007; RIOU e MASCLE, 2009), a Disseminação do Conhecimento em sustentabilidade (proposta por TIEN, CHUNG e TSAI, 2005; NY et al., 2006; BYGGETH, BROMAN e ROBÈRT, 2007; GUNTHER, SEBASTIAN e MARCO, 2007; KURCZEWSKI e LEWANDOWSKA, 2010; LEWANDOWSKA e KURCZEWSKI, 2010), as Políticas de RH voltadas a dimensão ambiental (conforme HANDFIELD et al., 2001; JABBOUR e SANTOS, 2008) parecem ser Métodos de Apoio ao DfE, voltados a reafirmação de aspectos ambientais na cultura organizacional, e seriam contingenciáveis ao estágio de implementação do DfE e/ou ao porte da empresa, pois foram apontados como muito importantes apenas pela empresa de grande porte em estágio avançado de implementação do DfE. 
Ainda em relação às Políticas de $\mathrm{RH}$ voltadas a dimensão ambiental (propostas por HANDFIELD et al., 2001; JABBOUR e SANTOS, 2008), a Empresa $Y$ afirma que o Setor de RH é que promove o jornal interno da empresa e outras políticas de Endomarketing. Também é no RH onde os novos funcionários recebem os treinamentos sobre as políticas ambientais da Empresa $\mathrm{Y}$, reafirmando a cultura organizacional voltada à responsabilidade ambiental. Portanto, as Políticas de $\mathrm{RH}$ voltadas a dimensão ambiental, também parecem ser importantes Métodos de Apoio ao DfE para empresas de grande porte e/ou em estágios mais avançados de implementação do DfE, pois auxiliam a condicionar a cultura organizacional voltada aos aspectos ambientais, o que em empresas de pequeno porte e/ou em fases iniciais de implementação do DfE é realizado de outras formas, como as reuniões e treinamentos.

Em relação à Avaliação de Desempenho dos Designers/Projetistas atrelada ao desempenho ambiental de seus projetos (conforme HANDFIELD et al., 2001), a Empresa $Y$ afirmou que os Gerentes e Diretores são avaliados por 6 competências onde se refletem os objetivos ambientais, no entanto, segundo a empresa, a cultura organizacional exerceria um maior impacto sobre os projetos. E nenhuma das duas empresas apresentou este tipo de método como importante para o DfE, onde a Empresa $X$ afirmou que o comprometimento com a meta exerceria maior impacto sobre os projetos. Entretanto, isto poderia indicar, mais uma vez, que em empresas de grande porte e em níveis mais avançados do DfE, devem existir normas e diretrizes para reafirmação da cultura organizacional.

Já a alta importância atribuída a Engenharia Simultânea (proposta por NY et al., 2006; BYGGETH, BROMAN e ROBÈRT, 2007; CAGNO e TRUCCO, 2007; LEE et al., 2007; CHALAL e GHOMARI, 2008; JIANJUN et al., 2008; BRAD, 2009; HARA et al., 2009; RIOU e MASCLE, 2009) pela Empresa $X$, pode revelar uma contingência em relação ao setor de atuação, visto que a Empresa $\mathrm{Y}$, não apontou este método como importante para o DfE.

Quanto às Ferramentas de Apoio ao DfE (conforme HANDFIELD et al., 2001; MAXWELL e VAN DER VORST, 2003; LINDAHL, 2006; NY et al., 2006; SOUSA e WALLACE, 2006; TINGSTRÖM, SWANSTROM e KARLSSON, 2006; BYGGETH, BROMAN e ROBÈRT, 2007; CAGNO e TRUCCO, 2007; STAIKOS e RAHIMIFARD, 2007; ALMEIDA et al., 2010; PIGOSSO et al., 2010), a Empresa $X$ afirmou que seriam um facilitador, no entanto, a empresa ainda não as possui. A Empresa $Y$ possui diversos softwares para o redesenho de estradas entre as plantações de eucalipto, de roteirização logística, de conjugação dos pedidos no sistema de produção, etc. No entanto, a Empresa Y aponta a utilização de ferramentas de apoio como complementar à cultura organizacional, à vigilância do sistema e à parceria do pessoal de Qualidade e Meio Ambiente. Neste sentido, pode se afirmar que estas podem auxiliar o processo, mas não foram apontadas como de extrema importância, já que sem um comprometimento com o DfE, estas não seriam nem ao menos adquiridas e/ou desenvolvidas. Portanto, parece que as Ferramentas de Apoio estariam presentes nos estágios mais avançados do DfE, muito mais como ferramentas auxiliares do que como um facilitador do DfE.

Em relação às Ferramentas utilizadas no PDP (Tabela 19), algumas conclusões puderam ser inferidas. A Empresa $X$ não utiliza ferramentas para o DfE e a Empresa $Y$ utiliza um Formulário sobre Aspectos Ambientais na primeira fase dos projetos. Com o estudo sobre as ferramentas utilizadas no PDP pelas duas empresas, pôde-se verificar se as exigências impostas às Ferramentas de Apoio ao 
DfE pela literatura, são equivalentes as das ferramentas tradicionais. $\mathrm{Na}$ Empresa $\mathrm{X}$ e na Empresa $\mathrm{Y}$ somente a ferramenta III fornece informações para decisões de trade-offs Tradicionais (conforme ZHANG, WANG e ZHANG, 1999; KHAN, SADIQ e VEITCH, 2004; KOBAYASHI, 2005; KOBAYASHI et al., 2005; LEIBRECHT, 2005; RUDENAUER et al., 2005; NY et al., 2006; SCHMIDT e BUTT, 2006; XU, CHEN e XIE, 2006; BYGGETH, BROMAN e ROBÈRT, 2007; CAGNO e TRUCCO, 2007; STAIKOS e RAHIMIFARD, 2007; CHOI, NIES E RAMANI, 2008; LI et al., 2008; WU, LO e HSU, 2008; HARA et al., 2009; KUO, WU e SHIEH, 2009; ALMEIDA et al., 2010; BOHM et al., 2010; DEVANATHAN et al., 2010; PALOUSIS, LUONG e ABHARY, 2010; VINODH, 2010).

Tabela 19 - Ferramentas utilizadas no PDP

\begin{tabular}{|c|c|c|c|c|c|c|c|c|c|c|c|}
\hline & \multicolumn{4}{|c|}{ Empresa X } & \multicolumn{7}{|c|}{ Empresa Y } \\
\hline & $\mathrm{I}$ & II & III & IV & $\mathrm{I}$ & II & III & IV & $\mathrm{V}$ & $\mathrm{VI}$ & VII \\
\hline É Rápida & 0 & 0 & $\mathrm{O}$ & $\mathrm{O}$ & 0 & 0 & $\mathrm{O}$ & $\mathrm{O}$ & $\mathrm{O}$ & 0 & $\mathrm{O}$ \\
\hline Adaptável às tarefas do dia-a-dia do PDP & $\mathrm{O}$ & $\mathrm{O}$ & $\mathrm{O}$ & $\mathrm{O}$ & $\mathrm{O}$ & $\mathrm{O}$ & $\mathrm{O}$ & $\mathrm{O}$ & $\mathrm{O}$ & $\mathrm{O}$ & $\mathrm{O}$ \\
\hline Integrada ao processo de tomada de decisão & $\mathrm{O}$ & $\mathrm{O}$ & $\mathrm{O}$ & $\mathrm{O}$ & O & $\mathrm{O}$ & $\mathrm{O}$ & $\mathrm{O}$ & $\mathrm{O}$ & $\mathrm{O}$ & $\mathrm{O}$ \\
\hline Obtentora de bons resultados & $\mathrm{O}$ & $\mathrm{O}$ & $\mathrm{O}$ & O & $\mathrm{O}$ & $\mathrm{O}$ & $\mathrm{O}$ & $\mathrm{O}$ & $\mathrm{O}$ & $\mathrm{O}$ & O \\
\hline Exige conhecimento e experiência do usuário & $\mathrm{O}$ & $\mathrm{O}$ & $\mathrm{O}$ & $\mathrm{O}$ & $\mathrm{O}$ & $\mathrm{O}$ & $\mathrm{O}$ & $\mathrm{O}$ & $\mathrm{O}$ & $\mathrm{O}$ & $\mathrm{O}$ \\
\hline Reduz custos & $\mathrm{O}$ & $\mathrm{O}$ & $\mathrm{O}$ & $\mathrm{O}$ & O & $\mathrm{O}$ & $\mathrm{O}$ & $\mathrm{O}$ & O & $\mathrm{O}$ & $\mathrm{O}$ \\
\hline $\begin{array}{l}\text { Projetos simples ou complexos } \\
\text { Esta integrada... }\end{array}$ & $\mathrm{O}$ & $\mathrm{O}$ & $\mathrm{O}$ & $\mathrm{O}$ & $\mathrm{O}$ & $\mathrm{O}$ & $\mathrm{O}$ & $\mathrm{O}$ & $\mathrm{O}$ & $\mathrm{O}$ & $\mathrm{O}$ \\
\hline$\rightarrow$ a ferramentas de outros setores da empresa & $\mathrm{X}$ & $\mathrm{X}$ & $\mathrm{O}$ & $\mathrm{X}$ & O & $\mathrm{O}$ & $\mathrm{O}$ & $\mathrm{O}$ & $\mathrm{O}$ & $\mathrm{O}$ & $\mathrm{O}$ \\
\hline$\rightarrow$ a outras ferramentas do PDP & $\mathrm{X}$ & $\mathrm{X}$ & $\mathrm{x}$ & $x$ & $\mathrm{O}$ & $\mathrm{O}$ & $\mathrm{O}$ & $\mathrm{O}$ & $\mathrm{O}$ & $\mathrm{O}$ & $\mathrm{O}$ \\
\hline$\rightarrow$ ao Design Assistido por Computador & $\mathrm{X}$ & $\mathrm{X}$ & $\mathrm{X}$ & $\mathrm{X}$ & $\mathrm{O}$ & $\mathrm{O}$ & $\mathrm{O}$ & $\mathrm{O}$ & $\mathrm{O}$ & $\mathrm{O}$ & $\mathrm{O}$ \\
\hline$\rightarrow$ a outros setores da empresa & $X$ & $\mathrm{X}$ & $\mathrm{X}$ & $\mathrm{X}$ & O & $\mathrm{O}$ & $\mathrm{O}$ & $\mathrm{O}$ & $\mathrm{O}$ & $\mathrm{O}$ & $\mathrm{O}$ \\
\hline $\begin{array}{c}\rightarrow \text { aos parceiros da cadeia de suprimentos } \\
\text { Facilita a troca de informações }\end{array}$ & $x$ & $\mathrm{O}$ & $\mathrm{O}$ & $X$ & $\mathrm{O}$ & $\mathrm{O}$ & $\mathrm{O}$ & $\mathrm{O}$ & $\mathrm{O}$ & $\mathrm{O}$ & $\mathrm{O}$ \\
\hline$\rightarrow$ entre as fases do PDP & $\mathrm{X}$ & $\mathrm{O}$ & $\mathrm{O}$ & $\mathrm{X}$ & O & $\mathrm{O}$ & $\mathrm{O}$ & $\mathrm{O}$ & $\mathrm{O}$ & $\mathrm{O}$ & $\mathrm{O}$ \\
\hline$\rightarrow$ entre as ferramentas do PDP & $x$ & $\mathrm{X}$ & $\mathrm{X}$ & $\mathrm{X}$ & $\mathrm{O}$ & $\mathrm{O}$ & 0 & $\mathrm{O}$ & $\mathrm{O}$ & $\mathrm{O}$ & $\mathrm{O}$ \\
\hline$\rightarrow$ com outros setores da empresa & $\mathrm{X}$ & $x$ & $x$ & $\mathrm{X}$ & O & $\mathrm{O}$ & $\mathrm{O}$ & $\mathrm{O}$ & $\mathrm{O}$ & $\mathrm{O}$ & $\mathrm{O}$ \\
\hline$\rightarrow$ com os parceiros da cadeia de suprimentos & $\mathrm{X}$ & $\mathrm{X}$ & $\mathrm{X}$ & $\mathrm{X}$ & O & $\mathrm{O}$ & $\mathrm{O}$ & $\mathrm{O}$ & O & $\mathrm{O}$ & $\mathrm{O}$ \\
\hline É de utilização obrigatória & $\mathrm{X}$ & $\mathrm{O}$ & $\mathrm{O}$ & $\mathrm{X}$ & O & $\mathrm{O}$ & $\mathrm{O}$ & $\mathrm{O}$ & O & $\mathrm{O}$ & $\mathrm{O}$ \\
\hline Aborda as necessidades dos clientes & $\mathrm{X}$ & $\mathrm{O}$ & $\mathrm{O}$ & $\mathrm{X}$ & O & $\mathrm{O}$ & $\mathrm{O}$ & $\mathrm{O}$ & $\mathrm{O}$ & $\mathrm{O}$ & $\mathrm{O}$ \\
\hline Aborda outros objetivos do PDP & $\mathrm{X}$ & $\mathrm{O}$ & $\mathrm{O}$ & $\mathrm{X}$ & $\mathrm{O}$ & $\mathrm{O}$ & $\mathrm{O}$ & $\mathrm{O}$ & $\mathrm{O}$ & $\mathrm{O}$ & $\mathrm{O}$ \\
\hline Reduz tempo & $x$ & $\mathrm{O}$ & O & $x$ & $\mathrm{O}$ & $\mathrm{O}$ & $\mathrm{O}$ & $\mathrm{O}$ & O & $\mathrm{O}$ & $\mathrm{O}$ \\
\hline É constantemente atualizada & $x$ & * & * & $x$ & / & l & l & l & l & l & / \\
\hline Possui banco de dados... & $x$ & $\mathrm{O}$ & $\mathrm{O}$ & $x$ & $\mathrm{O}$ & $\mathrm{O}$ & $\mathrm{O}$ & $\mathrm{O}$ & O & $\mathrm{O}$ & $\mathrm{O}$ \\
\hline ... que é customizado & $x$ & * & * & $x$ & / & l & / & l & l & l & / \\
\hline ... e constantemente atualizado & $x$ & * & * & $\mathrm{X}$ & / & / & / & / & 1 & / & / \\
\hline Quem escolheu/comprou/desenvolveu? & $\mathrm{X}$ & $\S !$ & {[} & $\mathrm{X}$ & $\&$ & $\&$ & $\&$ & $\&$ & $\&$ & $\&$ & $\&$ \\
\hline Fornece informações para decisões de trade-offs & $\mathrm{X}$ & $x$ & $\mathrm{~T}$ & $\mathrm{X}$ & $x$ & $\mathrm{X}$ & $\mathrm{T}$ & $x$ & $x$ & $\mathrm{X}$ & $\mathrm{X}$ \\
\hline Demanda extensos treinamentos & $x$ & $x$ & $\mathrm{X}$ & $\mathrm{X}$ & $\mathrm{O}$ & $\mathrm{O}$ & $\mathrm{O}$ & $\mathrm{O}$ & $\mathrm{O}$ & $\mathrm{O}$ & $\mathrm{O}$ \\
\hline É simples & $X$ & $\mathrm{X}$ & $\mathrm{X}$ & $\mathrm{X}$ & $\mathrm{O}$ & $\mathrm{O}$ & $\mathrm{O}$ & $\mathrm{O}$ & $\mathrm{O}$ & $\mathrm{O}$ & $\mathrm{O}$ \\
\hline É de fácil utilização & $\mathrm{X}$ & $\mathrm{X}$ & $\mathrm{X}$ & $\mathrm{X}$ & $\mathrm{O}$ & $\mathrm{O}$ & $\mathrm{O}$ & $\mathrm{O}$ & O & $\mathrm{O}$ & $\mathrm{O}$ \\
\hline Tornam o DfE mais ágil & $x$ & $\mathrm{X}$ & $\mathrm{X}$ & $\mathrm{X}$ & $\mathrm{O}$ & $\mathrm{O}$ & $\mathrm{O}$ & $\mathrm{O}$ & $\mathrm{O}$ & $\mathrm{O}$ & $\mathrm{O}$ \\
\hline Aborda a disposição a pagar do consumidor & $x$ & $\mathrm{X}$ & $\mathrm{X}$ & $X$ & $\mathrm{O}$ & $\mathrm{O}$ & $\mathrm{O}$ & $\mathrm{O}$ & $\mathrm{O}$ & $\mathrm{O}$ & $\mathrm{O}$ \\
\hline Aborda os custos do ciclo de vida & $\mathrm{X}$ & $\mathrm{x}$ & $\mathrm{X}$ & $\mathrm{X}$ & $\mathrm{O}$ & $\mathrm{O}$ & $\mathrm{O}$ & $\mathrm{O}$ & $\mathrm{O}$ & $\mathrm{O}$ & $\mathrm{O}$ \\
\hline Aborda aspectos sociais do ciclo de vida & $\mathrm{X}$ & $x$ & $\mathrm{X}$ & $\mathrm{X}$ & $x$ & $\mathrm{O}$ & $\mathrm{O}$ & $\mathrm{O}$ & $x$ & $x$ & $\mathrm{X}$ \\
\hline É uma lista de verificação & $X$ & $x$ & $\mathrm{X}$ & $\mathrm{X}$ & $x$ & $\mathrm{X}$ & $X$ & $x$ & $x$ & $\mathrm{O}$ & $\mathrm{X}$ \\
\hline Aborda os aspectos ambientais do ciclo de vida & $\mathrm{X}$ & $\mathrm{x}$ & $\mathrm{X}$ & $\mathrm{X}$ & $x$ & $\mathrm{X}$ & $\mathrm{X}$ & $x$ & $\mathrm{O}$ & & $\mathrm{X}$ \\
\hline É qualitativa & - & - & - & - & - & - & - & - & $\mathrm{O}$ & - & - \\
\hline É destinada a obtenção de rótulos ecológicos & - & - & - & - & - & - & - & - & $x$ & - & - \\
\hline $\begin{array}{c}\text { Disponibiliza fóruns para idéias, sucessos e insucessos } \\
\text { (Ferramenta de gestão do conhecimento) }\end{array}$ & $\mathrm{X}$ & $\mathrm{X}$ & $\mathrm{X}$ & $\mathrm{X}$ & $\mathrm{X}$ & $x$ & $X$ & $x$ & $x$ & $x$ & 0 \\
\hline
\end{tabular}

Fonte: Elaborado pelo autor. 
Na Empresa $X$ e na Empresa $Y$ todas as ferramentas utilizadas no PDP foram consideradas rápidas (conforme GUNGOR e GUPTA, 2001; HANDFIELD et al., 2001; NIELSEN e WENZEL, 2002; KOBAYASHI, 2005; KOBAYASHI et al., 2005; LINDAHL, 2006; TINGSTRÖM, SWANSTROM e KARLSSON, 2006; WU, LO e HSU, 2008; BALA et al., 2010; BOHM et al., 2010; SONG e LEE, 2010), adaptáveis as tarefas do dia-a-dia do PDP (proposto por HANDFIELD et al., 2001; NIELSEN e WENZEL, 2002; LINDAHL, 2006; SCHMIDT e BUTT, 2006; TINGSTRÖM, SWANSTROM e KARLSSON, 2006; ALMEIDA et al., 2010; BALA et al., 2010), integradas ao processo de tomada de decisão (destacado por ZHANG, WANG e ZHANG, 1999; KHAN, SADIQ e VEITCH, 2004; KOBAYASHI, 2005; KOBAYASHI et al., 2005; LEIBRECHT, 2005; RUDENAUER et al., 2005; NY et al., 2006; SCHMIDT e BUTT, 2006; XU, CHEN e XIE, 2006; BYGGETH, BROMAN e ROBÈRT, 2007; CAGNO e TRUCCO, 2007; STAIKOS e RAHIMIFARD, 2007; CHOI, NIES E RAMANI, 2008; JIANJUN et al., 2008; LI et al., 2008; WU, LO e HSU, 2008; HARA et al., 2009; KUO, WU e SHIEH, 2009; ALMEIDA et al., 2010; BOHM et al., 2010; DEVANATHAN et al., 2010; PALOUSIS, LUONG e ABHARY, 2010; VINODH, 2010) e obtentoras de bons resultados (conforme HANDFIELD et al., 2001; BAUMANN, BOONS e BRAGD; 2002; LINDAHL, 2006; SCHMIDT e BUTT, 2006; TINGSTRÖM, SWANSTROM e KARLSSON, 2006; GOTZSCH, 2008; JIANJUN et al., 2008; SCHIAVONE, PIERINI e ECKERT, 2008; VINODH, 2010), mas exigem conhecimento e experiência do usuário (proposto por ALTING e JOGENSEN, 1993; BOKS, 2006; DJASSEMI, 2009; KURCZEWSKI e LEWANDOWSKA, 2010; LEWANDOWSKA e KURCZEWSKI, 2010). Em contrapartida, todas reduzem custos (ver PIGOSSO et al., 2010) e podem ser utilizadas em projetos simples ou complexos (destacado por ALTING, 1995; JOHANSSON, 2006).

$\mathrm{Na}$ Empresa $\mathrm{X}$, somente a ferramenta III, e na Empresa $\mathrm{Y}$, todas as ferramentas estão integradas a ferramentas de outros setores da empresa (conforme MAXWELL e VAN DER VORST, 2003; SCHMIDT e BUTT, 2006; BYGGETH, BROMAN e ROBÈRT, 2007; JIANJUN et al., 2008; VINODH, 2010). Na verdade, na Empresa $Y$ a ferramenta VII integra todas as ferramentas do PDP entre si (destacado por ZHANG, WANG e ZHANG, 1999; KOBAYASHI, 2005; KOBAYASHI et al., 2005; SCHMIDT e BUTT, 2006; XU, CHEN e XIE, 2006; CAGNO e TRUCCO, 2007; LEE et al., 2007; SINGH, GOODYER e POPPLEWELL, 2007; LI et al., 2008; JIANJUN et al., 2008; BRAD, 2009; MENGONI, GERMANI e MANDORLI, 2009; RIOU e MASCLE, 2009; DEVANATHAN et al., 2010; VINODH, 2010; VINODH e RATHOD, 2010a), ao Design Assistido por Computador (conforme MAXWELL e VAN DER VORST, 2003; LEIBRECHT, 2005; BYGGETH, BROMAN e ROBÈRT, 2007; JIANJUN et al., 2008; CHU et al., 2009; MENGONI, GERMANI e MANDORLI, 2009; VINODH, 2010), com outros setores da empresa (apoiado por MAXWELL e VAN DER VORST, 2003; JIANJUN et al., 2008) facilitando a troca de informações (conforme ZHANG, WANG e ZHANG, 1999; KOBAYASHI, 2005; KOBAYASHI et al., 2005; SCHMIDT e BUTT, 2006; XU, CHEN e XIE, 2006; CAGNO e TRUCCO, 2007; LEE et al., 2007; SINGH, GOODYER e POPPLEWELL, 2007; GOTZSCH, 2008; JIANJUN et al., 2008; LI et al., 2008; JIANJUN et al., 2008; SCHIAVONE, PIERINI e ECKERT, 2008; BRAD, 2009; MENGONI, GERMANI e MANDORLI, 2009; RIOU e MASCLE, 2009; DEVANATHAN et 
al., 2010; VINODH, 2010; VINODH e RATHOD, 2010a). A ferramenta ainda disponibiliza fóruns para idéias, sucessos e insucessos, funcionando como uma ferramenta de gestão do conhecimento.

Na Empresa $Y$, todas e, na Empresa $X$, somente as ferramentas II e III são de utilização obrigatória (conforme TINGSTRÖM, SWANSTROM e KARLSSON, 2006), facilitam a troca de informações (proposto por ZHANG, WANG e ZHANG, 1999; KOBAYASHI, 2005; KOBAYASHI et al., 2005; SCHMIDT e BUTT, 2006; XU, CHEN e XIE, 2006; CAGNO e TRUCCO, 2007; LEE et al., 2007; SINGH, GOODYER e POPPLEWELL, 2007; GOTZSCH, 2008; JIANJUN et al., 2008; LI et al., 2008; JIANJUN et al., 2008; SCHIAVONE, PIERINI e ECKERT, 2008; BRAD, 2009; MENGONI, GERMANI e MANDORLI, 2009; RIOU e MASCLE, 2009; DEVANATHAN et al., 2010; VINODH, 2010; VINODH e RATHOD, 2010a) entre as fases do PDP, estão integradas aos parceiros da cadeia de suprimentos (conforme HART, 1995; FRYXELL e VRYZA, 1999; WESTKÄMPER, ALTING e ARNDT, 2000; DE BAKKER e NIJHOF, 2002; FIKSEL, 2003; MAXWELL e VAN DER VORST, 2003; PUJARI, WRIGHT e PEATTIE, 2003; ZHU e SARKIS, 2004; PUJARI, 2006; SAVASKAN e VAN WASSENHOVE, 2006; ABU BAKAR e RAHIMIFARD; 2007; BYGGETH, BROMAN e ROBÈRT, 2007; CAGNO e TRUCCO, 2007; EVANS, PARTIDARIO e LAMBERT, 2007; GE e WANG, 2007; JOHANSSON, LUTO e FLEISCHER; 2007; WAAGE, 2007; CHALAL e GHOMARI, 2008; GEHIN, ZWOLINSKI e BRISSAUD, 2008; GOTZSCH, 2008; JIANJUN et al., 2008; KURK e EAGAN, 2008; VACHON e KLASSEN, 2008; ZACKRISSON et al., 2008; KNIGHT e JENKINS, 2009; KOEHLER e WILDBOLZ, 2009; MENGONI, GERMANI e MANDORLI, 2009; RIOU e MASCLE, 2009; LEWANDOWSKA e KURCZEWSKI, 2010; RAMANI et al., 2010; TSENG, 2010a), podem ser abastecidas com restrições como as necessidades dos clientes (destacado por KOBAYASHI et al., 2005; RUDENAUER et al., 2005; BOVEA e WANG, 2007; CHALAL e GHOMARI, 2008; KUO, WU e SHIEH, 2009; LEWANDOWSKA e KURCZEWSKI, 2010; PIGOSSO et al., 2010), abordam diversos objetivos do PDP (defendido por SHU e FLOWERS, 1999; ZHANG, WANG e ZHANG, 1999; MANGUN e THURSTON, 2002; OKUMURA, MORIKUNI e OKINO, 2003; KHAN, SADIQ e VEITCH, 2004; KOBAYASHI, 2005; KOBAYASHI et al., 2005; RUDENAUER et al., 2005; XU, CHEN e XIE, 2006;BOVEA e WANG, 2007; CAGNO e TRUCCO, 2007; GIUDICE e FARGIONE, 2007; STAIKOS e RAHIMIFARD, 2007; SINGH, GOODYER e POPPLEWELL, 2007; CHALAL e GHOMARI, 2008; CHOI, NIES E RAMANI, 2008; JIANJUN et al., 2008; LI et al., 2008; WU, LO e HSU, 2008; BRAD, 2009; HARA et al., 2009; KUO, WU e SHIEH, 2009; MENGONI, GERMANI e MANDORLI, 2009; RIOU e MASCLE, 2009; DEVANATHAN et al., 2010; LUH, CHU e PAN, 2010; PALOUSIS, LUONG e ABHARY, 2010; VINODH e RATHOD, 2010a), reduzem tempo (PIGOSSO et al., 2010), são constantemente atualizadas (conforme proposto por NY et al., 2006; SCHMIDT e BUTT, 2006; BYGGETH, BROMAN e ROBÈRT, 2007) (pelo Responsável de TI na Empresa X e pelos Gestores de P\&D na Empresa Y), possuem banco de dados (ver ALTING, 1995) que é customizado (conforme ALTING e JOGENSEN, 1993; ALTING, 1995) e constantemente atualizado (defendido por NY et al., 2006; SCHMIDT e BUTT, 2006; BYGGETH, BROMAN e ROBÈRT, 2007) (em conjunto pelos usuários e o pessoal de TI, na Empresa X e pelos Gestores de P\&D, na Empresa Y).

Na Empresa X, a implementação da ferramenta II foi demandada por clientes e pela WEG após a incorporação e a ferramenta III foi escolhida pelos próprios usuários (projetistas). Na Empresa 
$\mathrm{Y}$, as ferramentas são desenvolvidas em parceria entre o fornecedor, equipe de $\mathrm{P} \& \mathrm{D}$, setor de suprimentos e o setor de $\mathrm{TI}$ da empresa. Dessa forma, também pode-se concluir que a escolha (conforme LINDAHL, 2006) ou desenvolvimento (proposto por SCHMIDT e BUTT, 2006) das Ferramentas de Apoio ao DfE, não precisaria ser feita somente pelos próprios Designers/Projetistas, no entanto, estes deveriam estar comprometidos com a meta de implementação (conforme postulado por ambas as empresas). Portanto, a hipótese postulada por Schmidt e Butt (2006), de que seria necessário deixar os usuários responsáveis pela sua parcela de responsabilidade no DfE, parece ser contestada na realidade já que ambas as empresas apontam a Integração entre os diversos setores da empresa como importante para o DfE. Neste caso, ao invés de capacitar os Designers/Projetistas em $\mathrm{Tl}$, ambos trabalham em conjunto. O mesmo foi apontado em relação aos Especialistas Ambientais na Empresa Y.

Interessante notar que a Empresa $X$ apontou que nenhuma das ferramentas demandou extensos treinamentos (conforme defendido por HANDFIELD et al., 2001; MAXWELL e VAN DER VORST, 2003; LINDAHL, 2006; TINGSTRÖM, SWANSTROM e KARLSSON, 2006), enquanto que a Empresa $Y$ considera extensos os treinamentos necessários para utilização de todas as ferramentas. No entanto, na Empresa $X$, nenhuma delas é considerada simples (conforme o proposto por KOBAYASHI, 2005; KOBAYASHI et al., 2005; VEZZOLI e SCIAMA, 2006; GOTZSCH, 2008; BALA et al., 2010; BOHM et al., 2010; COLLADO-RUIZ e OSTAD-AHMAD-GHORABI, 2010b; KISHITA et al., 2010; LUH, CHU e PAN, 2010; SONG e LEE, 2010) ou de fácil utilização (conforme HANDFIELD et al., 2001; MAXWELL e VAN DER VORST, 2003; LINDAHL, 2006; TINGSTRÖM, SWANSTROM e KARLSSON, 2006) ao contrário da Empresa $Y$ que aponta todas elas como fáceis de utilizar e simples após os treinamentos. Em relação à necessidade de extensos treinamentos, simplicidade e facilidade de utilização, as respostas bastante contraditórias revelam que seria necessário definir melhor o que se considera um treinamento extenso e uma ferramenta simples ou de fácil utilização, caracterizando uma das limitações do presente estudo.

$\mathrm{Na}$ Empresa $\mathrm{Y}$, considera-se que todas as ferramentas tornam o DfE mais ágil (conforme MAXWELL e VAN DER VORST, 2003; LEIBRECHT, 2005; BYGGETH, BROMAN e ROBÈRT, 2007; JIANJUN et al., 2008; CHU et al., 2009; MENGONI, GERMANI e MANDORLI, 2009; VINODH, 2010), abordam a disposição a pagar do consumidor (proposto por BOVEA e WANG, 2007) e os custos do ciclo de vida (conforme RUDENAUER et al., 2005; XU, CHEN e XIE, 2006; ALMEIDA et al., 2010; PALOUSIS, LUONG e ABHARY, 2010). Na Empresa Y, além da ferramenta IV, as ferramentas II e III também abordam aspectos sociais do ciclo de vida dos produtos (proposto por HAUSCHILD, WENZEL e ALTING, 1999; MAXWELL e VAN DER VORST, 2003; EVANS, PARTIDARIO e LAMBERT, 2007; HAUSCHILD, DREYER e JORGENSEN, 2008; KLOEPFFER, 2008; SCHMIDT e TAYLOR, 2008; BRAD, 2009; LEWANDOWSKA e KURCZEWSKI, 2010; PIGOSSO et al., 2010). A ferramenta VI é uma lista de verificação (conforme LUTTROPP e LAGERSTEDT, 2006; WONG, LEE e YUNG, 2010). A ferramenta $V$ é qualitativa (ver HUR et al., 2005; BOKS, 2006; BALA et al., 2010), baseada em uma planilha do Microsoft Excel abordando os aspectos ambientais do ciclo de vida (de acordo com VEERAKAMOLMAL E GUPTA, 1998; SHU e FLOWERS, 1999; GUNGOR e GUPTA, 2001; KOBAYASHI, 2005; KOBAYASHI et al., 2005; LEE et al., 2007; STAIKOS e RAHIMIFARD, 
2007; SINGH, GOODYER e POPPLEWELL, 2007; CHOI, NIES E RAMANI, 2008; JIANJUN et al., 2008; LI et al., 2008; WU, LO e HSU, 2008; RIOU e MASCLE, 2009; ALMEIDA et al., 2010; BAKKER et al., 2010; BOHM et al., 2010; PIGOSSO et al., 2010; SONG e LEE, 2010; VINODH e RATHOD, 2010a), onde os dados a respeito dos impactos ambientais do projeto são listados e enviados ao setor de meio ambiente, onde estudos mais quantitativos são realizados. No entanto, não é destinada a obtenção de rótulos ecológicos (proposto por KISHITA et al., 2010). Na Empresa X, estas percepções não foram encontradas.

Como pode ser observado na Tabela 20, ambas as empresas concordaram, moderadamente, com a hipótese de que a exposição a exemplos pode provocar fixação e redução da criatividade (conforme COLLADO-RUIZ e OSTAD-AHMAD-GHORABI, 2010b). Tanto a Empresa Y, quanto a Empresa $X$, afirmaram que: as ferramentas do DfE são pouco conhecidas e raramente utilizadas (conforme o proposto por HANDFIELD et al., 2001; BAUMANN, BOONS e BRAGD, 2002; LINDAHL, 2006); é importante que o método de apoio utilizado seja simples, flexível, pragmático (destacado por HANDFIELD et al., 2001; MAXWELL e VAN DER VORST, 2003; LINDAHL, 2006; TINGSTRÖM, SWANSTROM e KARLSSON, 2006); além das ferramentas é necessário um procedimento metodológico que apóie o DfE para se fazer um melhor uso destas (conforme ALTING e JOGENSEN, 1993; ALTING, 1995; NY et al., 2006; BYGGETH, BROMAN e ROBÈRT, 2007); os designers tem tempo e disposição para passar pelos diversos treinamentos do DfE, contestando o postulado por Handfield et al. (2001); o DfE não consome demasiadamente custos, tempo e pessoal, apesar de esta ter sido a visão inicial dos designers na Empresa X (conforme o apontado por MAXWELL e VAN DER VORST, 2003). Em relação às expectativas iniciais dos designers, ambas as empresas apontaram preocupações como prazo (ver ALTING, 1995; HANDFIELD et al., 2001), qualidade (conforme HANDFIELD et al., 2001) e custos (de acordo com ALTING, 1995; HANDFIELD et al., 2001). Já na Empresa Y, a flexibilidade (apontada por HANDFIELD et al., 2001) também foi apontada. Neste caso, estas hipóteses seriam menos contingenciáveis, sendo verificáveis em diferentes realidades.

Tabela 20 - Percepções dos designers sobre o DfE

\begin{tabular}{|c|c|c|}
\hline & Empresa X & Empresa Y \\
\hline A exposição a exemplos pode provocar fixação e redução da criatividade & $\mathrm{O}$ & $\mathrm{O}$ \\
\hline As ferramentas do DfE são pouco conhecidas e raramente utilizadas & O & O \\
\hline É importante que o método de apoio utilizado seja simples, flexível, pragmático & O & O \\
\hline $\begin{array}{c}\text { Além das ferramentas é necessário um procedimento metodológico que apóie o } \\
\text { DfE para se fazer um melhor uso destas }\end{array}$ & 0 & 0 \\
\hline $\begin{array}{l}\text { Os designers não têm tempo e disposição para passar pelos diversos } \\
\text { treinamentos do DfE }\end{array}$ & $\mathrm{X}$ & $\mathrm{X}$ \\
\hline $\begin{array}{c}\text { O DfE consome demasiadamente custos, tempo e pessoal } \\
\text { Os designers acreditam que o DfE afetaria negativamente o desempenho } \\
\text { empresarial, medido em termos de... }\end{array}$ & $\mathrm{X}$ & $\mathrm{X}$ \\
\hline$\rightarrow$ prazo & O & O \\
\hline$\rightarrow$ qualidade & O & O \\
\hline$\rightarrow$ custos & O & O \\
\hline$\rightarrow$ flexibilidade & $X$ & 0 \\
\hline $\begin{array}{l}\text { Os designers vêem as questões ambientais como restrições a serem vencidas } \\
\text { para se poder dar continuidade à próxima etapa do projeto }\end{array}$ & $\begin{array}{l}\text { característica } \\
\text { do projeto }\end{array}$ & 0 \\
\hline $\begin{array}{c}\text { Os designers estão à procura de orientação geral ao invés de uma direção } \\
\text { específica }\end{array}$ & O & 0 \\
\hline
\end{tabular}

*Legenda: X - Não concorda; O - Concorda; o - Concorda moderadamente

Fonte: Elaborado pelo autor. 
$\mathrm{Na}$ Empresa $\mathrm{Y}$, os designers vêem as questões ambientais como restrições a serem vencidas para se poder dar continuidade à próxima etapa do projeto (conforme ALTING, 1995; HANDFIELD et al., 2001) e na Empresa X, a palavra "restrição" foi substituída por "mais uma característica do projeto". Na Empresa $X$, os entrevistados afirmaram que: os designers estão à procura de orientação geral ao invés de uma direção específica (destacado por LINDAHL, 2006) enquanto que na Empresa $\mathrm{Y}, \mathrm{o}$ entrevistado concordou apenas moderadamente com esta afirmação.

Estas divergências entre as visões presentes nas equipes de P\&D das empresas poderiam indicar que diferenças entre tipo de negócio, cultura, porte e por conseqüência, estratégias do DfE implementadas, também influenciariam a forma como o DfE é percebido pelas empresas e seus colaboradores, contingenciando as motivações e benefícios percebidos, bem como os métodos de apoio ao DfE apropriados. Estes resultados poderiam indicar a necessidade de criação de um modelo contingencial de implementação do DfE levando em consideração, ao menos, três variáveis: nível/estágio de implementação do DfE, porte e mercado de atuação.

Em relação aos benefícios do DfE propostos por diversos autores (HUNT e AUSTER, 1990; PORTER e VAN DER LINDE, 1995; MILES e COVIN, 2000; PRESTON, 2001; MANGUN e THUSSTON, 2002; MAXWELL e VAN DER VORST, 2003; GINSBERG e BLOOM, 2004; SEIFFERT, 2005; TIEN, CHUNG e TSAI, 2005; GOTTBERG et al., 2006; TINGSTRÖM e KARLSSON, 2006; TINGSTRÖM, SWANSTROM e KARLSSON, 2006; BEVILACQUA, CIARAPICA e GIACCHETTA, 2007; CAGNO e TRUCCO, 2007; EVANS, PARTIDARIO e LAMBERT, 2007; GE e WANG, 2007; LEE et al., 2007; VAN BERKEL, 2007; CHOI, NIES e RAMANI, 2008; JABBOUR e SANTOS, 2008; NY et al., 2008; HARA et al., 2009; BOVESPA, 2010; FITZGERALD, HERRMANN e SCHMIDT, 2010; JABBOUR, 2010; PALOUSIS, LUONG e ABHARY, 2010; VINODH, 2010; VINODH e RATHOD, 2010a), estes poderiam ser contingenciados de acordo com o porte das empresas e estágio de implementação do DfE. Conforme se pode verificar na Tabela 21, a Melhoria no Relacionamento com os Fornecedores foi apontada apenas pela Empresa X, pois estes se tornariam fontes de informações ambientais. Provavelmente devido às suas características de empresa de grande porte e de produtora de suas principais matérias-primas, a Empresa $\mathrm{Y}$ busca parcerias muito mais a jusante do que a montante na cadeia de suprimentos, assumindo uma postura de orientação e educação em relação aos seus fornecedores. Este fenômeno também pode ser explicado devido ao estágio de implementação do DfE, visto que há muitos anos a empresa já implementa este tipo de prática, este tipo de benefício pode ter sido esquecido ou superado por outros tipos de benefícios.

Entretanto, apenas a Empresa $Y$ declarou se beneficiar da Redução de Custos, Novas Oportunidades de Negócios, e do Acesso mais fácil às fontes de recursos que podem financiar os seus projetos, provavelmente devido ao estágio de implementação do DfE. Benefícios como a Maior Satisfação dos Clientes e Maior Atratividade para Diversos Investidores, também apontados apenas pela Empresa $Y$, parecem estar relacionados às características do setor de atuação e do porte das empresas, respectivamente. A Empresa $Y$ também incluiu a maior facilidade de obtenção $e$ renovação de licenças de operação. Ainda devido a diferenças entre as empresas, capital aberto (Empresa Y) X capital fechado (Empresa X), o Aumento do Valor de suas Ações através da inclusão 
da empresa no ISE foi apontado apenas pela Empresa Y, que apesar de ainda não fazer parte deste índice, já está classificada como elegível para o ISE 2012. Já o Aumento do Valor das Ações através da inclusão da empresa no Índice Dow Jones de Sustentabilidade, ainda não é visualizado nem mesmo pela Empresa Y. O Aumento do Valor das Ações da empresa através da inclusão da empresa no ISE, bem como no DJSI parece estar mais relacionado ao porte e tipo de constituição da empresa (capital aberto $X$ capital fechado), mas também pode-se afirmar que esteja relacionado a níveis mais altos de integração de aspectos ambientais nas empresas, visto que este tipo de índice costuma levar em consideração aspectos mais estratégicos, não se restringindo ao DfE.

Tabela 21 - Benefícios do DfE

\begin{tabular}{|c|c|c|}
\hline & Empresa X & Empresa Y \\
\hline Melhoria no Relacionamento com os Fornecedores & $\mathrm{O}$ & $\bar{X}$ \\
\hline Redução de Custos & $\mathrm{X}$ & 0 \\
\hline Novas Oportunidades de Negócios & $\mathrm{X}$ & $\mathrm{O}$ \\
\hline $\begin{array}{l}\text { Acesso mais fácil às fontes de recursos que podem } \\
\text { financiar os seus projetos }\end{array}$ & $\mathrm{X}$ & O \\
\hline Maior Satisfação dos Clientes & $x$ & O \\
\hline $\begin{array}{c}\text { Maior facilidade de obtenção e renovação de licenças } \\
\text { de operação }\end{array}$ & $\mathrm{X}$ & $\mathrm{O}$ \\
\hline Maior Atratividade para Diversos Investidores & $\mathrm{X}$ & $\mathrm{O}$ \\
\hline $\begin{array}{c}\text { Aumento do Valor das Ações da empresa através da } \\
\text { inclusão no ISE }\end{array}$ & $\mathrm{X}$ & $\mathrm{O}$ \\
\hline $\begin{array}{c}\text { Aumento do Valor das Ações da empresa através da } \\
\text { inclusão no DJSI }\end{array}$ & $x$ & $\mathrm{X}$ \\
\hline $\begin{array}{c}\text { Melhoria na Reputação da Empresa } \\
\text { Vantagem Competitiva }\end{array}$ & devido ao Marketing & devido ao Marketing \\
\hline $\begin{array}{l}\text { Desenvolvimento de Capacidades em termos de } \\
\text { Conhecimentos e Competências }\end{array}$ & $\begin{array}{l}\text { "para todos os } \\
\text { funcionários" }\end{array}$ & $\begin{array}{l}\text { "para todos os } \\
\text { funcionários" }\end{array}$ \\
\hline Novas Oportunidades de Mercado & Mercado Externo & Fitoterápicos \\
\hline Melhoria da Funcionalidade dos Produtos & X & X \\
\hline
\end{tabular}

*Legenda: X - Não concorda; O - Concorda; o - Concorda moderadamente

Fonte: Elaborado pelo autor.

Ambas as empresas apontaram como benefícios do DfE, a Melhoria na Reputação da Empresa, a Vantagem Competitiva (segundo ambas as empresas, oriunda principalmente do Marketing), Novas Oportunidades de Mercado (a Empresa X aponta o Mercado Externo exportações, e a Empresa $Y$ apontou a possível comercialização dos fitoterápicos) e o Desenvolvimento de Capacidades em termos de Conhecimentos e Competências ("para todos os funcionários", segundo ambas as empresas), demonstrando benefícios que podem ser alcançados mesmo em estágios iniciais de implementação do DfE. Interessante notar, no entanto, que nenhuma das duas empresas apontou a Melhoria da Funcionalidade dos Produtos como um benefício do DfE. Isto poderia indicar que não existe a necessidade de os objetivos ambientais substituírem ou se sobreporem aos outros objetivos do PDP, já que nenhuma melhoria ambiental será alcançada a menos que os novos produtos sejam competitivos e possam substituir os produtos com menor desempenho ambiental, corroborando o postulado por Kuo, Wu e Shieh, 2009, Nielsen e Wenzel, 2002 e Pujari e Wright, 1999.

A Empresa $X$ trabalha com uma estratégia de portfólio, desenvolve produtos verdes e não verdes (conforme o proposto por MANGUN e THUSSTON, 2002; XU, ONG e NEE, 2007; LUH, CHU e PAN, 2010), com perspectiva de migração dos produtos "não verdes" para o Lead Free. Na 
Empresa $Y$, todos os produtos já estão de acordo com as diretrizes ambientais da empresa, o que pode indicar que a estratégia de portfólio venha a caracterizar um dos degraus entre os níveis de implementação do DfE. Neste sentido, nos estágios iniciais de implementação do DfE, as empresas manteriam uma estratégia de portfólio, e, em seguida, as motivações, acompanhadas pelos benefícios percebidos, impulsionariam a migração de todos os produtos para o DfE.

A hipótese de que os produtos com apelo ambiental não tem alcançado posições favoráveis no mercado (conforme KUO, WU e SHIEH, 2009) foi contestada pelas duas empresas, que afirmaram que os produtos apresentam o mesmo desempenho de mercado que os produtos sem apelo ambiental. Em relação à superioridade dos produtos com apelo ambiental quanto à competitividade, custos, lucratividade e desempenho funcional, o contexto mercadológico, nível de implementação do DfE ou da integração de aspectos ambientais na empresa podem influenciar os resultados, visto que apenas a Empresa $Y$ apontou este tipo de vantagem. No entanto, em nenhuma das empresas foi verificada a inferioridade dos produtos com apelo ambiental. Neste contexto, seriam necessárias pesquisas no sentido de verificar se fatores como mercado de atuação modificariam este cenário.

Ambas as empresas apontaram a fase de Extração de Matéria-Prima (Pré-Produção) como a fase do ciclo de vida de seus produtos onde residem a maior parte dos impactos ambientais. Em relação às estratégias do DfE propostas na literatura (ALTING, 1993; ALTING e JOGENSEN, 1993; AZZONE e a NOCI, 1996; GUNGOR e GUPTA, 1999; LENOX, KING e EHRENFELD, 2000; PERSSON, 2001; MAXWELL e VAN DER VORST, 2003; WANYAMA et al., 2003; PUJARI, PEATTIE e WRIGHT, 2004; KOBAYASHI et al., 2005; XU, CHEN e XIE, 2006; BYGGETH, BROMAN e ROBÈRT, 2007; BYGGETH e HOCHSCHORNER, 2006; CAGNO e TRUCCO, 2007; GOTZSCH, 2008; LI et al., 2008; BALA et al., 2010; LEWANDOWSKA e KURCZEWSKI, 2010; PIGOSSO et al., 2010; RAMANI et al., 2010; SONG e LEE, 2010; VINODH, 2010; VINODH e RATHOD, 2010a; WONG, LEE e YUNG, 2010), pôde-se evidenciar que a Empresa $X$ implementa estratégias voltadas às fases de Pré-Produção, Produção e Uso e pretende implementar estratégias voltadas ao Descarte, futuramente. A Empresa $\mathrm{Y}$ já implementa estratégias voltadas à todas as fases do ciclo de vida de seus produtos, Pré-Produção, Produção, Transporte, Uso e Descarte. Visto que em cada estágio do ciclo de vida dos produtos podem ser listadas diversas estratégias que variam de setor para setor, e que não existe, necessariamente, uma relação fechada entre as estratégias de cada fase do ciclo de vida dos produtos; pode-se afirmar que empresas, em estágios iniciais de implementação do DfE, implementam um menor número de Estratégias do DfE do que as empresas em estágios mais avançados de implementação do DfE. Além disso, um número maior de fases do ciclo de vida dos produtos que são abordadas por estas estratégias estaria diretamente ligado a estágios mais avançados de implementação do DfE, já que uma empresa pode implementar "n" estratégias do DfE voltadas a mesma fase do ciclo de vida do produto.

Desta forma, as empresas poderiam ser enquadradas no modelo apresentado na Figura 7. Este modelo poderia auxiliar na definição de estágios/níveis de implementação do DfE nas empresas para auxiliar na definição dos Métodos de Apoio ao DfE mais adequados para cada estágio de implementação do DfE, bem como na verificação de possíveis motivações para e benefícios do DfE. 


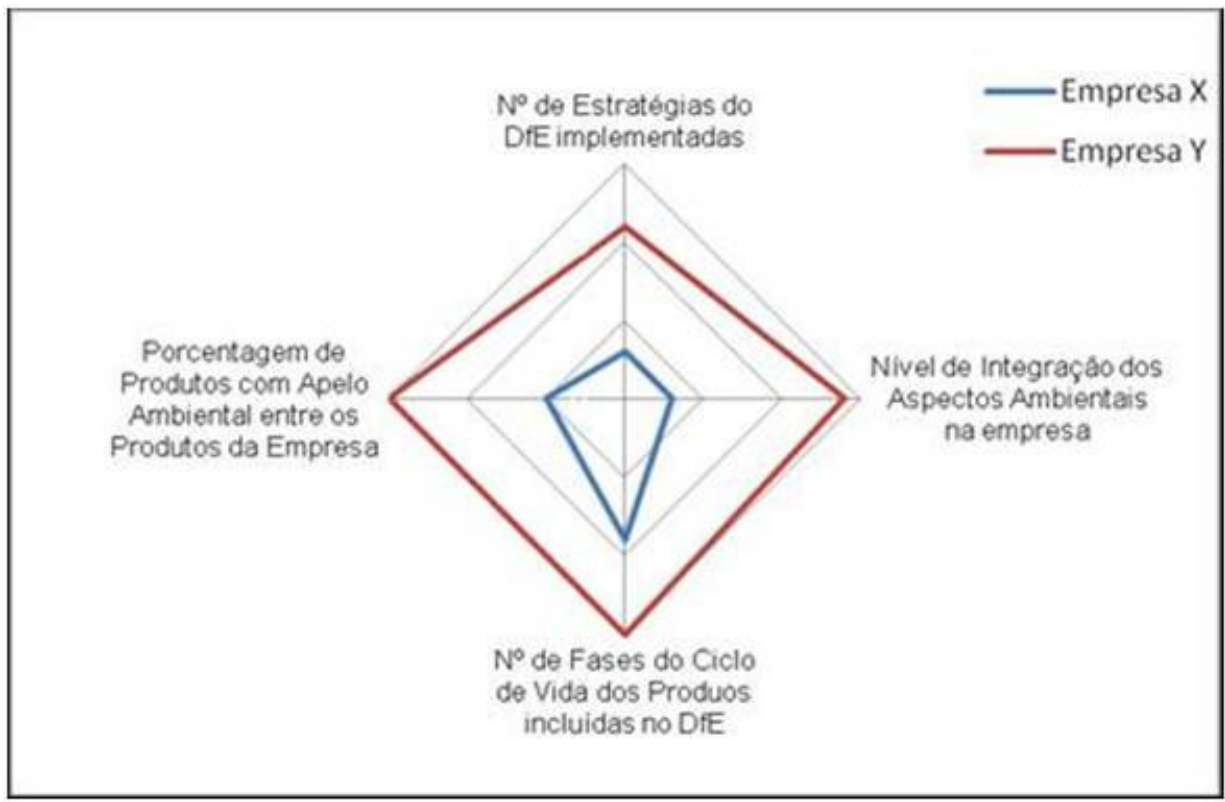

Figura 7 - Enquadramento das empresas estudadas em níveis de implementação do DfE Fonte: Elaborado pelo Autor

Entretanto, devido à natureza do presente estudo, fatores como porte, setor de atuação, severidade da legislação ambiental no setor e contexto mercadológico ainda precisariam ser estudados mais a fundo em pesquisas futuras. Na revisão da literatura, puderam-se verificar diversos modelos propostos para a integração de aspectos ambientais no PDP, alguns, inclusive incluindo os aspectos sociais no PDP. Também foi possível verificar que a nomenclatura para o DfE conta com diversos termos, o que além de dificultar as pesquisas neste sentido, pode indicar a necessidade de reunião destes estudos no sentido de se criar um modelo contingencial para o DfE.

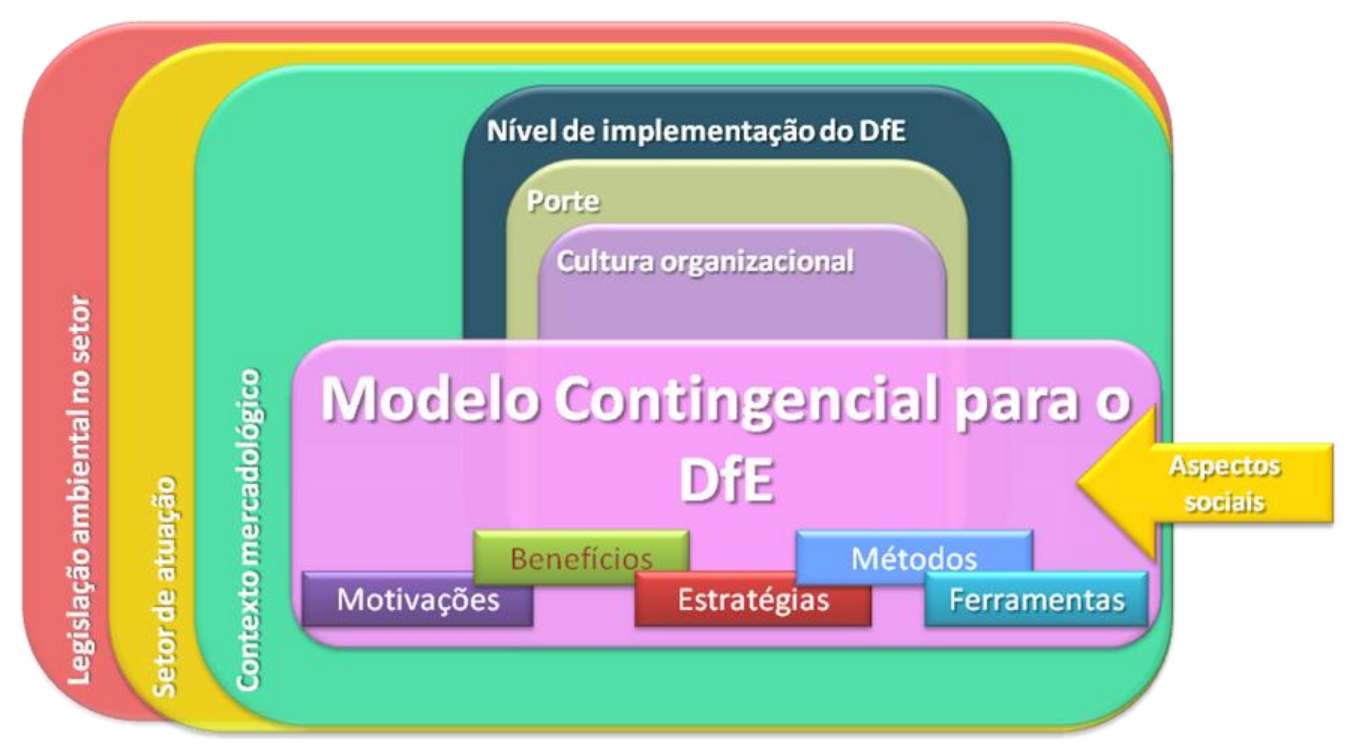

Figura 8 - Modelo Contingencial de implementação para o DfE Fonte: Elaborado pelo Autor

Com base no presente trabalho, pôde-se evidenciar que as principais motivações e benefícios do DfE, Estratégias do DfE, Métodos e Ferramentas de Apoio do DfE aparecem de forma contingencial em diferentes contextos. 


\section{CONCLUSÕES E SUGESTÕES PARA TRABALHOS FUTUROS}

Neste capítulo são apresentadas as conclusões do trabalho em relação aos objetivos e questões de pesquisa propostos e suas limitações. O objetivo geral do presente estudo, "Investigar como ocorre a integração de aspectos ambientais no PDP", foi dividido em dois objetivos específicos "Identificar como ocorre a escolha por determinados métodos e/ou ferramentas de apoio a integração de aspectos ambientais no PDP" e "Analisar como esses métodos e/ou ferramentas de apoio escolhidos são incorporados ao PDP".

$\mathrm{Na}$ revisão da literatura pode-se verificar que o processo de integração de aspectos ambientais no PDP é definido por diversas terminologias. Neste sentido, optou-se por utilizar o termo Design para o Ambiente (Design for Environment - DfE). A revisão da literatura também elencou as principais motivações e benefícios para o DfE, Estratégias de Design do DfE e os principais métodos e ferramentas de apoio ao DfE e está dividida em três principais eixos: Design para o Ambiente Motivações e Integração com da cadeia de suprimentos, Estratégias de Design do DfE (divididas de acordo com as fases do ciclo de vida dos produtos a que se reportam) e Métodos e Ferramentas de Apoio ao DfE (bem como os requisitos para estes Métodos e Ferramentas de Apoio).

Com base nos dados obtidos, a principal conclusão do presente estudo é de que não existe uma só forma de integração de aspectos ambientais no PDP. Nas empresas analisadas, o processo de integração de aspectos ambientais no PDP ocorre de forma contingencial, onde estas escolhem e implementam métodos e ferramentas de apoio ao DfE de acordo com o seu contexto mercadológico, porte, setor de atuação, severidade da legislação ambiental no setor, cultura organizacional e nível/estágio de implementação do DfE. Obviamente essa contatação é específica às empresas investigadas e o grau de generalização é limitado.

Pode-se inferir que ao postular motivações e benefícios para as empresas implementarem o DfE, a literatura poderia estar negligenciando a questão contingencial, ao desconsiderar as características particulares de cada tipo de empresa. Esta negligência poderia estar influenciando as escolhas das empresas estudadas no momento de optarem ou não pelo DfE, bem como nas escolhas por determinados Métodos e/ou Ferramentas ou mesmo Estratégias do DfE.

No presente estudo, determinados métodos de apoio ao DfE se revelaram mais importantes em estágios iniciais e, conforme a empresa e o PDP vão absorvendo os aspectos ambientais, estes vão sendo substituídos por outros métodos voltados a reafirmação destes aspectos na cultura organizacional. Além disso, verificou-se a presença das ferramentas de apoio ao DfE em estágios mais avançados de implementação do DfE. Dentro da conjuntura observada, também se evidenciou que em estágios iniciais de implementação do DfE as empresas trabalham com uma estratégia de portfólio, desenvolvendo produtos com e sem apelo ambiental e em estágios mais avançados de implementação do DfE, a empresa migra toda a sua carteira de desenvolvimento para o DfE.

Pôde-se evidenciar que a empresa, em estágio inicial de implementação do DfE, implementa um menor número de estratégias do DfE do que a empresa em estágio mais avançado de implementação do DfE. Além disso, um número maior de fases do ciclo de vida dos produtos que são abordadas por estas estratégias estaria diretamente ligado a estágios mais avançados de 
implementação do DfE, já que uma empresa pode implementar "n" estratégias do DfE voltadas a mesma fase do ciclo de vida do produto. Com base na realidade observada e visto que em cada Fase do Ciclo de Vida dos Produtos podem ser listadas diversas Estratégias que variam de setor para setor, e que não existe uma relação fechada entre as Estratégias de cada fase do ciclo de vida dos produtos, poderia-se afirmar que quanto maior é o número de estratégias do DfE adotadas pela empresa, mais alto é o seu nível de implementação do DfE.

De acordo com este estudo, também se poderia inferir que níveis mais altos de integração de aspectos ambientais nas empresas estariam diretamente relacionados a estágios mais avançados de implementação do DfE, impulsionando a implementação de um maior número de estratégias do DfE, bem como a efetividade desta implementação, já que a integração do PDP com outros setores da empresa como um método de apoio ao DfE foi apontada por empresas que atuam em setores e contextos diferentes. Neste sentido, também se verificou que em empresas em um estágio mais avançado de implementação do DfE, os objetivos ambientais estão expressos no planejamento estratégico e na cultura organizacional da empresa, mais uma demonstração de que níveis mais altos de integração de aspectos ambientais nas empresas estariam relacionados a estágios mais avançados de implementação do DfE. Entretanto, devido à natureza do presente estudo, fatores como porte, setor de atuação, severidade da legislação ambiental no setor e contexto mercadológico ainda precisariam ser estudados mais a fundo em pesquisas futuras. Estas pesquisas viabilizariam um esclarecimento às empresas sobre a melhor forma de implementação dos Métodos e/ou Ferramentas de Apoio ao DfE de acordo com as contingências verificadas no presente estudo. 


\section{REFERÊNCIAS}

ABU BAKAR, M.S.; RAHIMIFARD, S. Computer-aided recycling process planning for end-of-life electrical and electronic equipment. Proceedings of the Institution of Mechanical Engineers, Part B: Journal of Engineering Manufacture, v. 221, n. 8, p. 1369-1374, 2007.

ALBINO, V.; BALICE, A.; DANGELICO, R.M. Environmental strategies and green product development: An overview on sustainability-driven companies. Business Strategy and the Environment, v. 18, n. 2, p. 83-96, 2009.

ALMEIDA, C. M. V. B.; RODRIGUES, A. J. M.; BONILLA, S. H.; GIANNETTI, B.F. Emergy as a tool for Ecodesign: evaluating materials selection for beverage packages in Brazil. Journal of Cleaner Production, v. 18, n. 1, p. 32-43, 2010.

ALTING L. Life Cycle Engineering and Design. CIRP Annals - Manufacturing Technology, v. 44, n. 2, p. 569-580, 1995.

ALTING Prof. Ph.; JOGENSEN Ph. The Life Cycle Concept as a Basis for Sustainable Industrial Production. CIRP Annals - Manufacturing Technology, v. 42, n. 1, p.163-167, 1993.

AMMENBERG, J.; SUNDIN, E. Products in environmental management systems: the role of auditors. Journal of Cleaner Production, v. 13, n. 4, p. 417-431, 2005.

ANDERSSON, K.; EIDE, M.H.; LUNDQVIST, U.; MATTSSON, B. The feasibility of including sustainability in LCA for product development. Journal of Cleaner Production. v. 6, n. 3-4, p. 289-298, 1998.

AZZONE, G.; NOCI, G. Measuring the environmental performance of new products: An integrated approach. International Journal of Production Research, v. 34, n. 11, p. 3055-3078, 1996.

BAKKER, C.A.; WEVER, R.; TEOH, C.; DE CLERCQ S. Designing cradle-to-cradle products: A reality check. International Journal of Sustainable Engineering, v. 3, n. 1, p. 2-8, 2010.

BALA, A.; RAUGEI, M.; BENVENISTE, G.; GAZULLA, C.; FULLANA-I-PALMER, P. Simplified tools for global warming potential evaluation: When 'good enough' is best. International Journal of Life Cycle Assessment, v. 15, n. 5, p. 489-498, 2010.

BAUMANN, H.; BOONS, F.; BRAGD, A. Mapping the green product development field: engineering, policy and business perspectives. Journal of Cleaner Production, v. 10, n. 5, p. 409-425, 2002.

BENDAVID-VAL, A.; PERINE, C. Environmental competitiveness: completing the competitiveness paradigm. Chemonics International Inc., Washington, July 8, 2003.

BERCHICCI, L.; BODEWES, W. Bridging environmental issues with new product development. Business Strategy and the Environment, v. 14, n. 5, p. 272-285, 2005.

BERTO, R.M.V.S., NAKANO, D.N.A. Produção Científica nos Anais do Encontro Nacional de Engenharia de Produção: Um Levantamento de Métodos e Tipos de Pesquisa. Produção, v. 9, n. 2, p. 65-76, 2000.

BEVILACQUA, M.; CIARAPICA, F.E.; GIACCHETTA G. Development of a sustainable product lifecycle in manufacturing firms: A case study. International Journal of Production Research, v. 45, n. 18-19, p. 4073-4098, 2007.

BHAMRA, T.A. Ecodesign: the search for development new strategies in product. Proceedings of the Institution of Mechanical Engineers, Part B: Journal of Engineering Manufacture, v. 218, n. 5, p. 557569, 2004. 
BHANDER, G.S.; HAUSCHILD, M.; MCALOONE, T. Implementing life cycle assessment in product development. Environmental Progress, v. 22, n. 4, p. 255-267, 2003.

BLOMQUIST, T.; SANDSTROM, J. From issues to checkpoints and back: Managing green issues in R\&D. Business Strategy and the Environment, v. 13, n. 6, p. 363-373, 2004.

BOHM, M.R.; HAAPALA, K.R.; POPPA, K.; STONE, R.B.; TUMER I.Y. Integrating life cycle assessment into the conceptual phase of design using a design repository. Journal of Mechanical Design, Transactions of the ASME, v. 132, n. 9, p. 0910051-09100512, 2010.

BOKS, C. The soft side of ecodesign. Journal of Cleaner Production, v. 14, n. 15-16, p. 1346-1356, 2006.

BOVEA, M.D.; WANG, B. Redesign methodology for developing environmentally conscious products. International Journal of Production Research, v. 45, n. 18-19, p. 4057-4072, 2007.

BOVESPA: <http://www.bovespa.com.br>. Acesso em maio 2010.

BOYD, J.R. e WETFALL, H. Pesquisa Mercadológica: Textos e Casos. Rio de Janeiro: Fundação Getúlio Vargas, 1964.

BRAD, S. Concurrent multifunction deployment (CMFD). International Journal of Production Research, v. 47, n. 19, p. 5343-5376, 2009.

BYGGETH, S.; BROMAN, G.; ROBERT, K.H. A method for sustainable product development based on a modular system of guiding questions. Journal of Cleaner Production, v. 15, n. 1, p. 1-11, 2007.

BYGGETH, S.; HOCHSCHORNER, E. Handling trade-offs in ecodesign tools for sustainable product development and procurement. Journal of Cleaner Production, v. 14, n. 15-16, p. 1420-1430, 2006.

CAGNO E.; TRUCCO P. Integrated green and quality function deployment. International Journal of Product Lifecycle Management, v. 2, n. 1, p. 64-83, 2007.

CETESB - Companhia Ambiental do Estado de São Paulo: <http://www.cetesb.sp.gov.br/Tecnologia/producao_limpa/casos.asp>. Acesso em maio 2010.

CHALAL, R.; GHOMARI, A.R. TUPROD, an assistant Tool for the dUrable PROduct Design. International Journal of Environmental Technology and Management, v. 8, n. 1, p. 23-36, 2008.

CHEN, C. Design for the environment: A quality-based model for green product development. Management Science, v. 47, n. 2, p. 250-263, 2001.

CHOI, J. K.; NIES, L. F.; RAMANI, K. A framework for the integration of environmental and business aspects toward sustainable product development. Journal of Engineering Design, v. 19, n. 5, p. 431446, 2008.

CHU, C.-H.; LUH, Y.-P.; LI, T.-C.; CHEN H. Economical green product design based on simplified computer-aided product structure variation. Computers in Industry, v. 60, n. 7, p. 485,500, 2009.

CHUNG, C.; PENG, Q. A hybrid approach to selective-dissassembly sequence planning for demanufacturing and its implementation on the Internet. International Journal of Advanced Manufacturing Technology, v. 30, n. 5-6, p. 521-529, 2006.

CLARK, K.B.; WHEELWRIGHT, S.C. Managing new product and process development. New York: The Free Press, 1993.

COLLADO-RUIZ, D., CAPUZ-RIZO S.F. Modularity and ease of dissassembly: Study of electrical and electronic equipment. Journal of Mechanical Design, Transactions of the ASME, v. 132, n. 1, p. 0145021-0145024, 2010. 
COLLADO-RUIZ, D.; OSTAD-AHMAD-GHORABI, H. Fuon theory: Standardizing functional units for product design. Resources, Conservation and Recycling, v. 54, n. 10, p. 683-691, 2010a.

COLLADO-RUIZ, D.; OSTAD-AHMAD-GHORABI, H. Influence of environmental information on creativity. Design Studies, v. 31, n. 5, p. 479-498, 2010 b.

COOPER, R. G. Winning at New Products - Accelerating the Process from Idea to Launch. Perseus Books: Cambridge, 1993.

CORAZZA, R.I. Gestão ambiental e mudanças da estrutura organizacional. RAE Eletrônica, v. 2, n. 2, p. 1-23, 2003.

CULLEN, J.M.; ALLWOOD, J.M. The role ofwashing machines in life cycle assessment studies the dangers of using Ica for prioritization. Journal of Industrial Ecology, v. 13, n. 1, p. 27-37, 2009.

DE AZEVEDO, P.S.; NOLASCO, A.M. Incorporation of environmental requirements in the process of developing products in industries from custom furniture. Ciência Rural, v. 39, n. 8, p. 2422-2427, 2009.

DE BAKKER, F.; NIJHOF, A. Responsible chain management: A capability assessment framework. Business Strategy and the Environment, v. 11, n. 1, p. 63-75, 2002.

DE CALUWE, N. Business benefits from applied EcoDesign. IEEE Transactions on Electronics Packaging Manufacturing, v. 27, n. 4, p. 215-220, 2004.

DEVANATHAN, S.; RAMANUJAN, D.; BERNSTEIN, W.Z.; ZHAO, F.; RAMANI, K. Integration of Sustainability Into Early Design Through the Function Impact Matrix. Journal of Mechanical Design, v. 132, n. 8, número do artigo 081004, 2010.

DJASSEMI, M. Computer-based approach to material and process selection. Journal of Manufacturing Technology Management, v. 20, n. 7, p. 975-988, 2009.

DONAIRE, D. Gestão ambiental na empresa. 2. ed. São Paulo: Atlas, 1999.

DONG, J.; GIBSON, P.; ARNDT, G. Dissassembly sequence generation in recycling based on parts af cessibility and end-of-life strategy. Proceedings of the Institution of Mechanical Engineers, Part B: Journal of Engineering Manufacture, v. 221, n. 6, p. 1079-1085, 2007.

DOW JONES SUSTAINABILITY INDEXES (DJSI): <http://www.sustainability-index.com>. Acesso em maio 2010.

DUFLOU, J.; DEWULF, W.; SAS, P. Pro-active life cycle engineering support tools. CIRP Annals Manufacturing Technology, v. 52, n. 1, p. 29-32, 2003.

DURAIRAJ, S.K.; ONG, S.K.; NEE, A.Y.C.; TAN, R.B.H. Evaluation of life cycle cost analysis methodologies. Corporate Environmental Strategy, v. 9, n. 1, p. 30-39, 2002.

ELLRAM, L.M.; TATE, W.; CARTER, C.R. Applying 3DCE to environmentally responsible manufacturing practices. Journal of Cleaner Production, v. 16, n. 15, p. 1620-1631, 2008.

ERNZER, M.; WIMMER, W. From environmental assessment results to design for environment product changes: An evaluation of quantitative and qualitative methods. Journal of Engineering Design, v. 13, n. 3, p. 233-242, 2002.

EU-ELV. EU Directive 2000/53/EC of the European parliament and of the council on end-of-life vehicles (ELV), 2000.

EU-RoHS. EU Directive 2002/95/EC of the European parliament and of the council on restriction on hazardous substances (RoHS), 2002.

EU-WEEE. EU Directive 2002/96/EC of the European parliament and of the council on waste electrical and electronic equipment (WEEE), 2002. 
EVANS, S.; PARTIDARIO, P.J.; LAMBERT, J. Industrialization as a key element of sustainable product-service solutions. International Journal of Production Research, v. 45, n. 18-19, p. 4225-4246, 2007.

FELDMANN, K.; MEEDT, O.; TRAUTNER, S.; SCHELLER, H.; HOFFMAN, W. `Green Design Advisor': A tool for design for environment. Journal of Electronics Manufacturing, v. 9, n. 1, p. 17-28, 2000.

FIKSEL, J. Designing Resilient, Sustainable Systems. Environmental Science and Technology, v. 37, n. 23, p. 5330-5339, 2003.

FITCH, P.; COOPER, J.S. Life cycle modeling for adaptive and variant design. Part 2: Case study. Research in Engineering Design, v. 15, n. 4, p. 229-241, 2005b.

FITCH, P.; COOPER, J.S. Life-cycle modeling for adaptive and variant design. Part 1: Methodology. Research in Engineering Design, v. 15, n. 4, p. 216-228, 2005a.

FITZGERALD, D.P.; HERRMANN, J.W.; SCHMIDT, L.C. A conceptual design tool for resolving conflicts between product functionality and environmental impact. Journal of Mechanical Design, Transactions of the ASME, v. 132, n. 9, p. 0910061-09100611, 2010.

FORZA, C. Survey Research in Operations Management: a Process-based Perpective. International Journal of Operations \& Production Management, Vol. 22, No. 2, p. 152-194, 2002.

FRYXELL, G.E.; VRYZA, M. Managing environmental issues across multiple functions: an empirical study of corporate environmental departments and functional co-ordination. Journal of Environmental Management, v. 55, n. 1, p. 39-56, 1999.

FURTADO, J. S. Estratégias para prevenção de resíduos (não-produtos) em processos produtivos de bens e serviços. Consultoria Parceria FIA-FEA-USP - Programa de Gestão Estratégica Socioambiental, v_jul, 2007.

GE, C.P.; WANG, B. An activity-based modelling approach for assessing the key stakeholders' corporation in the eco-conscious design of electronic products. Journal of Engineering Design, v. 18, $\mathrm{n}$. 1, p. 55-71, 2007.

GEHIN, A.; ZWOLINSKI, P.; BRISSAUD, D. A tool to implement sustainable end-of-life strategies in the product development phase. Journal of Cleaner Production, v. 16, n. 5, p. 566-576, 2008.

GIL, A. C. Como elaborar projetos de pesquisa. São Paulo: Atlas, 1999.

GINSBERG, J. M.; BLOOM, P. N. Choosing the right green marketing strategy. MIT Sloan Management Review, v. 48, n. 1, p. 79-85, 2004.

GIUDICE, F.; FARGIONE, G. Dissassembly planning of mechanical systems for service and recovery: A genetic algorithms based approach. Journal of Intelligent Manufacturing, v. 18, n. 3, p. 313-329, 2007.

GONZALEZ-BENITO, J.; GONZALEZ-BENITO, O. Operations management practices linked to the adoption of ISO 14001: An empirical analysis of Spanish manufacturers. International Journal of Production Economics, v. 113, n. 1, p. 60-73, 2008 a.

GONZALEZ-BENITO, O.; GONZALEZ-BENITO, J. Implications of market orientation on the environmental transformation of industrial firms. Ecological Economics, v. 64, n. 4, p. 752-762, 2008b.

GOTTBERG, A.; MORRIS, J.; POLLARD, S.; MARK-HERBERT, C.; COOK, M. Producer responsibility, waste minimisation and the WEEE Directive: Case studies in eco-design from the European lighting sector. Science of The Total Environment, v. 359, n. 1-3, p. 38-56, 2006.

GOTZSCH, J. Key aspects of product attraction: A focus on eco-friendliness. International Journal of Environmental Technology and Management, v. 8, n. 1, p. 37-52, 2008. 
GUNGOR, A.; GUPTA, S.M. Dissassembly sequence plan generation using a branch-and-bound algorithm. International Journal of Production Research, v. 39, n. 3, p. 481-509, 2001.

GUNGOR, A.; GUPTA, S.M. Issues in environmentally conscious manufacturing and product recovery: a survey. Computers and Industrial Engineering, v. 36, n. 4, p. 811-853, 1999.

GUNTHER, S.; SEBASTIAN, K.; MARCO, Z. Approaches for sustainable manufacturing. Chinese Journal of Mechanical Engineering (English Edition), v. 20, n. 1, p. 86-90, 2007.

GUPTA A.K.; WILEMON D. Changing patterns in industrial R\&D management. Journal of Product Innovation Management, v. 13, n. 6, p. 497-511, 1996.

HAKKINEN, T.M. Sustainable building related new demands for product information and product model based design. Electronic Journal of Information Technology in Construction, v. 12, p. 19-37, 2007.

HANDFIELD, R.B.; MELNYK, S.A.; CALANTONE, R.J.; CURKOVIC S. Integrating environmental concerns into the design process: The gap between theory and practice. IEEE Transactions on Engineering Management, v. 48, n. 2, p. 189-208, 2001.

HARA, T.; ARAI, T.; SHIMOMURA, Y.; SAKAO, T. Service CAD system to integrate product and human activity for total value. CIRP Journal of Manufacturing Science and Technology, v. 1, n. 4, p. 262,271, 2009.

HART, C. Doing a literature search: a comprehensive guide for the social sciences. London. Sage Publications, 2001.

HART, S. L. A natural-resource-based view of the firm. Academy of Management, v. 20, n. 4, p. 9861014, 1995.

HAUSCHILD, M. Z.; DREYER, L.C.; JORGENSEN A. Assessing social impacts in a life cycle perspective-Lessons learned. CIRP Annals - Manufacturing Technology, v. 57, n. 1, p. 21-24, 2008.

HAUSCHILD, M. Z.; WENZEL, H.; ALTING L. Life cycle design - a route to the sustainable industrial culture? CIRP Annals - Manufacturing Technology, v. 48, n. 1, p. 393-396, 1999.

HAYES, R. H.; WHEELWRIGHT, S. C.; CLARK, K. B. Dynamic Manufacturing: creating the learning organization. New York: The Free Press, 1988.

HOUE, R.; GRABOT, B. Knowledge modeling for eco-design. Concurrent Engineering Research and Applications, v. 15, n. 1, p. 7-20, 2007.

HUANG, Y.C.; DING, H.B.; KAO, M.R. Salient stakeholder voices: Family business and green innovation adoption. Journal of Management and Organization, v. 15, n. 3, p. 309-326, 2009.

HUBER, J. Technological environmental innovations (TEls) in a chain-analytical and life-cycleanalytical perspective. Journal of Cleaner Production, v. 16, n. 18, p. 1980-1986, 2008.

HULA, A.; JALALI, K.; HAMZA, K.; SKERLOS, S.J.; SAITOU K. Multi-Criteria Decision-Making for Optimization of Product Dissassembly under Multiple Situations. Environmental Science and Technology, v. 37, n. 23, p. 5303-5313, 2003.

HUNT, C. B.; AUSTER, E. R. Proactive environmental management: avoiding the toxic trap. MIT Sloan Management Review, v. 31, n. 2, p. 7-18, 1990.

HUR, T.; LEE, J.; RYU, J.; KWON, E. Simplified LCA and matrix methods in identifying the environmental aspects of a product system. Journal of Environmental Management, v. 75, n. 3, p. 229237, 2005. 
IDIS - Instituto para o Desenvolvimento do Investimento Social: $<$ http://www.idis.org.br/biblioteca/charges/tripe_sustentabilidade_edit.jpg/view>. Acesso em outubro 2010.

INTERNATIONAL ORGANIZATION FOR STANDARDIZATION (ISO), ISO/TR 14040; Life Cycle Assessment - Principles and Framework, 2006.

INTERNATIONAL ORGANIZATION FOR STANDARDIZATION (ISO), ISO/TR 14062; Environmental Management - Integrating Environmental Aspects into Product Design and Development, 2002.

JABBOUR, C. J. C.; SANTOS, F. C. A. Desenvolvimento de produtos sustentáveis: o papel da gestão de pessoas. Revista de Administração Pública, v.41, n.2, p. 283-307, 2007.

JABBOUR, C.J.C. In the eye of the storm: Exploring the introduction of environmental issues in the production function in Brazilian companies. International Journal of Production Research, v. 48, n. 21, p. 6315-6339, 2010.

JABBOUR, C.J.C.; SANTOS, F.C.A. The central role of human resource management in the search for sustainable organizations. International Journal of Human Resource Management, v. 19, n. 12, p. 2133-2154, 2008.

JIANJUN, Y.; BAIYANG, J.; YIFENG G.; JINXIANG, D.; CHENGGANG, L. Research on evaluation methodologies of product life cycle engineering design (LCED) and development of its tools. International Journal of Computer Integrated Manufacturing, v. 21, n. 8, p. 923-942, 2008.

JOHANSSON, G. Incorporating environmental concern in product development: A study of project characteristics. Management of Environmental Quality, v. 17, n. 4, p. 421-436, 2006.

JOHANSSON, G., GREIF, A.; FLEISCHER, G. Managing the design/environment interface: Studies of integration mechanisms. International Journal of Production Research, v. 45, n. 18-19, p. 4041-4055, 2007.

JOHANSSON, G.; MAGNUSSON, T. Organising for environmental considerations in complex product development projects: implications from introducing a "Green" sub-project. Journal of Cleaner Production, v. 14, n. 15-16, p. 1368-1376, 2006.

KARA, S.; MANMEK, S.; KAEBERNICK, H.; IBBOTSON, S. Assessment of products for optimal lifetime. CIRP Annals - Manufacturing Technology, v. 57, n. 1, p. 1-4, 2008.

KARA, S.; MAZHAR, M.; KAEBERNICK, H.; AHMED, A. Determining the reuse potential of components based on life cycle data. CIRP Annals - Manufacturing Technology, v. 54, n. 1, p. 1-4, 2005.

KARA, S.; PORNPRASITPOL, P.; KAEBERNICK, H. Selective dissassembly sequencing: A methodology for the dissassembly of end-of-life products. CIRP Annals - Manufacturing Technology, v. 55 , n. 1, p. 37-40, 2006.

KAUTTO, P. New instruments - Old practices? The implications of environmental management systems and extended producer responsibilty for design for the environment. Business Strategy and the Environment, v. 15, n. 6, p. 377-388, 2006.

KHAN, F.I.; SADIQ, R.; VEITCH, B. Life cycle iNdeX (LInX): a new indexing procedure for process and product design and decision-making. Journal of Cleaner Production, v. 12, n. 1, p. 59-76, 2004.

KIM, J.-G.; JEON, H.-B.; KIM, H.-J.; LEE, D.-H.; XIROUCHAKIS, P. Dissassembly scheduling with capacity constraints: Minimizing the number of products disassembled. Proceedings of the Institution of Mechanical Engineers, Part B: Journal of Engineering Manufacture, v. 220, n. 9, p. 1473-1481, 2006.

KISHITA, Y.; LOW, B.H.; FUKUSHIGE, S.; UMEDA, Y.; SUZUKI, A.; KAWABE, T. Checklist-Based Assessment Methodology for Sustainable Design. Journal of Mechanical Design, v. 132, n. 9, 2010. 
KIVIMAA, P. Integrating environment for innovation: Experiences from product development in paper and packaging. Organization and Environment, v. 21, n. 1, p. 56-75, 2008.

KJAERHEIM, G. Cleaner production and sustainability. Journal of Cleaner Production, v. 13, n. 4, p. 329-339, 2005.

KLOEPFFER, W. Life cycle Sustainability assessment of products. International Journal of Life Cycle Assessment, v. 13, n. 2, p. 89-94, 2008.

KLOPFFER, W. Life-cycle based methods for sustainable product development. International Journal of Life Cycle Assessment, v. 8, n. 3, p. 157-159, 2003.

KNIGHT, P.; JENKINS, J.O. Adopting and applying eco-design techniques: a practitioners perspective. Journal of Cleaner Production, v. 17, n. 5, p. 549-558, 2009.

KOBAYASHI, H. Strategic evolution of eco-products: A product life cycle planning methodology. Research in Engineering Design, v. 16, n. 1-2, p. 1-16, 2005.

KOBAYASHI, Y.; KOBAYASHI, H.; HONGU, A.; SANEHIRA, K. A practical method for quantifying eco-efficiency using eco-design support tools. Journal of Industrial Ecology, v. 9, n. 4, p. 131-144, 2005.

KOEHLER, A.; WILDBOLZ, C. Comparing the Environmental Footprints of Home-Care and PersonalHygiene Products: The Relevance of Different Life-Cycle Phases. Environmental Science and Technology, v. 43, n. 22, p. 8643-8651, 2009.

KONGAR, E.; GUPTA, S.M. Dissassembly sequencing using genetic algorithm. International Journal of Advanced Manufacturing Technology, v. 30, n. 5-6, p. 497-506, 2006.

KROLL, E.; CARVER, B.S. Dissassembly analysis through time estimation and other metrics. Robotics and Computer-Integrated Manufacturing, v. 15, n. 3, p. 191-200, 1999.

KUNNARI, E.; VALKAMA, J.; KESKINEN, M.; MANSIKKAMAKI, P. Environmental evaluation of new technology: printed electronics case study. Journal of Cleaner Production, v. 17, n. 9, p. 791-799, 2009.

KUO, T.C. Dissassembly sequence and cost analysis for electromechanical products. Robotics and Computer-Integrated Manufacturing, v. 16, n. 1, p. 43-54, 2000.

KUO, T.-C.; WU, H.-H.; SHIEH, J.-I. Integration of environmental considerations in quality function deployment by using fuzzy logic. Expert Systems with Applications, v. 36, n. 3, p. 7148-7156, 2009.

KURCZEWSKI, P.; LEWANDOWSKA, A. ISO 14062 in theory and practice-ecodesign procedure. Part 2: Practical application. International Journal of Life Cycle Assessment, v. 15, n. 8, p. 777-784, 2010.

KURK, F.; EAGAN, P. The value of adding design-for-the-environment to pollution prevention assistance options. Journal of Cleaner Production, v. 16, n. 6, p. 722-726, 2008.

LEE, H.M.; LU, W.F.; SONG B.; SHEN, Z.; YANG, Z.; GAY, R.K.L. A framework for integrated manufacturing and product service system: Integrating service operations into product life cycle. International Journal of Services Operations and Informatics, v. 2, n. 1, p. 81-101, 2007.

LEE, J.; VELOSO, F.M.; HOUNSHELL, D.A.; RUBIN, E.S. Forcing technological change: A case of automobile emissions control technology development in the US. Technovation, v. 30, n. 4, p. 249-264, 2010.

LEE, J.J.; GEMBA, K.; KODAMA, F. Analyzing the innovation process for environmental performance improvement. Technological Forecasting and Social Change, v. 73, n. 3, p. 290-301, 2006.

LEE, S.G.; XU, X. Design for the environment: Life cycle assessment and sustainable packaging issues. International Journal of Environmental Technology and Management, v. 5, n. 1, p. 14-41, 2005. 
LEIBRECHT, S. Fundamental principles for CAD-based ecological assessments. International Journal of Life Cycle Assessment, v. 10, n. 6, p. 436-444, 2005.

LENOX, M.; KING, A.; EHRENFELD, J. An assessment of design-for-environment practices in leading US electronics firms. Interfaces, v. 30, n. 3, p. 83-94, 2000.

LEWANDOWSKA, A.; KURCZEWSKI, P. ISO 14062 in theory and practice-ecodesign procedure. Part 1: Structure and theory. International Journal of Life Cycle Assessment, v. 15, n. 8, p. 769-776, 2010.

LI, J.; ZHANG, H.-C.; GONZALEZ, M.A.; YU, S. A multi-objective fuzzy graph approach for modular formulation considering end-of-life issues. International Journal of Production Research, v. 46, n. 14, p. 4011-4033, 2008.

LINDAHL, M. Engineering designers' experience of design for environment methods and tools Requirement definitions from an interview study. Journal of Cleaner Production, v. 14, n. 5, p. 487-496, 2006.

LINK, S.; NAVEH, E. Standardization and discretion: Does the environmental standard ISO 14001 lead to performance benefits? IEEE Transactions on Engineering Management, v. 53, n. 4, p. 508-519, 2006.

LJUNGBERG, L.Y. Materials selection and design for development of sustainable products. Materials and Design, v. 28, n. 2, p. 466-479, 2007.

LUH, Y.-P.; CHU, C.-H.; PAN, C.-C. Data management of green product development with generic modularized product architecture. Computers in Industry, v. 61, n. 3, p. 223-234, 2010.

LUTTROPP, C.; JOHANSSON, J. Improved recycling with life cycle information tagged to the product. Journal of Cleaner Production, v. 18, n. 4, p. 346-354, 2010.

LUTTROPP, C.; LAGERSTEDT, J. EcoDesign and The Ten Golden Rules: generic advice for merging environmental aspects into product development. Journal of Cleaner Production, v. 14, n. 15-16, p. 1396-1408, 2006.

MAGRINI, A. Política e gestão ambiental: conceitos e instrumentos. In: Gestão Ambiental de Bacias Hidrográficas, por Alessandra Magrini e Marco Aurélio dos Santos. Rio de Janeiro: Instituto Virtual Internacional de Mudanças Globais - IVIG, 2001.

MANGUN, D.; THURSTON, D.L. Incorporating component reuse, remanufacture, and recycle into product portfolio design. IEEE Transactions on Engineering Management, v. 49, n. 4, p. 479-490, 2002.

MARCHAND, A.; WALKER, S. Product development and responsible consumption: designing alternatives for sustainable lifestyles. Journal of Cleaner Production, v. 16, n. 11, p. 1163-1169, 2008.

MARX, T.M.; DE PAULA, I.C.; SUM, F. Sustainable consumption in Brazil: Identification of preliminary requirements to guide product development and the definition of public policies. Natural Resources Forum, v. 34, n. 1, p. 51-62, 2010.

MASCLE, C.; ZHAO, H.P. Integrating environmental consciousness in product/process development based on life-cycle thinking. International Journal of Production Economics, v. 112, n. 1, p. 5-17, 2008.

MATTAR, F.N. Pesquisa de Marketing: Metodologia, Planejamento. São Paulo: Atlas, 1996.

MAXWELL, D.; VAN DER VORST, R. Developing sustainable products and services. Journal of Cleaner Production, v. 11, n. 8, p. 883-895, 2003.

MCALOONE, T. C. A competence-based approach to sustainable innovation teaching: Experiences within a new engineering program. Journal of Mechanical Design, v. 129, n. 7, p. 769-778, 2007. 
MENGONI, M.; GERMANI, M.; MANDORLI, F. A structured agile design approach to support customisation in wellness product development. International Journal of Computer Integrated Manufacturing, v. 22, n. 1, p. 42-54, 2009.

MIGUEL, P.A.C. Estudo de caso na engenharia de produção: estruturação e recomendações para sua condução. Produção, v. 17, n. 1, p. 216-229, Jan./Abr. 2007.

MILDENBERGER, U.; KHARE, A. Planning for an environment-friendly car. Technovation, v. 20, n. 4, p. 205-214, 2000.

MILES, M. P.; COVIN, J. G. Environmental marketing: a source of reputational, competitive and financial advantage. Journal of Business Ethics, v. 23, n. 3, p. 299-311, 2000.

NIELSEN, P.H.; WENZEL, H. Integration of environmental aspects in product development: a stepwise procedure based on quantitative life cycle assessment. Journal of Cleaner Production, v. 10, n. 3, p. 247-257, 2002.

NY, H.; HALLSTEDT, S.; ROBERT, K.-H.; BROMAN, G. Introducing Templates for Sustainable Product Development - A Case Study of Televisions at the Matsushita Electric Group. Journal of Industrial Ecology, v. 12, n. 4, p. 600-623, 2008.

NY, H.; MACDONALD, J.P.; BROMAN,, G.; YAMAMOTO, R.; ROBERT, K.H. Sustainability constraints as system boundaries - An approach to making life-cycle management strategic. Journal of Industrial Ecology, v. 10, n. 1, p. 61-77, 2006.

OKUMURA, S.; MORIKUNI, T.; OKINO, N. Environmental effects of physical life span of a reusable unit following functional and physical failures in a remanufacturing system. International Journal of Production Research, v. 41, n. 16, p. 3667-3687, 2003.

PALOUSIS, N.; LUONG, L.; ABHARY, K. Sustainability risk identification in product development. International Journal of Sustainable Engineering, v. 3, n. 2, p. 70-80, 2010.

PASKA, D. Facilitating substance phase-out through material information systems and improving environmental impacts in the recycling stage of a product. Natural Resources Forum, v. 34, n. 3, p. 200-210, 2010.

PERSSON, J.-G. Eco-indicators in product development. Proceedings of the Institution of Mechanical Engineers, Part B: Journal of Engineering Manufacture, v. 215, n. 5, p. 627-635, 2001.

PIGOSSO, D.C.A.; ZANETTE, E.T.; GUELERE, F.A.; OMETTO, A.R.; ROZENFELD, H. Ecodesign methods focused on remanufacturing. Journal of Cleaner Production, v. 18, n. 1, p. 21-31, 2010.

POLONSKY, M.; OTTMAN, J. Stakeholders in green product development process. Journal of Marketing Management, vol. 14, p. 533-557, 1998.

POMBO, F.R.; MAGRINI, A. Panorama de aplicação da norma ISO 14001 no Brasil. Gestão \& Produção, vol.15, n.1, p. 1-10, 2008.

PORTER, M. E.; LINDE, C. V. D. Green and competitive: endingthe stalemate. Harvard Business Review, v. 73, n. 5, p. 120-134, 1995.

PRESTON, L. Sustainability at HP: from theory to practice. Califórnia Management Review, v. 43, n. 3, p. 26-37, 2001.

PUJARI, D. Eco-innovation and new product development: Understanding the influences on market performance. Technovation, v. 26, n. 1, p. 76-85, 2006.

PUJARI, D.; PEATTIE, K.; WRIGHT, G. Organizational antecedents of environmental responsiveness in industrial new product development. Industrial Marketing Management, v. 33, n. 5, p. 381-391, 2004. 
PUJARI, D.; WRIGHT, G. Integrating environmental issues into product development: Understanding the dimensions of perceived driving forces and stakeholders. Journal of Euromarketing, v. 7, n. 4, p. 43-63, 1999.

PUJARI, D.; WRIGHT, G.; PEATTIE, K. Green and competitive: influences on environmental new product development performance. Journal of Business Research, v. 56, n. 8, p. 657-671, 2003.

QUELLA, F.; SCHMIDT, W.P. Integrating environmental aspects into product design and development - The new ISO TR 14062. International Journal of Life Cycle Assessment, v. 8, n. 2, p. 113-114, 2003.

RAMANI, K.; RAMANUJAN, D.; BERNSTEIN, W.Z.; ZHAO, F.; SUTHERLAND, J.; HANDWERKER, C.; CHOI, J.-K.; KIM, H.; THURSTON, D. Integrated sustainable life cycle design: A Review. Journal of Mechanical Design, Transactions of the ASME, v. 132, n. 9, p. 0910041-09100415, 2010.

RAUSAND, M.; UTNE, I.B. Product safety - Principles and practices in a life cycle perspective. Safety Science, v. 47, n. 7, p. 939-947, 2009.

RAY, S.; BOYACI, T.; ARAS, N. Optimal prices and trade-in rebates for durable, remanufacturable products. Manufacturing and Service Operations Management, v. 7, n. 3, p. 208-228, 2005.

RIOU, A.; MASCLE, C. Assisting designer using feature modeling for lifecycle. CAD Computer Aided Design, v. 41, n. 12, p. 1034-1049, 2009.

ROZENFELD, H. et al. Gestão de desenvolvimento de produtos. São Paulo: Saraiva, 2006.

RUDENAUER, I.; GENSCH, C.O.; GRIESSHAMMER, R.; BUNKE, D. Integrated environmental and economic assessment of products and processes - A method for eco-efficiency analysis. Journal of Industrial Ecology, v. 9, n. 4, p. 105-116, 2005.

SANCHES, C. S. Gestão ambiental proativa. RAE, v. 40, n. 1, p. 76-87, 2000.

SAND, J.C.; GU, P.; WATSON, G. HOME: House of modular enhancement - A tool for modular product redesign. Concurrent Engineering Research and Applications, v. 10, n. 2, p. 153-164, 2002.

SAVASKAN, R.C.; VAN WASSENHOVE, L.N. Reverse channel design: The case of competing retailers. Management Science, v. 52, n. 1, p. 1-14, 2006.

SCHIAVONE, F.; PIERINI, M.; ECKERT, V. Strategy-based approach to eco-design: Application to an automotive component. International Journal of Vehicle Design, v. 46, n. 2, p. 156-171, 2008.

SCHMIDT, W.P. Life cycle costing as part of design for environment - Environmental business cases. International Journal of Life Cycle Assessment, v. 8, n. 3, p. 167-174, 2003.

SCHMIDT, W.-P.; BUTT, F. Life cycle tools within Ford of Europe's product sustainability index case study Ford S-MAX \& Ford Galaxy. International Journal of Life Cycle Assessment, v. 11, n. 5, p. 315322, 2006.

SCHMIDT, W.-P.; TAYLOR, A. Sustainable management of vehicle design. International Journal of Vehicle Design, v. 46, n. 2, p. 143-155, 2008.

SEIFFERT, M. E. B. ISO 14001: sistemas de gestão ambiental. São Paulo: Atlas, 2005.

SELIGER, G.; ZETTL, M. Modularization as an enabler for cycle economy. CIRP Annals Manufacturing Technology, v. 57, n. 1, p. 133-136, 2008.

SENGE, P.; SMITH, B.; KRUSCHWITZ, N. A próxima ordem mundial. HSM Management, n.71, 2008.

SHARFMAN, M.; ELLINGTON, R.T.; MEO, M. The next step in becoming 'green': lifecycle orientated environmental management. Business Horizons, vol. 40, n. 3, p. 13-22, 1997. 
SHU, L.H.; FLOWERS, W.C. Application of a design-for-remanufacture framework to the selection of product life-cycle fastening and joining methods. Robotics and Computer-Integrated Manufacturing, v. 15, n. 3, p. 179-190, 1999.

SIMON, M.; POOLE, S.; SWEATMAN, A.; EVANS, S.; BHAMRA, T.; MCALOONE, T. Environmental priorities in strategic product development. Business Strategy and the Environment, v. 9, n. 6, p. 367$377,2000$.

SINDING, K. Environmental management beyond the boundaries of the firm: definitions and constraints. Business Strategy and the Environment, vol. 9, n. 2, p. 79-91, 2000.

SINGH, S.; GOODYER, J.; POPPLEWELL, K. Integrated environmental process planning for the design and manufacture of automotive components. International Journal of Production Research, c. 45, n. 18-19, p. 4189-4205, 2007.

SONG, J.-S.; LEE, K.-M. Development of a low-carbon product design system based on embedded GHG emissions. Resources, Conservation and Recycling, v. 54, n. 9, p. 547-556, 2010.

SOUSA, I.; WALLACE, D. Product classification to support approximate life-cycle assessment of design concepts. Technological Forecasting and Social Change, v. 73, n. 3, p. 228-249, 2006.

SOUZA, R. Case Research in Operations Management. EDEN Doctoral Seminar on Research Methodology in Operations Management, Brussels, Belgium, 31st Jan.- 4th Feb, 2005.

STAIKOS, T.; RAHIMIFARD, S. An end-of-life decision support tool for product recovery considerations in the footwear industry. International Journal of Computer Integrated Manufacturing, v. 20, n. 6, p. 602-615, 2007.

STRAZZA, C.; BORGHI, A.D.; BLENGINI, G.A.; GALLO, M. Definition of the methodology for a Sector EPD (Environmental Product Declaration): Case study of the average Italian cement. International Journal of Life Cycle Assessment, v. 15, n. 6, p. 540-548, 2010.

TIEN, S.-W.; CHUNG, Y.-C.; TSAI, C.-H. An empirical study on the correlation between environmental design implementation and business competitive advantages in Taiwan's industries. Technovation, v. 25, n. 7, p. 783-794, 2005.

TINGSTROM, J.; KARLSSON, R. The relationship between environmental analyses and the dialogue process in product development. Journal of Cleaner Production, v. 14, n. 15-16, p. 1409-1419, 2006.

TINGSTROM, J.; SWANSTROM, L.; KARLSSON, R. Sustainability management in product development projects - the ABB experience. Journal of Cleaner Production, v. 14, n. 15-16, p. 13771385, 2006.

TOFFEL, M.W. The growing strategic importance of end-of-life product management. California Management Review, v. 31, n. 3, p. 61-77, 2003.

TSENG, M.L. Using a hybrid MCDM model to evaluate firm environmental knowledge management in uncertainty. Applied Soft Computing, v. 11, n. 1, p. 1340-1352, 2010b.

TSENG, M.L. Using linguistic preferences and grey relational analysis to evaluate the environmental knowledge management capacity. Expert Systems with Applications, v. 37, n. 1, p. 70-81, 2010a.

ULRICH, K. T.; EPPINGER, S. D. Product Design and Development. New York: McGraw-Hill College, 1995.

UMEDA, Y.; KONDOH, S.; SHIMOMURA, Y.; TOMIYAMA, T. Development of design methodology for upgradable products based on function-behavior-state modeling. Artificial Intelligence for Engineering Design, Analysis and Manufacturing: AIEDAM, v. 19, n. 3, p. 161-182, 2005.

VACHON, S. Green supply chain practices and the selection of environmental technologies. International Journal of Production Research, v. 45, n. 18-19, p. 4357-4379, 2007. 
VACHON, S.; KLASSEN, R.D. Environmental management and manufacturing performance: The role of collaboration in the supply chain. International Journal of Production Economics, v. 111, n. 2, p. 299-315, 2008.

VACHON, S.; KLASSEN, R.D. Supply chain management and environmental technologies: The role of integration. International Journal of Production Research, v. 45, n. 2, p. 401-423, 2007.

VAN BERKEL, R. Eco-innovation: Opportunities for advancing waste prevention. International Journal of Environmental Technology and Management, v. 7, n. 5-6, p. 527-550, 2007.

VARANDAS JUNIOR, A. Estudo exploratório no desenvolvimento de novos produtos em empresas do segmento de aços planos do setor siderúrgico: uma abordagem no projeto do processo. $149 \mathrm{p}$. Dissertação (Mestrado) - Escola Politécnica da Universidade de São Paulo. Departamento de Engenharia de Produção. São Paulo, 2008.

VEERAKAMOLMAL, P.; GUPTA, S. M. Analysis of design efficiency for the disassembly of modular electronic products. Journal of Electronics Manufacturing, v. 9, n. 1, p. 79-95, 2000.

VEERAKAMOLMAL, P.; GUPTA, S. M. Optimal analysis of lot-size balancing for multiproducts selective disassembly. International Journal of Flexible Automation and Integrated Manufacturing, v.,6, n. 3, p. 245-269, 1998.

VEZZOLI, C.; SCIAMA, D. Life Cycle Design: from general methods to product type specific guidelines and checklists: a method adopted to develop a set of guidelines/checklist handbook for the ecoefficient design of NECTA vending machines. Journal of Cleaner Production, v. 14, n. 15-16, p. 13191325, 2006.

VINODH, S. Improvement of agility and sustainability: A case study in an Indian rotary switches manufacturing organization. . Journal of Cleaner Production, v. 18, n. 10-11, p. 1015-1020, 2010.

VINODH, S.; RATHOD, G. Application of QFD for enabling environmentally conscious design in an Indian rotary switch manufacturing organization. International Journal of Sustainable Engineering, v. 3, n. 2, p. 95-105, 2010b.

VINODH, S.; RATHOD, G. Integration of ECQFD and LCA for sustainable product design. Journal of Cleaner Production, v. 18, n. 8, p. 833-842, 2010a.

VOSS, C. et al. Case Research in Operations Management. International Journal of Operations and Production Management, v.22, n. 2, p. 195-219, 2002.

WAAGE, S.A. Re-considering product design: a practical "road-map" for integration of sustainability issues. Journal of Cleaner Production, v. 15, n. 7, p. 638-649, 2007.

WAGNER, M. On the relationship between environmental management, environmental innovation and patenting: Evidence from German manufacturing firms. Research Policy, v. 36, n. 10, p. 1587-1602, 2007.

WALKER, S. The chimera reified: Design, meaning and the post-consumerism object. Design Journal, v. 13, n. 1, p. 9-30, 2010.

WANYAMA, W.; ERTAS, A.; ZHANG, H.-C.; EKWARO-OSIRE S. Life-cycle engineering: Issues, tools and research. International Journal of Computer Integrated Manufacturing, v. 16, n. 4-5, p. 307-316, 2003.

WARDAK, A.; GORMAN, M.E.; SWAMI, N.; DESHPANDE, S. Identification of risks in the life cycle of nanotechnology-based products. Journal of Industrial Ecology, v. 12, n. 3, p. 435-448, 2008.

WESTKÄMPER, E. Assembly and disassembly processes in product life cycle perspectives. CIRP Annals - Manufacturing Technology, v. 52, n. 2, p. 579-588, 2003. 
WESTKÄMPER, E.; ALTING, L.; ARNDT, G. Life Cycle Management and Assessment: Approaches and visions towards sustainable manufacturing. CIRP Annals - Manufacturing Technology, v. 49, n. 2, p. 501-522, 2000.

WHEELER, W. A. The revival of reverse manufacturing. Journal of Business Strategy, vol. 13, n. 4, p. 8-13, 1992.

WHEELWRIGHT, S.; CLARK, K. Creating project plans to focus product development. Harvard Business Review, Cambridge, mar-apr. 1992.

WONG, Y.L.; LEE, K.M.; YUNG, K.C. Model scenario for integrated environmental product assessment at the use of raw materials stage of a product. Resources, Conservation and Recycling, v. 54, n. 11, p. 841-850, 2010.

WU, M.-C.; LO, Y.-F.; HSU, S.-H. A fuzzy CBR technique for generating product ideas. Expert Systems with Applications, v. 34, n. 1, p. 530-540, 2008.

XING, K.; BELUSKO, M.; LUONG, L.; ABHARY, K. An evaluation model of product upgradeability for remanufacture. International Journal of Advanced Manufacturing Technology, v. 35, n. 1-2, p. 1-14, 2007.

XU, Q.L.; ONG, S.K.; NEE, A.Y.C. Evaluation of product performance in product family design re-use. International Journal of Production Research, v. 45, n. 18-19, p. 4119-4141, 2007.

XU, X.; CHEN, J.L.-Q.; XIE, S.Q. Framework of a product lifecycle costing system. Journal of Computing and Information Science in Engineering, v. 6, n. 1, p. 69-77, 2006.

YIN, R. K. Estudo de Caso - Planejamento e Método. 2. ed. São Paulo: Bookman, 2001.

YUAN, C.Y.; DORNFELD, D.A. A schematic method for sustainable material selection of toxic chemicals in design and manufacturing. Journal of Mechanical Design, Transactions of the ASME, v. 132, n. 9, p. 0910141-0910147, 2010.

ZACKRISSON, M.; ROCHA, C.; CHRISTIANSEN, K.; JARNEHAMMAR, A. Stepwise environmental product declarations: ten SME case studies. Journal of Cleaner Production, v. 16, n. 17, p. 1872-1886, 2008.

ZHANG, Y.; WANG, H.-P.; ZHANG, C. Green QFD-II: A life cycle approach for environmentally conscious manufacturing by integrating LCA and LCC into QFD matrices. International Journal of Production Research, v. 37, n. 5, p. 1075-1091, 1999.

ZHU, Q.H.; SARKIS, J. Relationships between operational practices and performance among early adopters of green supply chain management practices in Chinese manufacturing enterprises. Journal of Operations Management, v. 22, n. 3, p. 265-289, 2004. 


\section{APÊNDICE A - Referências resultantes da Revisão da Literatura}

1. ABU BAKAR, M.S.; RAHIMIFARD, S. Computer-aided recycling process planning for end-of-life electrical and electronic equipment. Proceedings of the Institution of Mechanical Engineers, Part B: Journal of Engineering Manufacture, v. 221, n. 8, p. 1369-1374, 2007.

2. ALBINO, V.; BALICE, A.; DANGELICO, R.M. Environmental strategies and green product development: An overview on sustainability-driven companies. Business Strategy and the Environment, v. 18, n. 2, p. 83-96, 2009.

3. ALMEIDA, C. M. V. B.; RODRIGUES, A. J. M.; BONILLA, S. H.; GIANNETTI, B.F. Emergy as a tool for Ecodesign: evaluating materials selection for beverage packages in Brazil. Journal of Cleaner Production, v. 18, n. 1, p. 32-43, 2010.

4. ALTING L. Life Cycle Engineering and Design. CIRP Annals - Manufacturing Technology, v. 44, n. 2, p. 569-580, 1995.

5. ALTING Prof. Ph.; JOGENSEN Ph. The Life Cycle Concept as a Basis for Sustainable Industrial Production. CIRP Annals - Manufacturing Technology, v. 42, n. 1, p.163-167, 1993.

6. AMMENBERG, J.; SUNDIN, E. Products in environmental management systems: the role of auditors. Journal of Cleaner Production, v. 13, n. 4, p. 417-431, 2005.

7. ANDERSSON, K.; EIDE, M.H.; LUNDQVIST, U.; MATTSSON, B. The feasibility of including sustainability in LCA for product development. Journal of Cleaner Production. v. 6, n. 3-4, p. 289-298, 1998.

8. AZZONE, G.; NOCI, G. Measuring the environmental performance of new products: An integrated approach. International Journal of Production Research, v. 34, n. 11, p. 30553078, 1996.

9. BAKKER, C.A.; WEVER, R.; TEOH, C.; DE CLERCQ S. Designing cradle-to-cradle products: A reality check. International Journal of Sustainable Engineering, v. 3, n. 1, p. 2-8, 2010.

10. BALA, A.; RAUGEI, M.; BENVENISTE, G.; GAZULLA, C.; FULLANA-I-PALMER, P. Simplified tools for global warming potential evaluation: When 'good enough' is best. International Journal of Life Cycle Assessment, v. 15, n. 5, p. 489-498, 2010.

11. BAUMANN, H.; BOONS, F.; BRAGD, A. Mapping the green product development field: engineering, policy and business perspectives. Journal of Cleaner Production, v. 10, n. 5, p. 409-425, 2002.

12. BERCHICCI, L.; BODEWES, W. Bridging environmental issues with new product development. Business Strategy and the Environment, v. 14, n. 5, p. 272-285, 2005.

13. BEVILACQUA, M.; CIARAPICA, F.E.; GIACCHETTA G. Development of a sustainable product lifecycle in manufacturing firms: A case study. International Journal of Production Research, v. 45, n. 18-19, p. 4073-4098, 2007.

14. BHAMRA, T.A. Ecodesign: the search for development new strategies in product. Proceedings of the Institution of Mechanical Engineers, Part B: Journal of Engineering Manufacture, v. 218, n. 5, p. 557-569, 2004.

15. BHANDER, G.S.; HAUSCHILD, M.; MCALOONE, T. Implementing life cycle assessment in product development. Environmental Progress, v. 22, n. 4, p. 255-267, 2003.

16. BLOMQUIST, T.; SANDSTROM, J. From issues to checkpoints and back: Managing green issues in R\&D. Business Strategy and the Environment, v. 13, n. 6, p. 363-373, 2004.

17. BOHM, M.R.; HAAPALA, K.R.; POPPA, K.; STONE, R.B.; TUMER I.Y. Integrating life cycle assessment into the conceptual phase of design using a design repository. Journal of Mechanical Design, Transactions of the ASME, v. 132, n. 9, p. 0910051-09100512, 2010.

18. BOKS, C. The soft side of ecodesign. Journal of Cleaner Production, v. 14, n. 15-16, p. 13461356, 2006. 
19. BOVEA, M.D.; WANG, B. Redesign methodology for developing environmentally conscious products. International Journal of Production Research, v. 45, n. 18-19, p. 4057-4072, 2007.

20. BRAD, S. Concurrent multifunction deployment (CMFD). International Journal of Production Research, v. 47, n. 19, p. 5343-5376, 2009.

21. BYGGETH, S.; BROMAN, G.; ROBERT, K.H. A method for sustainable product development based on a modular system of guiding questions. Journal of Cleaner Production, v. 15, n. 1, p. 1-11, 2007.

22. BYGGETH, S.; HOCHSCHORNER, E. Handling trade-offs in ecodesign tools for sustainable product development and procurement. Journal of Cleaner Production, v. 14, n. 15-16, p. 14201430, 2006.

23. CAGNO E.; TRUCCO P. Integrated green and quality function deployment. International Journal of Product Lifecycle Management, v. 2, n. 1, p. 64-83, 2007.

24. CHALAL, R.; GHOMARI, A.R. TUPROD, an assistant Tool for the dUrable PROduct Design. International Journal of Environmental Technology and Management, v. 8, n. 1, p. 23-36, 2008.

25. CHEN, C. Design for the environment: A quality-based model for green product development. Management Science, v. 47, n. 2, p. 250-263, 2001.

26. CHOI, J. K.; NIES, L. F.; RAMANI, K. A framework for the integration of environmental and business aspects toward sustainable product development. Journal of Engineering Design, v. 19, n. 5, p. 431-446, 2008.

27. CHU, C.-H.; LUH, Y.-P.; LI, T.-C.; CHEN H. Economical green product design based on simplified computer-aided product structure variation. Computers in Industry, v. 60, n. 7, p. 485,500, 2009.

28. CHUNG, C.; PENG, Q. A hybrid approach to selective-disassembly sequence planning for demanufacturing and its implementation on the Internet. International Journal of Advanced Manufacturing Technology, v. 30, n. 5-6, p. 521-529, 2006.

29. COLLADO-RUIZ, D., CAPUZ-RIZO S.F. Modularity and ease of disassembly: Study of electrical and electronic equipment. Journal of Mechanical Design, Transactions of the ASME, v. 132, n. 1, p. 0145021-0145024, 2010.

30. COLLADO-RUIZ, D.; OSTAD-AHMAD-GHORABI, H. Fuon theory: Standardizing functional units for product design. Resources, Conservation and Recycling, v. 54, n. 10, p. 683-691, 2010a.

31. COLLADO-RUIZ, D.; OSTAD-AHMAD-GHORABI, H. Influence of environmental information on creativity. Design Studies, v. 31, n. 5, p. 479-498, 2010 b.

32. CULLEN, J.M.; ALLWOOD, J.M. The role ofwashing machines in life cycle assessment studies the dangers of using Ica for prioritization. Journal of Industrial Ecology, v. 13, n. 1, p. 27-37, 2009.

33. DE AZEVEDO, P.S.; NOLASCO, A.M. Incorporation of environmental requirements in the process of developing products in industries from custom furniture. Ciência Rural, v. 39, n. 8, p. 2422-2427, 2009.

34. DE BAKKER, F.; NIJHOF, A. Responsible chain management: A capability assessment framework. Business Strategy and the Environment, v. 11, n. 1, p. 63-75, 2002.

35. DE CALUWE, N. Business benefits from applied EcoDesign. IEEE Transactions on Electronics Packaging Manufacturing, v. 27, n. 4, p. 215-220, 2004.

36. DEVANATHAN, S.; RAMANUJAN, D.; BERNSTEIN, W.Z.; ZHAO, F.; RAMANI, K. Integration of Sustainability Into Early Design Through the Function Impact Matrix. Journal of Mechanical Design, v. 132, n. 8, número do artigo 081004, 2010.

37. DJASSEMI, M. Computer-based approach to material and process selection. Journal of Manufacturing Technology Management, v. 20, n. 7, p. 975-988, 2009. 
38. DONG, J.; GIBSON, P.; ARNDT, G. Dissassembly sequence generation in recycling based on parts af cessibility and end-of-life strategy. Proceedings of the Institution of Mechanical Engineers, Part B: Journal of Engineering Manufacture, v. 221, n. 6, p. 1079-1085, 2007.

39. DUFLOU, J.; DEWULF, W.; SAS, P. Pro-active life cycle engineering support tools. CIRP Annals - Manufacturing Technology, v. 52, n. 1, p. 29-32, 2003.

40. DURAIRAJ, S.K.; ONG, S.K.; NEE, A.Y.C.; TAN, R.B.H. Evaluation of life cycle cost analysis methodologies. Corporate Environmental Strategy, v. 9, n. 1, p. 30-39, 2002.

41. ELLRAM, L.M.; TATE, W.; CARTER, C.R. Applying 3DCE to environmentally responsible manufacturing practices. Journal of Cleaner Production, v. 16, n. 15, p. 1620-1631, 2008.

42. ERNZER, M.; WIMMER, W. From environmental assessment results to design for environment product changes: An evaluation of quantitative and qualitative methods. Journal of Engineering Design, v. 13, n. 3, p. 233-242, 2002.

43. EVANS, S.; PARTIDARIO, P.J.; LAMBERT, J. Industrialization as a key element of sustainable product-service solutions. International Journal of Production Research, v. 45, n. 18-19, p. 4225-4246, 2007.

44. FELDMANN, K.; MEEDT, O.; TRAUTNER, S.; SCHELLER, H.; HOFFMAN, W. 'Green Design Advisor': A tool for design for environment. Journal of Electronics Manufacturing, v. 9, n. 1, p. 17-28, 2000.

45. FIKSEL, J. Designing Resilient, Sustainable Systems. Environmental Science and Technology, v. 37, n. 23, p. $5330-5339,2003$.

46. FITCH, P.; COOPER, J.S. Life-cycle modeling for adaptive and variant design. Part 1: Methodology. Research in Engineering Design, v. 15, n. 4, p. 216-228, 2005a.

47. FITCH, P.; COOPER, J.S. Life cycle modeling for adaptive and variant design part 2: Case study. Research in Engineering Design, v. 15, n. 4, p. 229-241, 2005b.

48. FITZGERALD, D.P.; HERRMANN, J.W.; SCHMIDT, L.C. A conceptual design tool for resolving conflicts between product functionality and environmental impact. Journal of Mechanical Design, Transactions of the ASME, v. 132, n. 9, p. 0910061-09100611, 2010.

49. FRYXELL, G.E.; VRYZA, M. Managing environmental issues across multiple functions: an empirical study of corporate environmental departments and functional co-ordination. Journal of Environmental Management, v. 55, n. 1, p. 39-56, 1999.

50. GE, C.P.; WANG, B. An activity-based modelling approach for assessing the key stakeholders' corporation in the eco-conscious design of electronic products. Journal of Engineering Design, v. 18, n. 1, p. 55-71, 2007.

51. GEHIN, A.; ZWOLINSKI, P.; BRISSAUD, D. A tool to implement sustainable end-of-life strategies in the product development phase. Journal of Cleaner Production, v. 16, n. 5, p. 566576, 2008.

52. GIUDICE, F.; FARGIONE, G. Dissassembly planning of mechanical systems for service and recovery: A genetic algorithms based approach. Journal of Intelligent Manufacturing, v. 18, n. 3, p. 313-329, 2007.

53. GONZALEZ-BENITO, J.; GONZALEZ-BENITO, O. Operations management practices linked to the adoption of ISO 14001: An empirical analysis of Spanish manufacturers. International Journal of Production Economics, v. 113, n. 1, p. 60-73, 2008a.

54. GONZALEZ-BENITO, O.; GONZALEZ-BENITO, J. Implications of market orientation on the environmental transformation of industrial firms. Ecological Economics, v. 64, n. 4, p. 752-762, 2008b.

55. GOTTBERG, A.; MORRIS, J.; POLLARD, S.; MARK-HERBERT, C.; COOK, M. Producer responsibility, waste minimisation and the WEEE Directive: Case studies in eco-design from the European lighting sector. Science of The Total Environment, v. 359, n. 1-3, p. 38-56, 2006.

56. GOTZSCH, J. Key aspects of product attraction: A focus on eco-friendliness. International Journal of Environmental Technology and Management, v. 8, n. 1, p. 37-52, 2008. 
57. GUNGOR, A.; GUPTA, S.M. Dissassembly sequence plan generation using a branch-andbound algorithm. International Journal of Production Research, v. 39, n. 3, p. 481-509, 2001.

58. GUNGOR, A.; GUPTA, S.M. Issues in environmentally conscious manufacturing and product recovery: a survey. Computers and Industrial Engineering, v. 36, n. 4, p. 811-853, 1999.

59. GUNTHER, S.; SEBASTIAN, K.; MARCO, Z. Approaches for sustainable manufacturing. Chinese Journal of Mechanical Engineering (English Edition), v. 20, n. 1, p. 86-90, 2007.

60. GUPTA A.K.; WILEMON D. Changing patterns in industrial R\&D management. Journal of Product Innovation Management, v. 13, n. 6, p. 497-511, 1996.

61. HAKKINEN, T.M. Sustainable building related new demands for product information and product model based design. Electronic Journal of Information Technology in Construction, v. 12, p. 19-37, 2007.

62. HANDFIELD, R.B.; MELNYK, S.A.; CALANTONE, R.J.; CURKOVIC S. Integrating environmental concerns into the design process: The gap between theory and practice. IEEE Transactions on Engineering Management, v. 48, n. 2, p. 189-208, 2001.

63. HARA, T.; ARAI, T.; SHIMOMURA, Y.; SAKAO, T. Service CAD system to integrate product and human activity for total value. CIRP Journal of Manufacturing Science and Technology, v. 1, n. 4, p. 262,271, 2009.

64. HAUSCHILD, M. Z.; DREYER, L.C.; JORGENSEN A. Assessing social impacts in a life cycle perspective-Lessons learned. CIRP Annals - Manufacturing Technology, v. 57, n. 1, p. 21-24, 2008.

65. HAUSCHILD, M. Z.; WENZEL, H.; ALTING L. Life cycle design - a route to the sustainable industrial culture? CIRP Annals - Manufacturing Technology", v. 48, n. 1, p. 393-396, 1999.

66. HOUE, R.; GRABOT, B. Knowledge modeling for eco-design. Concurrent Engineering Research and Applications, v. 15, n. 1, p. 7-20, 2007.

67. HUANG, Y.C.; DING, H.B.; KAO, M.R. Salient stakeholder voices: Family business and green innovation adoption. Journal Of Management and Organization, v. 15, n. 3, p. 309-326, 2009.

68. HUBER, J. Technological environmental innovations (TEIs) in a chain-analytical and life-cycleanalytical perspective. Journal of Cleaner Production, v. 16, n. 18, p. 1980-1986, 2008.

69. HULA, A.; JALALI, K.; HAMZA, K.; SKERLOS, S.J.; SAITOU K. Multi-Criteria Decision-Making for Optimization of Product Disassembly under Multiple Situations. Environmental Science and Technology, v. 37, n. 23, p. 5303-5313, 2003.

70. HUR, T.; LEE, J.; RYU, J.; KWON, E. Simplified LCA and matrix methods in identifying the environmental aspects of a product system. Journal of Environmental Management, v. 75, n. 3, p. 229-237, 2005.

71. JABBOUR, C.J.C. In the eye of the storm: Exploring the introduction of environmental issues in the production function in Brazilian companies. International Journal of Production Research, $v$. 48, n. 21, p. 6315-6339, 2010.

72. JABBOUR, C.J.C.; SANTOS, F.C.A. The central role of human resource management in the search for sustainable organizations. International Journal of Human Resource Management, $v$. 19, n. 12, p. 2133-2154, 2008.

73. JIANJUN, Y.; BAIYANG, J.; YIFENG G.; JINXIANG, D.; CHENGGANG, L. Research on evaluation methodologies of product life cycle engineering design (LCED) and development of its tools. International Journal of Computer Integrated Manufacturing, v. 21, n. 8, p. 923-942, 2008.

74. JOHANSSON, G. Incorporating environmental concern in product development: A study of project characteristics. Management of Environmental Quality, v. 17, n. 4, p. 421-436, 2006.

75. JOHANSSON, G., GREIF, A.; FLEISCHER, G. Managing the design/environment interface: Studies of integration mechanisms. International Journal of Production Research, v. 45, n. 1819, p. 4041-4055, 2007. 
76. JOHANSSON, G.; MAGNUSSON, T. Organizing for environmental considerations in complex product development projects: implications from introducing a "Green" sub-project. Journal of Cleaner Production, v. 14, n. 15-16, p. 1368-1376, 2006.

77. KARA, S.; MANMEK, S.; KAEBERNICK, H.; IBBOTSON, S. Assessment of products for optimal lifetime. CIRP Annals - Manufacturing Technology, v. 57, n. 1, p. 1-4, 2008.

78. KARA, S.; MAZHAR, M.; KAEBERNICK, H.; AHMED, A. Determining the reuse potential of components based on life cycle data. CIRP Annals - Manufacturing Technology, v. 54, n. 1, p. 1-4, 2005.

79. KARA, S.; PORNPRASITPOL, P.; KAEBERNICK, H. Selective disassembly sequencing: A methodology for the disassembly of end-of-life products. CIRP Annals - Manufacturing Technology, v. 55, n. 1, p. 37-40, 2006.

80. KAUTTO, P. New instruments - Old practices? The implications of environmental management systems and extended producer responsibility for design for the environment. Business Strategy and the Environment, v. 15, n. 6, p. 377-388, 2006.

81. KHAN, F.I.; SADIQ, R.; VEITCH, B. Life cycle iNdeX (LInX): a new indexing procedure for process and product design and decision-making. Journal of Cleaner Production, v. 12, n. 1, p. 59-76, 2004.

82. KIM, J.-G.; JEON, H.-B.; KIM, H.-J.; LEE, D.-H.; XIROUCHAKIS, P. Disassembly scheduling with capacity constraints: Minimizing the number of products disassembled. Proceedings of the Institution of Mechanical Engineers, Part B: Journal of Engineering Manufacture, v. 220, n. 9, p. 1473-1481, 2006.

83. KISHITA, Y.; LOW, B.H.; FUKUSHIGE, S.; UMEDA, Y.; SUZUKI, A.; KAWABE, T. ChecklistBased Assessment Methodology for Sustainable Design. Journal of Mechanical Design, v. 132, n. 9, 2010.

84. KIVIMAA, P. Integrating environment for innovation: Experiences from product development in paper and packaging. Organization and Environment, v. 21, n. 1, p. 56-75, 2008.

85. KJAERHEIM, G. Cleaner production and sustainability. Journal of Cleaner Production, v. 13, n. 4, p. 329-339, 2005.

86. KLOEPFFER, W. Life cycle Sustainability assessment of products. International Journal of Life Cycle Assessment, v. 13, n. 2, p. 89-94, 2008.

87. KLOPFFER, W. Life-cycle based methods for sustainable product development. International Journal of Life Cycle Assessment, v. 8, n. 3, p. 157-159, 2003.

88. KNIGHT, P.; JENKINS, J.O. Adopting and applying eco-design techniques: a practitioners perspective. Journal of Cleaner Production, v. 17, n. 5, p. 549-558, 2009.

89. KOBAYASHI, H. Strategic evolution of eco-products: A product life cycle planning methodology. Research in Engineering Design, v. 16, n. 1-2, p. 1-16, 2005.

90. KOBAYASHI, Y.; KOBAYASHI, H.; HONGU, A.; SANEHIRA, K. A practical method for quantifying eco-efficiency using eco-design support tools. Journal of Industrial Ecology, v. 9, n. 4, p. 131-144, 2005.

91. KOEHLER, A.; WILDBOLZ, C. Comparing the Environmental Footprints of Home-Care and Personal-Hygiene Products: The Relevance of Different Life-Cycle Phases. Environmental Science and Technology, v. 43, n. 22, p. 8643-8651, 2009.

92. KONGAR, E.; GUPTA, S.M. Disassembly sequencing using genetic algorithm. International Journal of Advanced Manufacturing Technology, v. 30, n. 5-6, p. 497-506, 2006.

93. KROLL, E.; CARVER, B.S. Disassembly analysis through time estimation and other metrics. Robotics and Computer-Integrated Manufacturing, v. 15, n. 3, p. 191-200, 1999.

94. KUNNARI, E.; VALKAMA, J.; KESKINEN, M.; MANSIKKAMAKI, P. Environmental evaluation of new technology: printed electronics case study. Journal of Cleaner Production, v. 17, n. 9, p. 791-799, 2009. 
95. KUO, T.C. Disassembly sequence and cost analysis for electromechanical products. Robotics and Computer-Integrated Manufacturing, v. 16, n. 1, p. 43-54, 2000.

96. KUO, T.-C.; WU, H.-H.; SHIEH, J.-I. Integration of environmental considerations in quality function deployment by using fuzzy logic. Expert Systems with Applications, v. 36, n. 3, p. 71487156, 2009.

97. KURCZEWSKI, P.; LEWANDOWSKA, A. ISO 14062 in theory and practice-ecodesign procedure. Part 2: Practical application. International Journal of Life Cycle Assessment, v. 15, n. 8, p. 777-784, 2010.

98. KURK, F.; EAGAN, P. The value of adding design-for-the-environment to pollution prevention assistance options. Journal of Cleaner Production, v. 16, n. 6, p. 722-726, 2008.

99. LEE, H.M.; LU, W.F.; SONG B.; SHEN, Z.; YANG, Z.; GAY, R.K.L. A framework for integrated manufacturing and product service system: Integrating service operations into product life cycle. International Journal of Services Operations and Informatics, v. 2, n. 1, p. 81-101, 2007.

100. LEE, J.; VELOSO, F.M.; HOUNSHELL, D.A.; RUBIN, E.S. Forcing technological change: A case of automobile emissions control technology development in the US. Technovation, v. 30, n. 4, p. 249-264, 2010.

101. LEE, J.J.; GEMBA, K.; KODAMA, F. Analyzing the innovation process for environmental performance improvement. Technological Forecasting and Social Change, v. 73, n. 3, p. 290301, 2006.

102. LEE, S.G.; XU, X. Design for the environment: Life cycle assessment and sustainable packaging issues. International Journal of Environmental Technology and Management, v. 5, n. 1, p. 14-41, 2005.

103. LEIBRECHT, S. Fundamental principles for CAD-based ecological assessments. International Journal of Life Cycle Assessment, v. 10, n. 6, p. 436-444, 2005.

104. LENOX, M.; KING, A.; EHRENFELD, J. An assessment of design-for-environment practices in leading US electronics firms. Interfaces, v. 30, n. 3, p. 83-94, 2000.

105. LEWANDOWSKA, A.; KURCZEWSKI, P. ISO 14062 in theory and practice-ecodesign procedure. Part 1: Structure and theory. International Journal of Life Cycle Assessment, v. 15, n. 8, p. 769-776, 2010.

106. LI, J.; ZHANG, H.-C.; GONZALEZ, M.A.; YU, S. A multi-objective fuzzy graph approach for modular formulation considering end-of-life issues. International Journal of Production Research, v. 46, n. 14, p. 4011-4033, 2008.

107. LINDAHL, M. Engineering designers' experience of design for environment methods and tools Requirement definitions from an interview study. Journal of Cleaner Production, v. 14, n. 5, p. 487-496, 2006.

108. LINK, S.; NAVEH, E. Standardization and discretion: Does the environmental standard ISO 14001 lead to performance benefits? IEEE Transactions on Engineering Management, v. 53, $\mathrm{n}$. 4, p. 508-519, 2006.

109. LJUNGBERG, L.Y. Materials selection and design for development of sustainable products. Materials and Design, v. 28, n. 2, p. 466-479, 2007.

110. LUH, Y.-P.; CHU, C.-H.; PAN, C.-C. Data management of green product development with generic modularized product architecture. Computers in Industry, v. 61, n. 3, p. 223-234, 2010.

111. LUTTROPP, C.; JOHANSSON, J. Improved recycling with life cycle information tagged to the product. Journal of Cleaner Production, v. 18, n. 4, p. 346-354, 2010.

112. LUTTROPP, C.; LAGERSTEDT, J. EcoDesign and The Ten Golden Rules: generic advice for merging environmental aspects into product development. Journal of Cleaner Production, v. 14, n. 15-16, p. 1396-1408, 2006.

113. MANGUN, D.; THURSTON, D.L. Incorporating component reuse, remanufacture, and recycle into product portfolio design. IEEE Transactions on Engineering Management, v. 49, n. 4, p. 479-490, 2002. 
114. MARCHAND, A.; WALKER, S. Product development and responsible consumption: designing alternatives for sustainable lifestyles. Journal of Cleaner Production, v. 16, n. 11, p. 1163-1169, 2008.

115. MARX, T.M.; DE PAULA, I.C.; SUM, F. Sustainable consumption in Brazil: Identification of preliminary requirements to guide product development and the definition of public policies. Natural Resources Forum, v. 34, n. 1, p. 51-62, 2010.

116. MASCLE, C.; ZHAO, H.P. Integrating environmental consciousness in product/process development based on life-cycle thinking. International Journal of Production Economics, v. 112, n. 1, p. 5-17, 2008.

117. MAXWELL, D.; VAN DER VORST, R. Developing sustainable products and services. Journal of Cleaner Production, v. 11, n. 8, p. 883-895, 2003.

118. MCALOONE, T. C. A competence-based approach to sustainable innovation teaching: Experiences within a new engineering program. Journal of Mechanical Design, v. 129, n. 7, p. 769-778, 2007.

119. MENGONI, M.; GERMANI, M.; MANDORLI, F. A structured agile design approach to support customization in wellness product development. International Journal of Computer Integrated Manufacturing, v. 22, n. 1, p. 42-54, 2009.

120. MILDENBERGER, U.; KHARE, A. Planning for an environment-friendly car. Technovation, v. 20, n. 4, p. 205-214, 2000. Natural Resources Forum, v. 34, n. 3, p. 200-210, 2010.

121. NIELSEN, P.H.; WENZEL, H. Integration of environmental aspects in product development: a stepwise procedure based on quantitative life cycle assessment. Journal of Cleaner Production, v. 10, n. 3, p. 247-257, 2002.

122. NY, H.; HALLSTEDT, S.; ROBERT, K.-H.; BROMAN, G. Introducing Templates for Sustainable Product Development - A Case Study of Televisions at the Matsushita Electric Group. Journal of Industrial Ecology, v. 12, n. 4, p. 600-623, 2008.

123. NY, H.; MACDONALD, J.P.; BROMAN,, G.; YAMAMOTO, R.; ROBERT, K.H. Sustainability constraints as system boundaries - An approach to making life-cycle management strategic. Journal of Industrial Ecology, v. 10, n. 1, p. 61-77, 2006.

124. OKUMURA, S.; MORIKUNI, T.; OKINO, N. Environmental effects of physical life span of a reusable unit following functional and physical failures in a remanufacturing system. International Journal of Production Research, v. 41, n. 16, p. 3667-3687, 2003.

125. PALOUSIS, N.; LUONG, L.; ABHARY, K. Sustainability risk identification in product development. International Journal of Sustainable Engineering, v. 3, n. 2, p. 70-80, 2010.

126. PASKA, D. Facilitating substance phase-out through material information systems and improving environmental impacts in the recycling stage of a product. Natural Resources Forum, v. 34, n. 3, p. 200-210, 2010.

127. PERSSON, J.-G. Eco-indicators in product development. Proceedings of the Institution of Mechanical Engineers, Part B: Journal of Engineering Manufacture, v. 215, n. 5, p. 627-635, 2001.

128. PIGOSSO, D.C.A.; ZANETTE, E.T.; GUELERE, F.A.; OMETTO, A.R.; ROZENFELD, H. Ecodesign methods focused on remanufacturing. Journal of Cleaner Production, v. 18, n. 1, p. 21-31, 2010.

129. PUJARI, D. Eco-innovation and new product development: Understanding the influences on market performance. Technovation, v. 26, n. 1, p. 76-85, 2006.

130. PUJARI, D.; PEATTIE, K.; WRIGHT, G. Organizational antecedents of environmental responsiveness in industrial new product development. Industrial Marketing Management, v. 33, n. 5, p. 381-391, 2004.

131. PUJARI, D.; WRIGHT, G. Integrating environmental issues into product development: Understanding the dimensions of perceived driving forces and stakeholders. Journal of Euromarketing, v. 7, n. 4, p. 43-63, 1999. 
132. PUJARI, D.; WRIGHT, G.; PEATTIE, K. Green and competitive influences on environmental new product development performance. Journal of Business Research, v. 56, n. 8, p. 657-671, 2003.

133. QUELLA, F.; SCHMIDT, W.P. Integrating environmental aspects into product design and development - The new ISO TR 14062. International Journal of Life Cycle Assessment, v. 8, n. 2, p. 113-114, 2003.

134. RAMANI, K.; RAMANUJAN, D.; BERNSTEIN, W.Z.; ZHAO, F.; SUTHERLAND, J.; HANDWERKER, C.; CHOI, J.-K.; KIM, H.; THURSTON, D. Integrated sustainable life cycle design: A Review. Journal of Mechanical Design, Transactions of the ASME, v. 132, n. 9, p. 0910041-09100415, 2010.

135. RAUSAND, M.; UTNE, I.B. Product safety - Principles and practices in a life cycle perspective. Safety Science, v. 47, n. 7, p. 939-947, 2009.

136. RAY, S.; BOYACI, T.; ARAS, N. Optimal prices and trade-in rebates for durable, remanufacturable products. Manufacturing and Service Operations Management, v. 7, n. 3, p. 208-228, 2005.

137. RIOU, A.; MASCLE, C. Assisting designer using feature modeling for lifecycle. CAD Computer Aided Design, v. 41, n. 12, p. 1034-1049, 2009.

138. RUDENAUER, I.; GENSCH, C.O.; GRIESSHAMMER, R.; BUNKE, D. Integrated environmental and economic assessment of products and processes - A method for eco-efficiency analysis. Journal of Industrial Ecology, v. 9, n. 4, p. 105-116, 2005.

139. SAND, J.C.; GU, P.; WATSON, G. HOME: House of modular enhancement - A tool for modular product redesign. Concurrent Engineering Research and Applications, v. 10, n. 2, p. 153-164, 2002.

140. SAVASKAN, R.C.; VAN WASSENHOVE, L.N. Reverse channel design: The case of competing retailers. Management Science, v. 52, n. 1, p. 1-14, 2006.

141. SCHIAVONE, F.; PIERINI, M.; ECKERT, V. Strategy-based approach to eco-design: Application to an automotive component. International Journal of Vehicle Design, v. 46, n. 2, p. 156-171, 2008.

142. SCHMIDT, W.P. Life cycle costing as part of design for environment - Environmental business cases. International Journal of Life Cycle Assessment, v. 8, n. 3, p. 167-174, 2003.

143. SCHMIDT, W.-P.; BUTT, F. Life cycle tools within Ford of Europe's product sustainability index case study Ford S-MAX \& Ford Galaxy. International Journal of Life Cycle Assessment, v. 11, n. 5, p. 315-322, 2006.

144. SCHMIDT, W.-P.; TAYLOR, A. Sustainable management of vehicle design. International Journal of Vehicle Design, v. 46, n. 2, p. 143-155, 2008.

145. SELIGER, G.; ZETTL, M. Modularization as an enabler for cycle economy. CIRP Annals Manufacturing Technology, v. 57, n. 1, p. 133-136, 2008.

146. SHU, L.H.; FLOWERS, W.C. Application of a design-for-remanufacture framework to the selection of product life-cycle fastening and joining methods. Robotics and Computer-Integrated Manufacturing, v. 15, n. 3, p. 179-190, 1999.

147. SiMON, M.; POOLE, S.; SWEATMAN, A.; EVANS, S.; BHAMRA, T.; MCALOONE, T. Environmental priorities in strategic product development. Business Strategy and the Environment, v. 9, n. 6, p. 367-377, 2000.

148. SINGH, S.; GOODYER, J.; POPPLEWELL, K. Integrated environmental process planning for the design and manufacture of automotive components. International Journal of Production Research, c. 45, n. 18-19, p. 4189-4205, 2007.

149. SONG, J.-S.; LEE, K.-M. Development of a low-carbon product design system based on embedded GHG emissions. Resources, Conservation and Recycling, v. 54, n. 9, p. 547-556, 2010.

150. SOUSA, I.; WALLACE, D. Product classification to support approximate life-cycle assessment of design concepts. Technological Forecasting and Social Change, v. 73, n. 3, p. 228-249, 2006. 
151. STAIKOS, T.; RAHIMIFARD, S. An end-of-life decision support tool for product recovery considerations in the footwear industry. International Journal of Computer Integrated Manufacturing, v. 20, n. 6, p. 602-615, 2007.

152. STRAZZA, C.; BORGHI, A.D.; BLENGINI, G.A.; GALLO, M. Definition of the methodology for a Sector EPD (Environmental Product Declaration): Case study of the average Italian cement. International Journal of Life Cycle Assessment, v. 15, n. 6, p. 540-548, 2010.

153. TIEN, S.-W.; CHUNG, Y.-C.; TSAI, C.-H. An empirical study on the correlation between environmental design implementation and business competitive advantages in Taiwan's industries. Technovation, v. 25, n. 7, p. 783-794, 2005.

154. TINGSTROM, J.; KARLSSON, R. The relationship between environmental analyses and the dialogue process in product development. Journal of Cleaner Production, v. 14, n. 15-16, p. 1409-1419, 2006.

155. TINGSTROM, J.; SWANSTROM, L.; KARLSSON, R. Sustainability management in product development projects - the ABB experience. Journal of Cleaner Production, v. 14, n. 15-16, p. 1377-1385, 2006.

156. TOFFEL, M.W. The growing strategic importance of end-of-life product management. California Management Review, v. 31, n. 3, p. 61-77, 2003.

157. TSENG, M.L. Using a hybrid MCDM model to evaluate firm environmental knowledge management in uncertainty. Applied Soft Computing, v. 11, n. 1, p. 1340-1352, 2010.

158. TSENG, M.L. Using linguistic preferences and grey relational analysis to evaluate the environmental knowledge management capacity. Expert Systems with Applications, v. 37, n. 1, p. 70-81, 2010.

159. UMEDA, Y.; KONDOH, S.; SHIMOMURA, Y.; TOMIYAMA, T. Development of design methodology for upgradable products based on function-behavior-state modeling. Artificial Intelligence for Engineering Design, Analysis and Manufacturing: AIEDAM, v. 19, n. 3, p. 161182, 2005.

160. VACHON, S. Green supply chain practices and the selection of environmental technologies. International Journal of Production Research, v. 45, n. 18-19, p. 4357-4379, 2007.

161. VACHON, S.; KLASSEN, R.D. Environmental management and manufacturing performance: The role of collaboration in the supply chain. International Journal of Production Economics, v. 111, n. 2, p. 299-315, 2008.

162. VACHON, S.; KLASSEN, R.D. Supply chain management and environmental technologies: The role of integration. International Journal of Production Research, v. 45, n. 2, p. 401-423, 2007.

163. VAN BERKEL, R. Eco-innovation: Opportunities for advancing waste prevention", ,"International Journal of Environmental Technology and Management, v. 7, n. 5-6, p. 527-550, 2007.

164. VEERAKAMOLMAL, P.; GUPTA, S. M. Analysis of design efficiency for the disassembly of modular electronic products. Journal of Electronics Manufacturing, v. 9, n. 1, p. 79-95, 2000.

165. VEERAKAMOLMAL, P.; GUPTA, S. M. Optimal analysis of lot-size balancing for multiproducts selective disassembly. International Journal of Flexible Automation and Integrated Manufacturing, v.,6, n. 3, p. 245-269, 1998.

166. VEZZOLI, C.; SCIAMA, D. Life Cycle Design: from general methods to product type specific guidelines and checklists: a method adopted to develop a set of guidelines/checklist handbook for the eco-efficient design of NECTA vending machines. Journal of Cleaner Production, v. 14, n. 15-16, p. 1319-1325, 2006.

167. VINODH, S. Improvement of agility and sustainability: A case study in an Indian rotary switches manufacturing organization. . Journal of Cleaner Production, v. 18, n. 10-11, p. 1015-1020, 2010.

168. VINODH, S.; RATHOD, G. Application of QFD for enabling environmentally conscious design in an Indian rotary switch manufacturing organization. International Journal of Sustainable Engineering, v. 3, n. 2, p. 95-105, 2010. 
169. VINODH, S.; RATHOD, G. Integration of ECQFD and LCA for sustainable product design. Journal of Cleaner Production, v. 18, n. 8, p. 833-842, 2010.

170. WAAGE, S.A. Re-considering product design: a practical "road-map" for integration of sustainability issues. Journal of Cleaner Production, v. 15, n. 7, p. 638-649, 2007.

171. WAGNER, M. On the relationship between environmental management, environmental innovation and patenting: Evidence from German manufacturing firms. Research Policy, v. 36, n. 10, p. 1587-1602, 2007.

172. WALKER, S. The chimera reified: Design, meaning and the post-consumerism object. Design Journal, v. 13, n. 1, p. 9-30, 2010.

173. WANYAMA, W.; ERTAS, A.; ZHANG, H.-C.; EKWARO-OSIRE S. Life-cycle engineering: Issues, tools and research. International Journal of Computer Integrated Manufacturing, v. 16, n. 4-5, p. 307-316, 2003.

174. WARDAK, A.; GORMAN, M.E.; SWAMI, N.; DESHPANDE, S. Identification of risks in the life cycle of nanotechnology-based products. Journal of Industrial Ecology, v. 12, n. 3, p. 435-448, 2008.

175. WESTKÄMPER, E. Assembly and disassembly processes in product life cycle perspectives. CIRP Annals - Manufacturing Technology, v. 52, n. 2, p. 579-588, 2003.

176. WESTKÄMPER, E.; ALTING, L.; ARNDT, G. Life Cycle Management and Assessment: Approaches and visions towards sustainable manufacturing. CIRP Annals - Manufacturing Technology, v. 49, n. 2, p. 501-522, 2000.

177. WONG, Y.L.; LEE, K.M.; YUNG, K.C. Model scenario for integrated environmental product assessment at the use of raw materials stage of a product. Resources, Conservation and Recycling, v. 54, n. 11, p. 841-850, 2010.

178. WU, M.-C.; LO, Y.-F.; HSU, S.-H. A fuzzy CBR technique for generating product ideas. Expert Systems with Applications, v. 34, n. 1, p. 530-540, 2008.

179. XING, K.; BELUSKO, M.; LUONG, L.; ABHARY, K. An evaluation model of product upgradeability for remanufacture. International Journal of Advanced Manufacturing Technology, v. 35, n. 1-2, p. 1-14, 2007.

180. XU, Q.L.; ONG, S.K.; NEE, A.Y.C. Evaluation of product performance in product family design re-use. International Journal of Production Research, v. 45, n. 18-19, p. 4119-4141, 2007.

181. XU, X.; CHEN, J.L.-Q.; XIE, S.Q. Framework of a product lifecycle costing system. Journal of Computing and Information Science in Engineering, v. 6, n. 1, p. 69-77, 2006.

182. YUAN, C.Y.; DORNFELD, D.A. A schematic method for sustainable material selection of toxic chemicals in design and manufacturing. Journal of Mechanical Design, Transactions of the ASME, v. 132, n. 9, p. 0910141-0910147, 2010.

183. ZACKRISSON, M.; ROCHA, C.; CHRISTIANSEN, K.; JARNEHAMMAR, A. Stepwise environmental product declarations: ten SME case studies. Journal of Cleaner Production, v. 16, n. 17, p. 1872-1886, 2008.

184. ZHANG, Y.; WANG, H.-P.; ZHANG, C. Green QFD-II: A life cycle approach for environmentally conscious manufacturing by integrating LCA and LCC into QFD matrices. International Journal of Production Research, v. 37, n. 5, p. 1075-1091, 1999.

185. ZHU, Q.H.; SARKIS, J. Relationships between operational practices and performance among early adopters of green supply chain management practices in Chinese manufacturing enterprises. Journal of Operations Management, v. 22, n. 3, p. 265-289, 2004. 


\section{APÊNDICE B - Protocolo de Pesquisa}

Este Apêndice contém a estruturação do protocolo de pesquisa ${ }^{6}$, que está dividido em quatro etapas: visão global do projeto; procedimentos de campo; determinação das questões; e guia para elaboração da dissertação.

\section{Visão global do projeto}

O presente trabalho aborda a integração de aspectos ambientais no PDP em uma empresa especializada em fabricação de sensores eletrônicos para automação industrial, comercial e de proteção humana e em uma produtora, exportadora e recicladora de papéis nos mercados de papéis e cartões para embalagens, embalagens de papelão ondulado e sacos industriais, que também produz e comercializa madeira em toras. Pretende-se através do estudo de caso buscar as práticas e experiências das unidades de análise, que apresentam complementos à literatura atual, focando na parte do desenvolvimento de novos produtos, na escolha por determinado método e/ou ferramenta de apoio para a integração de aspectos ambientais no PDP e na incorporação destes métodos e/ou ferramentas de apoio escolhidos ao PDP.

\section{Procedimentos de campo}

Após definidos os itens para análise, esta etapa inicia com o contato via telefone e/ou e-mail, procurando situar os responsáveis pelo PDP das unidades de análise quanto aos objetivos da pesquisa para, em seguida, agendar a entrevista (Apêndice B) com o responsável pelo PDP. Após as entrevistas, os dados foram enviados aos entrevistados para verificação e possível correção.

\section{Determinação das questões}

A fim de se atingir objetivo geral e os objetivos específicos deste trabalho, o presente buscou respostas as seguintes questões de pesquisa:

- Como ocorre a escolha por determinados métodos e/ou ferramentas de apoio?

- Como os métodos e/ou ferramentas de apoio escolhidos são incorporados ao PDP?

Para chegar a dados que subsidiassem respostas para estas questões, foram utilizados dois instrumentos para coleta de dados: análise de documentos públicos das empresas e a realização de um entrevista, aplicando o Apêndice B.

\section{Guia para a elaboração da dissertação}

Para facilitar na elaboração da dissertação, é viável enquanto se faz a coleta de dados já ir escrevendo de forma estruturada os dados obtidos e fazendo análises preliminares dos resultados obtidos, e conseqüentemente publicando-os. Lembrando que a dissertação deve ser elaborada de forma adequada e ter um esquema conceitual claro, que demonstre confiabilidade nos procedimentos para possibilitar repetibilidade da pesquisa, apresentando os mesmos resultados.

\footnotetext{
${ }^{6}$ Adaptado do Protocolo de Pesquisa desenvolvido por Varandas (2008)
} 


\section{APÊNDICE C - Roteiro de Entrevista Semi-Estruturado}

O presente roteiro de entrevista destina-se ao estudo empírico sobre a maneira como o Design para o Ambiente (DfE - Design for Environment) é implementado nas empresas. A pesquisa faz parte da Dissertação de Mestrado em Engenharia da Produção na área de Qualidade e Engenharia do Produto de Luciana C. L. Silva na Escola Politécnica da Universidade de São Paulo (USP). Trata-se de um roteiro de entrevista semi-estruturado:

1. Abaixo descreva as fases do Processo de Desenvolvimento de Produtos da Empresa.

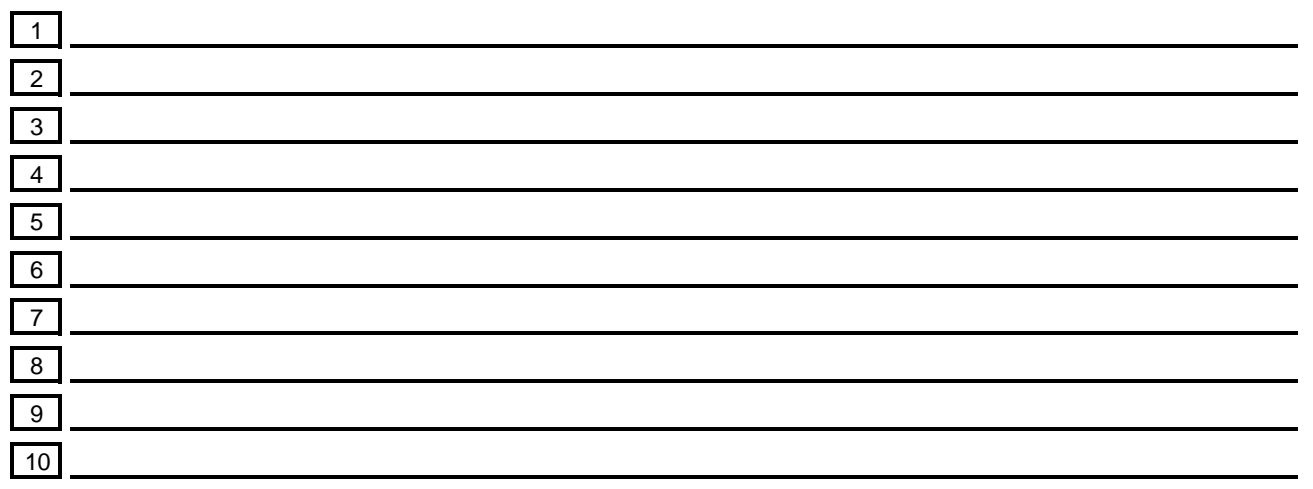

2. Na primeira coluna numere a ordem em que a empresa implementou (se implementou) os seguintes itens e na segunda coluna numere de 0 a 5 (0 para dificulta o DfE e 5 para facilita o DfE):

Design para o Ambiente - DfE

$\square \square$ Sistemas de Gestão Ambiental - SGA (HART, 1995; WAGNER, 2007; VACHON e KLASSEN, 2008)

$\square$ Sistemas de Gestão da Qualidade - SGQ (HART, 1995; VACHON e KLASSEN, 2008)

$\square \square$ — $\square \square$

$\square \square$

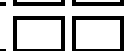

$\square \square$ Ferramentas da Qualidade (VINODH, 2010; VINODH e RATHOD, 2010a; VINODH e RATHOD, 2010b):

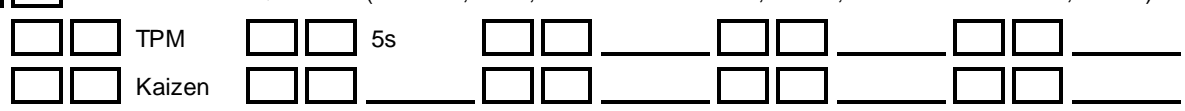

3. Existem normas e regulamentos ambientais de produtos para a área de atuação em que a empresa atua (PORTER e LINDE, 1995; HANDFIELD et al., 2001; KIM et al., 2006; SAVASKAN e VAN WASSENHOVE, 2006; FURTADO, 2007; FITZGERALD, HERRMANN e SCHMIDT, 2010; JABBOUR, 2010; LEE et al., 2010; LENOX, KING e EHRENFELD, 2010)?

Não $\square \operatorname{Sim}$

a) Se sim quais são estas normas?

b) Quem é responsável por estar atento ao surgimento destas normas (SCHMIDT e BUTT, 2006)?

4. A empresa exige Certificações / Declarações Ambientais de Produtos de seus fornecedores (ALTING, 1995; SINDING, 2000; SAVASKAN e VAN WASSENHOVE, 2006; ELLRAM, TATE e CARTER, 2008; HUBER, 2008; VACHON e KLASSEN, 2008; JABBOUR, 2010)?

Não $\square \operatorname{Sim}$

a) Se sim, quais são estas certificações ?

5. A empresa certifica os seus Produtos (MILES e COVIN, 2000; GINSBERG e BLOOM, 2004; SEIFFERT, 2005)?

$\square$ Não $\square \operatorname{Sim}$

a) Se sim, quais são estas certificações ? 
6. Assinale as motivações para a implementação do DfE (numere de 1 a 5 - 1 para pouco importante e 5 para muito importante) (HUNT e AUSTER, 1990; PORTER e VAN DER LINDE, 1995; GOTTBERG et al., 2006; KIM et al., 2006; TINGSTRÖM e KARLSSON, 2006; BEVILACQUA, CIARAPICA e GIACCHETTA, 2007; CAGNO e TRUCCO, 2007; GE e WANG, 2007; CHOI, NIES e RAMANI, 2008; FITZGERALD, HERRMANN e SCHMIDT, 2010; JABBOUR, 2010):
$\square$ Vantagem Competitiva
$\square$ Melhoraria da Imagem da Empresa
$\square$ Pressão da Opinião Pública
$\square$ Regulamentos mais rigorosos
$\square$ Aumentar a Qualidade em seus Produtos
$\square$ Maior produtividade
$\square$ Redução de Multas Ambientais
$\square$ Acesso a Novos Mercados
$\square$ Acesso a Mercados Externos
$\square$ Renovação do Mix deProdutos
$\square$ Proibição de Substâncias Perigosas
$\square$ Redução de Custos
$\square$ Exploração de Oportunidades de Inovações em Produtos
$\square$ Exploração de Oportunidades de Inovações em Processos
$\square$ Aumento do Valor de suas Ações através da inclusão da empresa no Indice Dow Jones de Sustentabilidade
$\square$ Atração de consumidores ambientalmente conscientes;
$\square$ Outros:

7. Assinale os benefícios do DfE (HUNT e AUSTER, 1990; PORTER e VAN DER LINDE, 1995; MILES e COVIN, 2000; PRESTON, 2001; MANGUN e THUSSTON, 2002; MAXWELL e VAN DER VORST, 2003; GINSBERG e BLOOM, 2004; SEIFFERT, 2005; TIEN, CHUNG e TSAI, 2005; GOTTBERG et al., 2006; TINGSTRÖM e KARLSSON, 2006; TINGSTRÖM, SWANSTROM e KARLSSON, 2006; BEVILACQUA, CIARAPICA e GIACCHETTA, 2007; CAGNO e TRUCCO, 2007; EVANS, PARTIDARIO e LAMBERT, 2007; GE e WANG, 2007; LEE et al., 2007; VAN BERKEL, 2007; CHOI, NIES e RAMANI, 2008; JABBOUR e SANTOS, 2008; NY et al., 2008; HARA et al., 2009; BOVESPA, 2010; FITZGERALD, HERRMANN e SCHMIDT, 2010; JABBOUR, 2010; PALOUSIS, LUONG e ABHARY, 2010; VINODH, 2010; VINODH e RATHOD, 2010a)

$\square$ Melhoria da Funcionalidade dos Produtos

$\square$ Redução de Custos

$\square$ Vantagem Competitiva

$\square$ Maior Satisfação dos Clientes

$\square$ Novas Oportunidades de Negócios

$\square$ Melhoria na Reputação da Empresa

$\square$ Maior Atratividade para Diversos Investidores

$\square$ Novas Oportunidades de Negócios

$\square$ Novas Oportunidades de Mercado

$\square$ Desenvolvimento de Capacidades em termos de Conhecimentos e Competências

$\square$ Aumento do Valor de suas Ações através da inclusão da empresa no ISE - Índice de Sustentabilidade Empresarial

$\square$ Aumento do Valor de suas Ações através da inclusão da empresa no Indice Dow Jones de Sustentabilidade

$\square$ Melhora no Relacionamento com os Fornecedores

$\square$ Acesso mais fácil às fontes de recursos que podem financiar os seus projetos

$\square$ Outros:

8. Quanto a relação entre desempenho dos produtos resultantes do DfE e dos produtos tradicionais, assinale as alternativas corretas:

A empresa trabalha com uma estratégia de portfólio (desenvolve produtos verdes e não verdes) (MANGUN e THUSSTON, 2002; XU, ONG e NEE, 2007; LUH, CHU e PAN, 2010)

Os produtos com apelo ambiental não tem alcançado uma posição favorável no mercado (KUO, WU e SHIEH, 2009)

Os produtos com apelo ambiental (1 para "nunca", 3 para "às vezes", 5 para "sempre"):
$\square$ São mais competitivos
Custam menos
$\square$ São mais lucrativos
Possuem melhor desempenho

9. Assinale os fatores que impulsionam o direcionamento das estratégias do DfE:

$\square$ Fluxos de informação e conhecimentos de consumidores (PUJARI e WRIGHT, 1999; TINGSTRÖM e KARLSSON, 2006)

$\square$ Fluxos de informação e conhecimentos de funcionários (LEE, GEMBA e KODAMA, 2006; JABBOUR e SANTOS, 2008)

Fluxos de informação e conhecimentos da sociedade (LEE, GEMBA e KODAMA, 2006). 
10. Assinale os objetivos do Processo de Desenvolvimento de Produtos (HUNT e AUSTER, 1990; PORTER e VAN DER LINDE, 1995; PUJARI e WRIGHT, 1999; BAUMANN et al., 2002; NIELSEN e WENZEL, 2002; MAXWELL e VAN DER VORST, 2003; CAGNO e TRUCCO, 2007; LI et al., 2008; KUO, WU e SHIEH, 2009; MENGONI, GERMANI e MANDORLI, 2009; PIGOSSO et al., 2010):

$\begin{array}{ll}\square \text { Qualidade } & \square \text { Tecnologia / Inovação } \\ \square \text { Custo } & \square \text { Funcionalidade } \\ \square \text { Estética } & \square \text { Impacto Ambiental } \\ \square \text { Ergonomia } \\ \end{array}$

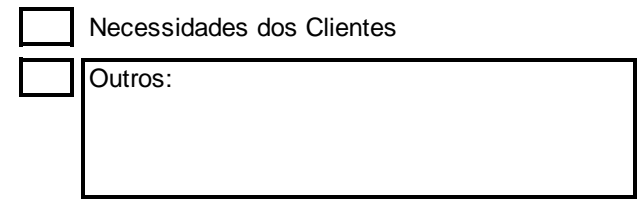

a) Existe priorização entre eles?

$\square$ Não $\square$ Sim:

11. Os objetivos ambientais estão expressos no planejamento estratégico da empresa?

$\square$ Não

Sim (ALTING e JOGENSEN, 1993; ANDERSSON et al., 1998; HANDFIELD et al., 2001; MAXWELL e VAN DER VORST, 2003)

13. Assinale em que fases do PDP os objetivos ambientais são integrados (ALTING e JOGENSEN, 1993; ALTING, 1995; ZHANG, WANG e ZHANG, 1999; NIELSEN e WENZEL, 2002; FITCH e COOPER, 2005a; KOBAYASHI, 2005; KOBAYASHI et al., 2005; JOHANSSON, 2006; CAGNO e TRUCCO, 2007; LEE et al., 2007; GOTZCH, 2008; MASCLE e ZHAO, 2008; NY et al., 2008; WARDAK et al., 2008; WU, LO e HSU, 2008; RIOU e MASCLE, 2009; BOHM et al., 2010; DEVANATHAN et al., 2010; FITZGERALD, HERRMANN e SCHMIDT, 2010; PIGOSSO et al., 2010; RAMANI et al., 2010; VINODH e RATHOD, 2010a; VINODH e RATHOD, 2010b):

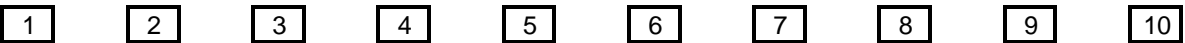 \\ Integração em série (ALTING e JOGENSEN, 1993; CAGNO e TRUCCO, 2007) \\ $\square$ Integração paralela (ALTING e JOGENSEN, 1993; CAGNO e TRUCCO, 2007) \\ $\square$ Integração na forma de check-points (HANDFIELD et al., 2001)}

14. Na primeira coluna assinale as iniciativas normalmente adotadas no DfE e atribua pesos de 1 a 5 , onde 5 corresponde às iniciativas muito adotadas e 1 para as iniciativas raramente adotadas (ALTING, 1993; ALTING e JOGENSEN, 1993; AZZONE e a NOCI, 1996; GUNGOR e GUPTA, 1999; LENOX, KING e EHRENFELD, 2000; PERSSON, 2001; MAXWELL e VAN DER VORST, 2003; WANYAMA et al., 2003; PUJARI, PEATTIE e WRIGHT, 2004; KOBAYASHI et al., 2005; BYGGETH e HOCHSCHORNER, 2006; XU, CHEN e XIE, 2006; BYGGETH, BROMAN e ROBÈRT, 2007; CAGNO e TRUCCO, 2007; GOTZSCH, 2008; LI et al., 2008; BALA et al., 2010; LEWANDOWSKA e KURCZEWSKI, 2010; PIGOSSO et al., 2010; RAMANI et al., 2010; SONG e LEE, 2010; VINODH, 2010; VINODH e RATHOD, 2010a; WONG, LEE e YUNG, 2010). Na segunda coluna numere de acordo com a fase do PDP em que são avaliadas:

A - Pré-Produção; B - Produção; C - Transporte; D - Uso; e E - Descarte

$\square \square A$ - Seleção de Materiais

$\square \square$ B - Melhoria da Performance dos Processos de Produção

$\square$ B - Redução de Despesas Gerais de Produção

$\square \square$ C - Design para Baixo Volume

$\square \square$ C - Design para Baixo Peso

$\square \square$ C - Produção em Forma Concentrada

$\square \square \mathrm{D}$ - Redução de consumo do produto (energia, água...)

$\square \square$ E - Design para a Reciclabilidade

$\square \square E$ - Design para a Reutilização

$\square \square$ E - Orientações de descarte aos usuários

$\square \square$ E - Design para a Capacidade de Atualização

$\square \square$

$\square \square$

$\square \square$

$\square \square$

$\square \square$ $\square \square$ c - Melhoria da Logística deTransportes

$\square \square$ D - Aumento da Eficiência Funcional

$\square \square$ D - Projeção do tempo de vida útil adequado

$\square$ D - Uso de Embalagens Recarregáveis

$\square \square$ D - Adaptação aos padrões de uso individual

$\square \square$ D - Orientações de utilização aos usuários

$\square \square D$ - Segurança do Produto

$\square \square$ E - Design para a Remanufaturabilidade

$\square \square$ E - Design para a Desmontagem

$\square \square$ E - Extensão da vida útil

$\square \square D$ - Design para a montagem

$\square \square$

$\square \square$

$\square \square$

$\square \square$

$\square \square$

$\square$ C - escolha de materiais para embalagens amigáveis ambientalmente

Quais fases do ciclo de vida dos produtos geram maior impacto ambiental? 


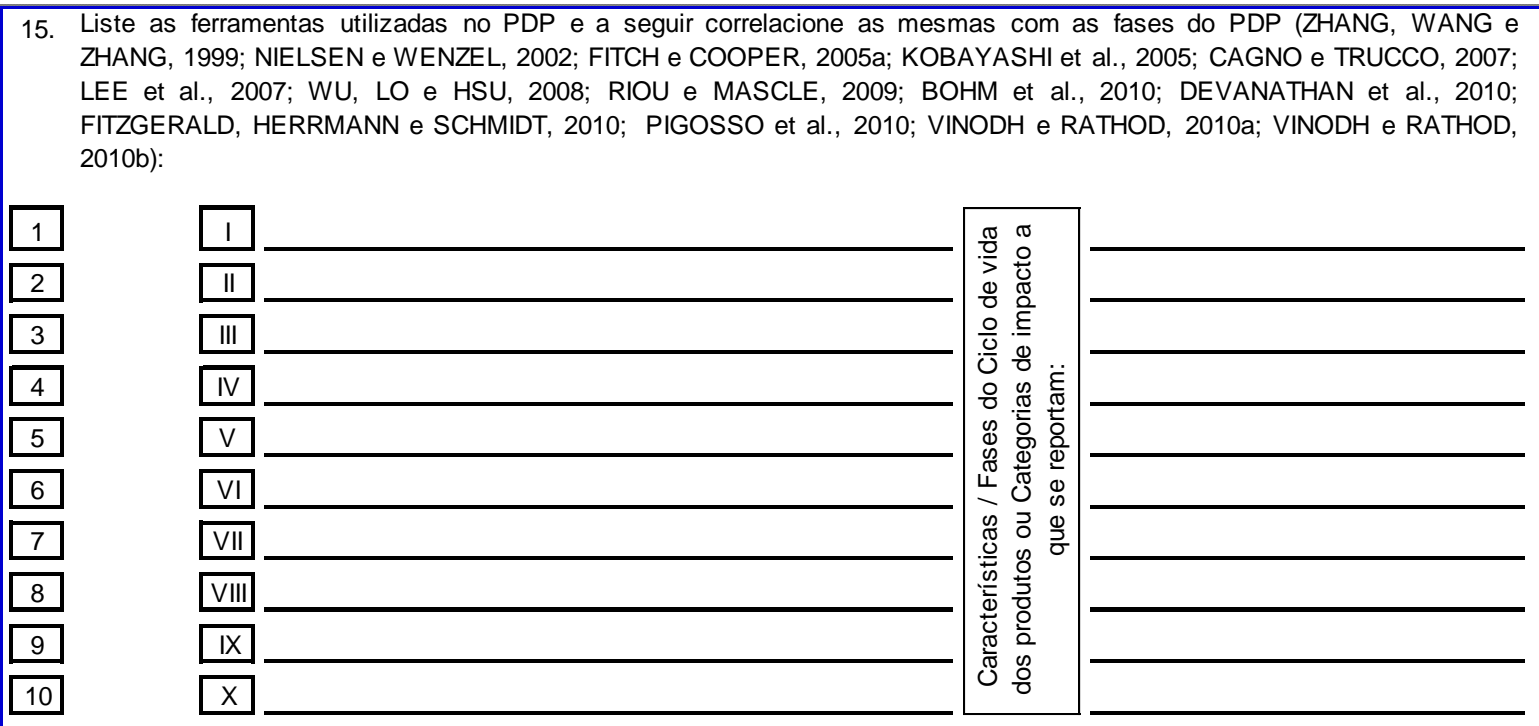

16. Em relação a estas ferramentas atribua pesos de 1 a 5 (1 para pouco importante e 5 para muito importante):

A sua utilização é obrigatória (TINGSTRÖM, SWANSTROM e KARLSSON, 2006)?

Necessidade de extensos treinamentos (HANDFIELD et al., 2001; MAXWELL e VAN DER VORST, 2003; LINDAHL, 2006; TINGSTRÖM, SWANSTROM E KARLSSON, 2006)

Fácil de Usar (HANDFIELD et al., 2001; MAXWELL e VAN DER $\square \square \square \square \square \square \square \square \square \square$ VORST, 2003; LINDAHL, 2006; TINGSTRÖM, SWANSTROM e KARLSSON, 2006)

Simples (KOBAYASHI, 2005; KOBAYASHI et al., 2005; VEZZOLI e SCIAMA, 2006; GOTZSCH, 2008; BALA et al., 2010; BOHM et al., 2010; COLLADO-RUIZ e OSTAD-AHMAD-GHORABI, 2010b KISHITA et al., 2010; LUH, CHU e PAN, 2010; SONG e LEE, 2010)

2010) / Qt para Quantitativa (ALTING, 1995; HUR et al., 2005; KLOEPFFER, 2008; BALA et al., 2010) / Sm para Semi-Quantitativa (ALTING, 1995; HUR et al., 2005; BALA et al., 2010; DEVANATHAN et al., 2010)

É rápida (GUNGOR e GUPTA, 2001; HANDFIELD et al., 2001; NIELSEN e WENZEL, 2002; KOBAYASHI, 2005; KOBAYASHI et al., \begin{tabular}{|l|l|l|l|l|l|l|l|l|l|}
\hline $\mathrm{I}$ & $\mathrm{II}$ & $\mathrm{III}$ & $\mathrm{IV}$ & $\mathrm{VI}$ & $\mathrm{VII}$ \\
\hline
\end{tabular} $\square \square \square \square \square \square \square \square \square \square$ 2005; LINDAHL, 2006; TINGSTRÖM, SWANSTROM e KARLSSON, 2006; WU, LO e HSU, 2008; BALA et al., 2010; BOHM et al., 2010; SONG e LEE, 2010)

Retorna bons resultados (HANDFIELD et al., 2001; BAUMANN, BOONS e BRAGD; 2002; LINDAHL, 2006; SCHMIDT e BUTT, 2006; TINGSTRÖM, SWANSTROM e KARLSSON, 2006; GOTZSCH, 2008; JIANJUN et al., 2008; SCHIAVONE, PIERINI e ECKERT, 2008; VINODH, 2010)

Adaptável às tarefas do dia-a-dia do PDP (HANDFIELD et al., 2001; NIELSEN e WENZEL, 2002; LINDAHL, 2006; SCHMIDT e BUTT, 2006; TINGSTRÖM, SWANSTROM e KARLSSON, 2006; ALMEIDA et al., 2010; BALA et al., 2010)

Exige conhecimento e experiência do usuário (ALTING e JOGENSEN, 1993; BOKS, 2006; DJASSEMI, 2009; KURCZEWSKI e LEWANDOWSKA, 2010; LEWANDOWSKA e KURCZEWSKI, 2010)

\section{Está integrada..}

a outras ferramentas do PDP (ZHANG, WANG e ZHANG, 1999; KOBAYASHI, 2005; KOBAYASHI et al., 2005; SCHMIDT e BUTT, 2006; XU, CHEN e XIE, 2006; CAGNO e TRUCCO, 2007; LEE et al., 2007; SINGH, GOODYER e POPPLEWELL, 2007 LI et al., 2008; JIANJUN et al., 2008; BRAD, 2009; MENGONI, GERMANI e MANDORLI, 2009; RIOU e MASCLE, 2009; DEVANATHAN et al., 2010; VINODH, 2010; VINODH e RATHOD, 2010a) 
ao processo de tomada de decisão (ZHANG, WANG e ZHANG, 1999; KHAN, SADIQ e VEITCH, 2004; KOBAYASHI, 2005; KOBAYASHI et al., 2005; LEIBRECHT, 2005; RUDENAUER et al., 2005; NY et al., 2006; SCHMIDT e BUTT, 2006; XU, CHEN e XIE, 2006; BYGGETH, BROMAN e ROBÈRT, 2007; CAGNO e TRUCCO, 2007; STAIKOS e RAHIMIFARD, 2007; CHOI, NIES E RAMANI, 2008; JIANJUN et al., 2008; LI et al., 2008; WU, LO e HSU, 2008; HARA et al., 2009; KUO, WU e SHIEH, 2009; ALMEIDA et al., 2010; BOHM et al., 2010; DEVANATHAN et al., 2010; PALOUSIS, LUONG e ABHARY, 2010; VINODH, 2010)

a ferramentas de outros setores da empresa (MAXWELL e VAN DER VORST, 2003; SCHMIDT e BUTT, 2006; BYGGETH, BROMAN e ROBÈRT, 2007; JIANJUN et al., 2008; VINODH, 2010)

com outros setores da empresa (MAXWELL e VAN DER $\square \square \square \square \square \square \square \square \square \square \square \square$ VORST, 2003; JIANJUN et al., 2008)

aos parceiros da cadeia de suprimentos (HART, 1995; FRYXELL e VRYZA, 1999; WESTKÄMPER, ALTING e ARNDT, 2000; DE BAKKER e NIJHOF, 2002; FIKSEL, 2003; MAXWELL e VAN DER VORST, 2003; PUJARI, WRIGHT e PEATTIE, 2003; ZHU e SARKIS, 2004; PUJARI, 2006; SAVASKAN E VAN WASSENHOVE, 2006; ABU BAKAR e RAHIMIFARD, 2007; BYGGETH, BROMAN e ROBÈRT, 2007; CAGNO e TRUCCO, 2007; EVANS, PARTIDARIO e LAMBERT, 2007; GE e WANG, 2007; JOHANSSON, LUTO e FLEISCHER; 2007; WAAGE, 2007; CHALAL e GHOMARI, 2008; GEHIN, ZWOLINSKI e BRISSAUD, 2008; GOTZSCH, 2008; JIANJUN et al., 2008; KURK e EAGAN, 2008; VACHON e KLASSEN, 2008; ZACKRISSON et al., 2008; KNIGHT e JENKINS, 2009; KOEHLER e WILDBOLZ, 2009; MENGONI, GERMANI e MANDORLI, 2009; RIOU e MASCLE, 2009; LEWANDOWSKA e KURCZEWSKI, 2010; RAMANI et al., 2010; TSENG, 2010a)

Facilita a troca de informações (ZHANG, WANG e ZHANG, 1999; KOBAYASHI, 2005; KOBAYASHI et al., 2005; SCHMIDT e BUTT, 2006; XU, CHEN e XIE, 2006; CAGNO e TRUCCO, 2007; LEE et al., 2007; SINGH, GOODYER e POPPLEWELL, 2007; GOTZSCH, 2008; JIANJUN et al., 2008; LI et al., 2008; JIANJUN et al., 2008; SCHIAVONE, PIERINI e ECKERT, 2008; BRAD, 2009; MENGONI, GERMANI e MANDORLI, 2009; RIOU e MASCLE, 2009; DEVANATHAN et al., 2010; VINODH, 2010; VINODH e RATHOD, 2010a)

entre as fases do PDP

entre as ferramentas do PDP

com outros setores da empresa

com os parceiros da cadeia de suprimentos

Está integrada ao Design Assistido por Computador (CAD) (MAXWELL e VAN DER VORST, 2003; LEIBRECHT, 2005; BYGGETH, BROMAN e ROBÈRT, 2007; JIANJUN et al., 2008; CHU et al., 2009; MENGONI, GERMANI e MANDORLI, 2009; VINODH,

Aborda as necessidades dos clientes (KOBAYASHI et al., 2005; RUDENAUER et al., 2005; BOVEA e WANG, 2007; CHALAL e GHOMARI, 2008; KUO, WU e SHIEH, 2009; LEWANDOWSKA e KURCZEWSKI, 2010; PIGOSSO et al., 2010)

Aborda a disposição a pagar do consumidor (BOVEA e WANG, 2007)

Aborda os custos do ciclo de vida (RUDENAUER et al., 2005; XU, CHEN e XIE, 2006; ALMEIDA et al., 2010; PALOUSIS, LUONG e ABHARY, 2010)

Aborda outros objetivos do PDP (SHU e FLOWERS, 1999; ZHANG, WANG e ZHANG, 1999; MANGUN e THURSTON, 2002; OKUMURA, MORIKUNI e OKINO, 2003; KHAN, SADIQ e VEITCH, 2004; KOBAYASHI, 2005; KOBAYASHI et al., 2005; RUDENAUER et al., 2005; XU, CHEN e XIE, 2006; BOVEA e WANG, 2007; CAGNO e TRUCCO, 2007; GIUDICE e FARGIONE, 2007; STAIKOS e RAHIMIFARD, 2007; SINGH, GOODYER e POPPLEWELL, 2007; CHALAL e GHOMARI, 2008; CHOI, NIES E RAMANI, 2008; JIANJUN et al., 2008; LI et al., 2008; WU, LO e HSU, 2008; BRAD, 2009; HARA et al., 2009; KUO, WU e SHIEH, 2009; MENGONI, GERMANI e MANDORLI, 2009; RIOU e MASCLE, 2009; DEVANATHAN et al., 2010; LUH, CHU e PAN, 2010; PALOUSIS, LUONG e ABHARY, 2010; VINODH e RATHOD, 2010a) 
Aborda os impactos ambientais do ciclo de vida (VEERAKAMOLMAL E GUPTA, 1998; SHU e FLOWERS, 1999; GUNGOR e GUPTA, 2001; KOBAYASHI, 2005; KOBAYASHI et al., 2005; LEE et al., 2007; STAIKOS e RAHIMIFARD, 2007; SINGH, GOODYER e POPPLEWELL, 2007; CHOI, NIES E RAMANI, 2008; JIANJUN et al., 2008; LI et al., 2008; WU, LO e HSU, 2008; RIOU e MASCLE, 2009; ALMEIDA et al., 2010; BAKKER et al., 2010; BOHM et al., 2010; PIGOSSO et al., 2010; SONG e LEE, 2010; VINODH e RATHOD,

Aborda aspectos sociais do ciclo de vida dos produtos (HAUSCHILD, WENZEL e ALTING, 1999; MAXWELL e VAN DER VORST, 2003; EVANS, PARTIDARIO e LAMBERT, 2007; HAUSCHILD, DREYER e JORGENSEN, 2008; KLOEPFFER, 2008; SCHMIDT e TAYLOR, 2008; BRAD, 2009; LEWANDOWSKA e KURCZEWSKI, 2010; PIGOSSO et al., 2010)

Fornece informações para decisões de trade-offs (ZHANG, WANG e ZHANG, 1999; KHAN, SADIQ e VEITCH, 2004; KOBAYASHI, 2005 KOBAYASHI et al., 2005; LEIBRECHT, 2005; RUDENAUER et al., 2005; NY et al., 2006; SCHMIDT e BUTT, 2006; XU, CHEN e XIE, 2006; BYGGETH, BROMAN e ROBÈRT, 2007; CAGNO e TRUCCO, 2007; STAIKOS e RAHIMIFARD, 2007; CHOI, NIES E RAMANI, 2008; Ll et al., 2008; WU, LO e HSU, 2008; HARA et al., 2009; KUO, WU e SHIEH, 2009; ALMEIDA et al., 2010; BOHM et al., 2010; DEVANATHAN et al., 2010; PALOUSIS, LUONG e ABHARY, 2010; VINODH, 2010)

\section{Ambientais \\ Tradicionais \\ Mistos}

Torna o DfE mais Ágil (MAXWELL e VAN DER VORST, 2003; LEIBRECHT, 2005; BYGGETH, BROMAN e ROBÈRT, 2007; JIANJUN et al., 2008; CHU et al., 2009; MENGONI, GERMANI e MANDORLI, 2009; VINODH, 2010)

Reduz custos (PIGOSSO et al., 2010)

Reduz tempo (PIGOSSO et al., 2010)

É utilizada em projetos simples (ALTING, 1995; JOHANSSON, 2006) É utilizada em projetos complexos (ALTING, 1995; JOHANSSON, 2006)

É uma lista de verificação (LUTTROPP e LAGERSTEDT, 2006; WONG, LEE e YUNG, 2010)

É destinada à obtenção de rótulos ecológicos (KISHITA et al., 2010). Qual?

É constantemente atualizada (NY et al., 2006; SCHMIDT e BUTT, 2006; BYGGETH, BROMAN e ROBÈRT, 2007)?

Por quem (SCHMIDT e BUTT, 2006)?

Disponibilidade de banco de dados (ALTING, 1995)

Banco de dados customizado (ALTING e JOGENSEN, 1993; ALTING, 1995)

Banco de dados constantemente atualizado (ALTING JOGENSEN, 1993; ALTING, 1995)

Por quem (SCHMIDT e BUTT, 2006)?

O usuário é (LINDAHL, 2006):

Quem escolheu / comprou (LINDAHL, 2006)?

Quem desenvolveu (SCHMIDT e BUTT, 2006)?

\begin{tabular}{|c|c|c|}
\hline \begin{tabular}{|l|}
$*$ \\
\end{tabular} & $\S$ & $\square$ \\
\hline \begin{tabular}{|l|}
$\&$ \\
\end{tabular} & $?$ & 1 \\
\hline$\%$ & $\$$ & 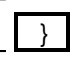 \\
\hline \begin{tabular}{|l|}
$@$ \\
\end{tabular} & $\#$ & $\square$ \\
\hline \begin{tabular}{|l|}
+ \\
\end{tabular} & $!$ & $\Delta$ \\
\hline
\end{tabular}


17. Numere os facilitadores do DfE de acordo com a sua concepção de 1 a 5 (1 para pouco importante e 5 para muito importante) e marque com um $\mathrm{X}$ os que a empresa utiliza:

Ferramentas de apoio ao DfE (HANDFIELD et al., 2001; MAXWELL e VAN DER VORST, 2003; LINDAHL, 2006; NY et al., 2006; SOUSA e WALLACE, 2006; TINGSTRÖM, SWANSTROM e KARLSSON, 2006; BYGGETH, BROMAN e ROBÈRT, 2007; CAGNO e TRUCCO, 2007; STAIKOS e RAHIMIFARD, 2007; ALMEIDA et al., 2010; PIGOSSO et al., 2010). Quais?

Integração do PDP com outros departamento da empresa (WESTKÄMPER, ALTING e ARNDT, 2000; FIKSEL, 2003; MAXWELL E VAN DER VORST, 2003; CHUNG E PENG, 2006; ABU BAKAR e RAHIMIFARD; 2007; EVANS, PARTIDARIO e LAMBERT, 2007; JOHANSSON, LUTO e FLEISCHER; 2007; GEHIN, ZWOLINSKI e BRISSAUD, 2008).

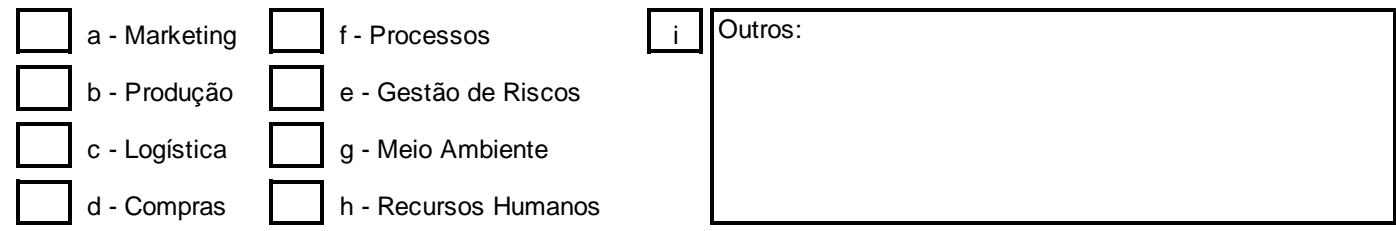

Integração do PDP com outras entidades. (WESTKÄMPER, ALTING e ARNDT, 2000; FIKSEL, 2003; MAXWELL e VAN DER VORST, 2003; CHUNG e PENG, 2006; ABU BAKAR e RAHIMIFARD; 2007; EVANS, PARTIDARIO e LAMBERT, 2007; JOHANSSON, LUTO e FLEISCHER; 2007; GEHIN, ZWOLINSKI E BRISSAUD, 2008; MARX, DE PAULA e SUM, 2010). Quais?

$\square$ Fornecedores $\square$ Varejistas
$\square$ Clientes $\quad \square$ Concorrentes
$\square$ Distribuidores $\quad \square$ Governo
$\square$ Recicladores

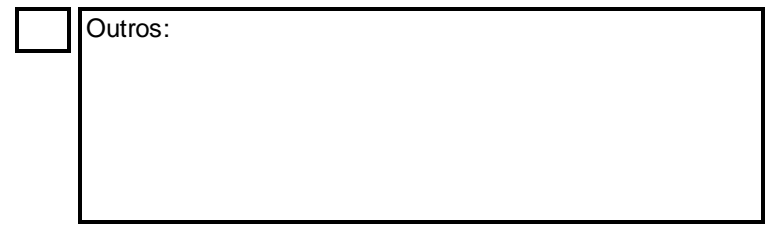

Treinamentos sobre o DfE (ALTING e JOGENSEN, 1993; ALTING, 1995; SCHMIDT e BUTT, 2006; NY et al., 2008)

Integração com a Alta Administração (LINDAHL, 2006; TINGSTRÖM, SWANSTROM e KARLSSON, 2006; NY et al., 2008; VINODH, 2010)

Acesso a Guias Setoriais (BALA et al., 2010)

Estimular a cooperação entre os diversos atores (HART, 1995; BYGGETH, BROMAN e ROBÈRT, 2007; EVANS, PARTIDARIO e LAMBERT, 2007; CHALAL e GHOMARI, 2008; NY et al., 2008)

Mecanismos de Gestão do Conhecimento Ambiental (ALTING e JOGENSEN, 1993; ALTING, 1995; HART, 1995; TIEN, CHUNG e TSAI, 2005; JOHANSSON, 2006; NY et al., 2006; TINGSTRÖM, SWANSTROM E KARLSSON, 2006; BYGGETH, BROMAN e ROBÈRT, 2007; GUNTHER, SEBASTIAN e MARCO, 2007; HOUE e GRABOT, 2007; KIVIMAA, 2008; NY et al., 2008; BOHM et al., 2010; FITZGERALD, HERMANN e SCHMIDT, 2010; KURCZEWSKI e LEWANDOWSKA, 2010; LEWANDOWSKA e KURCZEWSKI, 2010; TSENG, 2010a; TSENG, 2010b)

Clara definição de papéis e responsabilidades (TINGSTRÖM, SWANSTROM e KARLSSON, 2006; JOHANSSON e MAGNUSSON, 2006)

Integração com Especialistas Ambientais (ALTING e JOGENSEN, 1993; HANDFIELD et al., 2001; BAUMANN, BOONS e BRAGD, 2002; JOHANSSON E MAGNUSSON, 2006; SCHMIDT e BUTT, 2006; NY et al., 2008; KIVIMAA, 2008)

Especialistas Ambientais (ALTING e JOGENSEN, 1993; HANDFIELD et al., 2001; BAUMANN, BOONS E BRAGD, 2002; JOHANSSON E MAGNUSSON, 2006; SCHMIDT e BUTT, 2006; NY et al., 2008; KIVIMAA, 2008)

Exposição a exemplos de casos de sucesso (SCHMIDT, 2003; FITZGERALD, HERMANN e SCHMIDT, 2010)

Discussões sobre o DfE (JOHANSSON e MAGNUSSON, 2006; LINDAHL, 2006; NY et al., 2006; BYGGETH, BROMAN e ROBÈRT, 2007; GUNTHER, SEBASTIAN e MARCO, 2007; GOTZSCH, 2008; KIVIMAA, 2008; NY et al., 2008; PIGOSSO et Políticas de RH voltadas a dimensão ambiental (HANDFIELD et al., 2001; JABBOUR e SANTOS, 2008) al., 2010)

Comunicação com grupos de interesse relacionados ou organzações de apoio (TIEN, CHUNG e TSAl, 2005; TINGSTRÖM, SWANSTROM e KARLSSON, 2006)

Estudo Piloto (ALTING, 1995; JOHANSSON e MAGNUSSON, 2006; NY et al., 2006; BYGGETH, BROMAN e ROBÈRT, 2007)

Acesso a informações ambientais no grupo (TINGSTRÖM, SWANSTROM e KARLSSON, 2006)

Brainstormings (NY et al., 2006; BYGGETH, BROMAN e ROBÈRT, 2007)

Estimular a Criatividade (JOHANSSON e MAGNUSSON, 2006; NY et al., 2006; BYGGETH, BROMAN e ROBÈRT, 2007; VAN BERKEL, 2007; GOTZSCH, 2008; COLLADO-RUIZ e OSTADAHMAD-GHORABI, 2010b)

Designers capacitados em DfE (JOHANSSON, 2006; AZEVEDO e NOLASCO, 2009; DJASSEMI, 2009) 


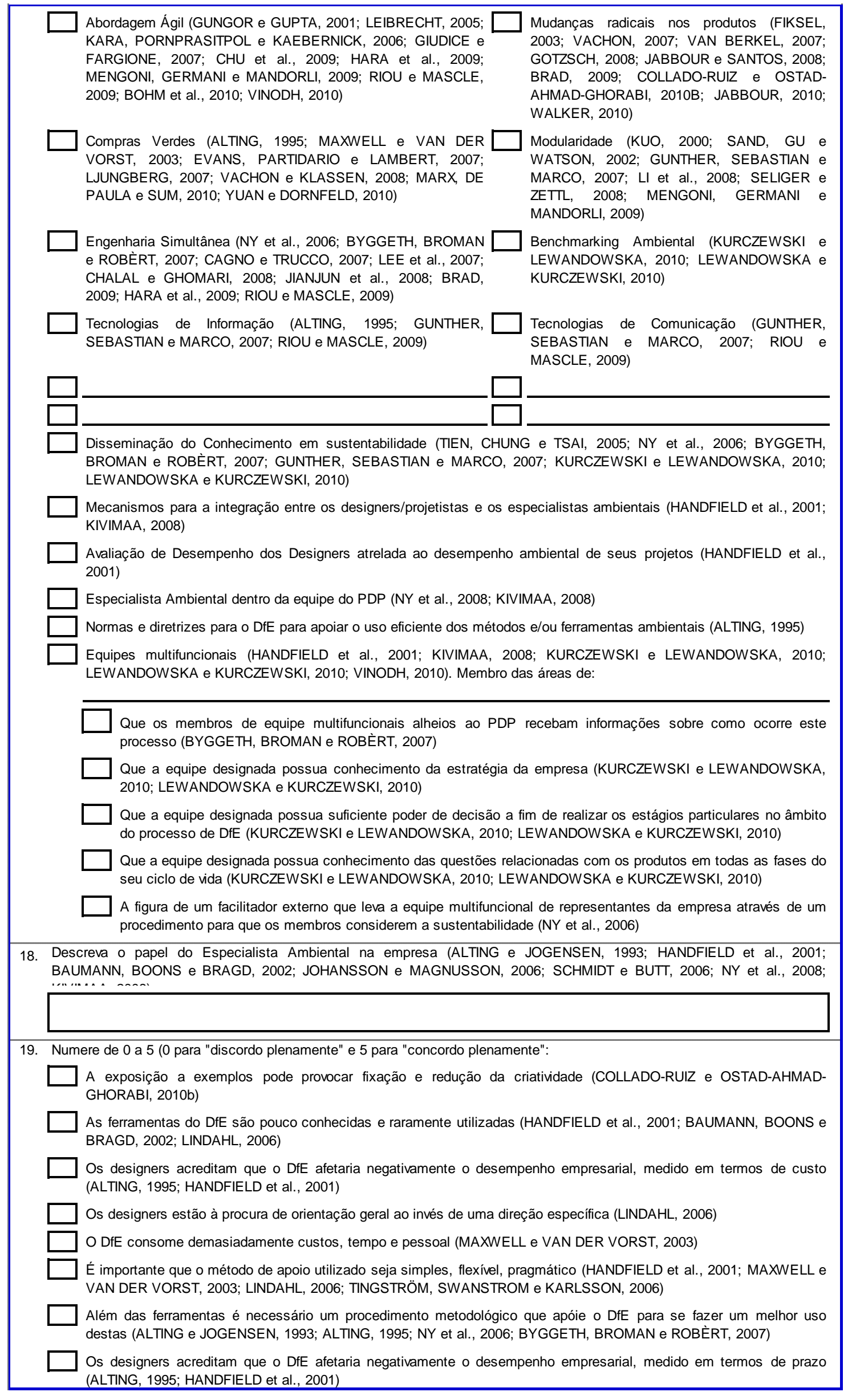


Os designers acreditam que o DfE afetaria negativamente o desempenho empresarial, medido em termos de qualidade (HANDFIELD et al., 2001)

Os designers acreditam que o DfE afetaria negativamente o desempenho empresarial, medido em termos de flexibilidade (HANDFIELD et al., 2001)

$\square$ Os designers não tem tempo para passar pelos diversos treinamentos das ferramentas DfE (HANDFIELD et al., 2001)

Os designers vêem as questões ambientais como restrições a serem vencidas para se poder dar continuidade à próxima etapa do projeto (ALTING, 1995; HANDFIELD et al., 2001)

20. Nos estudos ambientais, quais são as fronteiras definidas no sistema para análise (ALTING e JOGENSEN, 1993; ALTING, 1995; WESTKÄMPER, ALTING e ARNDT, 2000; LUTTROPP e LAGERSTEDT, 2006; KLOEPFFER, 2008; CULLEN e ALLWOOD, 2009; KOEHLER e WILDBOLZ, 2009; ALMEIDA et al., 2010; DEVANATHAN et al., 2010; RAMANI et al., 2010; SONG e LEE, 2010)?

Categoria de impacto:

Fases do ciclo de vida:

O usuário verifica se os limites do sistema coincidem com estudos de outros produtos (CULLEN e ALLWOOD, 2009)?

$\square$ Não $\square \operatorname{Sim}$

21. Como funciona o DfE na empresa? A empresa possui um método próprio? Como funciona?

22. Gostaria de acrescentar algo?

23. Autoriza a divulgação do nome da empresa?

Não $\square$ Sim 
ANEXO A - Formulário de Planejamento das Atividades de Projetos (PAP)

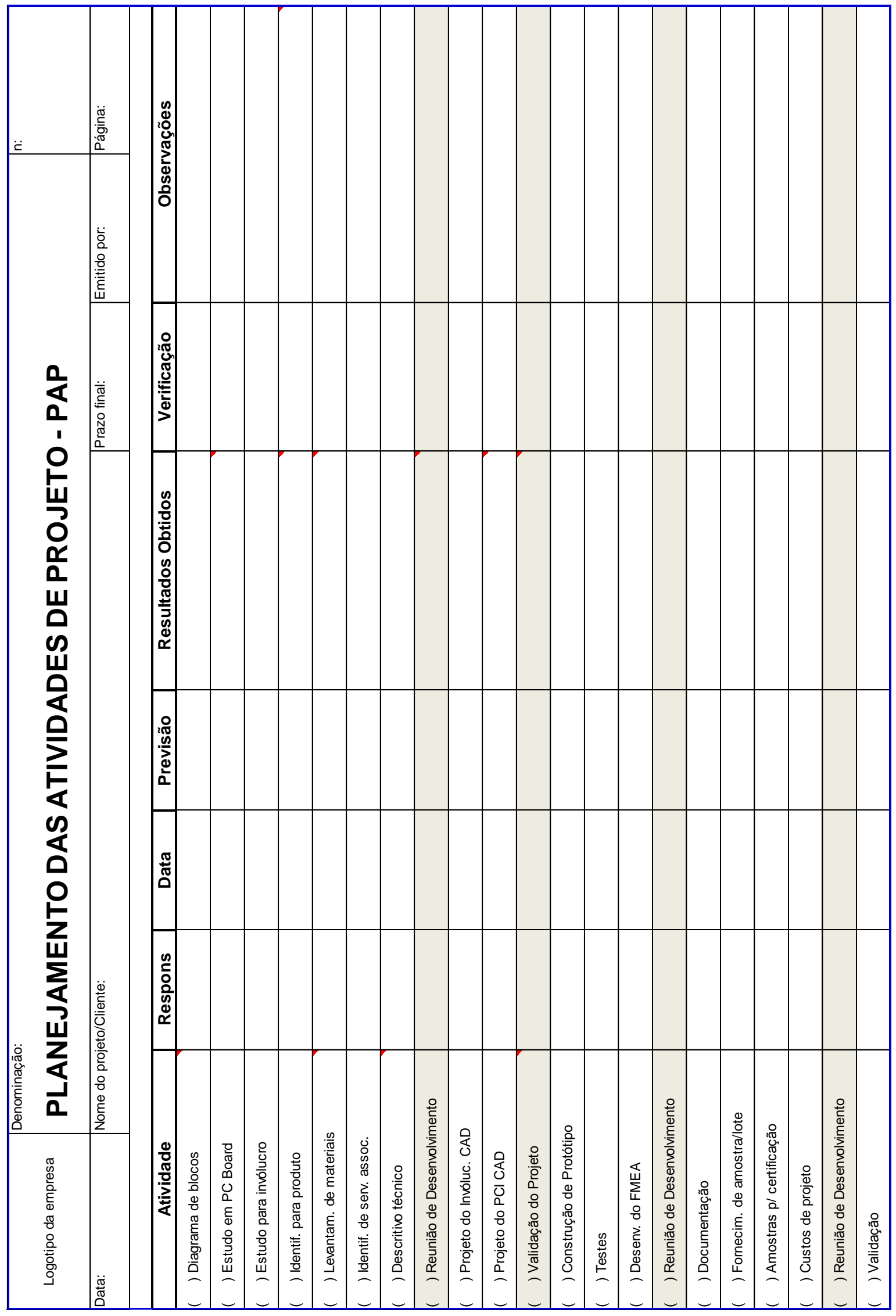


ANEXO B - Formulário de Planejamento das Atividades de Projetos (PAP) - exemplo de preenchimento

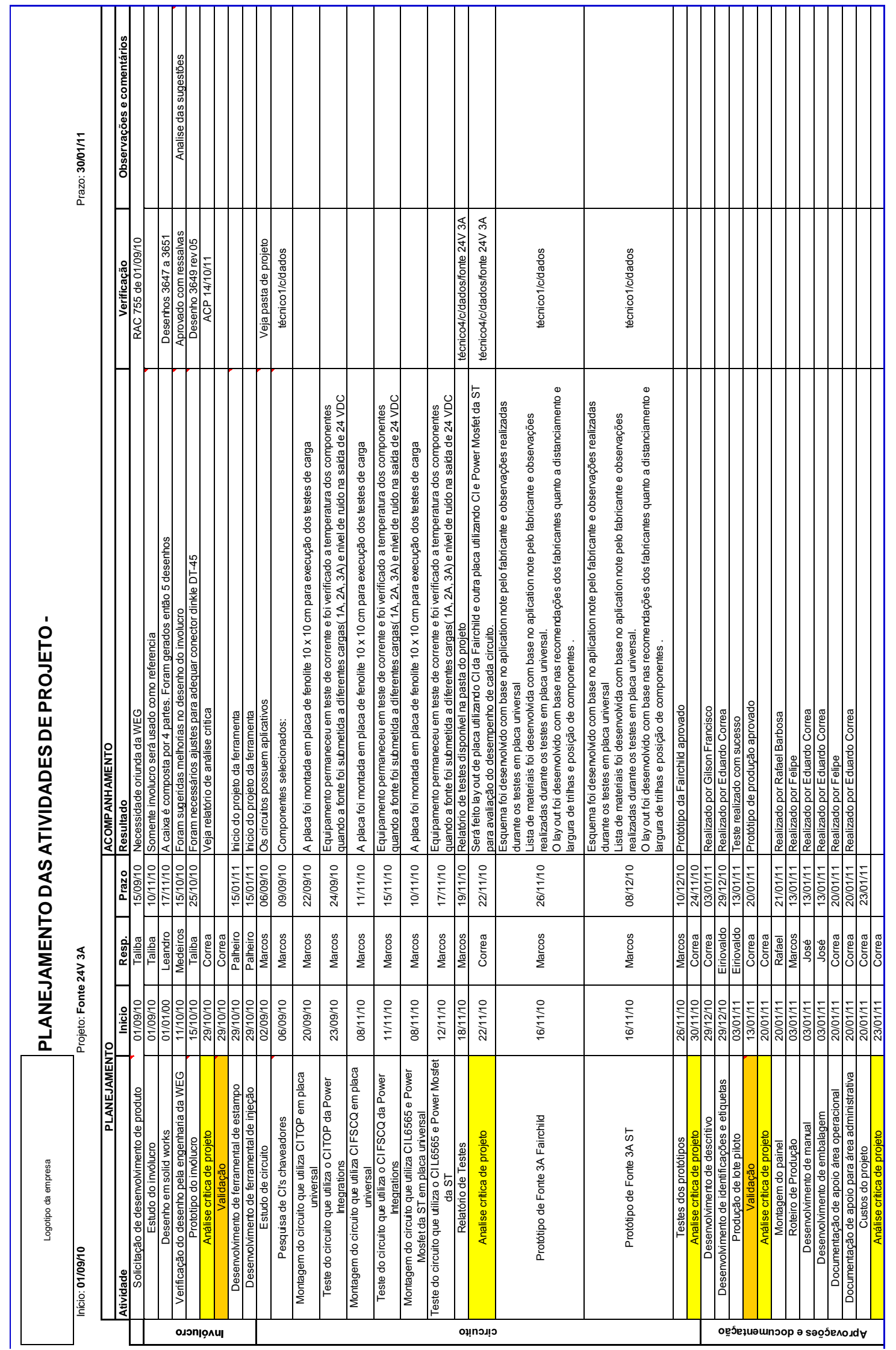

